Final Report

FHWA/IN/JTRP-2006/2

\title{
RAMP METERING AND HIGH OCCUPANCY VEHICLE FACILITIES: A SYNTHESIS STUDY
}

\author{
By \\ Abhishek Bhargava \\ Graduate Research Assistant \\ Euridice Oware \\ Graduate Research Assistant \\ Samuel Labi \\ Assistant Professor of Civil Engineering \\ Kumares C. Sinha \\ Olson Distinguished Professor of Civil Engineering \\ School of Civil Engineering \\ Purdue University \\ Joint Transportation Research Program \\ Project No. C-36-17PPP \\ File No. 8-4-68 \\ SPR- 2870 \\ Prepared in Cooperation with the \\ Indiana Department of Transportation and the \\ U.S. Department of Transportation \\ Federal Highway Administration
}

The contents of this report reflect the views of the authors who are responsible for the facts and the accuracy of the data presented herein. The contents do not necessarily reflect the official views or policies of the Indiana Department of Transportation or the

Federal Highway Administration at the time of publication. This report does not constitute a standard, specification, or regulation.

Purdue University

West Lafayette, Indiana 47907

May 2006 


\section{TECHNICAL Summary}

INDOT Research

Technology Transfer and Project Implementation Information

TRB Subject Code: 13-4 Passenger and Freight Movement

Publication No.FHWA/IN/JTRP-2006/2, SPR-2870

May 2006

Final Report

\section{Ramp Metering and High Occupancy Vehicle Facilities: A Synthesis Study}

\section{Introduction}

The study was carried out in response to a need stated by INDOT to investigate the effectiveness of high occupancy vehicle lanes and ramp metering as congestion mitigation strategies in the state of Indiana. A synthesis study was performed to provide a comprehensive review of the components, effectiveness, costs and implementation considerations of these techniques. The States using these strategies were identified and a detailed study of the state of the art and state of the practice was done. The findings from the synthesis study were used to develop a set of guidelines that may be followed for the implementation of these facilities. The study also included a feasibility analysis of these facilities on the I-70 freeway in Indianapolis, between I-65 and I-465.

\section{Findings}

High Occupancy Vehicle Lane and Ramp Metering facilities have been effective in congestion mitigation. The implementation of HOV lanes on freeways has increased the average vehicle occupancy and the person carrying capacity of the freeway at most sites. The HOV lanes offer travel time savings, vehicle operating cost savings and have proved to be cost effective. However the success of a HOV lane facility depends on how effectively and efficiently the support facilities such as ridership programs, enforcement policies, public education programs, park-and-ride lots and other parking facilities are implemented. A conducive travel pattern on the freeway corridor can enhance the effectiveness of the HOV lane. The feasibility study for the implementation of a concurrent flow lane HOV facility on I-70 showed that the HOV lane on I-70 WB would be economically feasible with significant travel time, vehicle operating cost and emission savings. It was found that the freeway section under study is not significantly congested in the EB direction during the ten analysis period (2006-2016). The economic feasibility of HOV lane was determined corresponding to three scenarios of growth in freeway average vehicle occupancy. The scenarios represented three levels of growth in HOV lane traffic volume. Two alternative approaches, add-a-lane and take-a-lane to HOV lane implementation, were evaluated. The add-a-lane approach was found to be more economically beneficial with higher travel time savings for vehicles in $\mathrm{HOV}$ and general purpose lanes. Further, it was found that the operation of the added lane as HOV lane will have more benefits than operating the added lane as a mixed flow lane. However, the implementation of the HOV lane on I-70 should ensure that the passenger throughput and vehicle throughput in the HOV lane is more than a minimum threshold. A HOV demand model for the Indianapolis area should be developed based on the socio-economic characteristics of the region to estimate the number of vehicles using the HOV lane.

Local traffic-responsive ramp metering was found to improve traffic conditions on the freeways by eliminating the stop-and-go conditions and hence increasing the freeway travel speed. The implementation of ramp metering reduces travel time and emissions on the freeway. However, the vehicles on the ramp experience delay and an increase in emissions. The overall impact of ramp metering on the system is positive as the travel time savings on the freeway compensate for the 
delay on the ramps. However, the emissions were found to increase in the system. The economic evaluation of the ramp metering facility on I-70 WB in Indianapolis, between I-65 and I-465, showed that local, traffic responsive, isolated ramp metering is economically feasible on all the ramps in the WB direction. However, a systemwide traffic responsive metering algorithm can be expected to yield more benefits by reducing the delay on the ramps. Also, the evaluated ramp metering system assumed no traffic diversion on to the side streets. The metering on the ramp was stopped, when the queue on the ramp exceeded capacity, and the vehicles were allowed to enter the freeway from the ramp irrespective of traffic conditions on the freeway. This reduces the benefits of ramp metering on some of the ramps. An algorithm that accounts for traffic diversion when queue spillback occurs at the ramp will increase the travel time savings on the freeway and may increase the system-wide benefits of ramp metering. It was therefore concluded that other ramp metering strategies should be evaluated and the behavior of the traffic in the system such as queue spillback on ramps, merging of ramp vehicles on the freeway, optimal spacing between metered ramps should be studied for implementing an optimal ramp metering plan.

\section{Implementation}

The study results provide the following products for congestion mitigation decision-support purposes: (i) a comprehensive review of the high occupancy vehicle lane and ramp metering facilities in the country, describing the facility components, costs involved and benefits of implementation, (ii) a set of guidelines that may be followed for the implementation of these facilities in Indiana, (iii) the feasibility of implementation of ramp metering and a high occupancy vehicle lane on I-70 freeway in Indianapolis, between I-65 and I-465. The economic evaluation of these facilities on I-70, presented in this report, can be considered as a preliminary evaluation of the feasibility of implementation of these facilities.

\section{Contacts}

For more information:

\author{
Prof. Kumares Sinha \\ Principal Investigator \\ School of Civil Engineering \\ Purdue University \\ West Lafayette IN 47907 \\ Phone: (765) 494-2211 \\ Fax: (765) 496-7996 \\ E-mail: $\underline{\text { sinha@ecn.purdue.edu }}$ \\ Prof. Samuel Labi \\ Co-Principal Investigator \\ School of Civil Engineering \\ Purdue University \\ West Lafayette IN 47907 \\ Phone: (765) 494-5926 \\ Fax: (765) 496-7996 \\ E-mail: labi@ecn.purdue.edu
}

\author{
Indiana Department of Transportation \\ Division of Research \\ 1205 Montgomery Street \\ P.O. Box 2279 \\ West Lafayette, IN 47906 \\ Phone: (765) 463-1521 \\ Fax: (765) 497-1665 \\ Purdue University \\ Joint Transportation Research Program \\ School of Civil Engineering \\ West Lafayette, IN 47907-1284 \\ Phone: (765) 494-9310 \\ Fax: (765) 496-7996 \\ E-mail: jtrp@ecn.purdue.edu \\ http://www.purdue.edu/jtrp
}




\section{ACKNOWLEDGEMENTS}

The authors recognize the support of employees from various state transportation agencies who were instrumental in providing information about existing ramp metering and HOV facilities. The authors are grateful to Mark Newland, Brad Steckler and John Nagle of INDOT for guidance and support. The assistance of Balagopal Panicker, Graduate Research Assistant, and Karen Hatke, JTRP Program Coordinator, are also acknowledged. 


\section{TABLE OF CONTENTS}

TABLE OF CONTENTS

LIST OF TABLES

LIST OF FIGURES iii

vi

ix

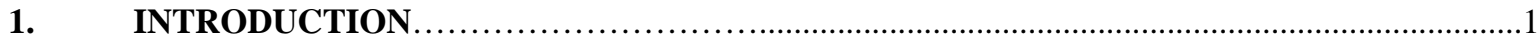

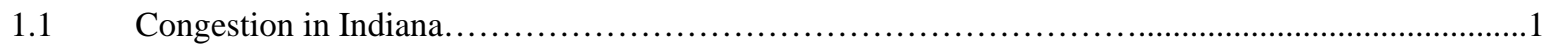

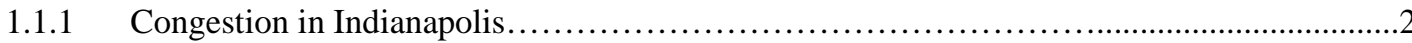

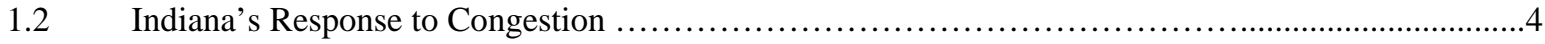

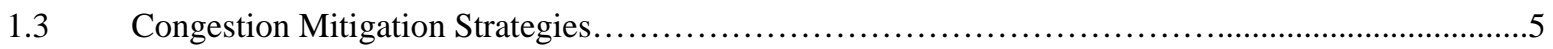

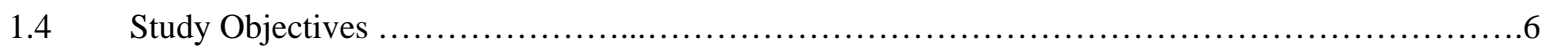

1.5 Survey of Ramp Metering and HOV Facilities in the United States..............................

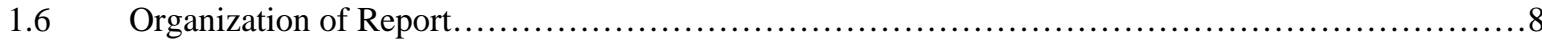

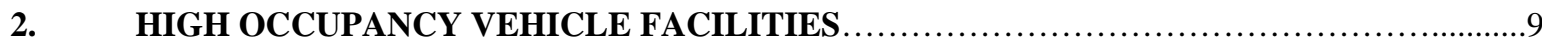

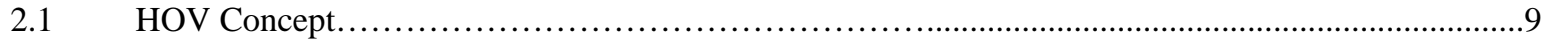

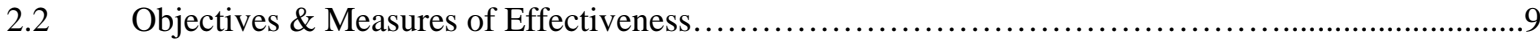

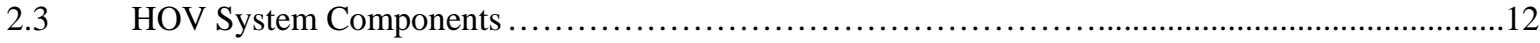

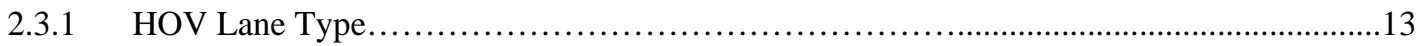

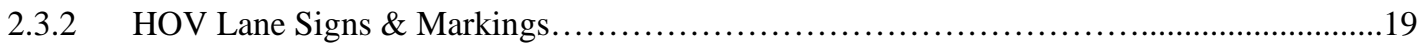

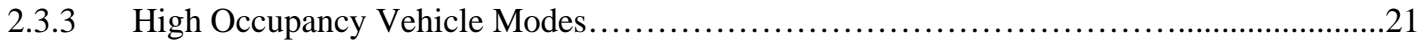

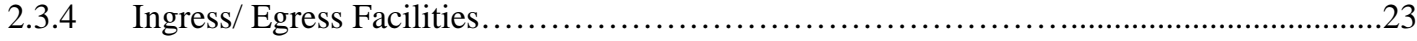

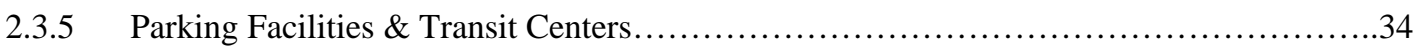

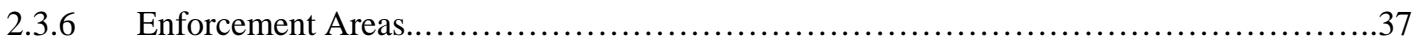

2.3.7 HOV Management Center............................................................

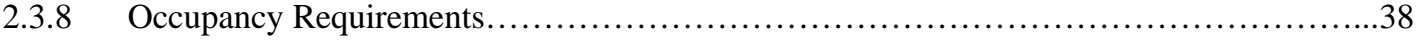

2.3.9 Operation Hours: Time Restrictions................................................... 40

2.3.10 Enforcement Policies....................................................................

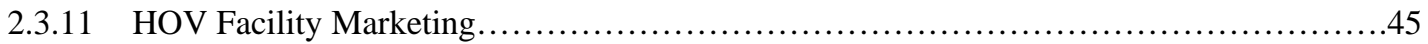


2.3.12 Incident Handling/ Special Events on HOV Lanes.....................................48

2.3.13 Ridership Programs................................................................... 48

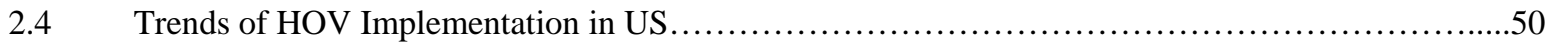

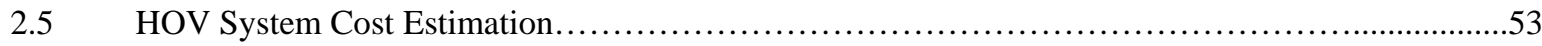

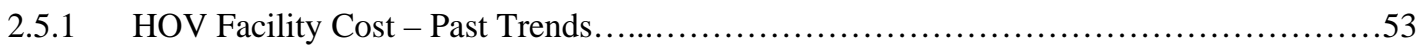

2.5.2 Cost Estimation by HOV System Components..........................................55

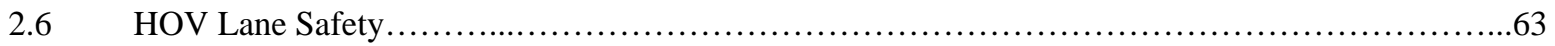

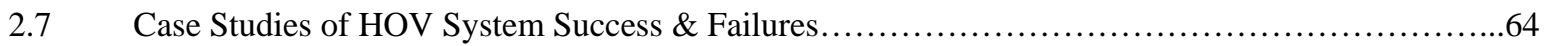

2.7.1 Nationwide HOV Lane Achievements...............................................64

2.7.2 HOV Lane Facilities in States....................................................... 72

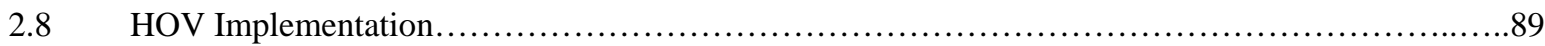

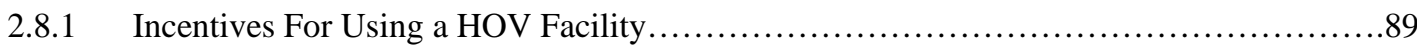

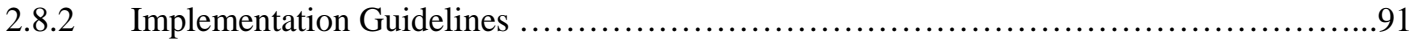

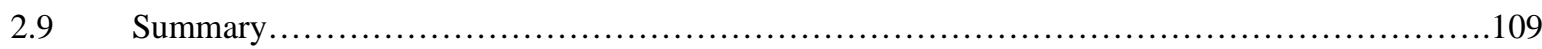

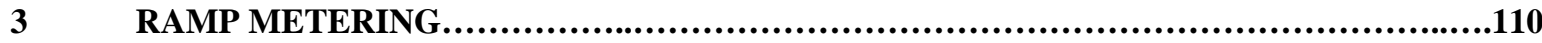

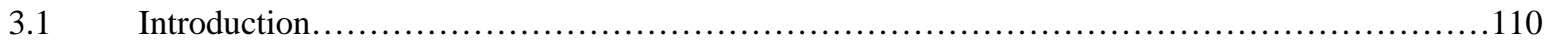

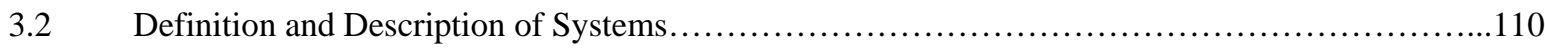

3.2.1 Ramp Metering Control Systems...................................................111

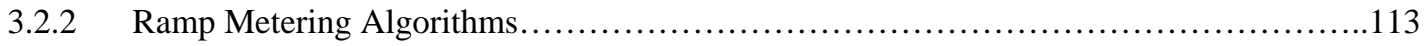

3.2.3 Single Lane vs Dual Lane Ramp Metering.........................................116

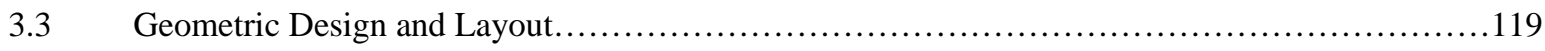

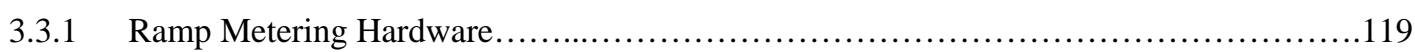

3.4 Ramp Metering Usage in the United States and Abroad...................................128

3.4.1 Ramp Metering in United States................................................ 128

3.4.2 Ramp Metering implementation outside of the United States...........................135

Effectiveness of Ramp Metering Operations.............................................

3.6. Costs of Ramp Metering Facilities.....................................................

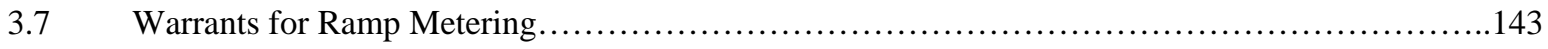

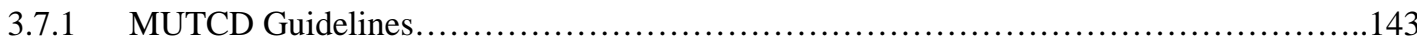

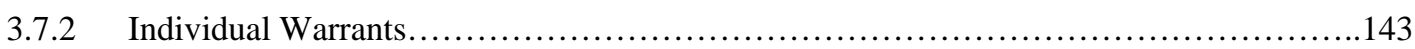

3.8 Ramp Metering Design and Implementation Considerations...................................145

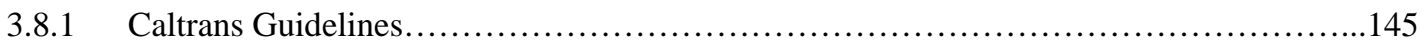

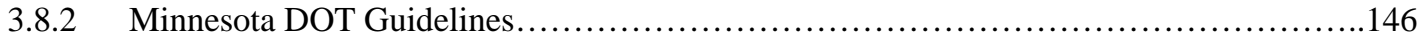

3.8.3 Washington DOT Guidelines....................................................... 146

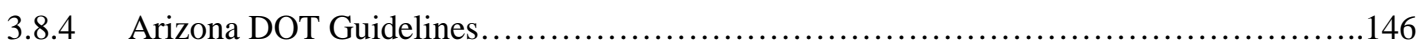

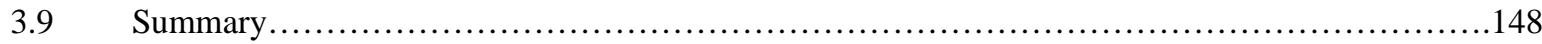




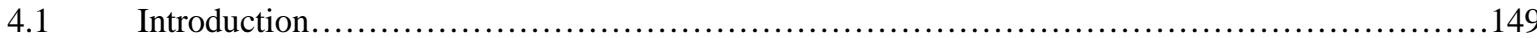

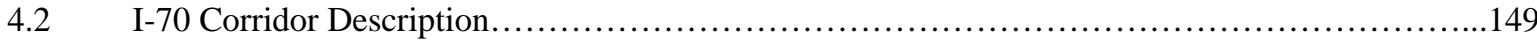

4.3 Economic Feasibility of HOV Facility Implementation....................................

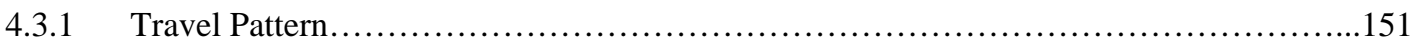

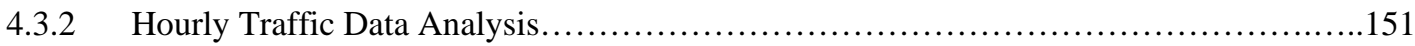

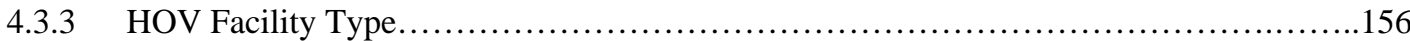

4.3.4 HOV Lane Traffic Estimation........................................................157

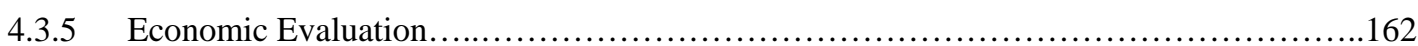

4.3.6 HOV Lane Implementation on I-70...............................................

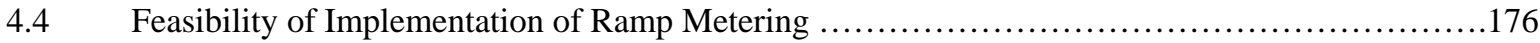

4.4.1 Feasibility of Freeway-to-Freeway Ramp Metering...................................177

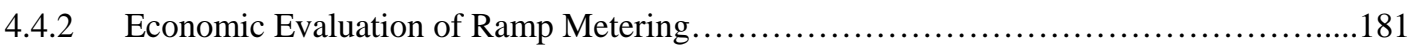

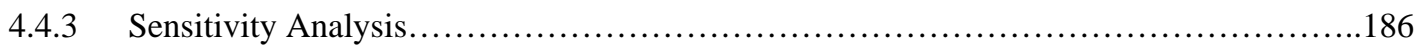

4.4.4 Implementation Feasibility of Ramp Metering........................................188

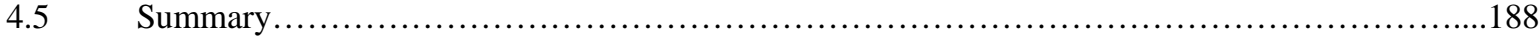

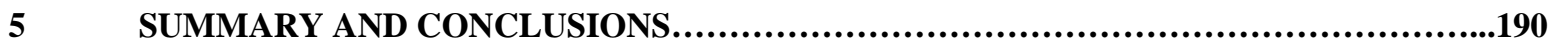

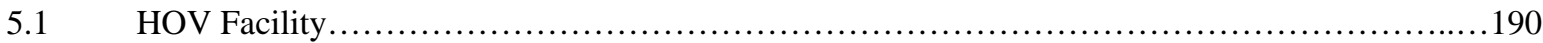

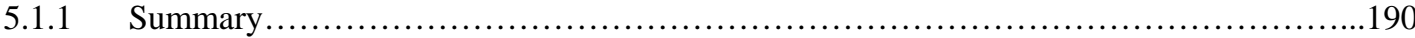

5.1.2 Conclusions on I-70 HOV Lane Implementation......................................190

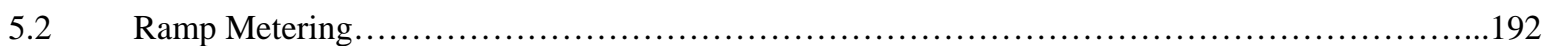

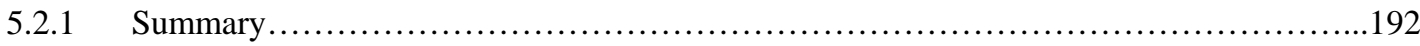

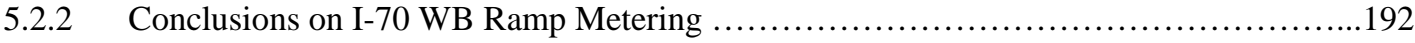

\section{REFERENCES}




\section{LIST OF TABLES}

Table

Page

Table 1.1: States Utilizing Ramp Metering and HOV Facilities in the United States...........................

Table 2.1: Typical HOV Goals and Objectives..............................................................10

Table 2.2: Suggested Objectives and Measures of Effectiveness.........................................11

Table 2.3: Benefit to Cost Ratio of HOV Projects in Texas...................................................19

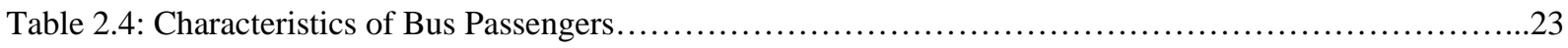

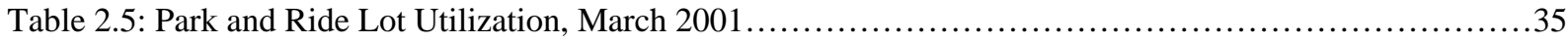

Table 2.6: Impact of changes in occupancy requirement on Katy Freeway HOV Lane...........................39

Table 2.7: Occupancy Requirement and Operating Hours of Exclusive HOV Facilities.........................41

Table 2.8: Advantages and Disadvantages of Full-Time Versus Part Time HOV Hours of Operation..............42

Table 2.9: Effect of Enforcement Strategies on I-80 in New Jersey.......................................43

Table 2.10: Enforcement Methodology and Resulting Violation Rates at HOV Facilities..........................45

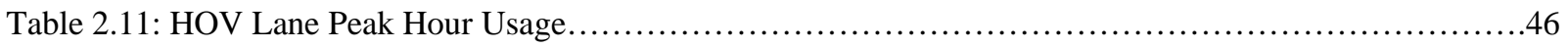

Table 2.12: Capital Cost of Exclusive Reversible Lane HOV Facilities (2005 Dollars) .......................53

Table 2.13: Capital Cost of Concurrent Flow Lane HOV Facilities (2005 Dollars)...........................54

Table 2.14: Capital Cost of Contra-Flow Lane HOV Facility (2005 Dollars) ...............................54

Table 2.15: Right of Way Cost for Additional lanes................................................... 55

Table 2.16: Cost of HOV Lane Addition in thousands of 2006 Dollars.........................................56

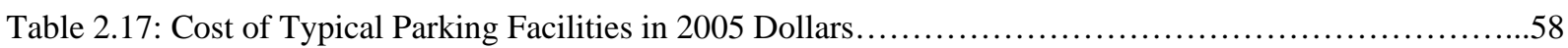

Table 2.18: Typical Parking Facility Construction Costs in 2000 Dollars........................................58

Table 2.19: Capital Cost Estimation for a Hypothetical 10-mile Concurrent Flow Lane HOV Facility............60

Table 2.20: Adjusted Annual Operation, Maintenance and Enforcement Costs for a HOV lane....................61

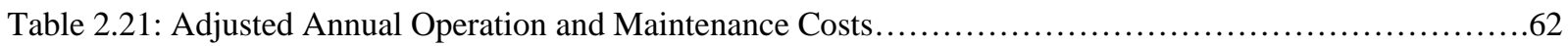

Table 2.22: Comparison of HOV and Adjacent Lane Accident Rates........................................63

Table 2.23: Percentage of HOV lane carpoolers who previously drove alone.................................64

Table 2.24: Estimated Reduction in the Number of SOVs in the General Purpose Lane Due to Carpoolong........65

Table 2.25: Percentage of HOV Lane bus riders who previously drove alone...............................66

Table 2.26: Estimated Reduction in Number of SOVs in GP Lane Due to Buses in HOV lane, Houston............66

Table 2.27: Estimated Reduction in Number of SOVs in GP Lane Due to Buses in HOV lane, Houston.............67 
Table 2.28: Average Vehicle Occupancy of some HOV Projects......................................68

Table 2.29: Increase in Average Peak Hour Bus Speed on Houston HOV Lanes....................................76

Table 2.30: Bus Operating Impacts of Improvements to Houston HOV System..............................77

Table 2.31: Speed Comparison of HOV and GP Lanes on I-15, Salt Lake City ................................79

Table 2.32: Travel Time Savings from HOV Lanes in Northern Virginia....................................82

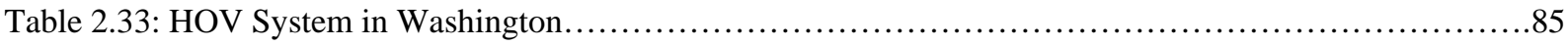

Table 2.34: Occupancy Restriction Based on Current Average Occupancy....................................94

Table 2.35: Factors to be considered in the implementation of Support Facilities............................101

Table 2.36: Region-wide HOV Demand Models....................................................

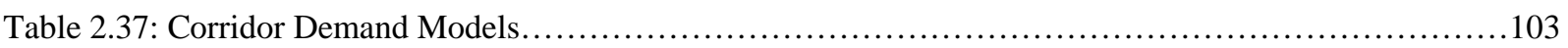

Table 2.38: Guidelines for HOV Lane Implementation..............................................108

Table 3.1: Available Ramp Metering Algorithms...........................................................113

Table 3.2: Sample Speed Control Lookup Table..........................................................114

Table 3.3: Sample Occupancy Control Lookup Table...................................................115

Table 3.4: Number of Pretimed Ramp Meters Deployed in Metropolitan Areas................................130

Table 3.5: Number of Traffic Responsive Ramp Meters Deployed in Metropolitan Areas.......................130

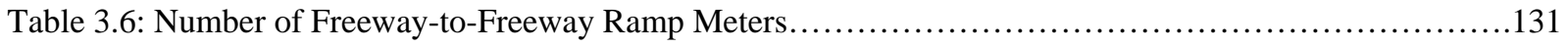

Table 3.7: Number of Centrally Controlled Ramp Meters............................................

Table 3.8: Number of HOV Bypass Lanes at Ramp Meters..........................................132

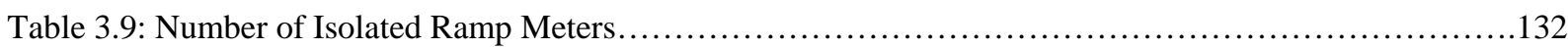

Table 3.10: Number of Ramp Meters Providing Priority for Transit Vehicles...................................133

Table 3.11: Operating Flow Signals by Freeway in Houston, Texas......................................134

Table 3.12: Phoenix-Area Ramp Meter Information, November 2004....................................135

Table 3.13: Ramp Meters outside United States....................................................

Table 3.14 Estimated Benefits of Ramp Metering Systems...............................................136

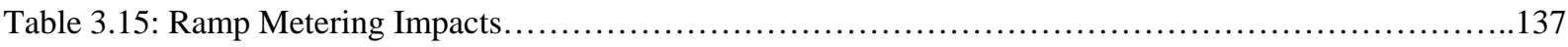

Table 3.16: Possible Cost of Ramp Metering Systems.....................................................

Table 3.17: Ramp Metering Cost Components For Different Places in the US...............................141

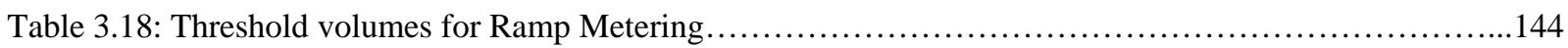

Table 3.19: Keys to a Successful Ramp Metering System, Minnesota Department of Transportation............147

Table 4.1: Traffic Entering From the On-Ramps along I-70 WB …...................................153

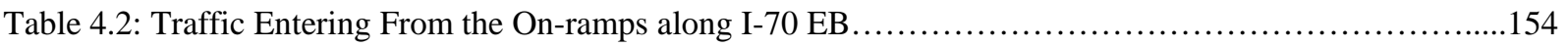

Table 4.3: Comparison of Traffic Volumes (2006) Entering I-70 WB During Morning Peak Period with Traffic Volume Exiting I-70 EB During Afternoon Peak Period...............................154

Table 4.4: Estimated Carpools Using the Freeway in Opening Year when Alternative 1 is Implemented.........158

Table 4.5: Estimated Carpools Using the Freeway in Opening Year when Alternative 2 is Implemented.........159 
Table 4.6: Estimated HOV Lane Volume in Opening Year when Alternative 1 is implemented.................160

Table 4.7: Estimated HOV Lane Volume in Opening Year when Alternative 2 is implemented...................160

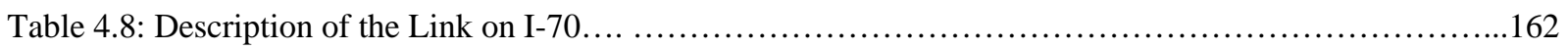

Table 4.9: Inputs to Congestion Management Software for Economic Evaluation of HOV Lane Alternatives....162

Table 4.10: Cost of HOV Lane Alternatives on I-70............................................

Table 4.11: Unit Emission Cost of Pollutants...................................................171

Table 4.12: Description of the On-Ramps in the I-70 WB Direction....................................

Table 4.13: Freeway Upstream and Ramp Traffic Volumes in Morning Peak Period on I-70 WB...............177

Table 4.14: Freeway-to-Freeway Metering Systems in District 7, California................................180

Table 4.15: Freeway-to-Freeway Ramp Metering Systems in Minnesota...................................181

Table 4.16: Total Cost of Ramp Metering \& Cost per Ramp for On-Ramps on I-70........................182

Table 4.17: Total Vehicle Hours and Travel Delay at Morning Peak on Ramp 3224..........................183

Table 4.18: System Fuel Cost Savings due to Metering on Ramp 3224....................................184

Table 4.19: Annual Estimates of Emission Savings (KG) due to Metering on Ramp 3224.....................185

Table 4.20: Annual Estimated of System Benefits and Costs Due to Metering on Ramp 3224..................185

Table 4.21: Analysis of Benefits and Costs Due to Metering on I-70 WB On-Ramps........................186 


\section{LIST OF FIGURES}

Figure

Page

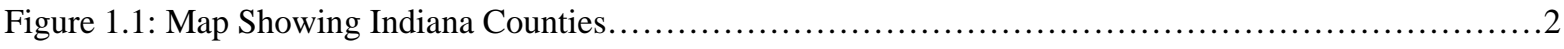

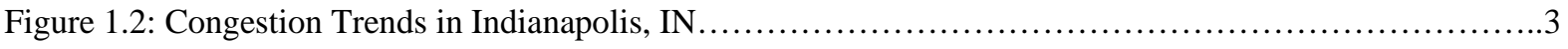

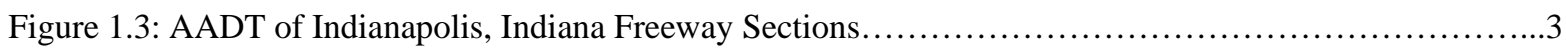

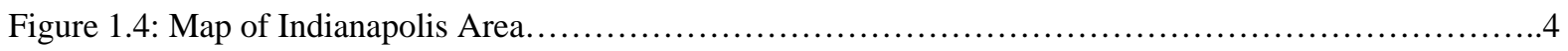

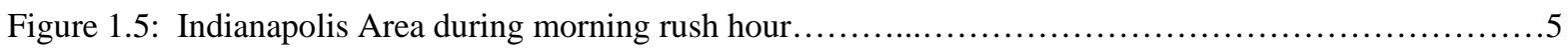

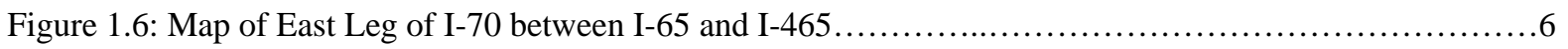

Figure 2.1: Number of Vehicles Required to carry 45 people..........................................

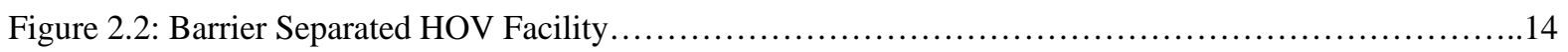

Figure 2.3: Exclusive two-Directional and Reversible HOV Facilities Concept..............................14

Figure 2.4: Buffer Separated Exclusive two-Directional HOV Facility.....................................15

Figure 2.5: Single Stripe Buffer (Double Yellow Line) - 0.6 m Wide..................................15

Figure 2.6: Painted Buffer (Double Yellow Stripes) - 1.2 m Wide......................................15

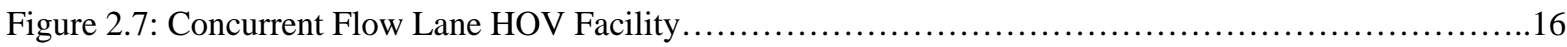

Figure 2.8 Barrier \& Pylon Separated Contra Flow HOV Facilities.....................................17

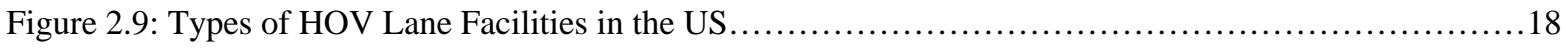

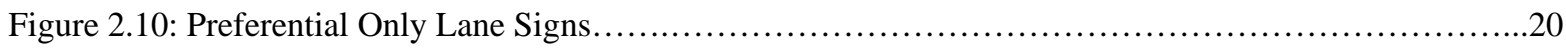

Figure 2.11: Bus Volume and Rider-ship on the HOV Lanes, Houston.......................................22

Figure 2.12: Impact of Bus Service on Average Vehicle Occupancy in Houston................................22

Figure 2.13: Slip Ramp at the beginning of a Contiguous HOV Facility...............................24

Figure 2.14: Slip Ramp at the beginning of a Barrier or Buffer Separated HOV Facility $\ldots \ldots \ldots \ldots \ldots \ldots \ldots \ldots \ldots .25$

Figure 2.15: Right lane drop at the end of concurrent, barrier and buffer separated HOV facility................25

Figure 2.16: Ingress/Exit at intermediate location for barrier-separated HOV lanes........................26

Figure 2.17: Ingress/Exit for buffer $(0.3 \mathrm{~m}-1.2 \mathrm{~m})$ separated HOV Lanes..................................26

Figure 2.18: Ingress/Exit for buffer-separated (3.6 m or wider) HOV lanes...............................26

Figure 2.19: Full Wish-bone ramp on North Freeway in Houston, Texas..................................28

Figure 2.20: Half Wish-bone Ramps on Eastex Freeway in Houston, Texas..................................28

Figure 2.21: T-Ramp on Eastex Freeway in Texas, Houston.............................................29 
Figure 2.22: Dual T-Ramp on I-45S (Gulf Freeway) in Houston, Texas................................29

Figure 2.23: Route 85/ US101 (South) HOV Direct Connector Project, San Jose................................30

Figure 2.24: Typical HOV Direct Connector Entrance and Exit.............................................31

Figure 2.25: HOV Lane Access Ramp Spacing for Northwest Freeway, Houston............................31

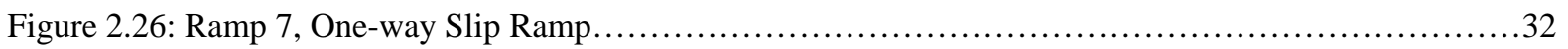

Figure 2.27: Ramp 6, One-way, Direct Access, Grade Separated T-Ramp..................................32

Figure 2.28: Ramp 5, Two-way, Direct Access, Grade Separated T-Ramp.................................33

Figure 2.29: Ramp 3, Full Wishbone Ramp (Grade Separated) ......................................

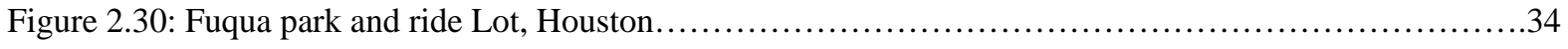

Figure 2.31: HOV Lane Direct Access Ramp from Kuykendahl Park-and-ride Lot...........................35

Figure 2.32: Example of a Lack of Enforcement Consideration......................................

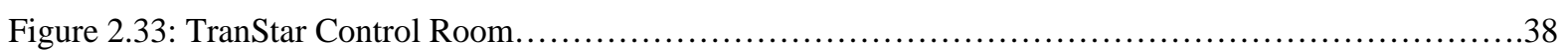

Figure 2.34: Trends in Lane-Miles of HOV Usage Based on Occupancy Requirements.........................39

Figure 2.35: Distribution of HOV route miles by hours of operation..................................... 40

Figure 2.36: Number of Violation Reports received in HERO Self Enforcement Program, Seattle..............44

Figure 2.37 Vehicle and Person Throughput in Peak direction across various HOV Facilities..................47

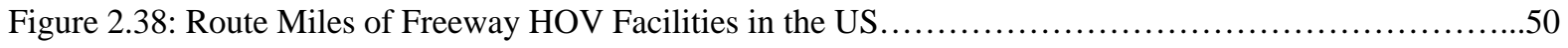

Figure 2.39: Growth Trends in Different Types of Freeway HOV Facilities..............................51

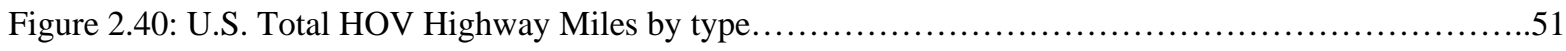

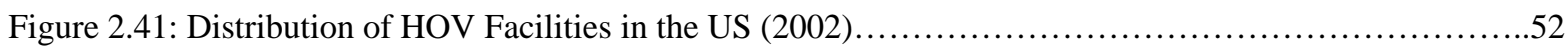

Figure 2.42: Average Mile Length of U.S. HOV Lanes by Type..........................................

Figure 2.43: Change in number of carpools after HOV implementation in Dallas............................66

Figure 2.44: Person Movement Efficiency of HOV Lane vs GP Lane.....................................69

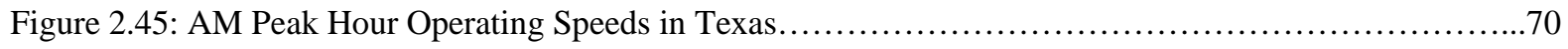

Figure 2.46: Average Peak Hour Travel Time Savings of HOV lanes on Freeways.........................71

Figure 2.47: Average flow by of HOV lane vehicles by Caltrans District................................73

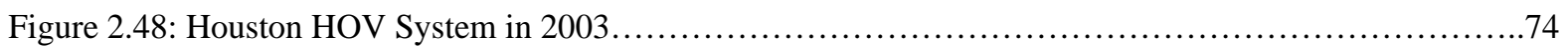

Figure 2.49: Air Quality and Energy Impacts of HOV Lanes in Houston.................................75

Figure 2.50: Bus Schedule Time, AM Peak Hour service to downtown Houston............................76

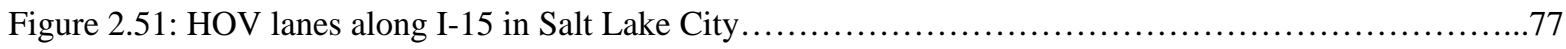

Figure 2.52: Traffic Volume Profile on HOV and GP Lanes on I-15 Salt Lake City Utah.....................78

Figure 2.53: Variation of Speed along the I-15 HOV and GP Lanes....................................79

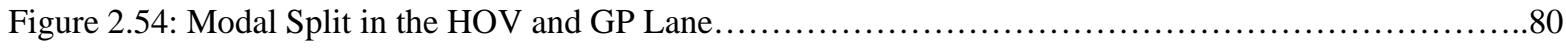

Figure 2.55: Change in Average Vehicle Occupancy at places in Salt Lake City with and without HOV.........80

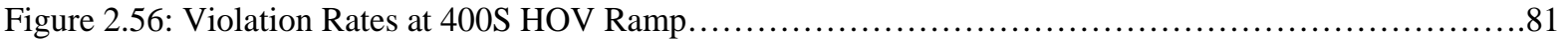

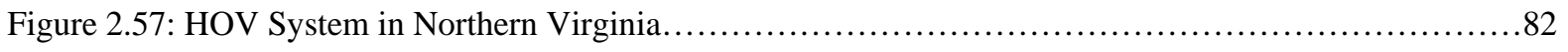


Figure 2.58: I-395 Shirley Highway HOV lanes AM Peak Hour Utilization............................. 83

Figure 2.59: HOV Lane vs GP Lane vehicle and person throughput on I-395 (2002)...........................84

Figure 2.60: HOV Lane vs GP Lane vehicle and person throughput on I-66 (2002)......................... 84

Figure 2.61: HOV Lane Facilities in Puget Sound Region, Seattle Washington................................85

Figure 2.62: Person and Vehicle Throughput on the I-5 HOV lanes in Seattle, Washington.....................86

Figure 2.63: Average Hourly Traffic Profile on HOV Lane and GP Lanes on I-5 in 2002 ....................86

Figure 2.64: HOV System in Houston and Northern Virginia with CBD as the Destination.....................92

Figure 2.65: Directional and Bi-directional Enforcement Area For Different Median Widths...................96

Figure 3.1: Local Traffic Responsive Ramp Metering System..........................................112

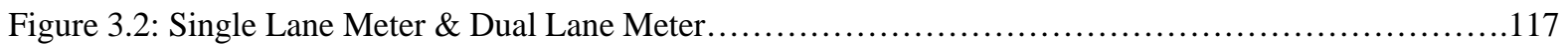

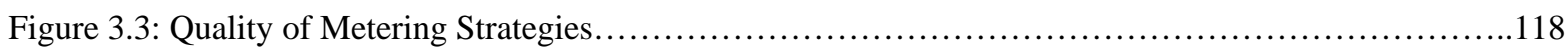

Figure 3.4: Overall Detector Layout for a typical Ramp Meter..........................................119

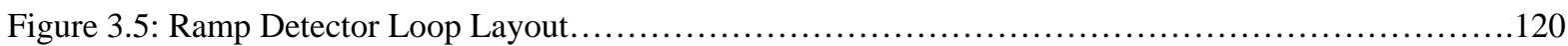

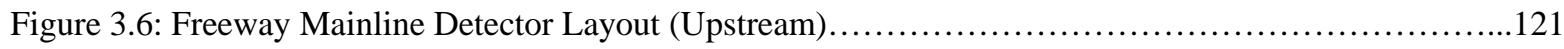

Figure 3.7: Typical Freeway Entrance with 1-Lane Ramp Meter............................................

Figure 3.8: Typical Freeway Entrance with 2-Lane Ramp Meter.....................................123

Figure 3.9: Typical Freeway Entrance Loop Ramp with 1-Lane Ramp Meter.............................124

Figure 3.10: Typical Freeway Entrance Loop Ramp with 2-Lane Ramp Meter...........................125

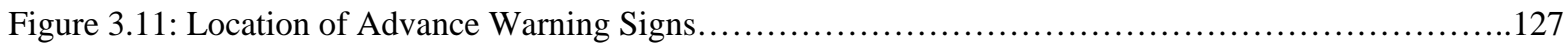

Figure 3.12: Ramp Metering Usage in the Metropolitan Areas in Group 1.............................128

Figure 3.13: Ramp Metering Usage in the Metropolitan Areas in Group 2 ...............................129

Figure 3.14: Ramps Controlled by Ramp Meter.................................................129

Figure 3.15: SR-520 EB Morning Congestion, I-5 to Lake Washington Blvd. in Sept. 2001.................139

Figure 4.1: I-70 Corridor Description in the EB and WB Direction.................................. 150

Figure 4.2 Estimated Speed Profile on I-70 in the year 2006 During the Peak Period........................152

Figure 4.3: Travel Pattern on I-70 between I-65 and I-465 in the EB and WB direction....................155

Figure 4.4: Percentage of Carpools in Total Traffic as a Function of Average Vehicle Occupancy...............159

Figure 4.5: Opening Year Speeds on GP Lane Before \& After HOV Lane Implementation of Alternative 1.. 161

Figure 4.6: Opening Year Speeds on GP Lane Before \& After HOV Lane Implementation of Alternative 2...161

Figure 4.7: Opening Year Speeds on GP Lane Speeds when added lane is not operated as HOV Lane.........161

Figure 4.8: Travel Time Savings over the analysis period due to HOV Facility Implementation................164

Figure 4.9: VOC Savings over Analysis Period due to HOV Facility Implementation.........................166

Figure 4.10: CO Emission Savings over Analysis Period due to HOV Facility Implementation.................167

Figure 4.11: $\mathrm{NO}_{\mathrm{x}}$ Emission Savings over Analysis Period due to HOV Facility Implementation.................168

Figure 4.12: HC Emission Savings over Analysis Period due to HOV Facility Implementation.................169 
Figure 4.13: Benefit to Cost Ratio of Concurrent Flow Lane HOV Facility Project Alternatives...............172 Figure 4.14(a): Comparison of Travel Time, VOC and Emission Savings over Analysis Period on Link $1 . . . .173$ Figure 4.14(b): Comparison of Travel Time, VOC and Emission Savings over Analysis Period on Link 2.....173 Figure 4.14(c): Comparison of Travel Time, VOC and Emission Savings over Analysis Period on Link 3.....174 Figure 4.14(d): Comparison of Travel Time, VOC and Emission Savings over Analysis Period on Link 4.....174 Figure 4.14(e): Comparison of Travel Time, VOC and Emission Savings over Analysis Period on Link $5 . . . .175$

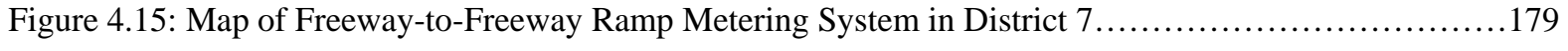

Figure 4.16: Map of Freeway-to-Freeway Ramp Metering System in Minnesota............................180

Figure 4.17: System Travel Time Savings per vehicle due to Ramp Metering..............................183

Figure 4.18: B/C Ratio of Ramp Metering Project on I-70 Ramps vs Discount Rate........................186

Figure 4.19: B/C Ratio of Ramp Metering Project on I-70 Ramps vs Travel Time Value.....................187

Figure 4.20: B/C Ratio of Ramp Metering Project on I-70 Ramps vs Fuel Efficiency........................187

Figure 4.21: B/C Ratio of Ramp Metering Project on I-70 Ramps vs Fuel Cost ...........................188 


\section{INTRODUCTION}

\subsection{CONGESTION IN INDIANA}

Traffic congestion has become a severe problem in Indiana. Congestion is present in every corner of the state and all of the cities and towns in between. While all of the road congestion documented in this report is severe, studies show that it will only get worse, with congestion expected to increase by 450 percent over the next ten years. The average amount of traffic per lane mile on major urban roads and highways in Indiana has increased by 37 percent between 1990 and 2003. According to the TRIP report, improved highway access and efficient travel are critical needs for many of the state's fast growing manufacturing companies. Expansion of economic development opportunities in Indiana requires improvement of its transportation infrastructure.

The population of Indiana increased 11\% from 1990 to 2000 with a total of about 6.2 million. Approximately $70 \%$ of the population is located in the state's urban areas and approximately $45 \%$ of the population is located in the three largest urban areas, Indianapolis, Gary and Fort Wayne. The TRIP report found the state's suburban roads have become outdated because they were not built to handle the high level of traffic they are now serving. Indiana's population is expected to increase by another 15 percent reaching 7.1 million by the year 2025 . Other conclusions from the TRIP report are as follows:

- Vehicle travel in Indiana has grown from 54 billion miles driven annually to 73 billion miles, an increase of 35 percent from 1990 to 2002. Furthermore, the total annual vehicle travel in Indiana is estimated to reach 115 billion miles by the year 2025, an increase of another 58 percent.

- Traffic delays in Indianapolis have quadrupled since 1990. It now takes 26 percent more time to complete an average trip in Indianapolis during rush hours than during the off-peak hours. This is a significant increase as compared to 1990 when it took about 6 percent longer to commute during the peak hours.

- The state's population is rapidly suburbanizing, with the fastest growth in Indiana occurring in the counties just outside of those with the largest cities, such as the seven counties surrounding Indianapolis (Marion County) and those surrounding Fort Wayne (Allen County). In addition, the two northern Indiana counties closest to Chicago - Lake and Porter - are among the fastest growing in Indiana.

- While the overall population of Indiana has increased by 11 percent since 1990, the population in the age group 25-34 has decreased by 9 percent indicating that the young adults are leaving the state for better job opportunities. Transportation improvements can play an important role in the economic development of Indiana.

\subsubsection{Congestion in Indianapolis: North-East Marion County}

The residential and commercial development in northeastern Marion County and surrounding areas have led to increased highway travel in that geographical area. Much of the traffic involves home- and work-based trips between downtown Indianapolis and northeastern Marion County. A significant proportion of these trips utilize the corridor linking Interstates 65, 465, and I-70. In the present situation, morning and evening rush hours are 
characterized by a large volume of traffic that tries to access the Interstate system, causing both I-65 and I-465 to experience significant periods of recurrent congestion. As Indianapolis continues to grow, the traffic problems will increase in the future unless there is appropriate planning to address the problem. Previous studies in Indiana have shown that the problem of urban traffic congestion is on the rise and will continue to increase in the foreseeable future [Whitford and Opsuth, 1997] unless appropriate congestion mitigation strategies are implemented. Figure 1.1 shows a map of counties in Indiana with Marion County highlighted.

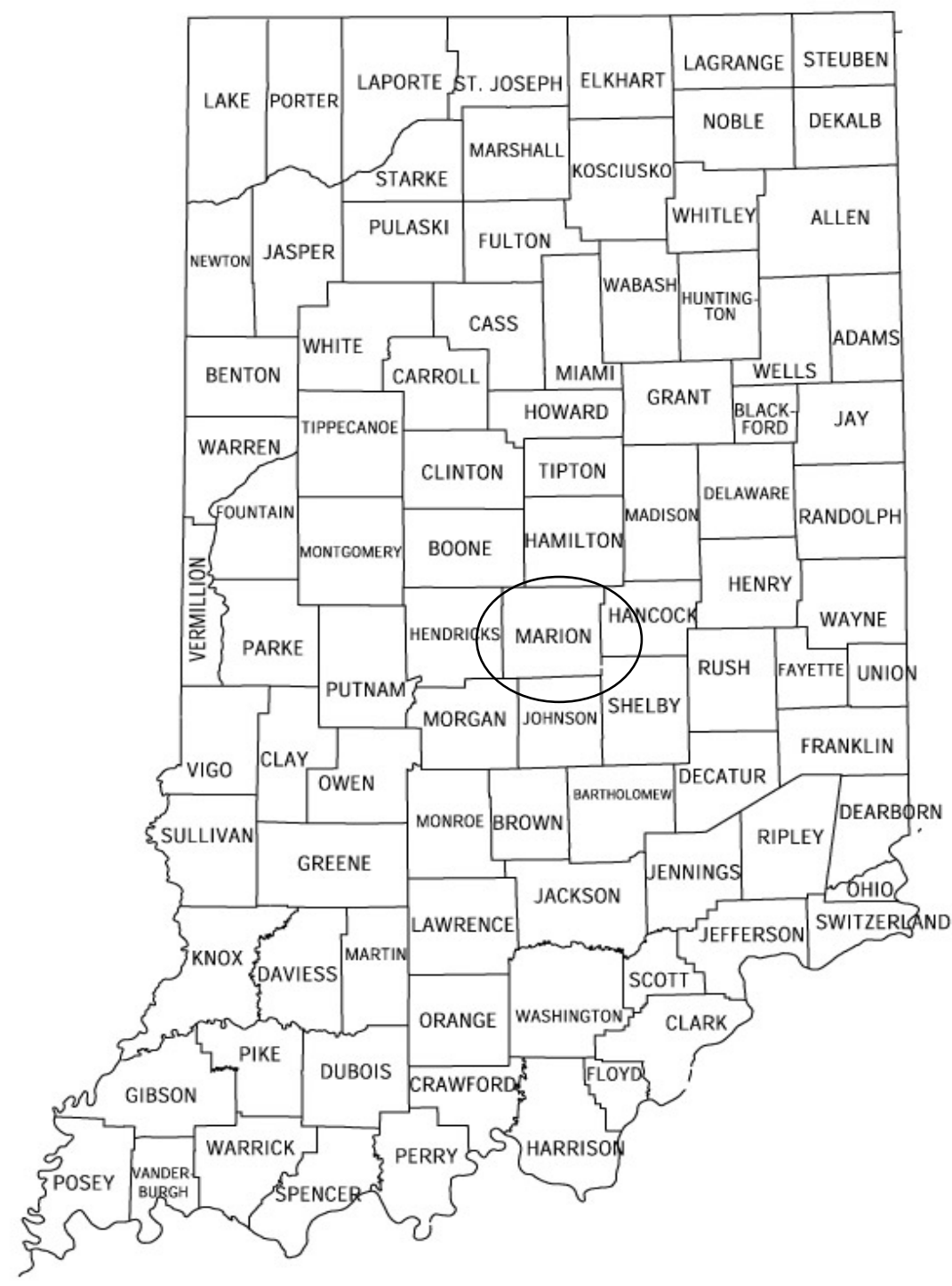

Figure 1.1: Map Showing Indiana Counties

The growth in congested freeway lane-miles in Indianapolis is shown in Figure 1.2. Congestion has increased from 13\% of the total network to 67\% between 1982 and 2002 [Schrank and Lomax, 2004]. Figure 1.3 shows the AADT on freeway sections in the Indianapolis area. 


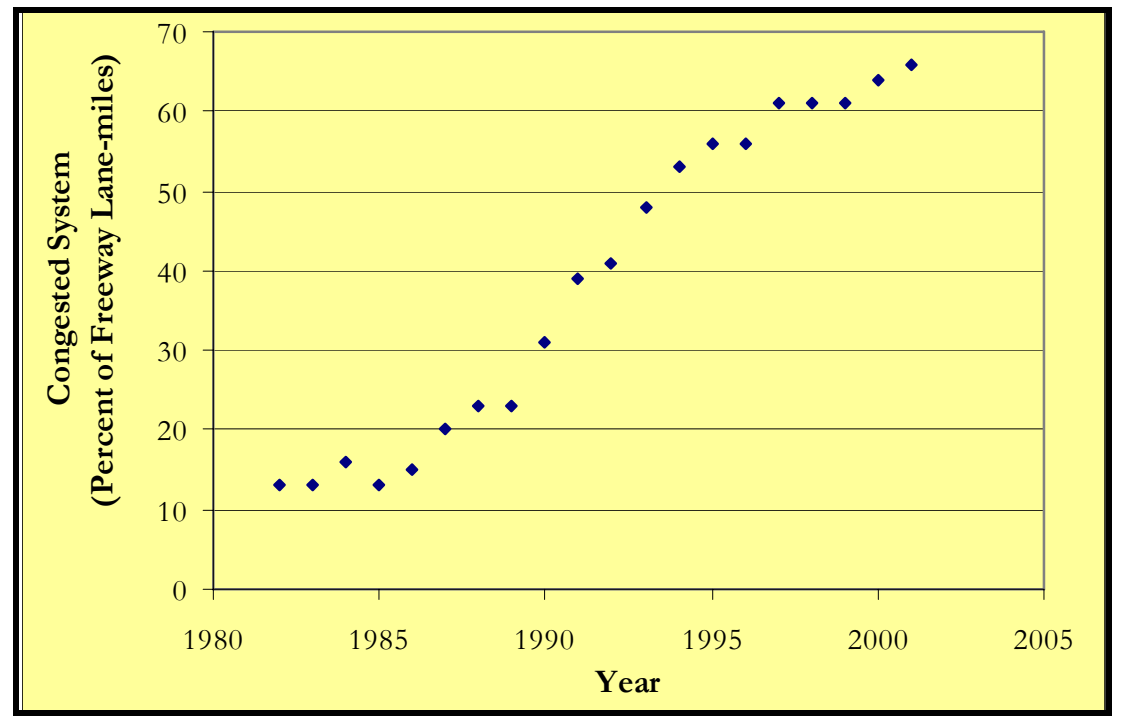

Figure 1.2: Congestion Trends in Indianapolis, IN

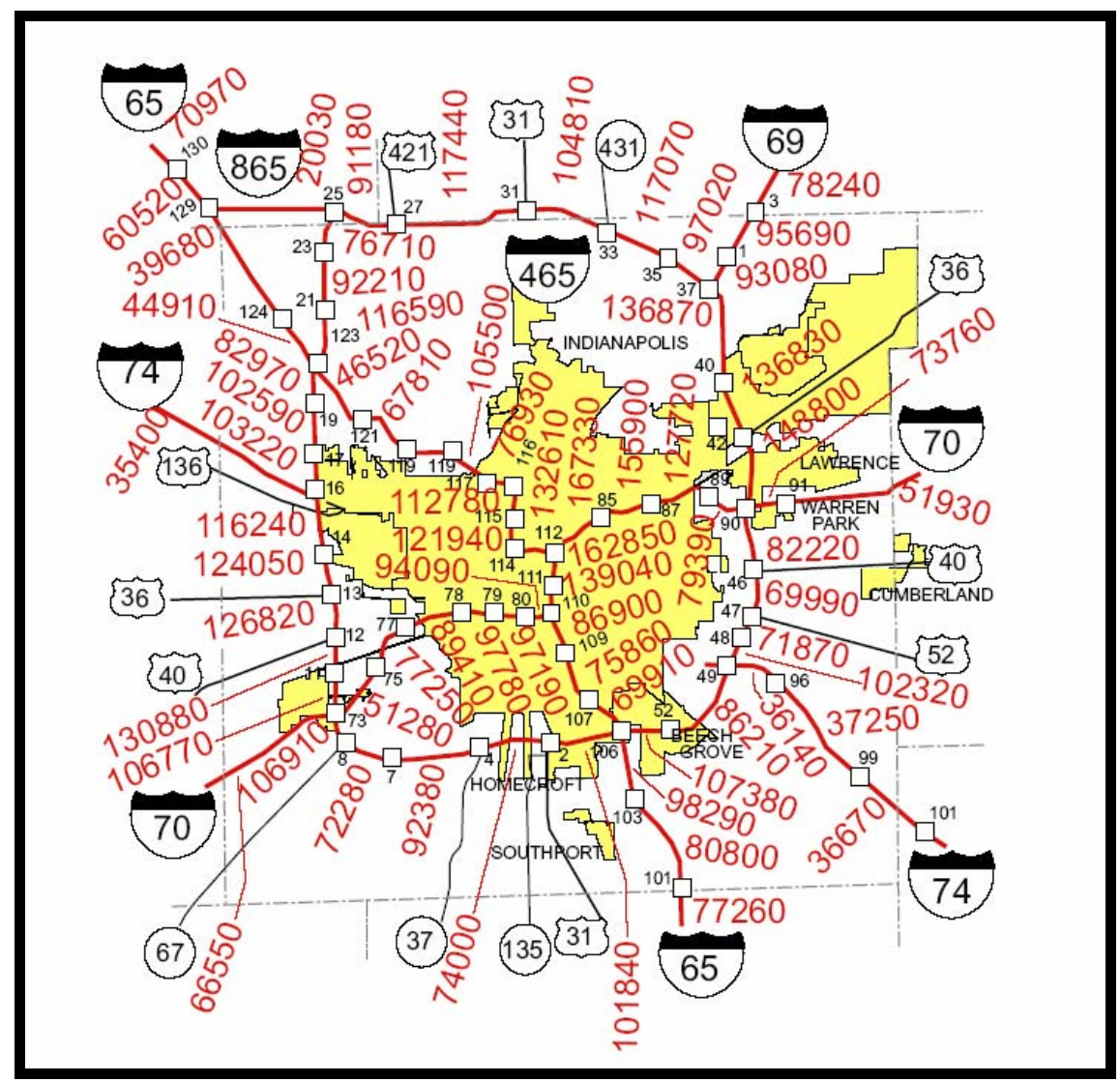

Figure 1.3: AADT of Indianapolis, Indiana Freeway Sections [INDOT, 2005] 


\subsection{INDIANA's RESPONSE TO CONGESTION}

Indiana has implemented the Hoosier Helpers freeway incident response system to ease the non-recurring congestion. In this program trucks travel on the interstates in Indianapolis and other areas of the state and assist motorists who are stranded, remove debris from roads, and help during accidents and other emergencies. Also Indiana provides message signs in work zones. Indiana currently has an intelligent transportation system called TrafficWise which uses technology to detect highway congestion and assess the reasons for this traffic. The program is intended to make driving easier and safer, particularly in the major metropolitan areas of Indiana. The system provides this information to motorists, dispatchers, and emergency responders. In addition, the following initiatives are in place to assist travelers:

- Indianapolis Street Closure \& Restriction Information

- Motorist Information from the Indiana Department of Transportation which includes Construction \& Road Conditions

- $\quad$ TRIMARC - Louisville/Southern Indiana Traffic Information

A local news channel, WTHR, Eyewitness News, in Indianapolis maintains 8 traffic cameras in the Indianapolis area. The image in Figure 1.4 is a map showing the locations of available traffic cameras. Figure shows a photograph of morning rush hour traffic at I-69 and I-465 [WTHR, 2004].

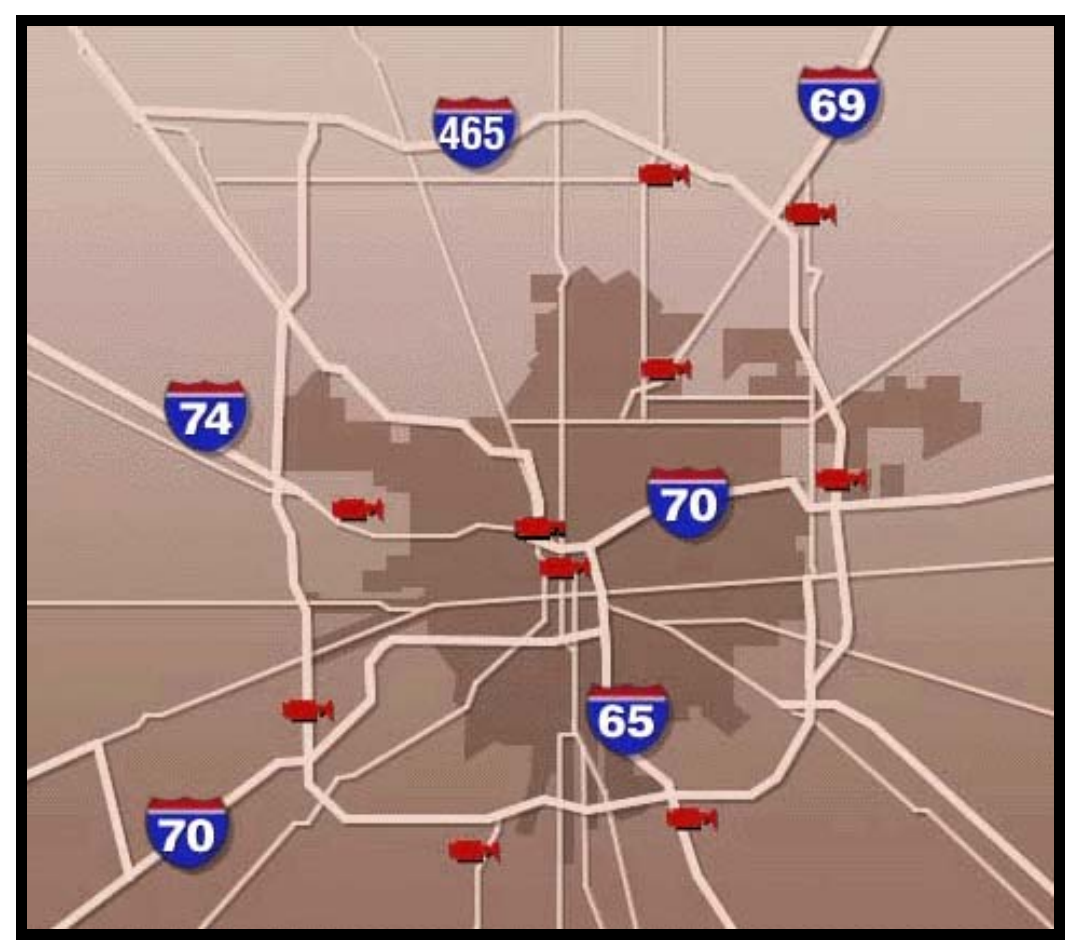

Figure 1.4: Map of Indianapolis Area

Source: WTHR Indianapolis, http:/www.wthr.com 


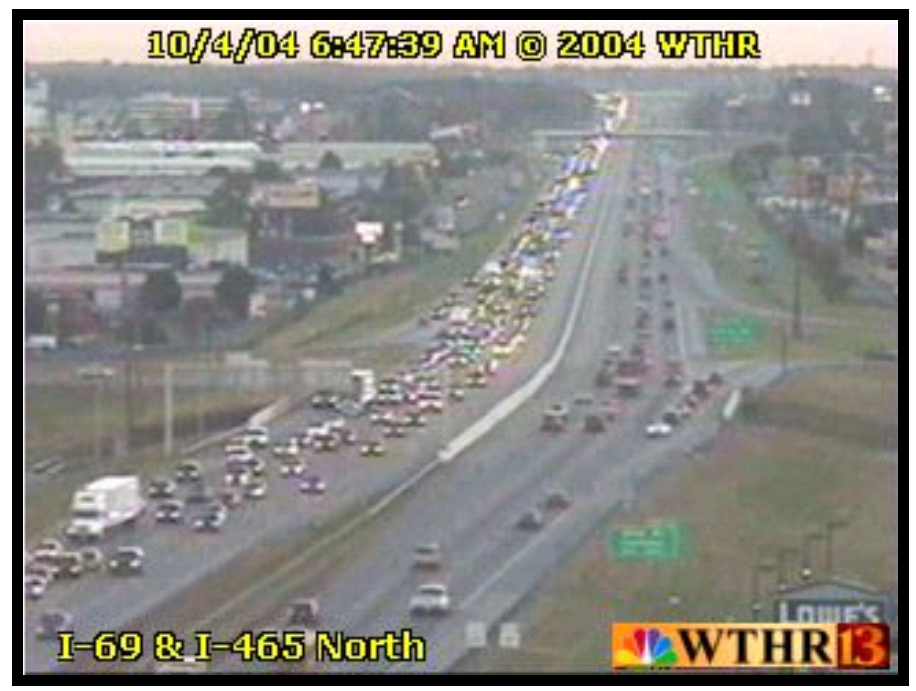

Figure 1.5: Indianapolis Area during morning rush hour Source: WTHR Indianapolis, http:/www.wthr.com

The development of the Indiana Congestion Management System (CMS) began in June 1993 by the Joint Highway Research Project (JHRP) of Purdue University and INDOT. Gunawardena and Sinha [1994] developed a set of guidelines for the implementation of a prototype for congestion management framework in Indiana. A nationwide survey of state transportation agencies and a survey for Indiana MPOs were included in the research. Choocharukul et al. [2002] developed a methodology for evaluating the cost-effectiveness of congestion mitigation projects.

\subsection{CONGESTION MITIGATION STRATEGIES}

Traditional techniques for relieving congestion have included building new roadways and adding lanes to existing freeways and roadways. However, these methods are costly and may not provide sufficient capacity to meet future demand. Other congestion mitigation methods include implementing public transportation systems or encouraging the use of transit and carpooling. Systems such as Transportation Systems Management (TSM), Incident Management Systems, and Traveler Information Systems are all directed to congestion mitigation. Ramp Metering and High Occupancy Vehicle (HOV) facilities are currently being utilized in many states in the United States and in other countries [NCHRP, 1998] to relieve congestion. Other physical congestion mitigation techniques include variable message signs, highway advisory radio, and traffic control centers (including freeway surveillance). Other policy related congestion mitigation techniques include travel demand management measures such as staggered work hours, car pooling, parking restrictions, congestion pricing, enforcement and truck restrictions.

This study focuses on the implementation of ramp metering and HOV lanes in addressing congestion and evaluates the economic feasibility of these projects on a section of I-70 in the Indianapolis area. 


\subsection{STUDY OBJECTIVES}

The objectives of this study are broadly summarized as follows:

- To conduct a synthesis study on high-occupancy vehicle facilities and ramp metering facilities in the United States to provide a comprehensive review of the state of the art and state of the practice, including the effectiveness, costs, and policy considerations of implementing these techniques.

- To evaluate the feasibility of implementing ramp metering and HOV facilities in the Indianapolis freeway corridor. The section that is considered is the east leg of the I-70 corridor from I-65 to I-465 between downtown Indianapolis and Northeastern Marion County, as shown in Figure 1.6. Preliminary screening will be conducted based on warrants and practices adopted in other states.

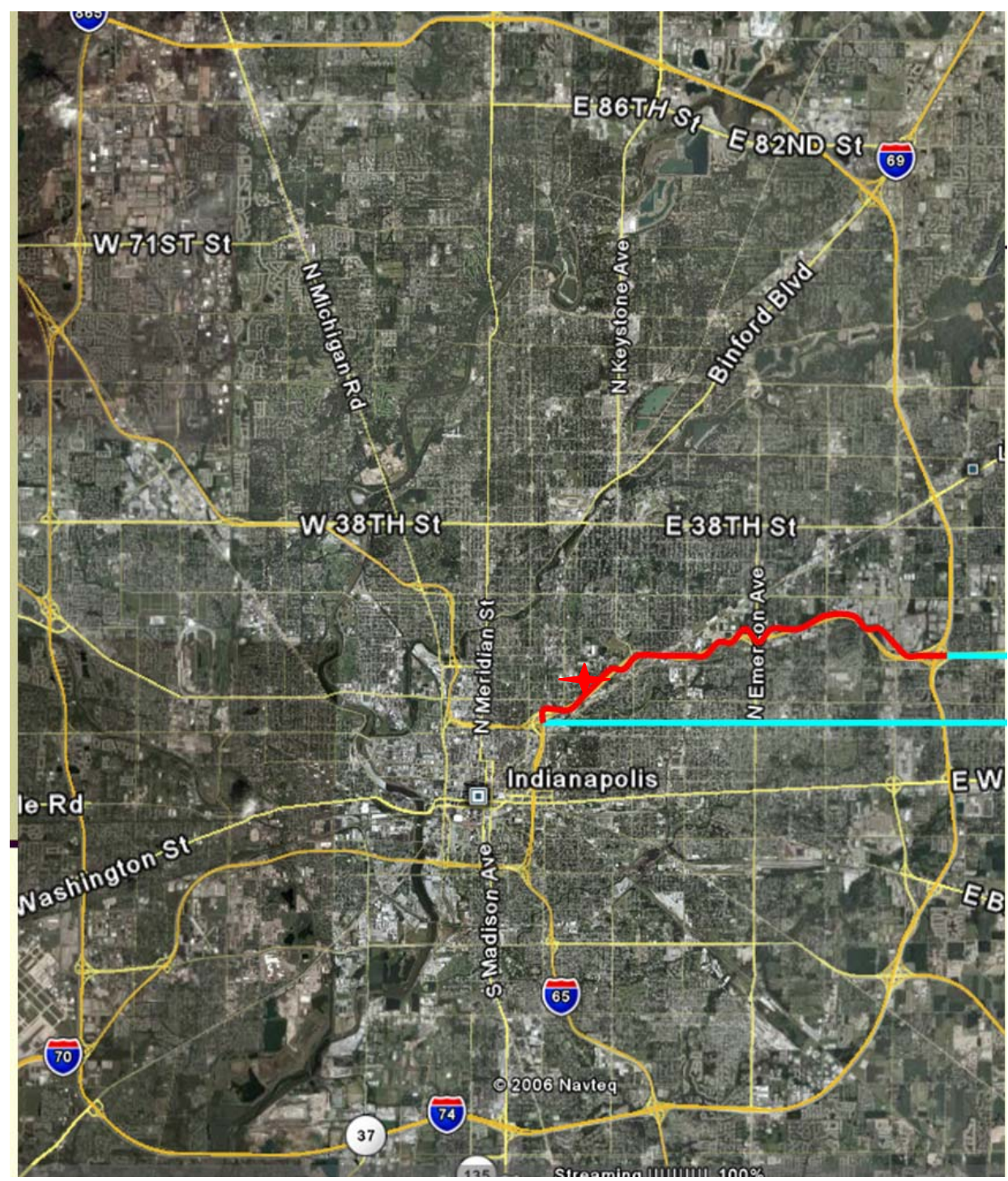

Figure 1.6: Map of East Leg of I-70 between I-65 and I-465 


\subsection{SURVEY OF HOV AND RAMP METERING FACILITIES IN THE US}

A review of ramp metering and HOV facilities in the United States was conducted as a part of this synthesis study. The states utilizing these facilities were identified from the USDOT ITS deployment study [USDOT, 2004]. Table 1.1 presents a list of the states which currently have ramp metering and/or HOV facilities.

Table 1.1: States Utilizing Ramp Metering and HOV Facilities in the United States

\begin{tabular}{|l|cc|}
\hline State & HOV & $\begin{array}{c}\text { Ramp } \\
\text { Metering }\end{array}$ \\
\hline Arizona & YES & YES \\
California & YES & YES \\
Colorado & YES & YES \\
Connecticut & YES & NO \\
Delaware & NO & YES \\
Florida & YES & NO \\
Georgia & YES & YES \\
Hawaii & YES & NO \\
Illinois & YES & YES \\
Massachusetts & YES & NO \\
Maryland & YES & NO \\
Michigan & NO & YES \\
Minnesota & YES & YES \\
New Jersey & YES & YES \\
New York & YES & YES \\
Ohio & NO & YES \\
Oregon & YES & YES \\
Pennsylvania & YES & YES \\
Tennessee & YES & NO \\
Texas & YES & YES \\
Utah & YES & YES \\
Virginia & YES & NO \\
Washington & YES & YES \\
Wisconsin & NO & YES \\
\hline
\end{tabular}

In order to obtain information about the ramp metering and HOV facilities currently being used, appropriate states were contacted for the following information:

- $\quad$ Location and descriptions of the ramp metering and/or HOV facilities.

- Measured impacts of these congestion mitigation techniques (such as change in travel time, number of accidents, fuel emissions).

- Estimated costs associated with construction, maintenance, and operation of the ramp metering and/or HOV systems.

- $\quad$ Published reports on the design, implementation, or evaluation of the systems. 


\subsection{ORGANIZATION OF REPORT}

This report has been organized into five chapters. Chapter 1 presents the extent of congestion in Indiana, existing congestion mitigation strategies that have been deployed in the state, objectives and scope of the report. Chapter 2 presents a synthesis study of the various High Occupancy Vehicle lane facilities in the US. A set of guidelines and warrants have been presented that can be used to determine the feasibility of a HOV lane project. Chapter 3 presents a synthesis study of ramp metering projects in the US. The warrants and guidelines for implementation of ramp metering are presented in this chapter. Chapter 4 discusses the economic feasibility of HOV Lanes and ramp metering on the east leg of I-70 between I-65 and I-465 in Indiana. The results of economic evaluation of HOV facility and ramp metering projects on I-70 have been presented in this chapter. The last chapter presents a summary of the synthesis study and conclusions from the economic evaluation of ramp metering and HOV project on the east leg of I-70. 


\section{HOV Lane Facilities}

\subsection{HOV CONCEPT}

The implementation of a HOV lane involves the reserving of a highway lane exclusively for use by selected vehicles that carry several passengers. HOV lanes have the potential to move more people in fewer vehicles thereby reducing congestion, improve person moving capability and reliability, and efficiently utilize the available roadway infrastructure and transit fleet [Fuhs and Obenberger, 2002]. A primary motive for HOV lane implementation is the reduction of travel time and increase in travel time reliability. HOV lanes encourage carpooling and transit use by providing faster travel times for these high-occupancy vehicles. According to the HOV Systems Manual [NCHRP, 1998], "HOV facilities are intended to help maximize the person carrying capacity of the roadway by altering the design and/or operation of the facility to provide priority treatment for high-occupancy vehicles.” The concept of HOV lanes is demonstrated in Figure 2.1. It will take 45 single occupancy vehicles to carry as many persons as one bus or six vans of eight person capacity or 15 cars with three persons or 22 cars with two persons in each. The goals and objectives often reflect local transportation priorities and a response to local transportation issues and needs.

\begin{tabular}{|c|c|c|}
\hline Bus & त्या & 1 \\
\hline Vanpool (8) & 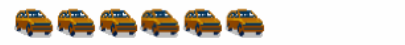 & 6 \\
\hline Carpool (3) & Don & 15 \\
\hline Carpool (2) & 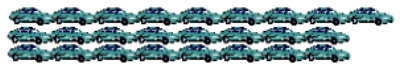 & 22 \\
\hline $\begin{array}{l}\text { Single Occupant } \\
\text { Automobile }\end{array}$ & 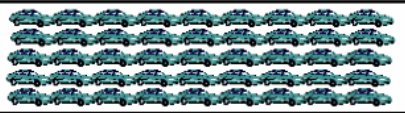 & 45 \\
\hline
\end{tabular}

Figure 2.1: Number of Vehicles required to carry 45 people [Turnbull, 1992]

The intent of HOV Lanes is not to force people to change their driving habits against their will. Rather, the objective is to provide a travel alternative to the travelers which they will find attractive enough to change from driving alone to using a high occupancy vehicle.

This chapter discusses the various HOV system types, components, objectives and measures of effectiveness, costs/benefits. Also the chapter reviews successful and failed HOV projects and suggests some guidelines that may be followed for determining economic feasibility of HOV lanes on freeway corridors in Indiana. The discussion in this chapter is limited to freeway HOV lanes. 


\subsection{OBJECTIVES AND MEASURES OF EFFECTIVENESS}

By the end of year 2002, over $130 \mathrm{HOV}$ lane projects involving over 2,400 lane miles had been implemented in the US. Most of these projects were proposed with the primary objective of reducing congestion by inducing more people to travel in fewer vehicles. However, the projects also achieved several other objectives such as air quality improvement. The relative importance of these objectives varies from location to location depending upon the priorities set by the local authorities. Table 2.1 shows the HOV lane objectives categorized by the HOV locations. Table 2.2 shows a list of common objectives set for a typical HOV lane project. Table 2.2 also presents the measures of effectiveness that are used to assess the extent to which the objectives are achieved. A discussion of the major objectives is presented below:

(a) Induce mode shift from drive-alone to high occupancy modes thereby increasing the person carrying capacity of the roadway (per-lane efficiency) and average vehicle occupancy

While automobile ridership increased in the U.S., the average vehicle occupancy for home-to-work trips decreased from 1.3 in 1977 to about 1.14 in 1995 [Martin, 2002]. The main objective of a HOV facility is to induce a shift from single occupancy vehicles to high occupancy vehicles by providing travel incentives. This “mode shift” will increase the average number of travelers in one vehicle which in turn increases the person carrying capacity of the roadway. Successful HOV lane projects have simply not diverted the high occupancy vehicles from general purpose (GP) lanes to the HOV lane, but have also generated new high occupancy vehicles, resulting in increased average vehicle occupancy. The ultimate goal is to reduce the number of vehicle trips even if the person trips are not reduced thereby reducing vehicle-facility congestion.

Table 2.1: Typical HOV Goals and Objectives [Henderson, 2002]

\begin{tabular}{|c|l|}
\hline Area Scope & \multicolumn{1}{|c|}{ HOV Goals and Objectives } \\
\hline \hline \multirow{3}{*}{ National (FHWA) } & Move more people in fewer vehicles \\
& Provide travel time savings \\
& Provide reliable and predictable travel times \\
\hline \multirow{5}{*}{ State of California } & Increase people-moving capacity \\
& Reduce congestion \\
& Provide travel time and cost savings \\
& Increase system efficiency \\
& Improve air quality \\
\hline \multirow{2}{*}{ Minneapolis, Minnesota } & Maximize people-moving capacity \\
& Provide support for bus services and rideshare programs \\
\hline \multirow{3}{*}{ State of Texas } & Increase people per vehicle \\
& Preserve person-movement capacity \\
& Enhance bus operations \\
\hline \multirow{3}{*}{ State of Washington } & Maximize people-moving capacity \\
& Mitigate transportation related pollution \\
& Reduce fuel consumption \\
\hline \multirow{5}{*}{ Washington, D.C. } & Increase people per vehicle \\
& Preserve person-movement capacity \\
& Enhance bus transit operations \\
& Support air quality improvements \\
& Provide predictable travel times \\
\hline
\end{tabular}


Table 2.2: Suggested Objectives and Measures of Effectiveness [Henderson, 2002]

\begin{tabular}{|c|c|}
\hline Objective & Measure of Effectiveness \\
\hline $\begin{array}{l}\text { The HOV facility should improve the capability of a } \\
\text { congested freeway corridor to move more people by } \\
\text { increasing the number of persons per vehicle. }\end{array}$ & $\begin{array}{l}\text { Actual and percent increase in the person-movement efficiency } \\
\text { Actual and percent increase in average vehicle occupancy rate } \\
\text { Actual and percent increase in Carpools and Vanpools } \\
\text { Actual and percent increase in bus riders }\end{array}$ \\
\hline $\begin{array}{l}\text { The HOV facility should increase the operating } \\
\text { efficiency of bus service in the freeway corridor. }\end{array}$ & $\begin{array}{l}\text { Improvement in vehicle productivity (operating cost per vehicle-mile, } \\
\text { operating } \\
\text { cost per passenger, operating cost per passenger-mile) } \\
\text { Improved bus schedule adherence (on-time performance) } \\
\text { Improved bus safety (accident rates) }\end{array}$ \\
\hline $\begin{array}{l}\text { The HOV facility should provide travel time savings } \\
\text { and a more reliable trip time to HOVs utilizing the } \\
\text { facility. }\end{array}$ & $\begin{array}{l}\text { Peak-period, peak-direction travel time in the HOV lane(s) should be } \\
\text { less than the } \\
\text { adjacent general-purpose freeway lanes } \\
\text { Increase in travel time reliability for vehicles using the HOV lane(s) }\end{array}$ \\
\hline $\begin{array}{l}\text { The HOV facility should have favorable impacts on air } \\
\text { quality and energy consumption. }\end{array}$ & $\begin{array}{l}\text { Reduction in emissions } \\
\text { Reduction in total fuel consumption } \\
\text { Reduction the growth of vehicle-miles of travel (VMT) and vehicle- } \\
\text { hours of travel (VHT) }\end{array}$ \\
\hline $\begin{array}{l}\text { The HOV facility should increase the per-lane } \\
\text { efficiency of the total freeway corridor. }\end{array}$ & $\begin{array}{l}\text { Improvement in the peak-hour per-lane efficiency of the total facility } \\
\text { The HOV facility should not unduly impact the operation of the freeway } \\
\text { general purpose lanes. } \\
\text { The level of service in the freeway general-purpose lanes should not } \\
\text { decline }\end{array}$ \\
\hline $\begin{array}{l}\text { The HOV facility should be safe and should not } \\
\text { unduly impact the safety of the freeway general- } \\
\text { purpose lanes. }\end{array}$ & $\begin{array}{l}\text { Number and severity of accidents for HOV and general-purpose lanes } \\
\text { Accident rate per million vehicle-miles of travel } \\
\text { Accident rate per million passenger-miles of travel }\end{array}$ \\
\hline The HOV facility should have public support. & $\begin{array}{l}\text { Support for the facility among users, non-users, general public, and } \\
\text { policy makers } \\
\text { Violation rates (percent of vehicles not meeting the occupancy } \\
\text { requirement) }\end{array}$ \\
\hline $\begin{array}{l}\text { The HOV facility should be a cost-effective } \\
\text { transportation improvement. }\end{array}$ & Benefit-cost ratio \\
\hline
\end{tabular}

\section{(b) Reduced total travel time and improved reliability}

The implementation of the HOV lanes is expected to reduce the travel time in peak hour and peak direction for the vehicles traveling in the HOV lanes. For this to happen, the speed of travel in the HOV lane should exceed that on the general purpose lanes before the HOV implementation. The HOV lanes are also expected to improve trip reliability by ensuring that no delays occur on the corridor due to recurrent congestion. To ensure reliability in the prediction of trip travel times, the travel speeds on the HOV lanes should also remain more or less constant during the day. Stable and high travel speeds can be achieved on the HOV lanes as long as demand does not exceed capacity on the HOV lanes.

\section{(c) Improve efficiency and economy of public transit operations}

HOV facilities are expected to improve the operating efficiency of bus services that use the freeway corridor by reducing their travel time, improving schedule adherence, increasing bus operating speeds, improving service 
reliability (frequency) and reducing overall operating costs of transit agency. The measures of effectiveness used to assess improved transit efficiency include:

- Reduced travel time of buses on freeway due to improved speed

- Improved schedule adherence measured by on-time performance

- Improved safety, by a reduction in vehicle accident rates

- Improvement in service reliability measured in terms of increased frequency

- Improvement in vehicle productivity measured in terms of operating cost per vehicle mile, operating cost per passenger or per passenger mile

Improved transit efficiency helps in attracting more passengers in the transit system thereby inducing more people to travel on buses in HOV lanes. This could improve the overall average vehicle occupancy on the freeway thereby reducing congestion.

\section{(d) Air quality and energy impacts}

HOV facilities are expected to have favorable impacts on air quality and energy consumption. Air pollution can be reduced substantially by ridesharing. Van-pools, for example, can achieve up to 80 percent reductions for hydrocarbons, carbon monoxide, particulates and $\mathrm{NO}_{\mathrm{x}}$ emissions over single-person auto travel [California Legislative Analyst's Office, 2000]. The extent of improvement in air quality can be measured in terms of reduced emissions, reduced total fuel consumption and reduction in growth of vehicle miles of travel.

\subsection{HOV SYSTEM COMPONENTS}

The components of a HOV system can vary widely from one location to another. FHWA (1992) describes HOV lane facility as a system rather than a highway project and defines HOV systems as "the collective application of physical facilities, programs, and policies that are effectively integrated to provide a comprehensive application of HOV incentives in a corridor or region." The components in the HOV system can broadly be categorized as follows:

- The physical components which comprise fixed assets such as the HOV lane, parking facilities, ingress/egress ramps and transit centers

- The operational components which comprise policies regarding occupancy requirements, time-of-day restrictions, enforcement programs and marketing plans.

The physical components of the HOV system include the following:

\subsubsection{HOV Lane Type}

The major types of HOV lanes currently in use in the United States are described in this section. The choice of a particular type for implementation at a given location depends on a number of factors including congestion levels, space, costs, availability of funds as well as the influence of the other elements of the HOV system. Different types of HOV lane systems are as follows: 


\subsubsection{Separate Right of Way HOV Facility}

This type of HOV facility is a roadway or lane(s) developed in a separate right of way and designated for the exclusive use by high occupancy vehicles. Most existing facilities of this type are designed for and utilized by buses only. Most are 2 lane, 2 directional facilities. Examples are:

- South and East Bus-way in Pittsburgh, Pennsylvania

- Transit-way system in Ottawa Ontario Canada

\subsubsection{Exclusive HOV Facility in a Freeway Right of Way}

This type of HOV facility is a lane constructed ("add-a-lane” approach) within the freeway right of way. In the case of exclusive facilities, the HOV lanes are physically separated from the general purpose lanes by physical barriers or buffers and the lanes are used exclusively by high occupancy vehicle modes. Exclusive facilities have the advantage that the physical separation tends to minimize violation rates thereby facilitating HOV enforcement. Also public approval is expected to be higher if a newly constructed lane is designated as HOV compared to the scenario when an existing general purpose lane is converted to an HOV lane. As such most transportation agencies seem to prefer this HOV facility type. The capacity of these facilities is generally in the range of 1500-2000 vphpl. The disadvantage is the relatively high cost involved in land acquisition and facility development. These facilities are of two types: exclusive barrier separated and exclusive reversible.

\section{a. Exclusive Barrier-Separated HOV Facility}

Figure 2.2 shows an exclusive barrier separated HOV facility. Barrier-separated HOV facilities can be used for reversible or two-way operations. Two-directional facilities consist of at least one HOV lane operating in each direction simultaneously. Exclusive Reversible HOV Lane facilities, on the other hand, consist of one or more HOV lanes operating for a portion of day in one direction and for the remaining portion of the day in the opposite direction. The operation of the exclusive reversible HOV lane(s) is suspended for a couple of hours between the peak periods in order to reverse the flow in the HOV facility. Two-way operation is considered most desirable when space and cost considerations are not major concerns.

Barrier-separated HOV facilities offer the following advantages irrespective of whether they are operated as two-way or reversible facilities.

- Ease of enforcement (violations can be enforced at ingress/egress locations)

- Ease of incident management

- Unimpeded HOV operation without interference from the mixed flow lanes

- Lower violation rates

- High level of driver comfort 


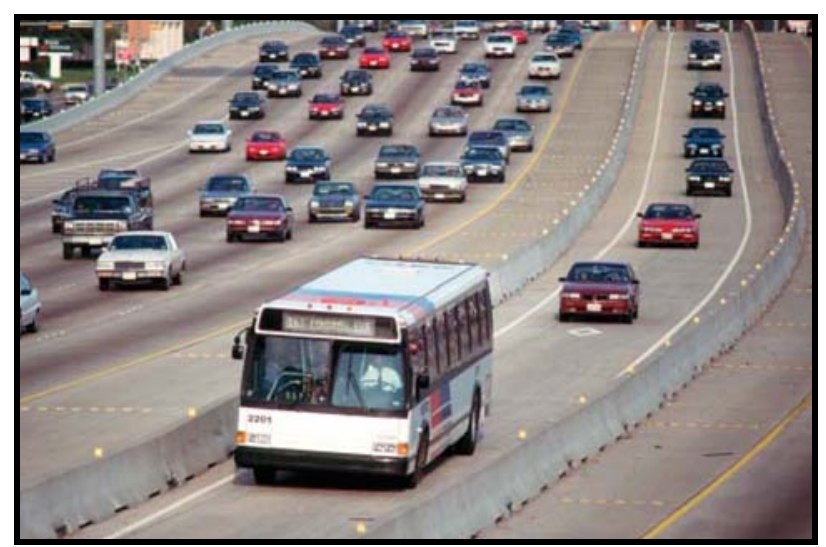

Figure 2.2: Barrier Separated HOV Facility [Houston, 2003]

A reversible barrier-separated HOV facility is considered when the project is severely constrained by right of way and environmental considerations and when the flow in the peak direction exceeds $65 \%$ of traffic [Caltrans, 2003]. This option of reversible HOV lanes provides capacity in the peak direction with less right of way requirement than that required by exclusive two-directional HOV lanes. Figure 2.3 shows schematically the exclusive two-directional and reversible HOV facilities.
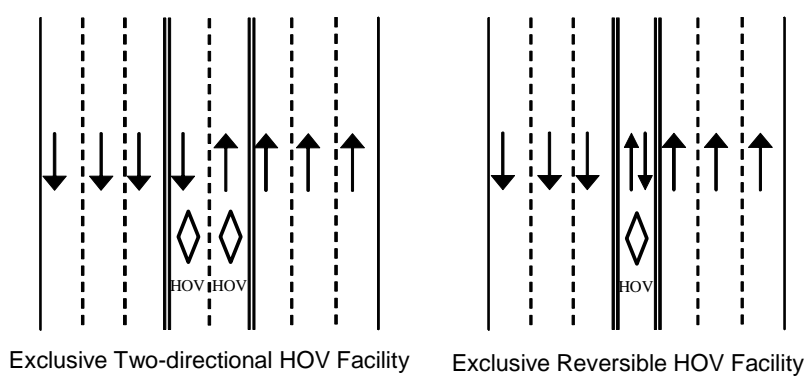

Figure 2.3: Exclusive two-Directional and Reversible HOV Facilities Concept

\section{b. Exclusive Buffer-Separated HOV Facility}

This facility can also be operated as a two-directional or reversible HOV Facility. However, the HOV lanes are separated from the GP lanes using a painted buffer instead of concrete barriers. The width of the buffer is generally less than $1.2 \mathrm{~m}$. Buffers of width $3.6 \mathrm{~m}$ or higher are typically used only if there is adequate width to provide $3.0 \mathrm{~m}$ or wide shoulders left of the HOV lane. Buffer widths between $1.2 \mathrm{~m}$ to $3.6 \mathrm{~m}$ are typically not recommended because they may create an illusion that they are safe places to stop [Caltrans, 2003].

The buffer separated HOV facilities provide the motorists with a better level of service than the concurrent flow lane HOV facilities. Compared to the concurrent flow lane HOV facilities, buffer separated HOV facilities 
provide the higher driver comfort, extra margin of Safety because of extra maneuvering area and reduced impact of incidents on adjoining HOV and mixed flow lanes. Figure 2.4 shows a buffer separated HOV facility.

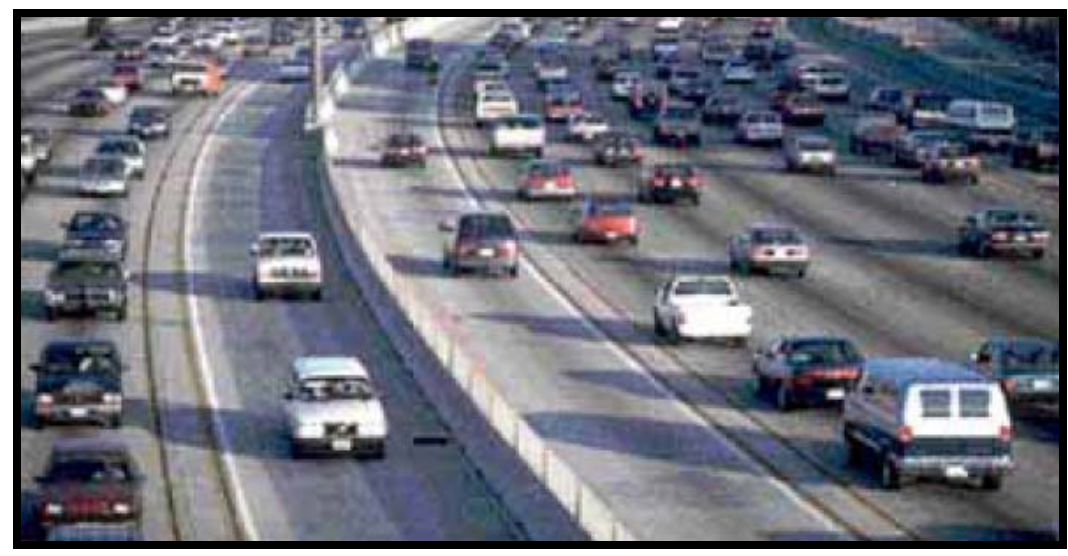

Figure 2.4: Buffer Separated Exclusive two-Directional HOV Facility

The buffer can be designed in two ways, as shown in Figures 2.5 and 2.6.

(i) Single Stripe Buffer (Double Yellow Line)

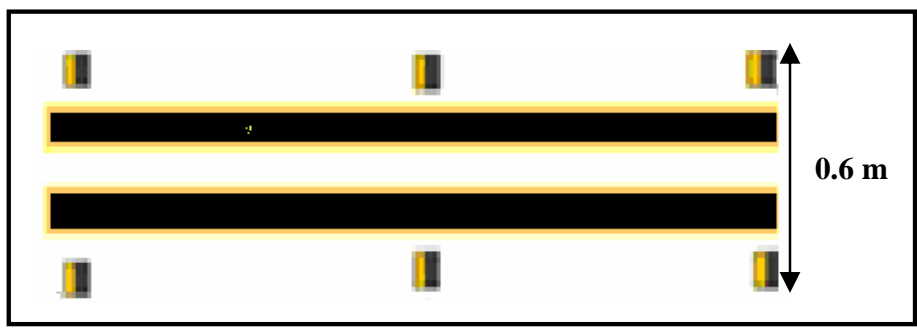

Figure 2.5: Single Stripe Buffer (Double Yellow Line) - 0.6 m Wide

(ii) Painted Buffer (Two double Yellow stripes)

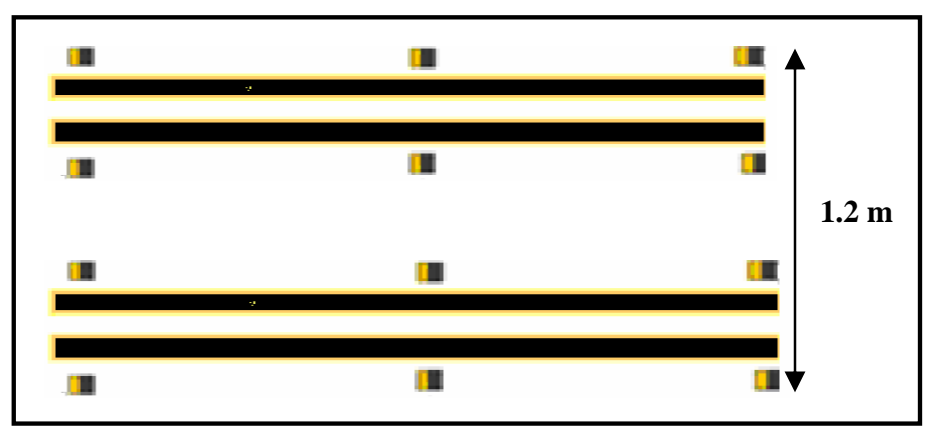

Figure 2.6: Painted Buffer (Double Yellow Stripes) - $1.2 \mathrm{~m}$ Wide 


\subsubsection{Concurrent Flow (Contiguous) HOV Facility}

Concurrent flow lanes are defined as a freeway lane in the same direction of travel and are not physically separated from the general purpose lanes. They can be operational for all or a portion of the day. Concurrent flow lanes are typically located on the inner lanes or shoulder of the freeway. These lanes are usually delineated by paint striping. Concurrent HOV facilities are generally implemented on freeways with short duration, high volume, peak commute periods. Concurrent flow lane facilities can also be used when sufficient right of way is not available for barrier or buffer separation of the HOV lane from the general purpose lane. These facilities are easy to implement as no detailed design for construction of ingress/egress is required except for at the beginning and end of the HOV facility. Depending upon the traffic and congestion level the concurrent flow HOV lane can be implemented in both directions simultaneously (Figure 2.7) or separately with morning peak hour operation in one direction and evening peak hour operation in the other direction. If peak period occurs in one direction only, the HOV lane is operated in that direction only as a concurrent flow lane.

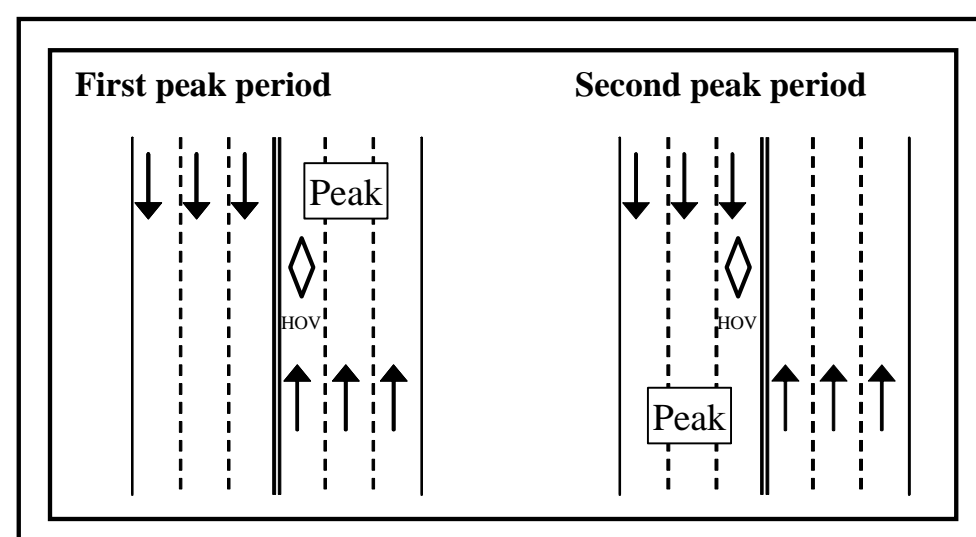

(a) Only one peak direction in each peak period

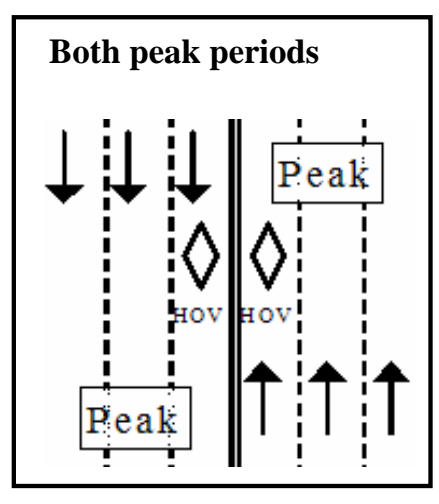

(b) Two peak directions in each peak period

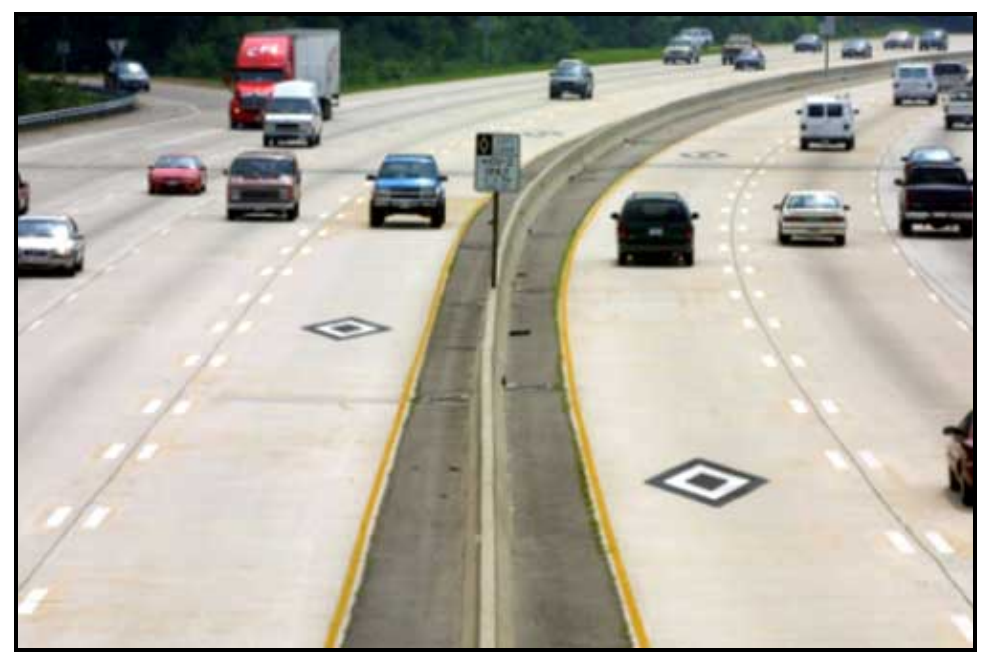

Figure 2.7: Concurrent Flow Lane HOV Facility 


\subsubsection{Contra-flow HOV Facility}

Contraflow lanes are best suited when the traffic volume in one direction during the peak period is considerably higher than the traffic volume in the other direction. In such a situation, one general purpose lane from the off-peak direction is converted to an HOV lane for the peak flow direction. The directional split has to be high (more than 65/35) for the contra-flow lane facility to be implemented. These facilities operate only during the peak period. Contraflow HOV lanes are considered if traffic congestion in one direction is so severe that operation of one of the lanes as a concurrent flow HOV lane in this direction is also not able to improve the traffic conditions. The consideration of contra flow HOV lanes becomes even more important when sufficient right of way is not available for addition of a new lane which could be operated as a HOV lane during the peak period. The motive behind the implementation of this type of HOV facility is to ensure that no unnecessary construction is done if the existing roadway capacity (both directions combined) is capable of providing an uncongested travel during the peak period. There are examples of contraflow HOV facilities in the New York City area such as the eastbound approach to the Lincoln Tunnel, and portions of the Long Island and Gowanus Expressways. In the Dallas area along East R.L. Thornton (l-30 East) corridor, a movable concrete barrier was used to separate the HOV lane from the GP lanes. Figure 2.8 demonstrates the contraflow concept.
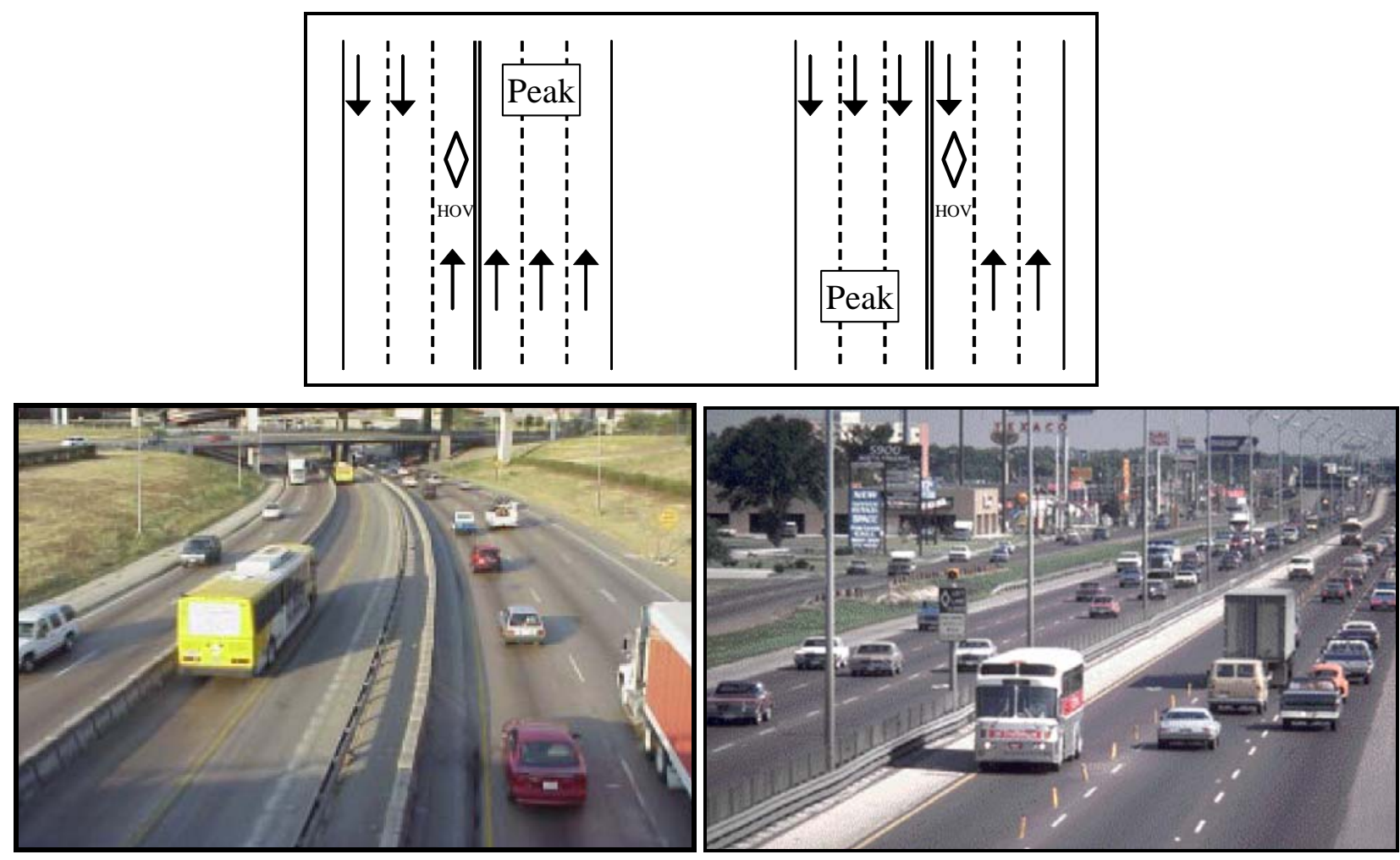

Figure 2.8: Barrier \& Pylon Separated Contra Flow HOV Facilities 
Figure 2.9 summarizes the various types of HOV facilities that have been implemented in the US over the last three decades.

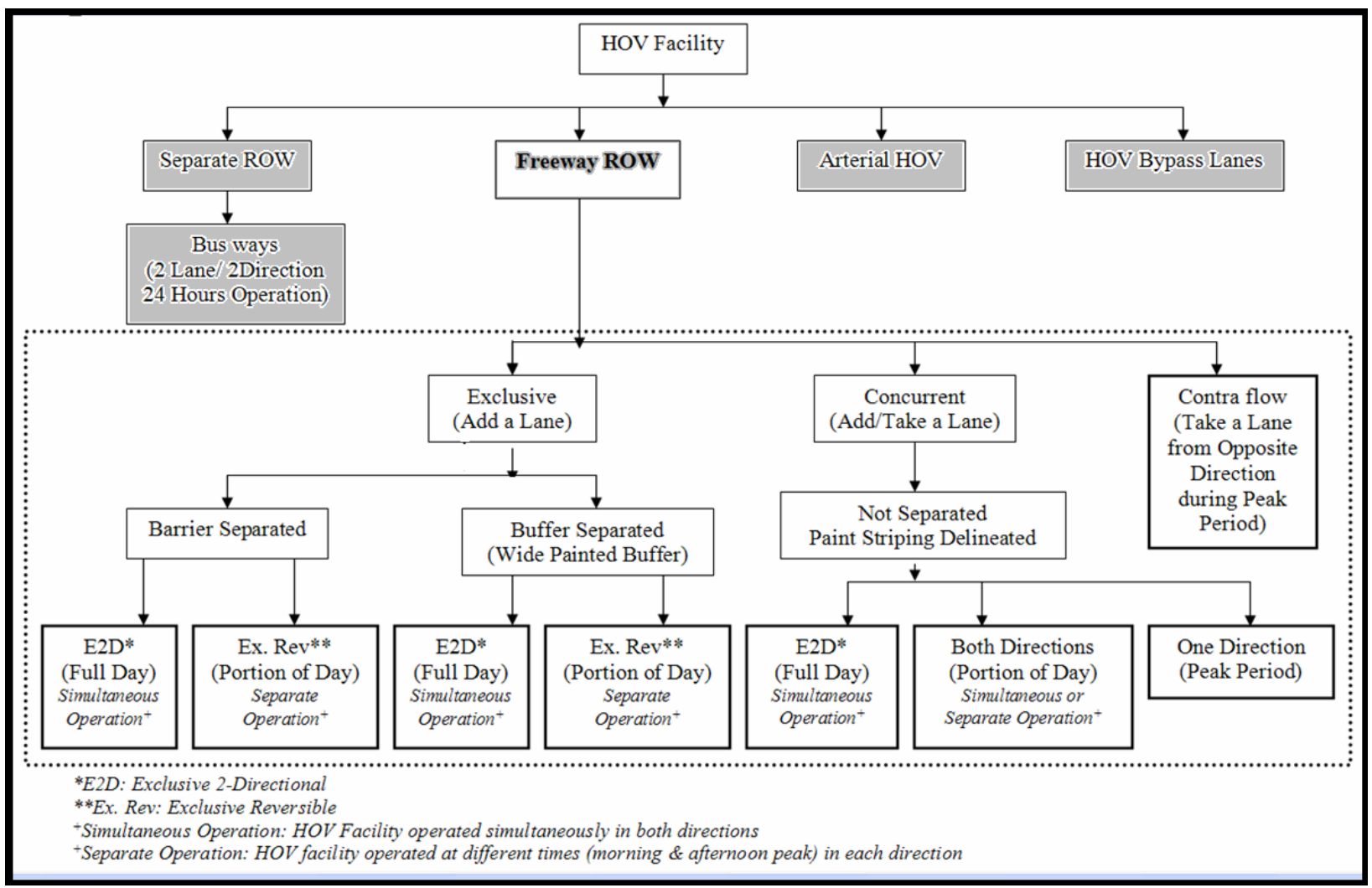

Figure 2.9: Types of HOV Lane Facilities in the US

There are three ways of implementing a HOV lane on a freeway - adding a lane by increasing the right of way, utilizing the existing shoulder (restriping shoulder) or median; and converting an existing general purpose lane to a HOV lane. The first two approaches fall under the category of add-a-lane approach because the HOV lane is added without taking away a general purpose lane while the last one falls under the category of take-a-lane approach. The add-a-lane approach is generally preferred over the take-a-lane approach. Most of the HOV projects on North American Freeways have been implemented by using the add-a-lane approach [Fisher, 1997]. As a result the construction of HOV facilities in general increases the capacity of the original road lanes for SOVs. Most of the agencies have abstained from using the take-a-lane approach for HOV lane implementation due to possible public opposition and political concerns.

The take-a-lane approach can be highly controversial as exemplified in the case of Santa Monica Freeway in Los Angeles in 1976. The controversy generated by this project because of take a lane approach caused it to be terminated. Since then, all the HOV projects implemented in the Los Angeles County were based on add-a-lane approach. The Los Angeles County has more than 425 lane miles of HOV lanes on 14 corridors. Almost all of these projects are buffer-separated exclusive 2-directional HOV lanes that are operated for 24 hours. However, the add-a- 
lane approach may not prove to be a cost effective congestion mitigation strategy. The cost of the add-a-lane approach can involve the purchase of additional right of way which can significantly lower its cost effectiveness. Besides, the addition of a lane and its designation as a HOV lane can be considered a road widening strategy for congestion mitigation. However, the benefits derived from the designation of the added lane as an HOV lane can be much more than those derived from just increasing the corridor capacity by adding lanes. In a Texas HOV facility study [Stockton et al., 1999], the benefit-to-cost ratios for seven established HOV projects were determined. These ratios were compared to the hypothetical case where two freeway general purpose lanes were added instead of a newly constructed barrier separated exclusive reversible HOV lane. The results (Table 2.3) showed that adding a new lane for HOVs could prove to be more cost-effective than the construction of a general purpose lane in each direction.

Table 2.3: Benefit to Cost Ratio of HOV Projects in Texas [Stockton et al. 1999]

\begin{tabular}{|c|c|c|c|}
\hline HOV Facility & $\begin{array}{c}\text { HOV Facility } \\
\text { Type }\end{array}$ & $\begin{array}{c}\text { Benefit to Cost } \\
\text { Ratio For } \\
\text { HOV Lane }\end{array}$ & $\begin{array}{l}\text { Benefit to Cost Ratio } \\
\text { for Two General } \\
\text { Purpose Lanes }\end{array}$ \\
\hline Katy Freeway, Houston & \multirow{5}{*}{$\begin{array}{c}\text { Exclusive } \\
\text { Reversible Barrier } \\
\text { Spearated Median } \\
\text { HOV Lane }\end{array}$} & $15: 1$ & 9:1 \\
\hline Gulf Freeway Houston & & 9:1 & 4:1 \\
\hline Southwest Freeway, Houston & & $8: 1$ & $5: 1$ \\
\hline Northwest Freeway, Houston & & $7: 1$ & $6: 1$ \\
\hline North Freeway, Houston & & 4:1 & 4:1 \\
\hline East R.L. Thornton Freeway, Dallas & Contraflow & 28:1 & $10: 1$ \\
\hline Stemmons Freeway, Dallas & Concurrent & 48:1 & 43:1 \\
\hline
\end{tabular}

The right of way costs involved with the add-a-lane approach can be lowered by adding a lane in the freeway median or by constructing a lane by re-striping of shoulders. This process of accommodating an additional lane (HOV lane) within the existing freeway right of way may reduce or completely eliminate the costs involved in the purchase of right of way for HOV implementation. Gard, Jovanis and Narasayya (1994) surveyed a random sample of Californians in 1993 and found the following preferences for HOV construction.

- Restripe shoulder: $40 \%$

- Add New Lane: 30\%

- Convert Existing Travel Lane: 30\%

The support for converting an existing general purpose lane to an HOV lane went up to 67\%, if the HOV lane addition was intended to fill in gaps in an existing HOV lane network. Leman, Pauly and Schiller (1993) showed that most early HOV lanes were converted lanes and that there were several successful converted HOV and bus-only lanes.

\subsubsection{HOV Lane Signs and Markings}

HOV lane signs and markings have to be considered because most of the HOV facilities have been installed alongside the existing general purpose lanes. The objective is to ensure safety on the freeway. The general purpose 
lanes and HOV facility have very distinctive operating characteristics. Since one system is superimposed on another, the space for signs and markings is very restrictive and varies depending upon the type of geometric configuration (contiguous, buffer-separated) and mode of operation (operating hours and occupancy requirement).

Figure 2.10 shows the preferential only lane signs that are commonly found on the HOV lanes. In addition to the preferential only lane signs, guide signs are placed at the beginning of the HOV facility so as to guide the traffic from the general purpose lanes to the HOV lane. Special reversible only lane signs have to be placed when the HOV lane is operated as a reversible lane. HOV markings act as a supplement to the signs and are basically used to differentiate the HOV lane from the adjacent general purpose lane thereby conveying a message that only high occupancy vehicles can use the HOV lane. The guidelines for the implementation of HOV lane signs and markings can be based upon the general principles in the Manual of Uniform Traffic Control Devices or can be developed by the respective DOTs as a supplement to the MUTCD principles. For example, California supplement to the MUTCD includes certain guidelines for the HOV lane signs and markings.

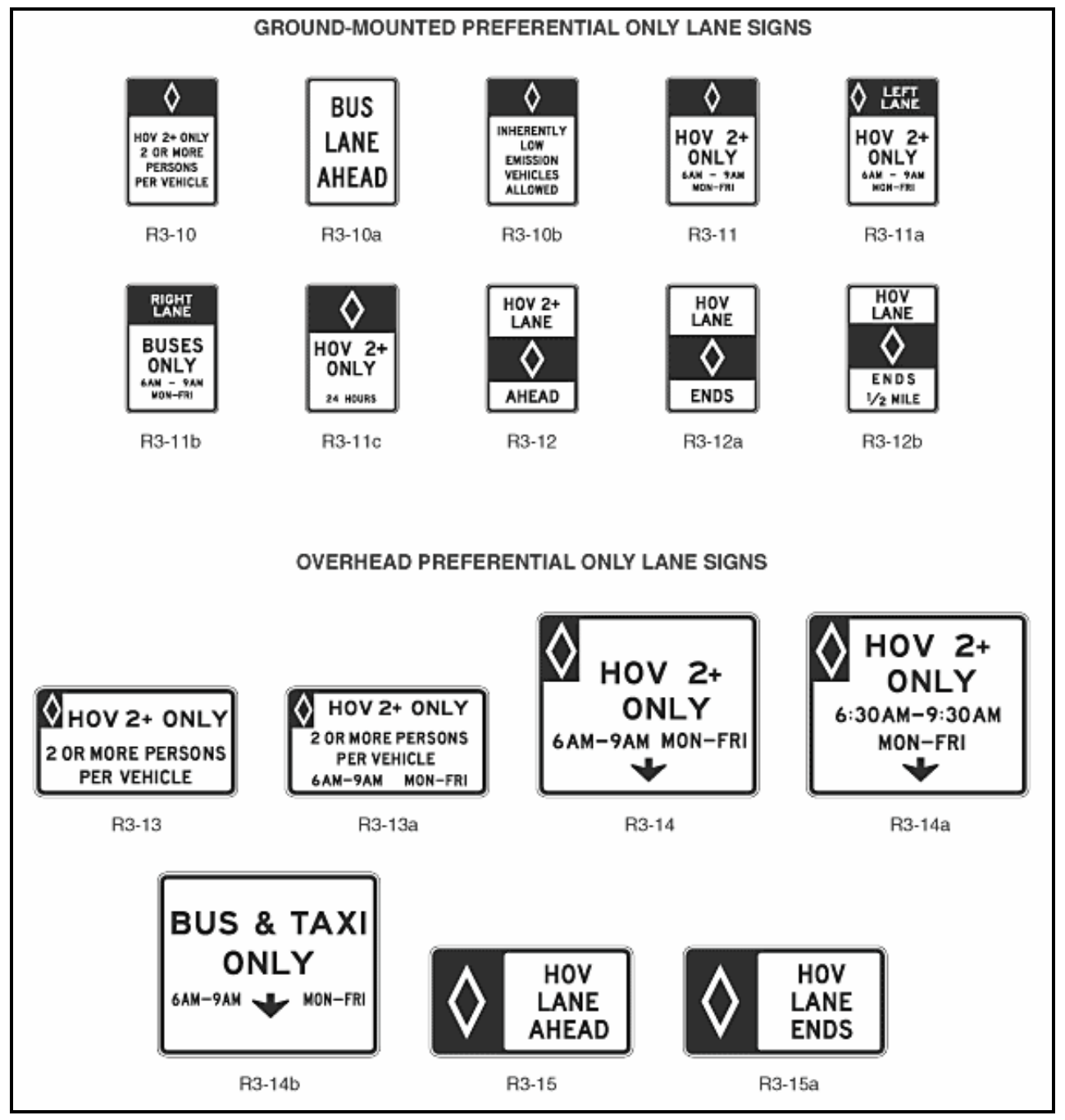

Figure 2.10: Preferential Only Lane Signs [MUTCD, 2003] 
The pavement marking on the HOV lane mainly includes the lane separation in the form of buffers (Figures 2.5 and 2.6). The concurrent HOV lane facility is often separated from the general purpose lanes by a single striped line. Shoulder markings and diamond markings to designate a HOV lane are other forms of markings typically found on the HOV lane.

\subsubsection{High Occupancy Vehicle Modes}

Carpools, vanpools and buses are classed as HOV vehicle types. Vanpools can carry eight to fifteen persons per vehicle while buses can carry as many as 45-55 passengers per bus. The carpools are allowed to use the HOV lane provided they satisfy the minimum requirement of two, three or four persons per vehicle set forth for the HOV facility. When planning an HOV system, it is important to identify which of these vehicle modes are expected to use the system and the number of vehicles of each type. For most HOV facilities implemented in the US, all the three high occupancy vehicle modes were allowed to use the HOV lanes. The occupancy requirement for carpools may change over time depending upon the extent of the use of the HOV facility and congestion in the general purpose lanes. Sometimes, the use of HOV lanes can also be opened to motorcycles, emergency vehicles and even the SOVs (provided they pay a toll for using the HOV lanes). California allows the low-emission vehicles to use the HOV lanes. In August 2005, a bill was passed to allow hybrid vehicles to use the HOV lanes in California.

It should be noted that not all the eligible carpools and vanpools will move to the HOV lanes. Some use the general purpose lane either because they find it inconvenient to use the change lanes to get into the HOV lanes or because the length of their trip on the HOV lane is not large enough so that they can derive significant travel time benefits. Furthermore, the designation of an added lane as an HOV lane may sometimes bring down the level of congestion in the general purpose lane thus making it more attractive to the commuters.

\subsubsection{Bus Service}

Most of the highly successful HOV lane projects have a significant number of buses using the HOV lanes. The presence of buses on the HOV lanes helps in significantly increasing the overall average vehicle occupancy of the freeway. For example, in Houston, Texas the express bus service is operated by METRO (Metropolitan Transit Authority of Harris County) in the radial direction with downtown Houston as the major destination. METRO provides the bus service in each of the six HOV lane corridors with frequent trips from the major park-and-ride lots.

The number of buses operating in the peak hour in 2001 ranged from 21-54 across the various HOV facilities in Houston [Levinson et al., 2003]. The average number of passengers traveling in the buses and the total number of buses operating on each of the six HOV facilities daily and during the am-pm peak hours is presented in Figure 2.11. The am/pm peak period average vehicle occupancy on these corridors is shown in the Figure 2.12. The overall average vehicle occupancy on these corridors increased significantly because of the number of passengers riding the buses and the number of buses operating on these corridors. The average vehicle occupancy for carpools during the am/pm peak period HOV operation was approximately 2.1 for all the HOV facilities in Houston in 2005. However, the overall average vehicle occupancy in the HOV lanes increased with the number of buses plying on the corridors. The overall average vehicle occupancy for the HOV lane was in the range of $3.0-4.0$ for all the HOV 
facilities except the Eastex HOV lanes. The ratio of the number of carpools and vanpools to the number of buses on the Eastex HOV lanes is less as compared to the other HOV lanes thereby resulting in higher overall average vehicle occupancy.
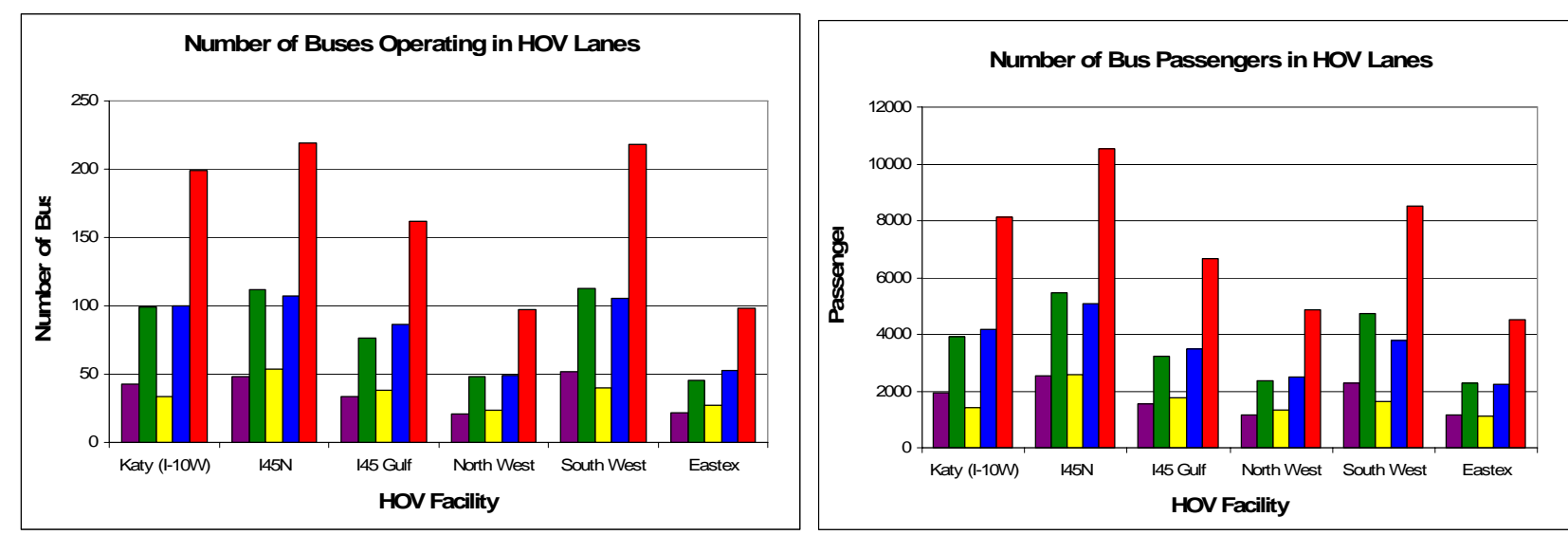

AM Peak Hour

$\square$ AM Peak Period

$\square$ PM Peak Hour

PM Peak Period

$\square$ Daily Total

Figure 2.11: Bus Volume and Rider-ship on the HOV Lanes, Houston [Levinson et al., 2003]
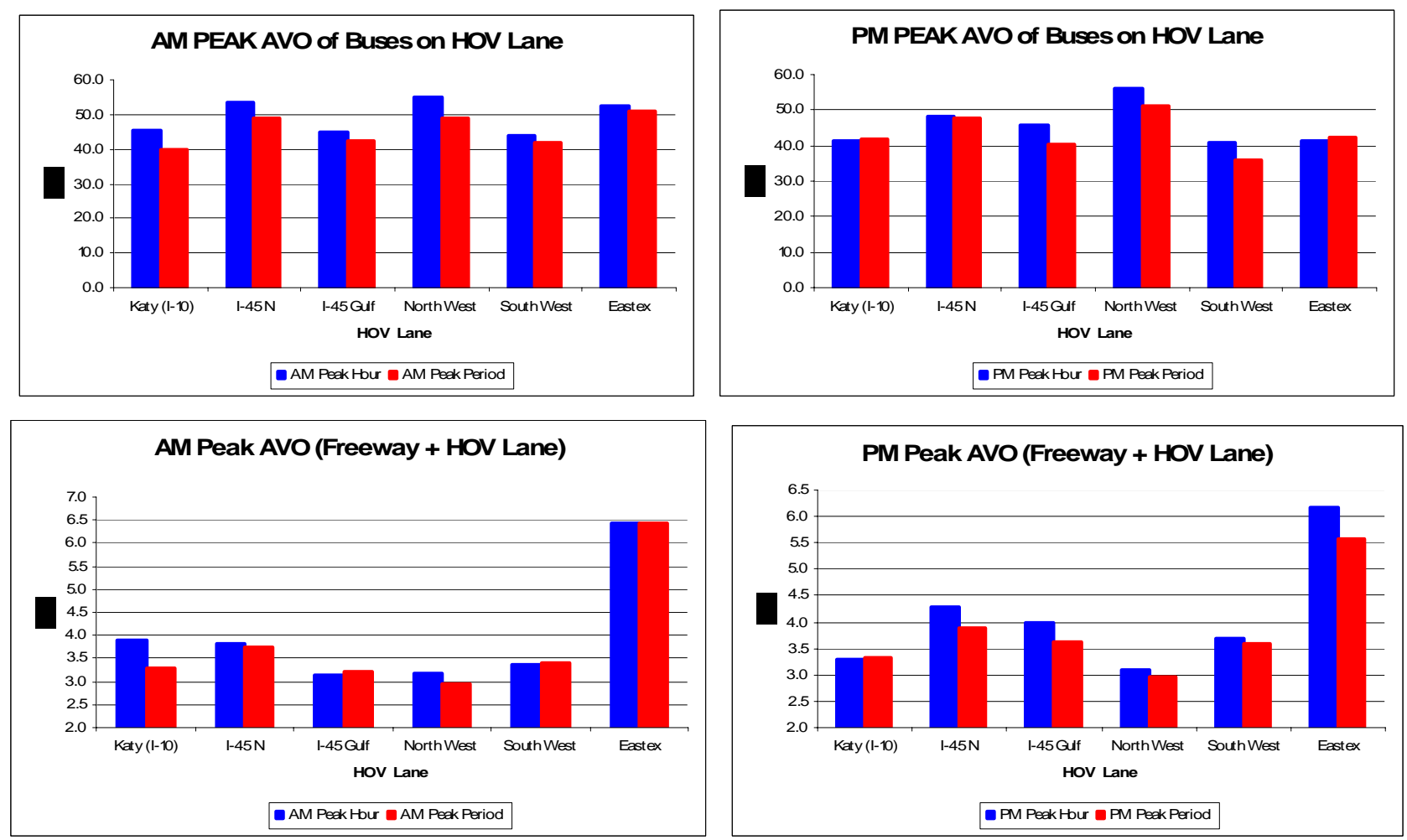

Figure 2.12: Impact of Bus Service on Average Vehicle Occupancy in Houston [Levinson et al., 2003] 
The implementation of a bus service can hence drastically reduce the number of vehicles on the freeway, fuel consumption, emissions and vehicle operating costs. Table 2.4 shows the characteristics of the bus passengers in the HOV lane for four of the HOV facilities in Houston. It was observed that about $91 \%$ of the bus passengers in the HOV system comprising of these freeways, owned an automobile and yet chose to ride on buses. Between 38\%-46\% of the bus passengers used to drive alone before the implementation of the HOV lanes on each of these freeways. The percent of bus riders who previously used to carpool is as high as $16 \%$ on all the corridors. Hence, as many as $60 \%$ of the bus passengers decided to use the bus to travel on the freeway instead of carpooling or using a personal vehicle. More than 600 buses were operating daily on these four corridors in Houston in 2003 with average bus occupancy of 45-50 passengers. The four corridors carried more than 25,000 bus passengers daily among themselves in 2003. The decrease in the number of vehicles and congestion on these freeways can be estimated given that $90 \%$ of these people had a personal automobile and more than $60 \%$ used to drive before they shifted to buses.

Table 2.4: Characteristics of Bus Passengers [Levinson et al., 2003]

\begin{tabular}{|c|c|c|c|c|c|}
\hline Item & & $\begin{array}{c}\text { Katy (I- } \\
\text { 10) }\end{array}$ & $\begin{array}{c}\text { North (I- } \\
45)\end{array}$ & Gulf & $\begin{array}{c}\text { Northwest } \\
\text { (US290) }\end{array}$ \\
\hline \multicolumn{2}{|c|}{ Automobile Availability } & $91 \%$ & $95 \%$ & $89 \%$ & $92 \%$ \\
\hline \multirow{6}{*}{ Prior Mode } & Drove Alone & $46 \%$ & $39 \%$ & $38 \%$ & $43 \%$ \\
\hline & Carpooled & $8 \%$ & $9 \%$ & $8 \%$ & $12 \%$ \\
\hline & Vanpooled & $8 \%$ & $8 \%$ & $6 \%$ & $8 \%$ \\
\hline & Bus & $1 \%$ & $15 \%$ & $30 \%$ & $3 \%$ \\
\hline & Did not make Trip & $30 \%$ & $28 \%$ & $18 \%$ & $25 \%$ \\
\hline & Other & $5 \%$ & $1 \%$ & $0 \%$ & $0 \%$ \\
\hline \multirow{5}{*}{$\begin{array}{l}\text { Reasons for using } \\
\text { Express Bus } \\
\text { Service }\end{array}$} & Cheaper than Driving & $46 \%$ & & & $52 \%$ \\
\hline & Part of Fare & $48 \%$ & & & $57 \%$ \\
\hline & Saves Time & $39 \%$ & & & $26 \%$ \\
\hline & Time to do Things & $75 \%$ & & & $94 \%$ \\
\hline & No Car & $5 \%$ & & & \\
\hline \multirow{6}{*}{ Access Mode } & Walk & $1 \%$ & & & $1 \%$ \\
\hline & Bus & & & & \\
\hline & Auto Driver & $88 \%$ & & & $88 \%$ \\
\hline & Carpooled & $9 \%$ & & & $8 \%$ \\
\hline & Dropped Off & $1 \%$ & & & $1 \%$ \\
\hline & Other & $1 \%$ & & & $1 \%$ \\
\hline \multirow{4}{*}{ Trip Purpose } & Work & $99 \%$ & & & $99 \%$ \\
\hline & School & $0.4 \%$ & & & $0.6 \%$ \\
\hline & Personal Business & & & & \\
\hline & Other & $0.6 \%$ & & & $0.4 \%$ \\
\hline
\end{tabular}

\subsubsection{Ingress/ Egress Facilities}

Ingress/Egress facilities are provided for vehicles to change from HOV lanes to GP lanes and vice versa along the HOV facility. A variety of treatments can be used to provide ingress and egress (access to and from) an HOV lane. Ensuring that buses, vanpools, and carpools can easily and safely merge into and out of an HOV facility is critical to the success of the facility. The type of treatment depends on the type of HOV facility. Ingress/Egress ramps are 
provided at regular intervals in the case of HOV facilities such as exclusive two-directional facilities where the HOV lane is physically separated from the general purpose lanes. The spacing of these ramps must be arrived at only after a careful analysis. Providing a large spacing between access points can result in under utilization of the facility. Overly close spacing can result in the interruption of traffic flow in HOV lanes and frequent weaving traffic in general purpose lanes.

\subsubsection{Slip Ramps}

Slip ramps may be used at the start, end, and intermediate points of an exclusive HOV lane. Slip ramps provide a break in the barrier or buffer allowing HOVs to enter and exit the HOV lane. Slip ramps are less expensive than direct access ramps, but conflicts may arise with vehicles merging into and out of the adjacent freeway lanes. Most of the HOV lane facilities start/end with this type of ramp.

\section{(a) Ingress/ Egress at Start/End of HOV Facility}

The design requirements for the ingress/egress of vehicles at the beginning and end of a HOV facility are different from the requirements for intermediate points of the HOV facility. The geometric design at the beginning and end of a HOV facility is crucial especially with all the HOV vehicles entering or leaving the HOV lanes at these points. The geometric design varies with the type of HOV facility. Figure 2.13 shows a slip ramp to enter a barrier or buffer separated HOV Facility. Figure 2.14 shows the slip ramp for a contiguous/concurrent flow lane HOV facility. Contiguous and buffer separated HOV lanes are separated from the general purpose using painted stripes and a wide $(0.3 \mathrm{~m}-3.6 \mathrm{~m})$ painted buffer respectively. HOV lanes typically begin on the left of the first general purpose lane as a new lane. The following geometric design guidelines have been proposed by Caltrans at the beginning of the HOV facility [Caltrans, 2003]:

- For a Buffer Separated Facility, a minimum of $400 \mathrm{~m}$ of dashed white line should be offered to provide consistency of appearance with ingress and egress areas.

- The beginning of any buffer should begin no earlier than a distance equivalent to $200 \mathrm{~m}$ per lane change required for entering the HOV lane from the nearest on-ramp.

- Additional length of the dashed white lines may be desired if visibility of the striping is compromised within the $400 \mathrm{~m}$ distance; for example at locations where vertical and horizontal curves are present.

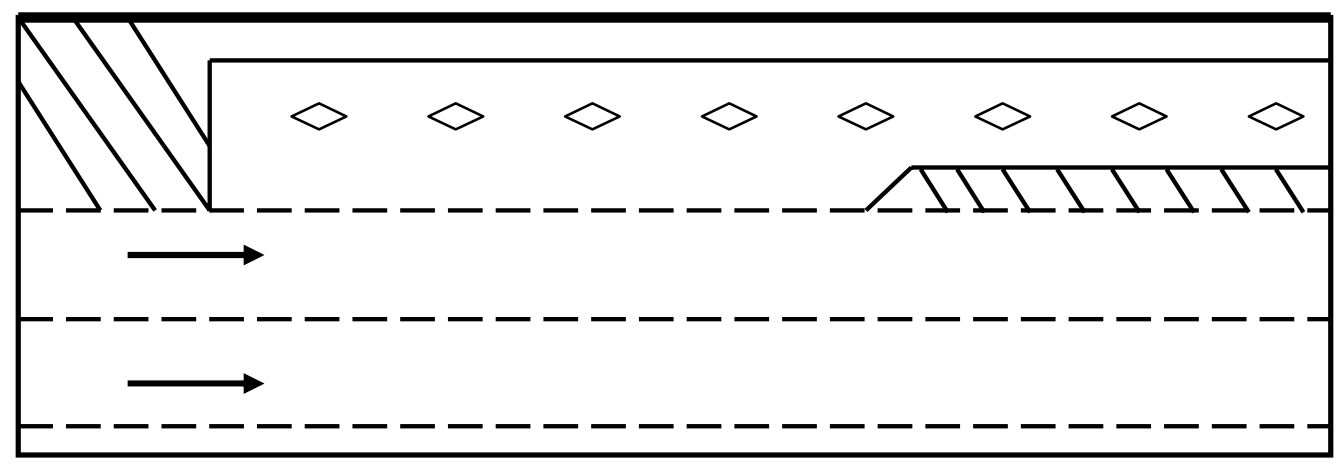

Figure 2.13: Slip Ramp at the beginning of a Barrier or Buffer Separated HOV Facility 


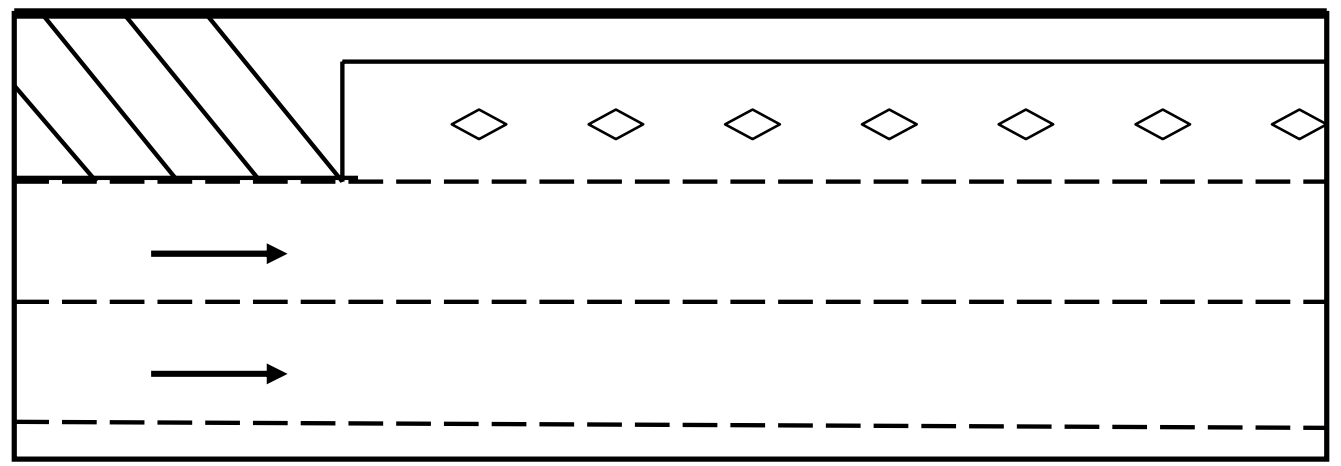

Figure 2.14: Slip Ramp at the beginning of a Contiguous HOV Facility

According to Caltrans [2003], the HOV lane should end in a continuing lane which enables the HOV traffic to continue without a merge. At the end of HOV lane facility, the outermost general purpose lane is dropped as shown in Figure 2.15. In California, any exception to this case needs an explanation followed by request for approval by Caltrans. In addition, Caltrans stipulates the following geometric requirements towards the end of the HOV facility:

- If the HOV lane has to be merged back into the freeway traffic, a minimum of $400 \mathrm{~m}$ of dashed white line (920 m desirable) should be provided before the end of the HOV lane taper begins. Additional length may be desired to achieve enhanced or improved visibility of dashed striping at locations where horizontal or vertical alignment varies.

- No less than 200 m per lane change should be provided from the end of the buffer to the next off-ramp or connector. Where feasible, greater length may be desired.

- The outside mixed flow lane can also be dropped at an off-ramp. Engineering analysis is essential with this alternative to ensure that congestion does not result near the lane drop location. Typically there should be a high demand exiting the off-ramp where the lane drop is considered.

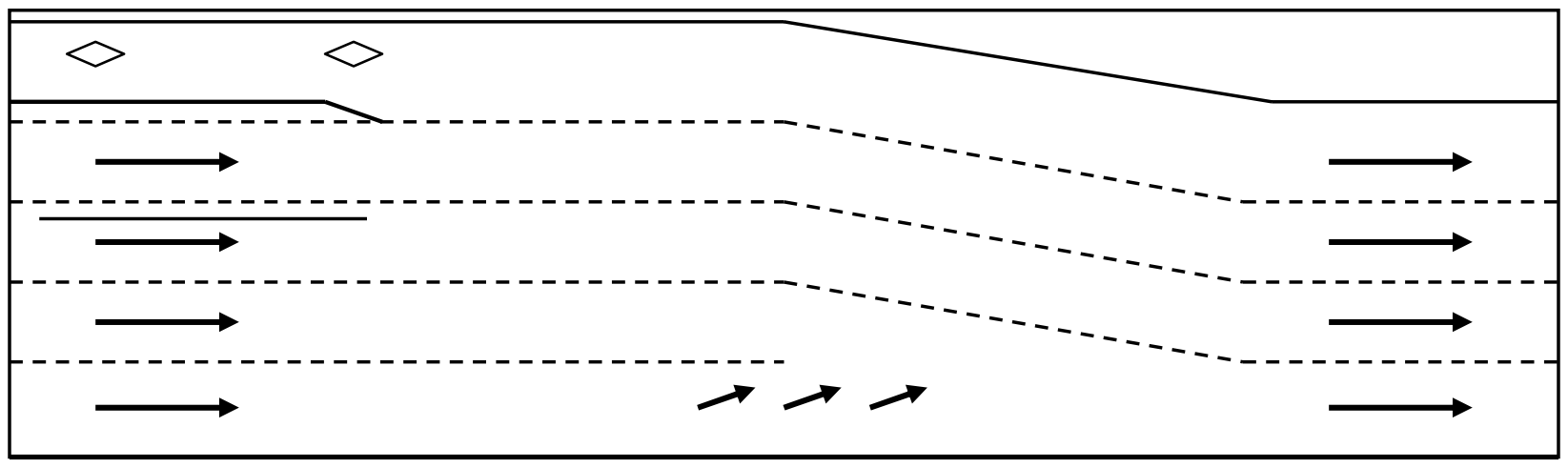

Figure 2.15: Right lane drop for Concurrent, Barrier and Buffer Separated HOV Facilities 


\section{(b) Ingress/Egress From HOV Lanes at Intermediate Location}

For Barrier Separated HOV Facilities, At-grade channelized openings are provided in the physical barriers so as to provide an ingress/egress from/to the general purpose lanes. This at-grade opening can be accomplished with the construction of a weave lane. The weave lane helps in the merging of the HOV traffic with the mixed flow traffic. A minimum length for the weave lane is often stipulated (at Caltrans $400 \mathrm{~m}$ minimum is used). The geometric design recommended by Caltrans [2003] is shown in Figure 2.16.

For Buffer-Separated HOV Facilities, the at-grade ingress and exit for the buffer-separated HOV lanes is typically provided using channelized openings (Figure 2.17).

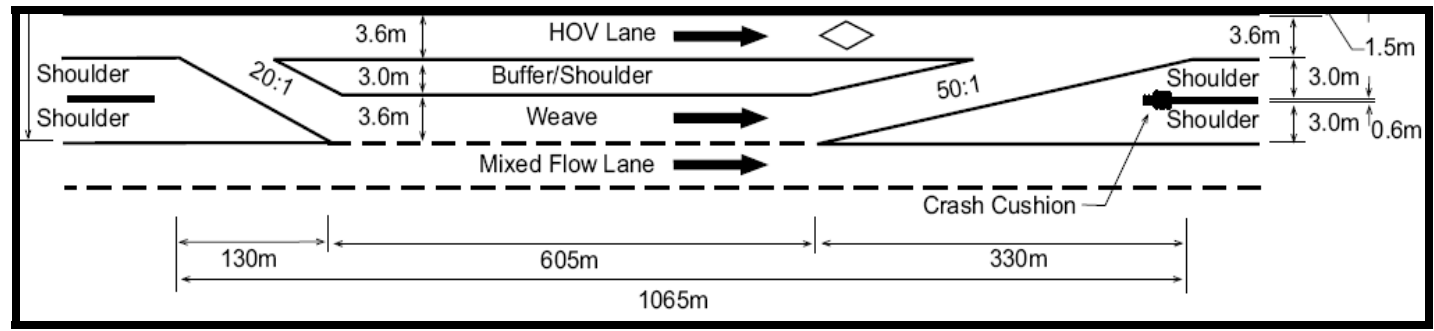

Figure 2.16: Ingress/Exit at Intermediate Location for Barrier-Separated HOV lanes

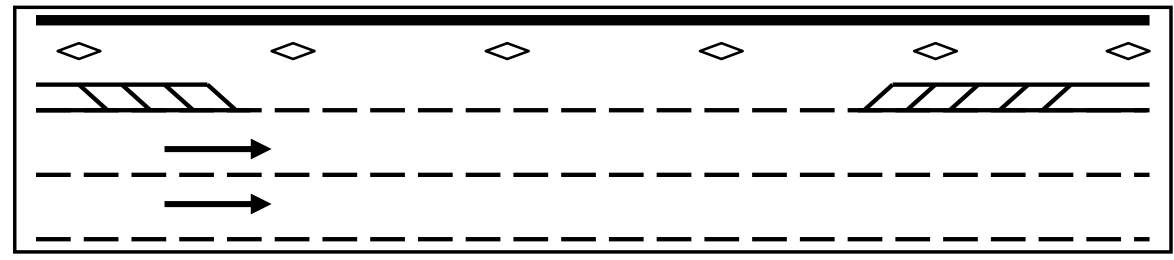

Figure 2.17: Ingress/Exit for Buffer (0.3m-1.2m) Separated HOV Lanes

The geometric design varies with the width of the buffer. The geometric design shown in Figure 2.17 is for buffer widths ranging between $0.3 \mathrm{~m}-1.2 \mathrm{~m}$. For buffer widths $3.6 \mathrm{~m}$ or wider a weave lane, is accommodated for vehicles entering or leaving the HOV facility. Figure 2.18 shows the at-grade ingress and exit for the bufferseparated HOV facilities with $3.6 \mathrm{~m}$ or wider buffers.

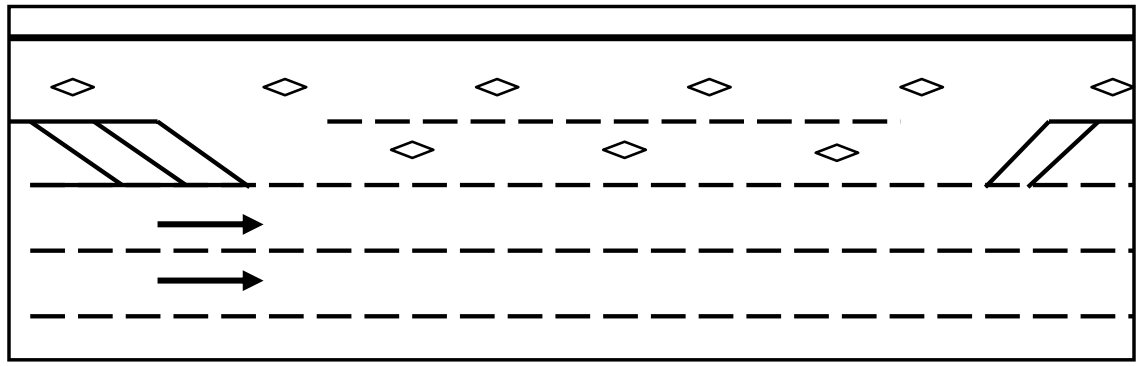

Figure 2.18: Ingress/Exit for Buffer-Separated (3.6 m or wider) HOV Lanes 
In addition to the weave lane, access can also be provided to and from barrier/buffer-separated facilities using:

- Freeway to Freeway Connection through Direct HOV Ramp connectors (e.g. South California)

- $\quad$ Median drop ramps from over-crossings or under-crossings

For the contiguous HOV lane facilities, no buffer or barrier separates the HOV lane from the GP lane. Hence the access to HOV lanes is continuous throughout the length of the HOV facility. This type of merging, where, vehicles can move from the HOV lanes to the GP lanes and vice versa directly is called 'Direct Merging'. Direct merges are usually used with concurrent (contiguous) flow HOV lanes which are not physically separated from the general purpose lanes and represent the lowest capital cost alternative. Continuous ingress and egress may be allowed along the entire HOV facility in the corridor (for contiguous HOV Facility), or specific access points may be designated at strategic points along the corridor. (for buffer-separated HOV facilities with buffer width less than $0.3 \mathrm{~m}$ to $1.2 \mathrm{~m}$ ). Barrier-separated HOV facilities and buffer-separated HOV facilities with buffer width $3.6 \mathrm{~m}$ or wider have the provision of a weave lane (as shown in Figure 2.16 earlier) and hence the merging is not direct.

A potential disadvantage with this kind of 'direct merging' approach is that conflicts may arise with HOVs merging across the general purpose lanes to enter the HOV lanes and with HOVs merging back into the regular traffic lanes. For example, the 16-mile concurrent flow HOV lane added on I-15 (Salt Lake City, Utah) is separated from the GP lanes using a painted stripe with open access to HOV lanes from/to GP lanes along the entire corridor. On one hand this provides flexibility to the users of the HOV lanes but on the other this increases the violation rate. The violation rate for I-15 was observed to be in the range of $15 \%$ which is marginally higher than the national average of $10 \%$ [Martin et al., 2002].

\subsubsection{Direct Access Ramps}

Grade separated or direct access ramps provide exclusive ingress and egress for HOVs. A variety of design treatments may be used, including drop ramps, T-ramps, Y-ramps, and flyover ramps. Direct ramps may provide access from adjacent roadways, park-and-ride lots, and transit stations. Direct access ramps may involve significant capital costs, but the travel time savings provided to HOVs and the safety benefits may justify the additional costs associated with these types of treatments. Direct access ramps in Houston are used to connect the Park and Ride lots to the HOV lanes directly. Out of the 32 park and ride facilities in 10 are connected to the HOV lanes by Direct Access ramps. All the transit centers in Houston are connected to the HOV lanes through direct access ramps. The direct access ramps can be of the following types:

\section{(i) Wishbone Ramps:}

The wishbone access ramp is one of the distinctive structures on Houston's freeway system allowing vehicles to make a direct connection between a central transit way and the freeway frontage roads. There are 4 full wishbone ramps in Houston: 2 on the North Freeway, 1 on the Gulf Freeway and 1 on the Eastex Freeway. The wishbone ramp shown in the Figure 2.19 is on the North freeway (a few miles north of downtown) and was completed in 1998. 

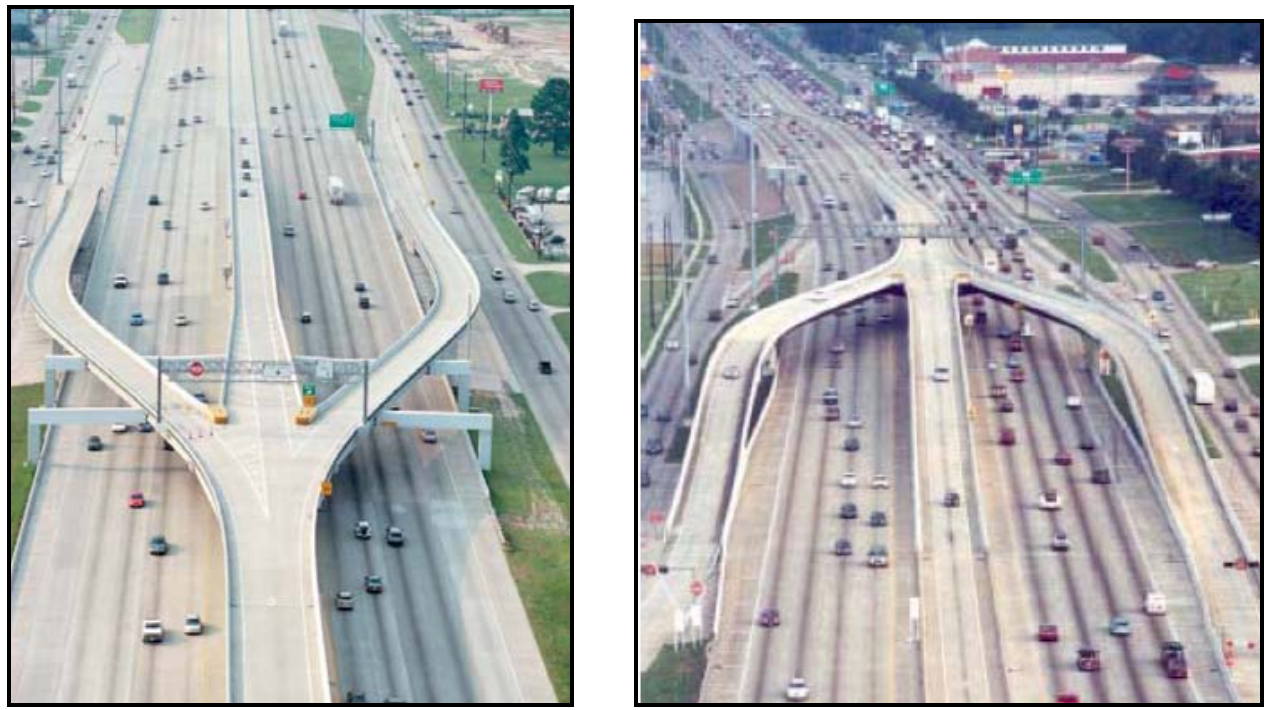

Figure 2.19: Full Wish-bone Ramp on North Freeway in Houston, Texas [Slotboom, 2003]

Figure 2.20 shows a half wishbone ramp located on the Eastex Expressway. This design allows the southbound transit way vehicles to exit to the freeway mainlines.

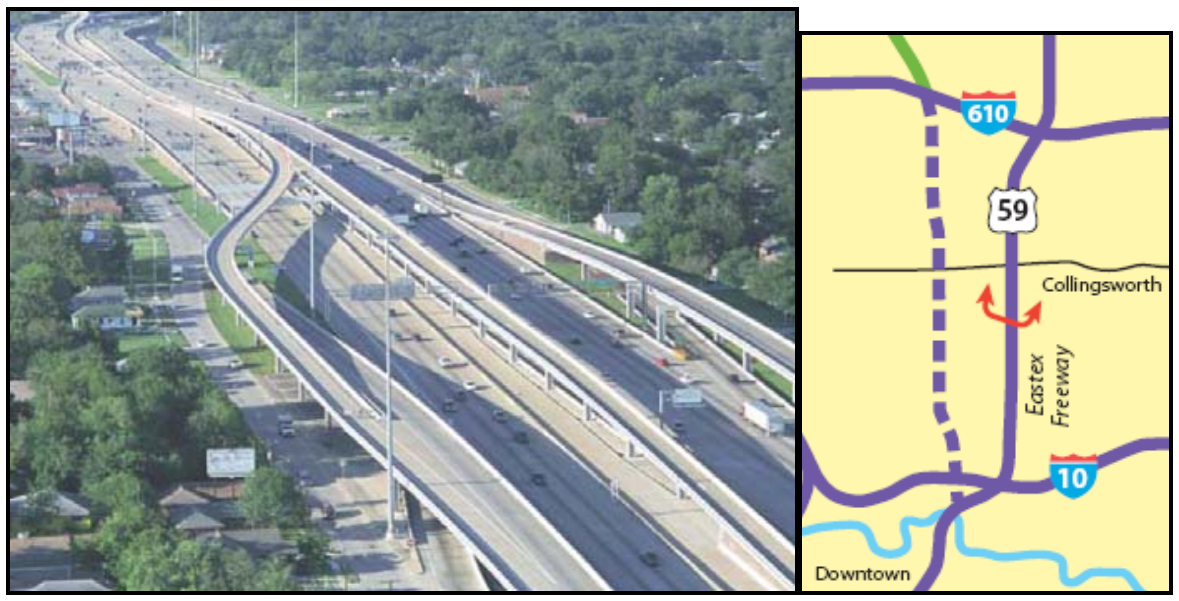

Figure 2.20: Half Wish-bone Ramp on Eastex Freeway in Houston, Texas [Slotboom, 2003]

\section{(ii) T-Ramp}

The T-ramp is shown in Figure 2.21. It is one of the most common structures on the Houston's transitway system. Because of its widespread use in Houston, this structure is often referred to as "Texas T" in the transportation community. This type of ramp is generally used to connect the transit way to an adjacent transit center or park and ride lot, crossing over the freeway mainlines and the frontage road. 


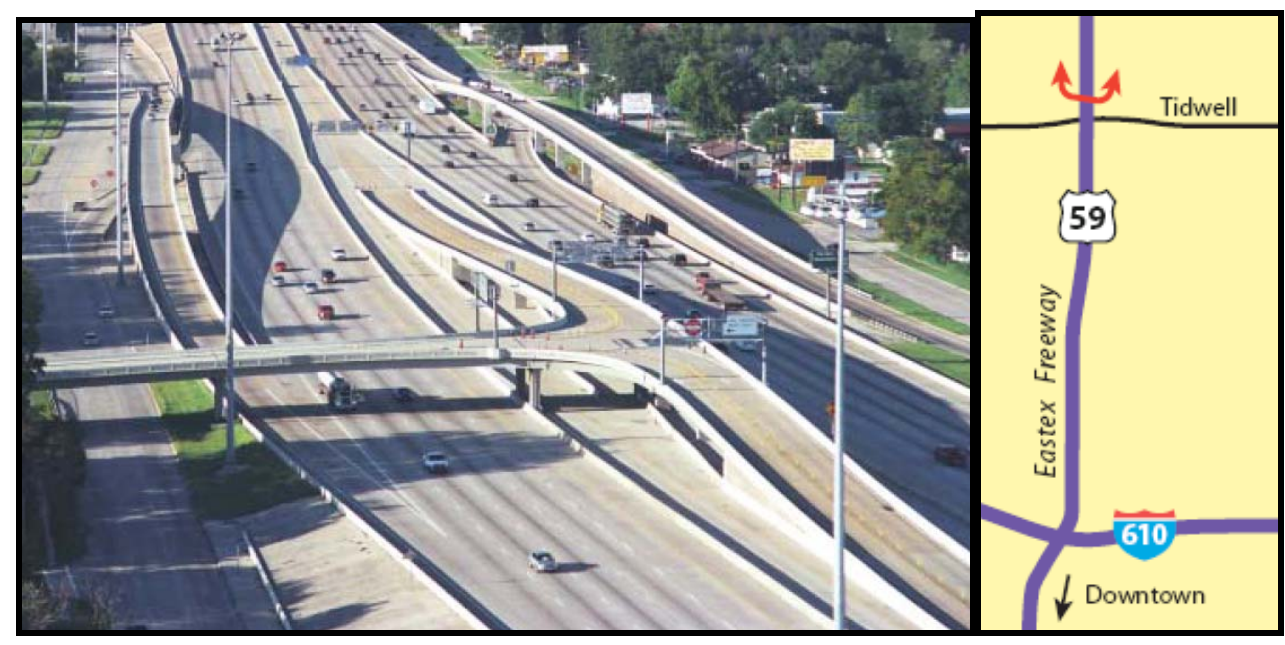

Figure 2.21: T-Ramp on Eastex Freeway in Texas, Houston [Slotboom, 2003]

The dual T-ramp shown in the Figure 2.22 on the gulf freeway provides access to the transit-way from both sides of the freeway.

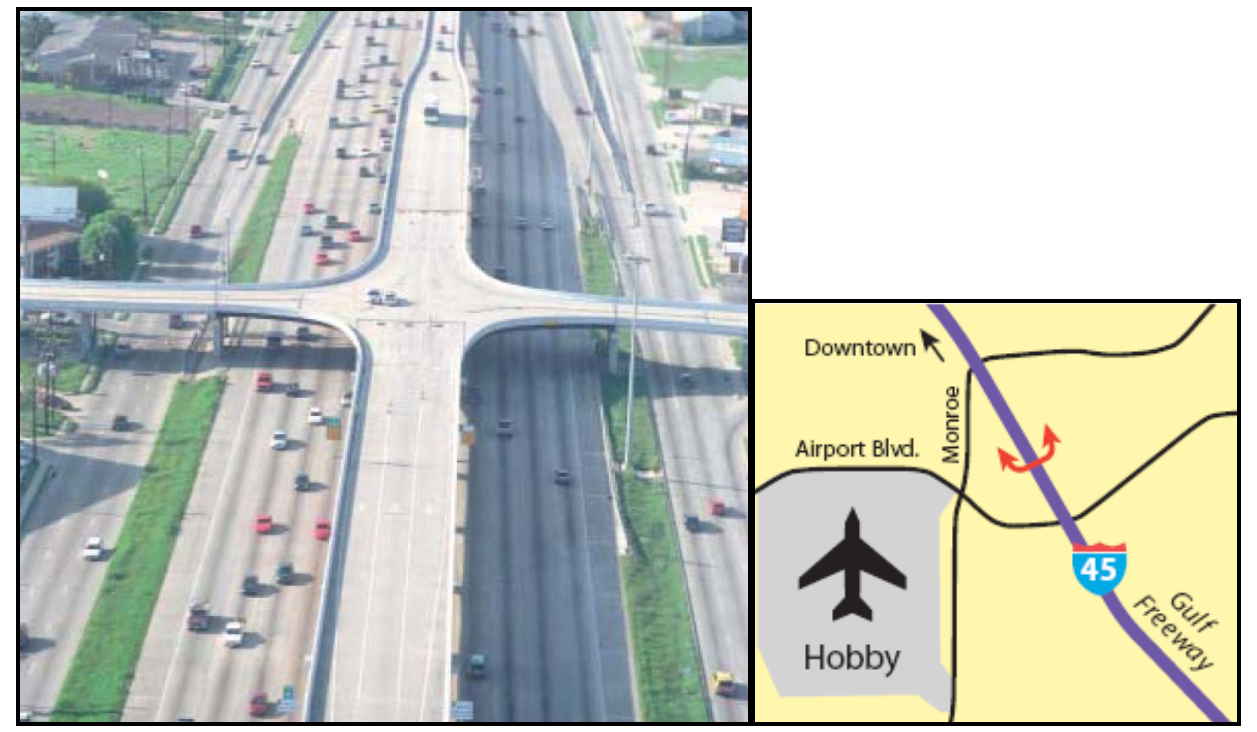

Figure 2.22: Dual T-Ramp on I-45S (Gulf Freeway) in Houston, Texas [Slotboom, 2003]

The various types of HOV direct access ramps described in this section can also be categorized based upon the way of operation i.e., one-way or two-way ramps. One-way ramps operate as entrance ramps in the morning and exit ramps in the evening or vice versa. The two ramps allow the vehicles to travel in both directions in the morning and evening peak periods. In addition to one-way and two-way operation these ramps can also be operated as cross ramps. Cross Ramps are designed to allow access to/from both sides of the freeway. For example, the dual T-ramp (Figure 2.22) in Houston is a cross ramp providing access to freeway HOV lanes from both sides of the freeway. 


\subsubsection{Direct HOV Connector Ramps}

These ramps allow HOVs to move directly from one freeway HOV lane to another freeway HOV lane, without leaving the commuter lane to exit the freeway only to merge back into the HOV lane on the next freeway. HOV direct connector ramps thus provide un-interrupted HOV access between freeways. Freeway-to-freeway HOV lane connections involve significant capital costs, but may be appropriate in areas with extensive networks of HOV facilities and where travel demand warrants.

The map in Figure 2.23 shows a planned HOV direct connector ramp between I-85 and US-101in south San Jose. The project comprises HOV direct connector ramps from northbound US 101 to northbound route 85 and from southbound route 85 to southbound US 101. In addition, this project consists of a general purpose lane connector from southbound US 101 to northbound route 85. The widening of US 101 is also planned as a part of the project. The construction of the direct connector HOV ramps was scheduled to be complete by 2004. The entire project is scheduled to be completed by spring 2006. Figure 2.24 shows the Caltrans [2003] recommended typical HOV direct connector design at the freeway entrance and exit.

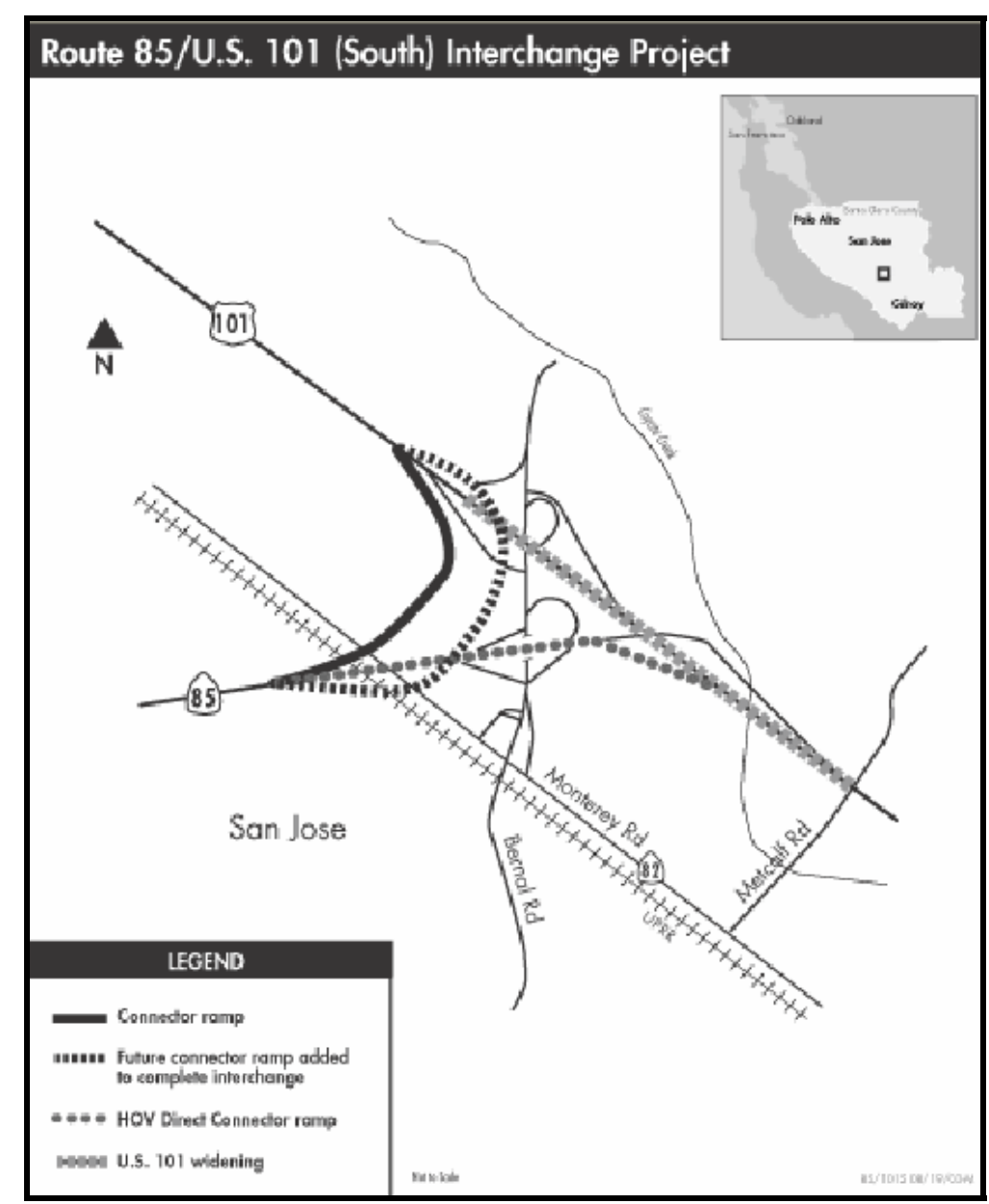

Figure 2.23: Route 85/ US101 (South) HOV Direct Connector Project, San Jose 


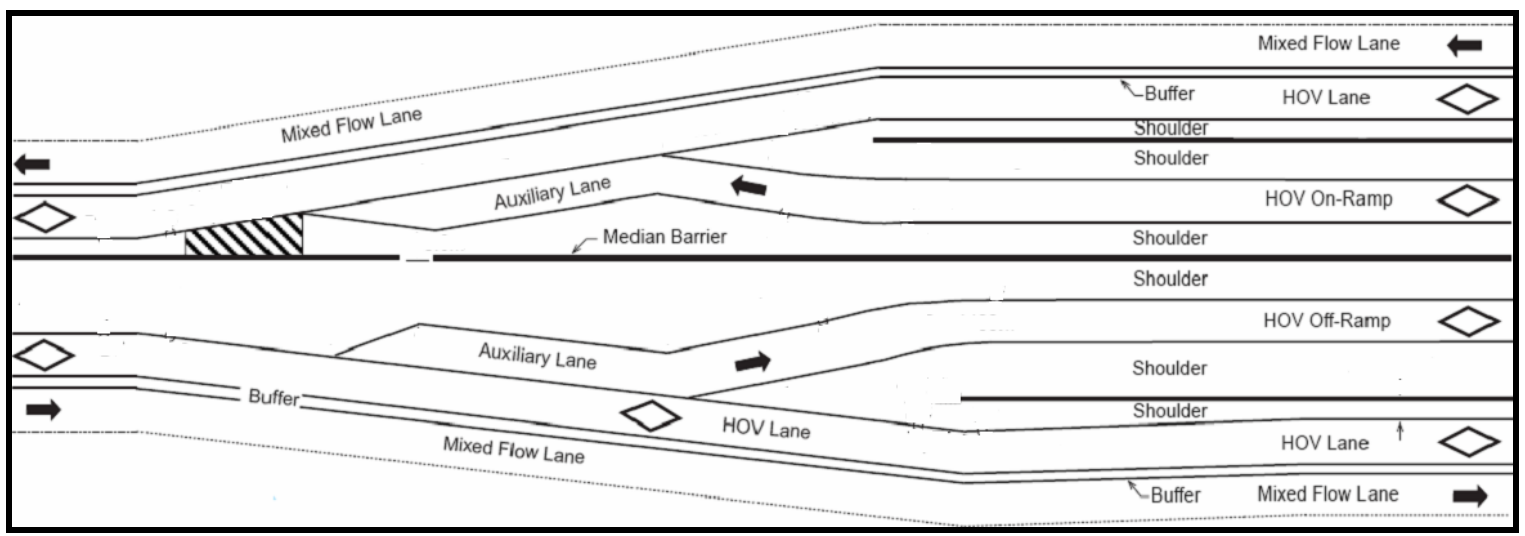

Figure 2.24: Typical HOV Direct Connector Entrance and Exit

The Orange County HOV network in South California includes direct HOV to HOV connector ramps at six interchanges: I-5/I-405 (El Toro Y), and the I-5/SR-55 and I-5/SR-57 transit-ways. The construction of a direct HOV connector for the I-405/SR-55 interchange was underway in 2004.

A HOV facility in a single corridor can utilize various types of HOV ramps depending upon the number of vehicles trying to access the HOV lanes, the location of the park and ride lot or transit center, the amount of space available for construction and several other factors. The location of the access/egress ramps on the Northwest freeway (US-290) corridor in Texas, Houston is shown in the Figure 2.25.

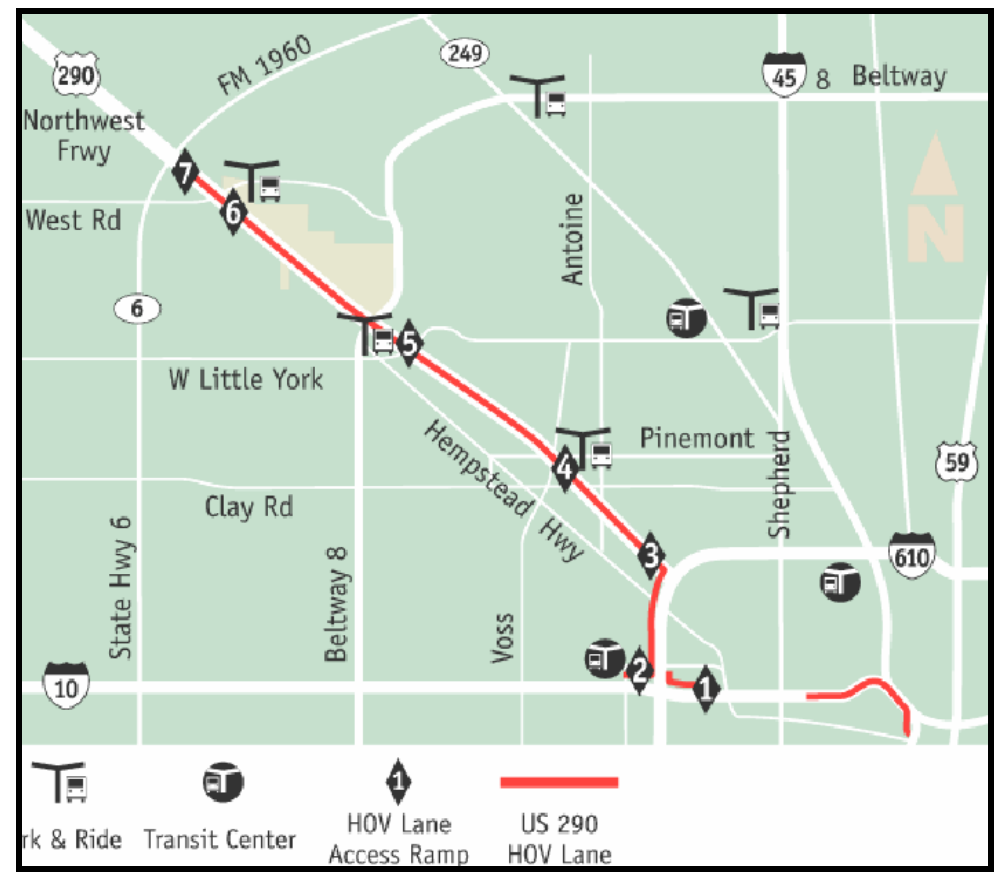

Figure 2.25: HOV Lane Access Ramp Spacing for Northwest Freeway, Houston [METRO, 2005] 
The ramps are located near the park-and-ride lots and transit centers. These ramps are being operated as a one way ramp or two way ramp with varying direct access ramp configurations. For example, Ramp 7 (Figure 2.26) is operated as a one-way ramp with inbound traffic towards downtown using it as an entrance ramp into the HOV lane and the outbound traffic from the downtown using it as an exit ramp during the PM peak hours. This ramp acts as an entrance ramp at the start of the HOV facility during the AM peak period and as an exit ramp at the end of the HOV facility during the PM peak period.
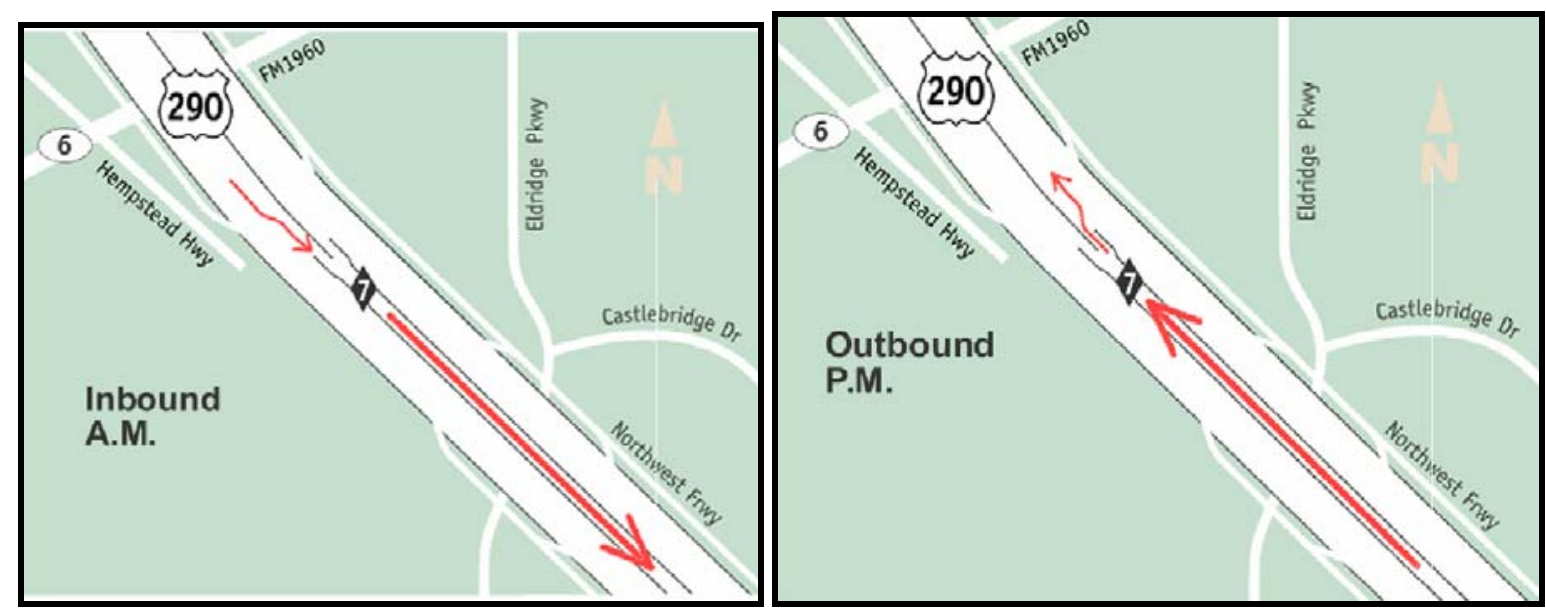

Figure 2.26: Ramp 7, One-way Slip Ramp [METRO, 2005]

Figure 2.27 shows the details of Ramp 6 which is a one-way, direct access, grade separated T-ramp on the Northwest freeway corridor. This type of ramp is used to provide direct access from the transit center or park and ride lots to the HOV lane.
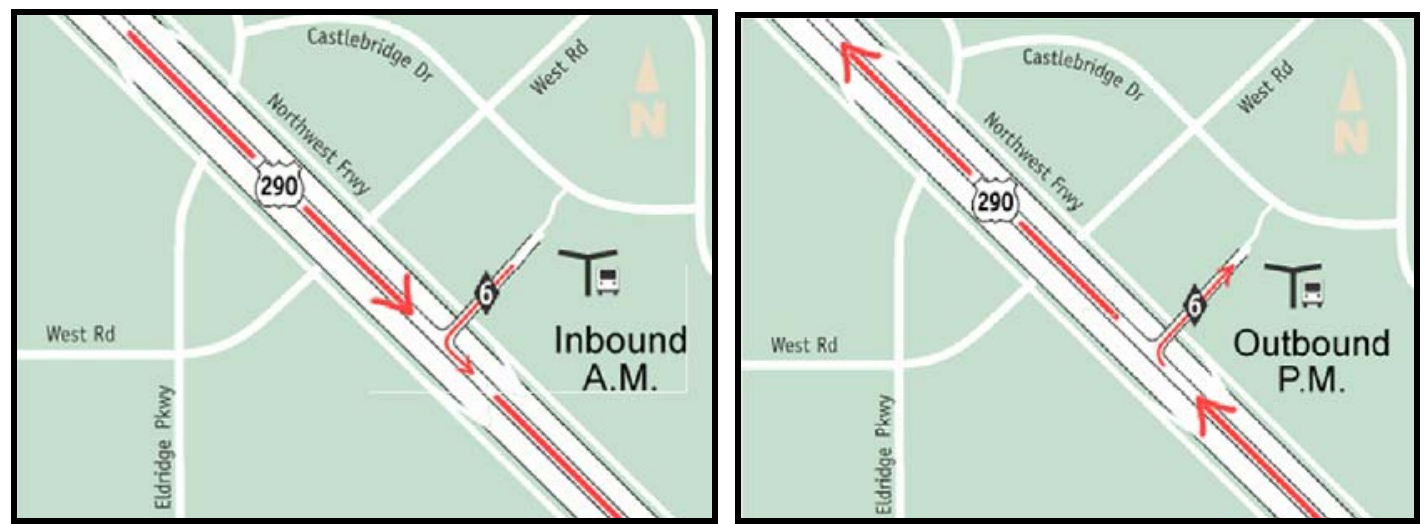

Figure 2.27: Ramp 6, One-way, Direct Access, Grade Separated T-Ramp [METRO, 2005] 
Figure 2.28 shows the details of Ramp 5 which is a two-way, direct access, grade separated T-ramp. This ramp allows the vehicles to enter as well as exit from the park and ride facility using the T-ramp so as to enter or exit the HOV lanes. Ramp 4 on this freeway operates in a similar way as Ramp 5.
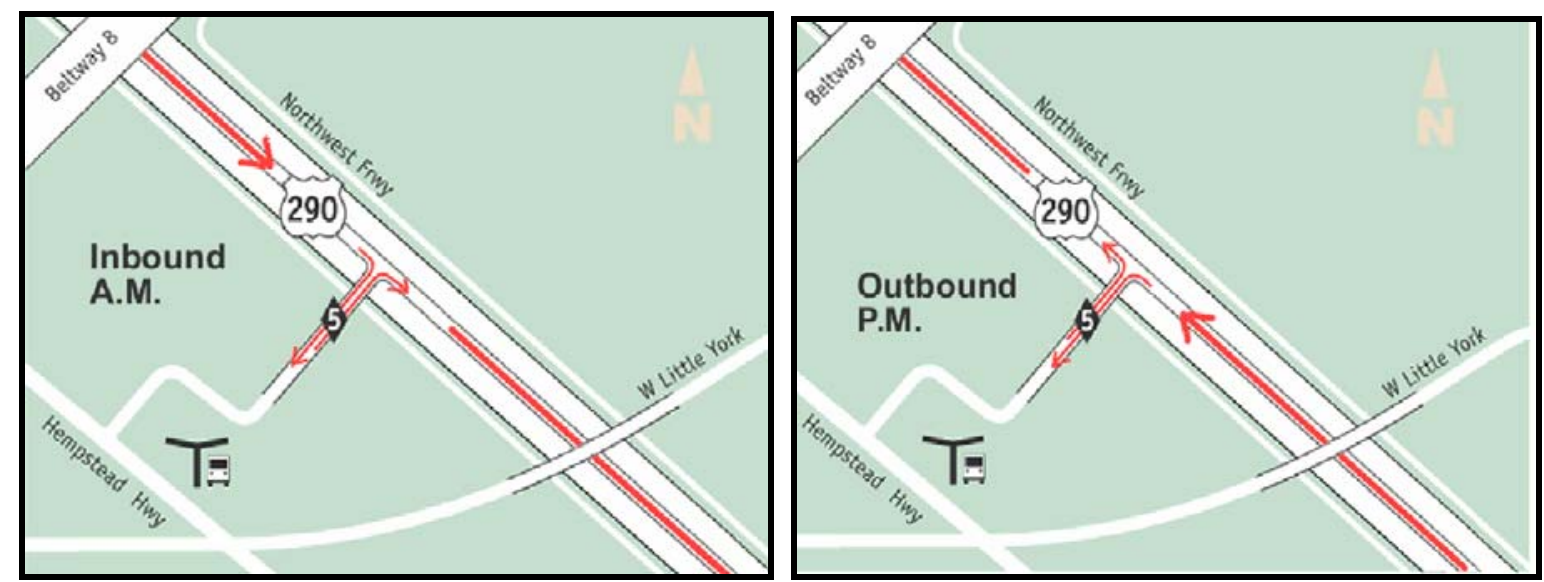

Figure 2.28: Ramp 5, Two-way, Direct Access, Grade Separated T-Ramp [METRO, 2005]

Ramp 3 (Figure 2.29) on the northwest freeway is a direct access ramp with full-wishbone configuration. The ramp connects the HOV lane to the frontage roads. The freeway segment south of the wishbone ramp between Ramps 2 and 3, operates as a two-directional HOV facility during both the am and the pm peak hours. The HOV facility operates two way only for this section of the freeway. For the remaining freeway, am HOV traffic moves in the direction of downtown and the pm HOV traffic moves away from downtown.
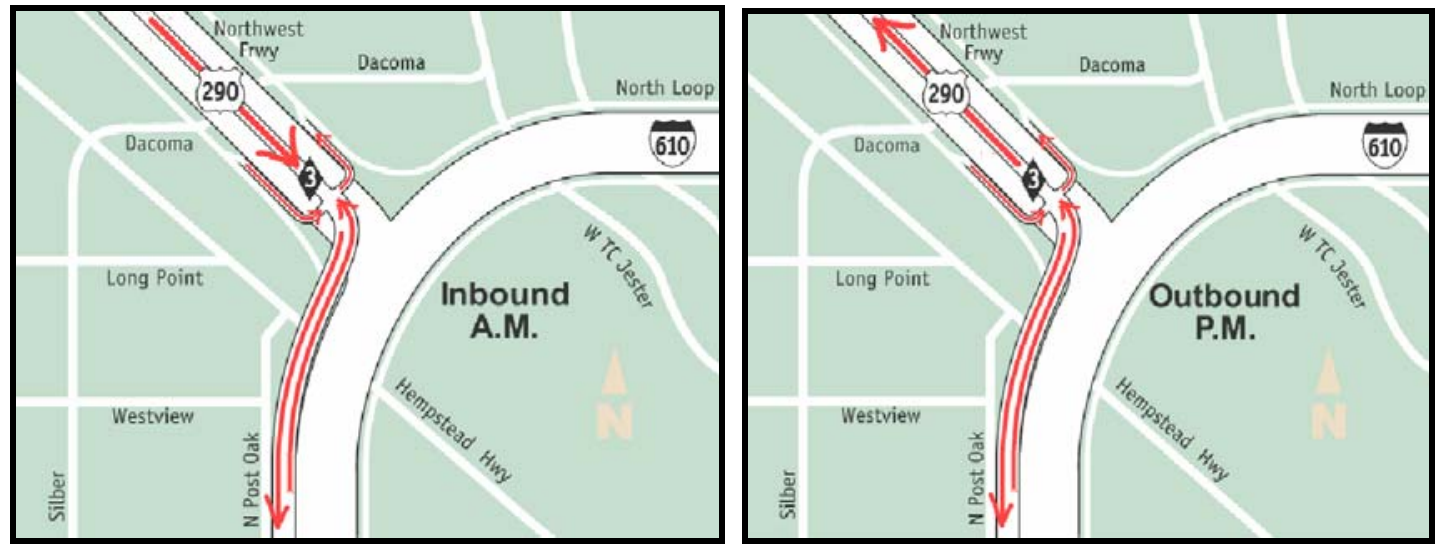

Figure 2.29: Ramp 3, Full Wishbone Ramp (Grade Separated) [METRO, 2005] 


\subsubsection{Parking Facilities and Transit Centers}

Several parking alternatives can be implemented in a HOV system. Parking facilities can have a major impact on the number of carpools formed. The following parking provisions are most common:

- Provision of parking lots and transit centers at the beginning and along the facility length in order to facilitate ridesharing

- Parking facilities at the transit pick up centers or transfer centers

- Parking facilities at the destination, that is at the end of the HOV Facility so as to encourage the use of high occupancy vehicles

\subsubsection{Park-and-Ride / Park-and-Pool Lots}

The park-and-ride lots enable the commuters who drive alone to park their vehicles and form carpools/vanpools or use transit. In addition to the facilitation in carpooling and vanpooling, park-and-ride facilities also enable easy access to the HOV facility. Depending on the system design, park and ride facilities can impact the HOV system at the origin of trips or destination of trips or both. Parking facilities can also be located at intermediate points along the HOV corridor length depending upon the travel demand. Figure 2.30 shows the Fuqua park-and-ride lot and transit station along the Gulf (1-45 South) freeway.

The number and the size of park-and-ride facilities varies from one location to another. Parking lots of less than 300 spaces seem to be most common, although a number of exclusive HOV lanes are served by park-and-ride lots with over 1000 spaces amongst them. However, the estimation for the demand of park-and-ride facilities is a major challenge even today [Fuhs and Obenberger, 2002].

For example, there were 32 park and ride lots in Houston with 31,694 parking spaces available as per the March 2001 statistics [Levinson et al., 2003]. The number of parking ride lots supporting each HOV lane in Houston varies between three and eight. The larger park-and-ride lots have direct access to the HOV lanes and transit stations with passenger amenities. There are spaces for between 900 and 2,500 automobiles at nineteen parking lots. The number of parking spaces in each corridor ranges from slightly over 3,000 to almost 7,500 . About $55 \%$ of these parking spaces get filled each day. Table 2.5 shows the distribution of the park and ride lots for Houston freeways.

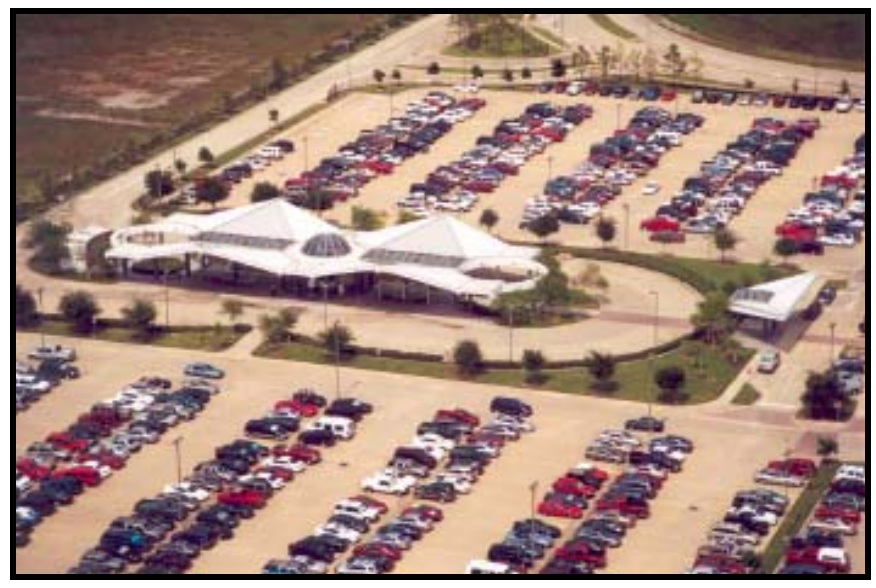

Figure 2.30: Fuqua park and ride Lot, Houston [Turnbull, 2003] 
The establishment of the park-and-ride lots is not the responsibility of a single organization. In California, there were 450 park and ride lots in 2002. About 210 of these were established by the DOT, 120 by the transit and other agencies involved and another 120 were private parking lots. Large shopping complexes can provide parking for HOVs.

Table 2.5: Park and Ride Lot Utilization, March 2001 [Levinson et al. 2003]

\begin{tabular}{|c|c|c|c|c|}
\hline Freeway & $\begin{array}{c}\text { Number of } \\
\text { Facilities }\end{array}$ & $\begin{array}{c}\text { Lot Capacity in } \\
\text { Spaces }\end{array}$ & $\begin{array}{c}\text { Daily Parked } \\
\text { Vehicles }\end{array}$ & $\begin{array}{c}\text { Percent of Lot } \\
\text { Capacity }\end{array}$ \\
\hline Katy (I-10 West) & 6 & 5649 & 3512 & $62.2 \%$ \\
\hline North (I-45) & 5 & 7313 & 4009 & $54.8 \%$ \\
\hline Gulf (I-45) & 5 & 3581 & 2505 & $70 \%$ \\
\hline Northwest (US-290) & 4 & 3990 & 2618 & $65.6 \%$ \\
\hline Southwest (US 59) & 8 & 7363 & 3360 & $45.6 \%$ \\
\hline Eastex (US 59) & 4 & 3798 & 1495 & $39.4 \%$ \\
\hline Total & $\mathbf{3 2}$ & $\mathbf{3 1 , 6 9 4}$ & $\mathbf{1 7 , 4 9 9}$ & $\mathbf{5 5 . 2 \%}$ \\
\hline
\end{tabular}

Source: HOV lane Utilization Quarterly Report. Prepared by Texas Transportation Institute for Metropolitan Transit Authority of Harris County

\subsubsection{Transit Centers}

Another way to provide parking for the HOV system is to integrate the transit (bus) pick-up centers with the HOV park-and-ride lots. This can be accomplished by the use of transfer centers, where, for example, a group of carpoolers can park, transfer onto a bus system and then travel to downtown areas of employment. At the same time a group of SOV passengers can park their individual vehicles at the transfer center and pool to form a carpool/vanpool. Such a facility can serve as the center for the formation of carpools, vanpools and can also serve as a transit center. In Houston four transit centers were established with direct access to five HOV lanes [Levinson et al., 2003]. All these transit centers have direct grade separated connectors (ramps) to the HOV lane. Figure 2.31 shows a transit center in Houston with direct access to the HOV lanes.

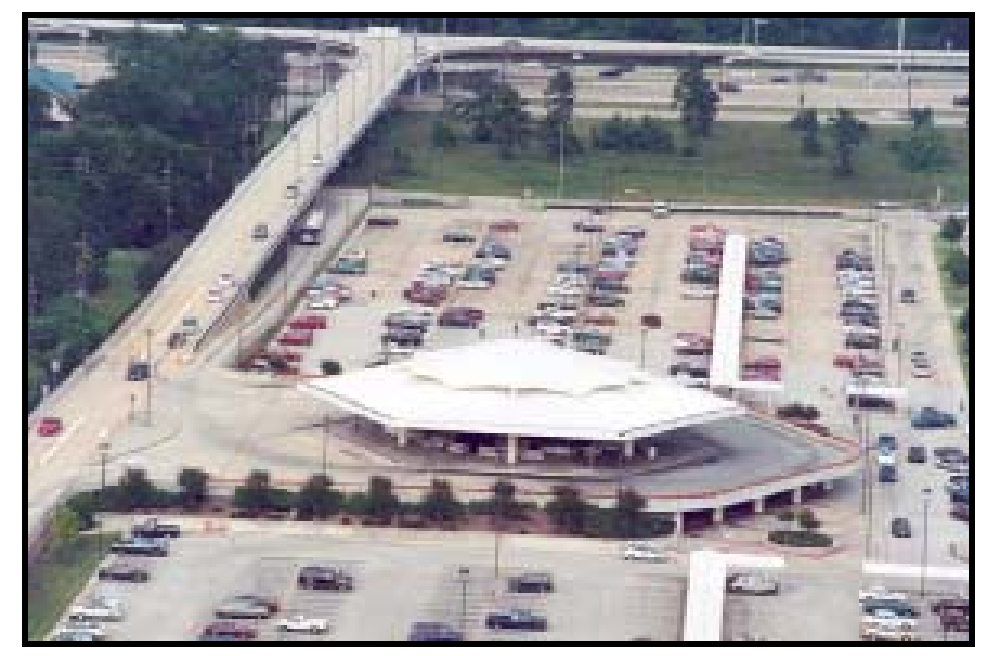

Figure 2.31: HOV Lane Direct Access Ramp from Kuykendahl Park-and-ride Lot [Turnbull, 2003] 


\subsubsection{Preferential Parking at Destination}

A third parking alternative is preferential parking. On-street preferential parking programs at the parking destination can encourage carpooling and vanpooling. The destination typically is a work place, but could also be non-work related, such as a shopping center. This type of parking is easily provided by businesses that have ample parking supplies and can be offered to the carpooler as an incentive to be a HOV user. Parking incentives are based on two concepts:

\section{(i) Parking Availability}

The following parking incentives can be considered for encouraging the use of HOVs:

- Poolers are allowed to park downtown all day at specific metered locations

- Poolers are exempted from hourly parking limits and enjoy spaces closer to building entrances

- Banning the parking of SOVs on residential street or nearby free parking facilities

\section{(ii) Parking Cost Savings}

Preferential pricing HOV facilities are highly effective. Free or subsidized parking encourages the use of automobiles. Costly parking encourages public transit or ridesharing. Incentives that could be provided include [Totten and Settina, 1993]:

- Poolers exempted from meter fees at parking destination (say, in downtown).

- Providing less employee parking and charging full prices to SOVs.

- Eliminating free employee parking for Single Occupancy Vehicles.

Several agencies in the past have successfully implemented parking programs that have led to an increase in HOV usage. For example, Johnson and Higgins, a brokerage firm located in downtown Seattle, charged \$180 per month for parking to the SOVs. As a result, only 23 percent of employees were SOV users in the company, compared to an area wide rate of 43 percent. The success of the program was credited to the high parking fee for SOVs [EPA, 1998].

A Los Angeles based company, ARCO, implemented one of the most successful employer-initiated transportation programs for its 2,200 employees [Totten and Settina, 1993] in the early 1980s. ARCO employees were given transportation choices with 50\% subsidies for SOVs, $75 \%$ for two person carpools and $100 \%$ for three person carpools for any parking space owned or leased by ARCO. Approximately 56\% of the ARCO employees were reported as using HOV's in 1982. Seattle implemented a preferential parking system that charges \$17 per month for carpools and vanpools and \$4 to \$6 per day for single occupant vehicles [Poplaski and Demetsky, 1994].

The Canadian government, increased its parking rates for federal employees in Ottawa [Totten and Settina, 1993], resulting in:

- $23 \%$ reduction in employees driving to work,

- $16 \%$ increase in transit rider-ship among federal employees

- $83 \%$ reduction in use of SOVs

- Increase in average vehicle occupancy from 1.22 to 1.41 


\subsubsection{Enforcement Areas}

Enforcement considerations are very important during the planning, design and operational phase of any HOV project. The construction of enforcement areas is required in the absence of technology to detect occupancy violation. The construction of enforcement areas is critical in the implementation of enforcement policies and from the point of view of the safety of the patrolling officer. Enforcement techniques used on the mainline HOV lane depends on the design of the facility. The various types of enforcement policies will be discussed later in this report. This section focuses on the enforcement areas.

Detection of occupancy violations by video technology is not yet sufficiently reliable to eliminate on-thescene verification by an officer. Parsons et al. (2005), found that although various technologies have been tested to detect the number of persons in a vehicle, "no traffic court in any state or foreign country currently accepts any substitute technology for visual inspection of occupancy when upholding citations written for this offense." Therefore the construction of enforcement areas becomes critical in any HOV project. Existing HOV facilities with violation rate more than $10 \%$ should also consider the construction of these enforcement areas. Figure 2.32 shows two examples of the lack of enforcement area considerations.
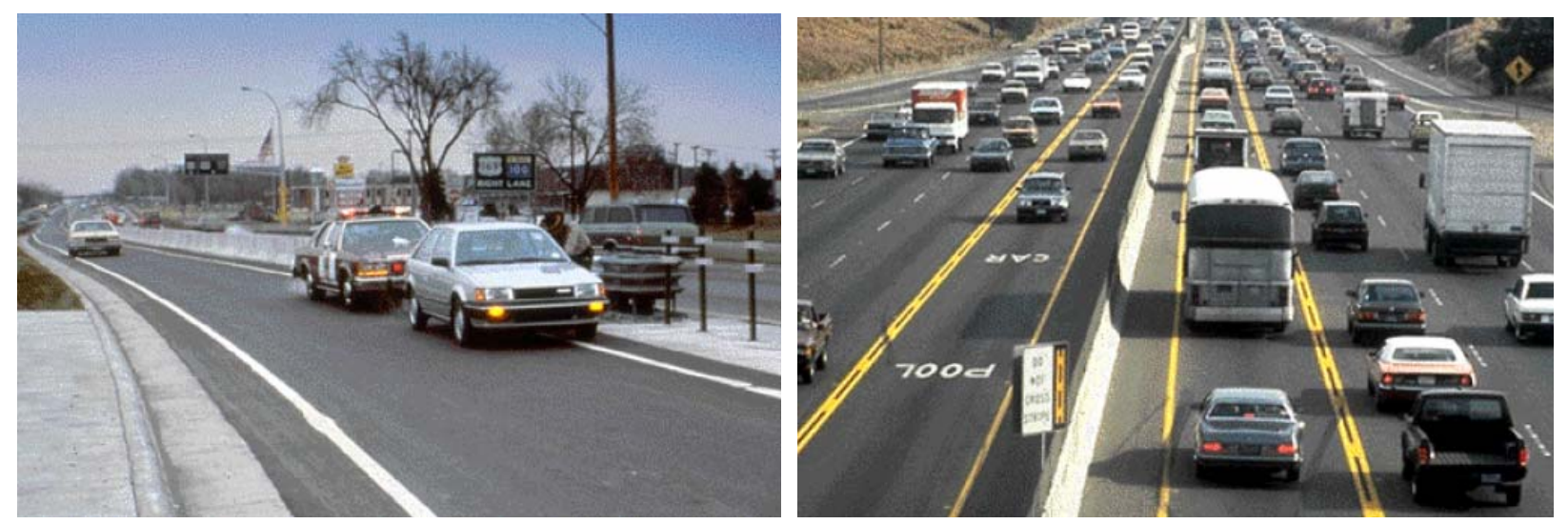

Figure 2.32: Example of a Lack of Enforcement Consideration

The enforcement services in California on two of the most popular managed lanes, SR-91 and I-15, have been contracted to the California Highway Patrol (CHP). METRO police officers provide enforcement on Houston area HOV lanes. The transit police at the Dallas Area Rapid Transit (DART) are responsible for the enforcement on Dallas HOV lanes. Enforcement on the HOV lanes on I-35W and I-394 in the twin cities metropolitan area is provided by the Golden valley police and the state patrol officers [Cothron, 2003].

\subsubsection{HOV Management Center}

Houston has a high-tech HOV management center which manages the HOV lanes through a series of variable message signs. A fibre optic cable links the TranStar control centre to the closed circuit television cameras (CCTV). 
The traffic flow on the freeway can be monitored with the help of these cameras. The control center is also linked to the computerized traffic signals on the arterial roadways and freeway feeder streets. METRO's buses feed traffic information to TranStar while getting congestion updates in return [Levinson et al. 2003]. Figure 2.33 shows a TranStar control room. Such a high-tech traffic management center can ensure effective operation of the HOV lanes. However the requirement of such a center depends upon the type of the HOV facility, available funds and size of the HOV system. The implementation depends on the decision of local authorities upon how they plan to monitor the operations on the HOV lanes and get a feedback on the effectiveness of these lanes.

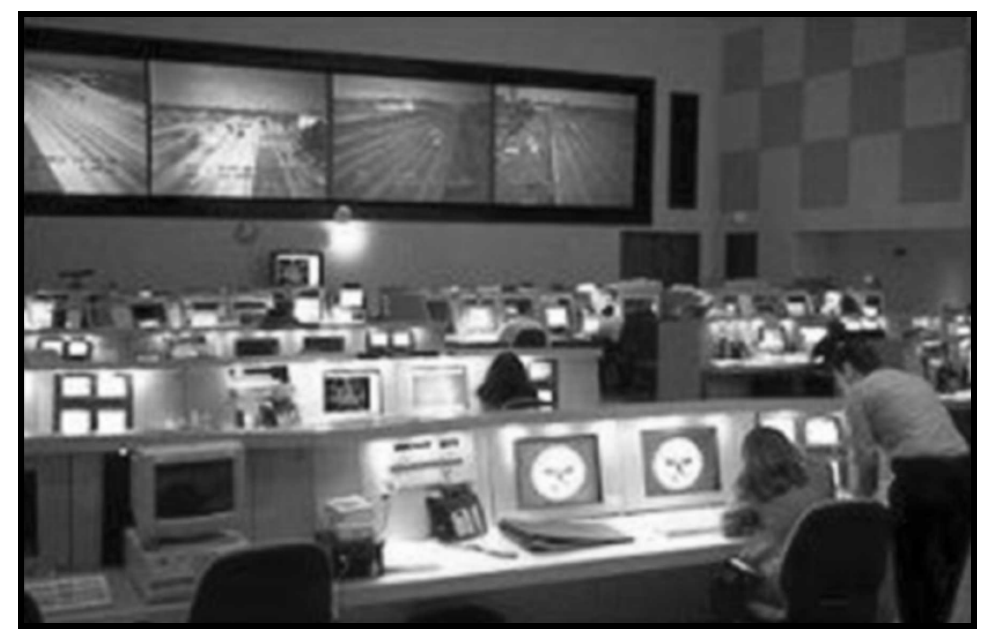

Figure 2.33: TranStar Control Room [Levinson et al., 2003]

The operational components of the HOV system include the following:

\subsubsection{Occupancy Requirements}

The number of vehicles using a HOV lane depends on the HOV lane occupancy requirement. Most facilities require two or more occupants per vehicle (2+) to qualify for HOV lane use. There are also a few facilities that require more than three $\left(3^{+}\right)$occupants per vehicle. The occupancy rate that qualifies for HOV use is best determined by the expected utilization of HOV lanes. Some planners believe that the occupancy rate should be initially set high and then set lower if the utilization of HOV is very low; other planners believe that the opposite is true. The advantage of starting with a $2+$ occupancy requirement is that it encourages the formation of a larger number of carpools. This is because it is easier for drive-alone commuters to form a carpool with 2 people than with 3 or more people. On the other hand, with a low occupancy requirement, the HOV system may reach its capacity too soon. A 3+ system has the advantage that a better level of service can be guaranteed in the HOV lanes. This can be especially helpful if the area has a strong transit oriented focus. The disadvantage is the possibility of an adverse public reaction because HOV lanes are likely to appear less occupied if a 3+ occupancy requirement is deployed.

Since the HOV lane volume may change with time, consideration of these factors can result in changes in the occupancy requirements from time to time. Most of the operational components of the HOV system may change 
over time depending upon the HOV lane usage and congestion on the freeway (HOV and GP lanes). For most of the HOV facilities implemented in various parts of the country, the occupancy requirement has changed with time since the opening year so as to obtain the maximum benefits out of HOV lane implementation. For example, the effect of changes in the occupancy requirements on the Katy Freeway HOV lane in Houston is shown in Table 2.6. The number of carpools using the HOV lane increased significantly with the 2+ occupancy requirement enforced in 1986.

Predicted HOV lane traffic volume can also be used for setting up the initial occupancy restrictions. For example, if the number of vehicles using the HOV lane with a 3+ occupancy requirement is less than $400 \mathrm{vphpl}$, then a 2+ occupancy requirement can be set because otherwise the facility will appear underutilized. On the other hand, if the number of vehicles using the HOV lane varies in the range of 400-800 per hour, assuming a 2+ occupancy requirement, then $2+$ occupancy restrictions should be set. If the number of vehicles using the facility increase and the HOV lanes appear to become congested, the occupancy requirement can later be raised to $3+$.

Table 2.6: Impact of Changes in Occupancy Requirement on Katy Freeway HOV Lane [Turnbull, 2003]

\begin{tabular}{|c|c|c|c|c|c|}
\hline \multirow{2}{*}{$\begin{array}{c}\text { Vehicle Eligibility and } \\
\text { Vehicle Occupancy } \\
\text { Requirements } \\
\end{array}$} & \multirow{2}{*}{$\begin{array}{c}\text { Date } \\
\text { (Time after } \\
\text { opening) } \\
\end{array}$} & \multicolumn{4}{|c|}{ AM Peak Hour HOV Lane Vehicle Volumes } \\
\hline & & Carpools & Vanpools & Buses & Total \\
\hline $\begin{array}{c}\text { Buses and Authorized } \\
\text { Vanpools }\end{array}$ & October 1984 & - & 66 & 20 & 86 \\
\hline $\begin{array}{l}\text { Buses, Authorized Vanpools } \\
\text { and Authorized 4+ Carpools }\end{array}$ & $\begin{array}{l}\text { April } 1985 \\
\text { (6 months) } \\
\end{array}$ & 3 & 68 & 25 & 96 \\
\hline $\begin{array}{l}\text { Buses , Authorized Vanpools, } \\
\text { and Authorized 3+ Carpools }\end{array}$ & $\begin{array}{c}\text { September } 1985 \\
(1 \text { year })\end{array}$ & 53 & 59 & 31 & 143 \\
\hline \multirow{2}{*}{$\begin{array}{l}\text { Buses, Vanpools, and 2+ } \\
\text { Carpools }\end{array}$} & $\begin{array}{l}\text { November } 1986 \\
\text { (2 years) }\end{array}$ & 1,195 & 38 & 32 & 1,265 \\
\hline & $\begin{array}{l}\text { November } 1987 \\
\text { (3 years) }\end{array}$ & 1,453 & 21 & 37 & 1,511 \\
\hline
\end{tabular}

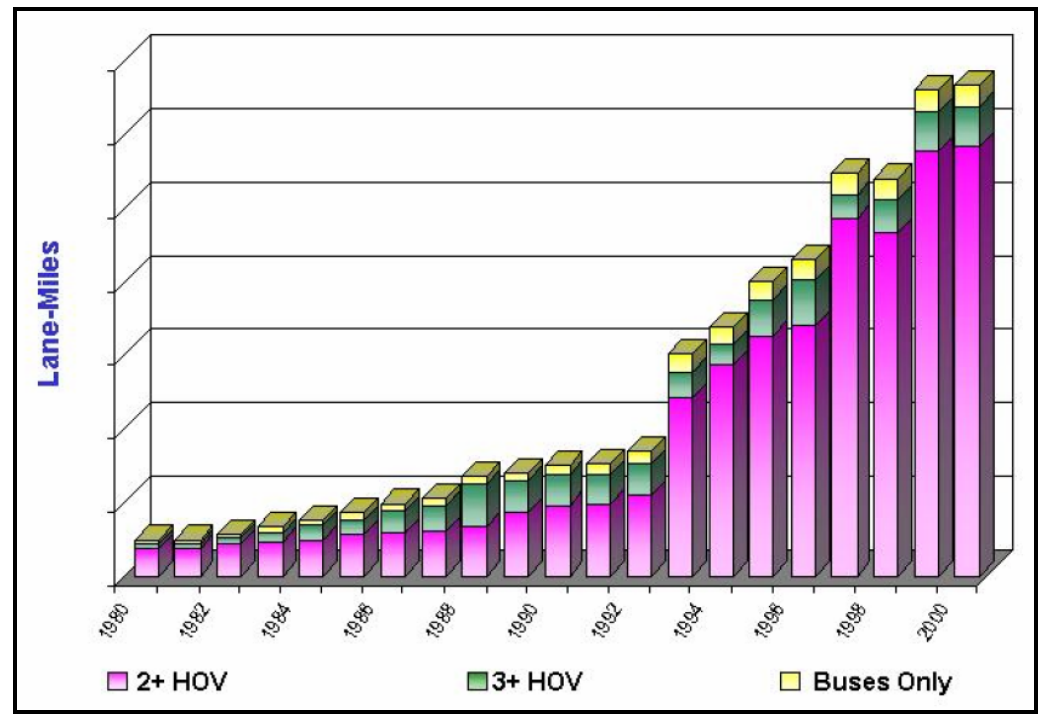

Figure 2.34: Trends in HOV Lane-Miles Based on Occupancy Requirements [Fuhs and Obenberger, 2002] 
The Shirley Highway (I-395) in Northern Virginia is another example of a successful HOV lane implementation where occupancy restrictions have changed with time. The highway was opened as a five-mile busway in 1969 during the reconstruction of I-395. In December 1973, the highway was opened as a barrierseparated two-lane reversible HOV facility with 4+ occupancy requirement for carpools and vanpools. In 1989, the occupancy requirement was changed to $3+$ and since then the freeway has maintained this occupancy requirement. In 2005, over 50,000 people used the Shirley highway HOV lanes during the morning rush hours with approximately 40,000 people moving in carpools (3+) and vanpools [Morrison \& Counts, 2005]. Figure 2.34 shows the trends in HOV lane-miles based on occupancy requirements. Table 2.8 shows the occupancy requirements for some of the HOV facilities in US.

On the Katy Freeway and US 290 Northwest Freeway the occupancy requirement is 3+ during the two peak hours of the morning and afternoon peak periods ( $5 \mathrm{am}-12 \mathrm{pm}$ and $2 \mathrm{pm}-9 \mathrm{pm}$, respectively). For the remaining peak period the occupancy requirement changes to 2+. This 2-hour peak period is referred to as the "peak of the peak" in Houston and further demonstrates that the occupancy requirements can be flexible and can change depending upon the performance of the HOV lanes and the overall freeway corridor.

\subsubsection{Operating Hours: Time Restrictions}

Time restriction for lanes designated for HOV use are of two types: those that are open for HOV use throughout the day; and those that are open for only part of or the entire peak period. For example: the exclusive reversible HOV facilities in Houston are operated from 5:00 am to 12:00 pm in the morning and from 2:00 pm to 9:00 pm in the evening. The facility is closed for two hrs in the afternoon for reversing the direction of flow. Year 2002 statistics show that approximately $50 \%$ of the HOV in the US are operated without break that is twenty-four hours a day and seven days a week (Figure 2.35). Table 2.7 shows operating hours of selected HOV facilities in the US. For part time HOV facilities, the HOV lanes are open to all traffic during non-peak hours.

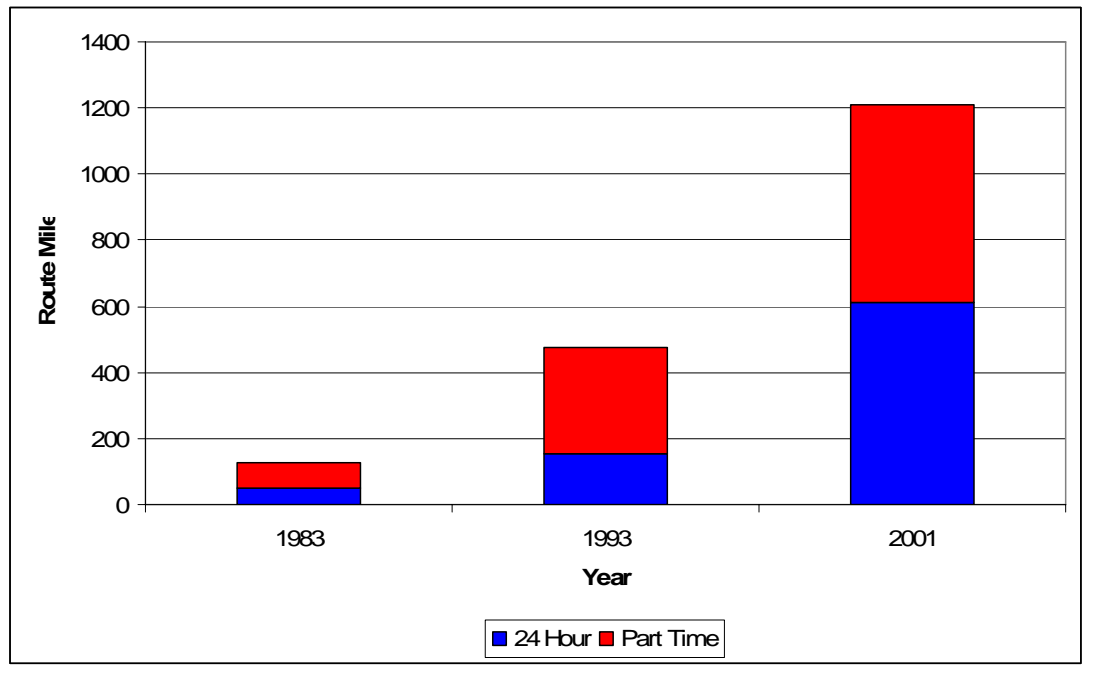

Figure 2.35: Distribution of HOV route miles by hours of operation [Fuhs and Obenberger, 2002] 
Table 2.7: Occupancy Requirement and Operating Hours of Exclusive HOV Facilities [Fuhs, 2005]

\begin{tabular}{|c|c|c|c|c|}
\hline HOV Facility & $\begin{array}{l}\text { Length of } \\
\text { HOV } \\
\text { Facility } \\
\text { (miles) } \\
\end{array}$ & Type of HOV Facility & HOV Operation Period & Eligibility Requirements \\
\hline \multicolumn{5}{|c|}{ Exclusive Reversible Barrier Separated } \\
\hline $\begin{array}{c}\text { Northern Virginia I395 (Shirley } \\
\text { Highway) }\end{array}$ & 27 & $\begin{array}{c}2 \text { Lane Barrier Separated } \\
\text { Exclusive Reverrsible }\end{array}$ & $\begin{array}{c}\text { 6-9 am NB } \\
\text { 3:30-6:00 am SB } \\
\end{array}$ & $3+\mathrm{HOVs}$ \\
\hline Seattle, WA I-5 North & $\begin{array}{l}\text { 4.3 SB and } \\
1.9 \mathrm{NB}\end{array}$ & $\begin{array}{l}\text { 2-4 Lane Barrier Separated } \\
\text { Exclusive Reversible }\end{array}$ & $\begin{array}{c}\text { 5-11 am SB } \\
12 \mathrm{pm}-11 \mathrm{pm} \mathrm{NB}\end{array}$ & $\begin{array}{c}\text { GP in 3-4 Lane section, 2+ } \\
\text { HOVs on Ramps and } 2 \text { lane } \\
\text { sections }\end{array}$ \\
\hline I-10 Katy Freeway, Houston & 16 & $\begin{array}{c}1 \text { Lane Barrier Separated } \\
\text { Reversible }\end{array}$ & $\begin{array}{c}5 \text { am - } 12 \text { noon EB } \\
2 \text { pm - } 9 \text { pm WB }\end{array}$ & $\begin{array}{c}3+\text { HOVs during Peak of } \\
\text { Peak Period and } 2+\text { during } \\
\text { the remaining Peak }\end{array}$ \\
\hline I-45 Gulf Freeway, Houston & 13.1 & $\begin{array}{l}\text { 1 Lane Barrier Separated } \\
\text { Reversible }\end{array}$ & $\begin{array}{c}5 \mathrm{am}-12 \text { noon } \\
1 \mathrm{pm}-9 \mathrm{pm}\end{array}$ & $2+\mathrm{HOVs}$ \\
\hline $\begin{array}{c}\text { US } 290 \text { Northwest Freeway, } \\
\text { Houston }\end{array}$ & 13.5 & $\begin{array}{c}1 \text { Lane Barrier Separated } \\
\text { Reversible }\end{array}$ & $\begin{array}{l}5 \text { am - } 12 \text { noon } \\
1 \text { pm - } 9 \text { pm }\end{array}$ & $\begin{array}{l}3+\text { HOVs during Peak of } \\
\text { Peak Period and } 2+\text { during } \\
\text { the remaining Peak }\end{array}$ \\
\hline I-45 North Freeway, Houston & 19.7 & $\begin{array}{l}1 \text { Lane Barrier Separated } \\
\text { Reversible }\end{array}$ & $\begin{array}{c}5 \text { am - } 12 \text { noon } \\
1 \mathrm{pm}-9 \mathrm{pm}\end{array}$ & $2+\mathrm{HOVs}$ \\
\hline US 59 Eastex Freeway, Houston & 5 & $\begin{array}{l}1 \text { Lane Barrier Separated } \\
\text { Reversible }\end{array}$ & $\begin{array}{c}5 \text { am - } 12 \text { noon } \\
1 \mathrm{pm}-9 \mathrm{pm}\end{array}$ & Buses only \\
\hline \multicolumn{5}{|c|}{ Exclusive 2-Directional Barrier Separated } \\
\hline $\begin{array}{c}\text { Sal Bernardino Fwy, I-10 (El } \\
\text { Monte) Los Angeles, CA }\end{array}$ & 4 & \begin{tabular}{|c|}
2 Barrier Separated HOV \\
lanes, 1 each direction
\end{tabular} & 24 hours & $3+$ \\
\hline Orange County, CA I-5 & 4.5 & $\begin{array}{l}\text { 1-2 HOV Lane Each } \\
\text { Direction }\end{array}$ & 24 hours & $2+$ \\
\hline $\begin{array}{l}\text { US } 290 \text { Northwest Freeway, } \\
\text { Houston }\end{array}$ & 1.5 & $1 \mathrm{HOV}$ lane each direction & $\begin{array}{c}5 \text { am - } 12 \text { noon } \\
2 \mathrm{pm}-9 \mathrm{pm}\end{array}$ & $2+$ \\
\hline Seattle, WA I-90 & 1.5 & $1 \mathrm{HOV}$ lane each direction & 24 hours & $2+$ \\
\hline \multicolumn{5}{|c|}{ Exclusive 2-Directional Buffer Separated } \\
\hline Salt Lake City, UT, I-15 & 16 & 1 HOV lane each direction & 24 Hours & $2+$ \\
\hline Seattle, WA I-5 North & 13.3 & \begin{tabular}{|c|} 
Single Solid Stripe \\
Separated HOV Facility \\
with 1 lane in each direction
\end{tabular} & 24 Hours & $2+$ \\
\hline I-10 Katy Freeway, Houston & 5.5 & $\begin{array}{c}\text { Narrow Buffer Separated } \\
5.5 \text { mile section with } 1 \mathrm{HOV} \\
\text { lane each Direction }\end{array}$ & $\begin{array}{c}5 \text { am - } 12 \text { noon EB } \\
2 \text { pm - } 9 \text { pm WB }\end{array}$ & $\begin{array}{l}3+\text { HOVs during Peak of } \\
\text { Peak Period and } 2+\text { during } \\
\text { the remaining Peak }\end{array}$ \\
\hline SR 91, Los Angeles County, CA & 14.3 & $\begin{array}{c}\text { Buffer Separated with } 1 \\
\text { HOV lane each direction }\end{array}$ & 24 hours & $2+$ \\
\hline I-405, Orange County, CA & 24 & $\begin{array}{c}\text { Buffer Separated with } \\
\text { 1-2 HOV lane each direction }\end{array}$ & 24 hours & $2+$ \\
\hline SR 55, Orange County, CA & 12.3 & \begin{tabular}{|c|} 
Buffer Separated with 1 \\
HOV lane each direction
\end{tabular} & 24 hours & $2+$ \\
\hline \multicolumn{5}{|c|}{ Contraflow HOV Lane } \\
\hline $\begin{array}{c}\text { Gowanus Expressway, Brooklyn } \\
\text { Battery Tunnel }\end{array}$ & 6.2 & $\begin{array}{c}\text { HOV Operation in Inbound } \\
\text { Direction with } 1 \text { lane } \\
\text { (Moveable Barrier) }\end{array}$ & $6-10 \mathrm{am}$ & $2+$ \\
\hline $\begin{array}{c}\text { I495 Long Island Expressway, } \\
\text { NY }\end{array}$ & 4 & $\begin{array}{c}\text { 1 Lane operated as } \\
\text { contraflow lane }\end{array}$ & $7-10 \mathrm{am}$ & Buses, Vanpools \\
\hline $\begin{array}{c}\text { Dallas TX, I-30 (East R.L. } \\
\text { Thornton Fwy.) }\end{array}$ & 5.2 & $\begin{array}{c}1 \text { lane operated as } \\
\text { contraflow lane in each peak } \\
\text { direction with moveable } \\
\text { barriers }\end{array}$ & $\begin{array}{l}6-9 \mathrm{am} \\
4-7 \mathrm{pm}\end{array}$ & $2+$ \\
\hline $\begin{array}{l}\text { Boston, MA I-93 Southeast } \\
\text { Expy. }\end{array}$ & 6 & $\begin{array}{c}1 \text { lane operated as } \\
\text { contraflow lane in each peak } \\
\text { direction with moveable } \\
\text { barriers }\end{array}$ & $\begin{array}{l}\text { 6-10 am } \\
3-7 \mathrm{pm}\end{array}$ & $2+$ \\
\hline
\end{tabular}


Table 2.8: Advantages and Disadvantages of Full-Time \& Part Time Operating Hours [Parsons, 2002]

\begin{tabular}{|c|c|c|}
\hline Criterion & Full-Time(24 Hour) Operations & $\begin{array}{l}\text { Part-Time Operations } \\
\text { (with general purpose use of lanes } \\
\text { during other times) }\end{array}$ \\
\hline \multirow[t]{2}{*}{ Travel Time Savings } & \multirow{2}{*}{$\begin{array}{l}\text { Potential for HOV travel time savings whenever } \\
\text { congestion is present in the general-purpose lane }\end{array}$} & $\begin{array}{l}\text { Potential for HOV travel time savings only } \\
\text { during periods of part-time operation }\end{array}$ \\
\hline & & No impact if midday traffic is uncongested \\
\hline \multirow[t]{2}{*}{ Trip Reliability } & \multirow{2}{*}{$\begin{array}{l}\text { High level of HOV travel time reliability } \\
\text { throughout the day regardless of conditions in } \\
\text { the general purpose lanes }\end{array}$} & $\begin{array}{l}\text { Provides HOV travel time reliability only } \\
\text { during periods of part time operation }\end{array}$ \\
\hline & & No impact if midday traffic is uncongested \\
\hline \multirow{2}{*}{$\begin{array}{l}\text { Person Carrying } \\
\text { Capacity/Throughput }\end{array}$} & $\begin{array}{l}\text { Maintains option for high person carrying } \\
\text { capacity and throughput at all times }\end{array}$ & $\begin{array}{l}\text { Facilitates higher levels of person throughput } \\
\text { during part time operations only }\end{array}$ \\
\hline & $\begin{array}{l}\text { Facilitates higher levels of person throughput } \\
\text { throughout the day }\end{array}$ & $\begin{array}{l}\text { Facilitates higher levels of vehicular throughput } \\
\text { during periods of general purpose use of lane }\end{array}$ \\
\hline \multirow[t]{2}{*}{ Enforcement } & $\begin{array}{l}\text { Simplifies "enforceability" by eliminating } \\
\text { confusion over how and when the lanes can be } \\
\text { used }\end{array}$ & $\begin{array}{l}\text { Potential confusion on the part of motorists may } \\
\text { contribute to higher violations (particularly near } \\
\text { the beginning or end of the part time operation) }\end{array}$ \\
\hline & $\begin{array}{l}\text { Enforcement costs may be higher due to the need } \\
\text { for ongoing enforcement. }\end{array}$ & Increases the difficulty of enforcement \\
\hline \multirow{2}{*}{$\begin{array}{l}\text { Adjoining HOV } \\
\text { Facilities/Systems }\end{array}$} & \multicolumn{2}{|c|}{ A uniform policy for hours of operation is essential for a corridor and desirable for a region } \\
\hline & \multicolumn{2}{|c|}{$\begin{array}{l}\text { If adjoining facilities, or even neighboring regions, have contrasting hours of operation policies, } \\
\text { then motorist confusion, violation rates and enforcement difficulties are likely to increase }\end{array}$} \\
\hline \multirow[t]{2}{*}{ Safety } & \multicolumn{2}{|c|}{$\begin{array}{l}\text { HOV Facilities are often granted design exceptions (e.g., minimal shoulders, narrower lanes, or left } \\
\text { side ramps) based on the expectation that they would generally experience lower vehicular volumes } \\
\text { than a general purpose lane. }\end{array}$} \\
\hline & \multicolumn{2}{|c|}{$\begin{array}{l}\text { Allowing general purpose use, and presumably higher volumes, on these facilities during "off-peak" } \\
\text { times may be a safety concern }\end{array}$} \\
\hline Transit Operations & $\begin{array}{l}\text { Facilitates transit speed and reliability } \\
\text { throughout the day }\end{array}$ & $\begin{array}{l}\text { Facilitates transit speed and reliability during } \\
\text { the part-time operations period only }\end{array}$ \\
\hline \multirow[b]{2}{*}{$\begin{array}{l}\text { General-Purpose } \\
\text { Operations }\end{array}$} & \multirow[b]{2}{*}{$\begin{array}{l}\text { Does not provide additional capacity for general- } \\
\text { purpose traffic at any time of the day }\end{array}$} & $\begin{array}{l}\text { Provides additional capacity for general- } \\
\text { purpose traffic during the off-peak }\end{array}$ \\
\hline & & $\begin{array}{l}\text { Most beneficial to traffic during the shoulders } \\
\text { of the peak, and during times of unexpected } \\
\text { congestion such as during incidents or special } \\
\text { events }\end{array}$ \\
\hline \multirow{2}{*}{ Ingress/Egress Policy } & \multirow{2}{*}{$\begin{array}{l}\text { Conducive to limited ingress/egress operations } \\
\text { (e.g., buffer or barrier separated facilities with } \\
\text { designated ingress/egress points), but also has } \\
\text { been shown to work with unlimited open } \\
\text { ingress/egress operations. }\end{array}$} & $\begin{array}{l}\text { Most compatible with unlimited ingress/egress } \\
\text { operations and contiguous HOV lanes skip- } \\
\text { striped similarly to other general purpose lanes }\end{array}$ \\
\hline & & $\begin{array}{l}\text { Part time operations on a buffer-separated } \\
\text { facility with limited ingress/egress points may } \\
\text { cause motorist confusion, safety and } \\
\text { enforcement concerns. }\end{array}$ \\
\hline \multirow[t]{2}{*}{$\begin{array}{l}\text { Direct Access } \\
\text { Facilities }\end{array}$} & \multirow[t]{2}{*}{$\begin{array}{l}\text { Compatible with an HOV "system", including } \\
\text { use of direct access ramps to the arterial system, } \\
\text { and direct connector ramps at interchanges }\end{array}$} & $\begin{array}{l}\text { May necessitate the limitation or elimination of } \\
\text { the use of some types of HOV direct access } \\
\text { facilities, such as left side drop ramps, or } \\
\text { connector ramps that were designed and } \\
\text { approved for volumes indicative of HOV-only } \\
\text { use }\end{array}$ \\
\hline & & $\begin{array}{l}\text { If general-purpose traffic is allowed to use left } \\
\text { side ramps, undesirable left-to-right side } \\
\text { weaving could result. }\end{array}$ \\
\hline $\begin{array}{l}\text { Signing and } \\
\text { Pavement Markings }\end{array}$ & Simplifies signing and pavement markings & $\begin{array}{l}\text { Requires additional signing and/or pavement } \\
\text { marking for clarification of part-time } \\
\text { operations. }\end{array}$ \\
\hline \multirow[t]{2}{*}{ Public Perception } & $\begin{array}{l}\text { Can encourage off-peak ridesharing and transit } \\
\text { use }\end{array}$ & $\begin{array}{l}\text { Does not encourage off-peak ridesharing or } \\
\text { transit use }\end{array}$ \\
\hline & $\begin{array}{l}\text { Possible negative public perception if the facility } \\
\text { is not well used during off-peak times }\end{array}$ & $\begin{array}{l}\text { Reduces potential for public perception of } \\
\text { "empty lane" syndrome during off-peak times }\end{array}$ \\
\hline
\end{tabular}


Northern California has short periods of congestion that do not extend for most part of the day. Therefore, most HOV facilities in that region operate the concurrent flow lanes in each direction during the peak periods only. In Southern California on the other hand, congestion generally extends to 13-14 hours a day. Therefore, there HOV systems generally comprise exclusive buffer-separated lanes operating for 24 hours in each direction. The Puget Sound region in Seattle operates its paint stripe delineated concurrent flow HOV lanes on a 24-hour basis, a change from the initial situation where the facility was operated as part time HOV lanes. Table 2.8 summarizes the advantages and disadvantages of full-time and part-time operation based on experiences drawn from various HOV lane locations. Figure 2.35 shows the trend in growth of full-time and part-time HOV lane facilities. The full-time HOV operation has become more common since 1993, primarily because of the significant increase in level and hours of congestion over the last decade.

\subsubsection{Enforcement Policies}

Effective enforcement is critical to the success of HOV facilities. The average violation rate in the country is in the range of $10-15 \%$. To a large extent violation rates are influenced by the type of facility. Concurrent facilities have the highest violation rates because they lack physical separation from the general purpose lanes thus making it easy for violators to switch between the general purpose and HOV lanes with impunity.

Enforcement strategies by highway patrol play a crucial role in HOV system success. For example, the violation rates corresponding to various enforcement strategies deployed by Highway Patrol along I-80 in New Jersey are summarized in Table 2.9. A higher enforcement frequency results in lower violation rates. Random times of enforcement results in lower violations as against a fixed schedule. It has also been observed that higher violation rates occur in HOV facilities that operate part-time, especially close to the time when a lane's status changes from HOV to general purpose and vice-versa.

Table 2.9: Effect of Enforcement Strategies on I-80 in New Jersey [Cambridge Systematics, 2001]

\begin{tabular}{|c|c|c|c|}
\hline Enforcement Strategy & I-80 EB: \% Violations & I-80 WB: \% Violations & Average \% Violations \\
\hline Five days per week & $6.9 \%$ & $6.1 \%$ & $6.5 \%$ \\
Three days per week & $10.4 \%$ & $24.3 \%$ & $17.4 \%$ \\
Six random peaks per week (4 patrollers) & $4.6 \%$ & $5.2 \%$ & $4.9 \%$ \\
Eight random peaks per week (3 patrollers) & $7.6 \%$ & $6.9 \%$ & $7.3 \%$ \\
\hline
\end{tabular}

The importance of enforcement area construction was discussed in section 1.3.6. Enforcement of occupancy requirements can be greatly facilitated by appropriate physical design. Providing adequate shoulder length can allow police officers to monitor and to pull over the violators. Enforcement areas can also be classified as low speed or high speed and by HOV/GP separation mechanism. Low speed enforcement areas are generally associated with at the access points to the HOV lane. High speed enforcement areas are associated with HOV facilities that with a large number of access points along the length of the HOV facility. 
In the beginning stages of implementation, defaulters are typically let off with warnings, and more stringent penalties are applied after the initial phases. The enforcement strategies can be categorized as follows:

- Routine Enforcement: Using the existing freeway patrols to monitor the violation of the HOV lanes. Police officers could note down the license plate number of defaulters and a warning or ticket could be issued by mail. For example, METRO police officers provide HOV lane enforcement for Houston HOV lanes. At least one METRO police officer is present in the HOV lane corridor during the hours of operation at specific enforcement areas that do not interfere with the flow of traffic. If enforcement areas are deemed necessary, their design is typically considered at the planning stages of the HOV facility.

- Special Enforcement: Dedicated equipment and manpower are used specifically to monitor the managed lanes. Alternate methodologies such as video detection technology may be used to identify defaulters. Recent advances in the automated enforcement technologies have reduced the need of the number of the dedicated enforcement areas. For example, HOV Lane enforcement program in the city of Toronto, Canada is a technology based enforcement strategy. HOV facilities on I-10 Katy Freeway, US 290 (North west freeway) are in the process of transition to technology based enforcement.

- Selective Enforcement: Combination of the above two strategies is used for specific events such as opening of a new facility or to tackle the high violation rates.

- Self Enforcement: This strategy is based on monitoring of HOV lane violators by other users of the HOV lane or the GP Lane. For example, State of Washington has successfully deployed an enforcement program called HERO where HOV users are encouraged to call a designated number (206-764-HERO) or submit an electronic complaint to report violators. The violators are not issued tickets under this program because they were not actually observed by the Washington State Patrol (WSP). The violators are mailed instructional material describing the purpose of HOV. Repeat offenders are issued warnings through the mail. Figure 2.36 shows the number of violation reports received during 1994-2002 in the HERO program.

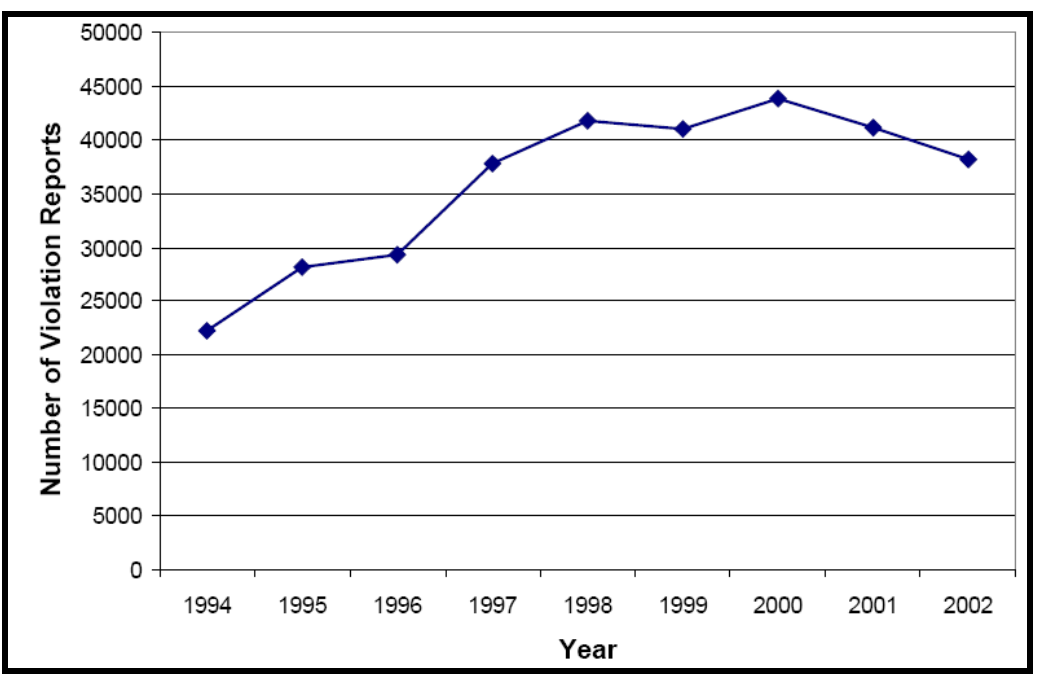

Figure 2.36: Number of Violation Reports Received in HERO Self Enforcement Program, Seattle [Nee, 2004] 
Enforcement techniques, number of deployments, fine amount and percentage violation are shown in Table 2.10 for some of the HOV facilities in the United States.

Table 2.10: Enforcement Methodology and Resulting Violation Rates at HOV Facilities [FTA, 1992]

\begin{tabular}{|c|c|c|c|c|c|}
\hline HOV Facility & Enforcement Methodology & $\begin{array}{c}\text { Persons } \\
\text { Deployed For } \\
\text { Enforcement }\end{array}$ & $\begin{array}{c}\text { Peak } \\
\text { Hour } \\
\text { Violation } \\
\text { Rate } \\
\end{array}$ & $\begin{array}{c}\text { Peak } \\
\text { Period } \\
\text { Violation } \\
\text { Rate } \\
\end{array}$ & $\begin{array}{c}\text { Fine } \\
\text { Amount }\end{array}$ \\
\hline \multicolumn{6}{|c|}{$\begin{array}{l}\text { Facility in Separate ROW } \\
\end{array}$} \\
\hline Ottawa, Canada & Charged with Trespassing & 3 & $1 \%$ & $1 \%$ & $\$ 53.75$ \\
\hline $\begin{array}{l}\text { South and East Busways, } \\
\text { Pittsburgh }\end{array}$ & Citation & 4 & $1 \%$ & $1 \%$ & $\$ 300+$ Court \\
\hline \multicolumn{6}{|c|}{$\begin{array}{l}\text { Reversible Flow } \\
\end{array}$} \\
\hline $\begin{array}{l}\text { Houston, I-45, I-10, } \\
\text { US290 }\end{array}$ & $\begin{array}{l}\text { Special Citiation Areas, } \\
\text { Vehicles Diverted }\end{array}$ & 2 & $1 \%$ & NA & $\$ 75$ \\
\hline I-395 Virginia & Citations By Mail & 2 to 5 & $5 \%$ & $15 \%$ & $\$ 50$ \\
\hline I-15 Sandiego & Vehicles Stopped & 2 & $3 \%$ & $5 \%$ & $\$ 246+$ Court \\
\hline \multicolumn{6}{|c|}{2 way Barrier Separated HOV Facility } \\
\hline I-10 Los Angeles & Citation on Shoulder & 2 & $11 \%$ & $11 \%$ & $\$ 246+$ Court \\
\hline \multicolumn{6}{|c|}{2 Way Buffer Separated HOV Facility } \\
\hline $\begin{array}{l}\text { Route } 55 \text { and I-405, } \\
\text { Orange County }\end{array}$ & Special Citation Areas & 6 & $6 \%$ & $7 \%$ & $\$ 246+$ Court \\
\hline Route 91, (Los Angeles) & Special Citation Areas & 6 & $7 \%$ & $7 \%$ & $\$ 246+$ Court \\
\hline I-95 Fort Lee, NJ & Vehicles Stopped & 1 & $30 \%$ & $30 \%$ & $\$ 50$ \\
\hline Moanalua (Honolulu) & Vehicles Diverted & 3 & $20 \%$ & $20 \%$ & $\$ 40$ \\
\hline I-4 (Orlando) & Not Enforced & 0 & $75 \%$ & $75 \%$ & $\$ 43.50$ \\
\hline $\begin{array}{l}\text { US 101, Route } 237 \text { (San } \\
\text { Francisco) }\end{array}$ & Vehicles Diverted & 1 to 7 & $5 \%$ & $10 \%$ & $\$ 50-\$ 500$ \\
\hline I-5, I-405 Seattle WA & $\begin{array}{l}\text { License Plates Identified and } \\
\text { Hero Program }\end{array}$ & NA & $11 \%$ & $11 \%$ & $\$ 47$ \\
\hline SR520 (Seattle) & $\begin{array}{l}\text { License Plates Identified and } \\
\text { Hero Program }\end{array}$ & NA & $8 \%$ & $8 \%$ & $\$ 47$ \\
\hline
\end{tabular}

\subsubsection{HOV Facility Marketing}

The biggest challenge in the implementation of a new HOV facility is public acceptability. Positive public perception is critical to the success of HOV systems. Past studies have shown that public generally deems HOV facilities to be successful only when such facilities are operating at or near capacity. The public has to be informed that even though HOV lanes might seem underutilized in terms of number of vehicles, they could be still doing a superior job in comparison to general purpose lanes in terms of people throughput and total travel time savings. In addition to enforcement and monitoring, ongoing education and awareness campaigns are necessary to make the public aware of the benefits accruing to individual commuters and to the society at large. The marketing strategy in Houston uses reduced driving stress along with savings in time and money to encourage people to carpool. In addition, HOV marketing and ridesharing services have been provided through Houston's METRO transit website.

The public misconception of HOV lanes, particularly when such facilities seem to be less congested than general purpose lanes, could be addressed through education of the general public with facts and numbers from various HOV facilities in the country. A congested lane carries 2000-2200 vehicles per hour per lane while a severely congested lane can carry 2400 vehicles per hour. The ideal capacity of an urban freeway section according 
to the Highway Capacity Manual (HCM) is 2,200 vphpl. The actual capacity of such a freeway section is calculated after adjusting for the lane width, shoulder width, presence of heavy vehicles [HCM] and is typically in the range of 1700-1900 vphpl. The capacity of the HOV lanes has been set lower (1600 vphpl) at most of the places to ensure proper level of service.

Table 2.11 shows the usage of the HOV lanes during the peak hour at several places. Most of the HOV lane facilities at these places carry 900-1000 vphpl with a 2+ occupancy requirement. California, which has one of the largest HOV lane network in the country (more than 1100 lane-miles) is operating the HOV lanes at 98\% capacity (1600 vphpl) in Orange County, 62.5\% capacity in Los Angeles County and 75\% capacity in Sacramento region. The HOV lanes in Texas, Portland, Washington, Vancouver and Boston operate in the range of 41-59\% of their capacity during the peak hour. These percentages may seem low for a peak hour operation. However, the HOV lanes carry more passengers per vehicle and hence the low vehicle throughput is compensated for by a high average vehicle occupancy. Most of the HOV lanes in these regions are operated with a 2+ occupancy restriction. Therefore, even if the average vehicle occupancy on the HOV lanes is assumed to be minimum (say 2.0), the total number of passengers carried by the HOV lane is comparable to a congested GP lane, if the HOV lane carries 900-1000 vphpl.

Table 2.11: HOV Lane Peak Hour Usage [(Caltrans, 2004); (Parsons, 2002); (FTA, 1992)]

\begin{tabular}{|c|c|c|c|c|}
\hline \multirow[t]{2}{*}{ Location } & \multicolumn{2}{|c|}{$\begin{array}{c}\text { HOV Peak Hour Lane Volume } \\
\text { vphpl (Year) }\end{array}$} & \multicolumn{2}{|c|}{$\begin{array}{c}\% \text { Capacity } \\
(\text { Capacity = } 1600 \text { vphpl })\end{array}$} \\
\hline & Lower & Upper & Lower & Upper \\
\hline Orange County, CA & \multicolumn{2}{|c|}{$1,568(1998)$} & \multicolumn{2}{|c|}{$98 \%$} \\
\hline Los Angeles County, CA & \multicolumn{2}{|c|}{$1,000(1998)$} & \multicolumn{2}{|c|}{$75 \%$} \\
\hline Oakland area, CA & \multicolumn{2}{|c|}{$900(1998)$} & \multicolumn{2}{|c|}{$56 \%$} \\
\hline Sacramento region, CA & \multicolumn{2}{|c|}{$1,200(1998)$} & \multicolumn{2}{|c|}{$63 \%$} \\
\hline San Bernardino County, CA & \multicolumn{2}{|c|}{$800(1998)$} & \multicolumn{2}{|c|}{$50 \%$} \\
\hline San Diego, CA & \multicolumn{2}{|c|}{$900(1998)$} & \multicolumn{2}{|c|}{$56 \%$} \\
\hline Washington, DC & 663 & 1713 & $41 \%$ & $107 \%$ \\
\hline Texas (Houston Dallas) & 799 & 1429 & $50 \%$ & $89 \%$ \\
\hline Portland, OR & 800 & 900 & $50 \%$ & $56 \%$ \\
\hline $\begin{array}{l}\text { Washington (Seattle and } \\
\text { Vancouver) }\end{array}$ & 290 & 1550 & $18 \%$ & $97 \%$ \\
\hline Vancouver, B.C. & \multicolumn{2}{|c|}{723} & \multicolumn{2}{|c|}{$45 \%$} \\
\hline Boston, MA & \multicolumn{2}{|c|}{949} & \multicolumn{2}{|c|}{$59 \%$} \\
\hline
\end{tabular}

The passenger and vehicle throughput on the HOV lanes on some freeway corridors was plotted using the 2001 vehicle and passenger volumes (Figure 2.37). It was observed that the average vehicle throughput was approximately 1100 vphpl during the peak period. That is, on an average the HOV lanes were operating at $68 \%$ of their capacity (1600 vphpl). Despite of the low vehicle throughput, the average passenger throughput is approximately 3000 passengers/hour/lane which is significantly more than a severely congested GP lane. A lower vehicle throughput also ensures high level of service on the HOV lane. However, these conclusions cannot be generalized for all HOV facilities. This information can be used to educate commuters in the region where HOV facility is being considered so that public opposition can be minimized and more people can be attracted to use the HOV facility. 


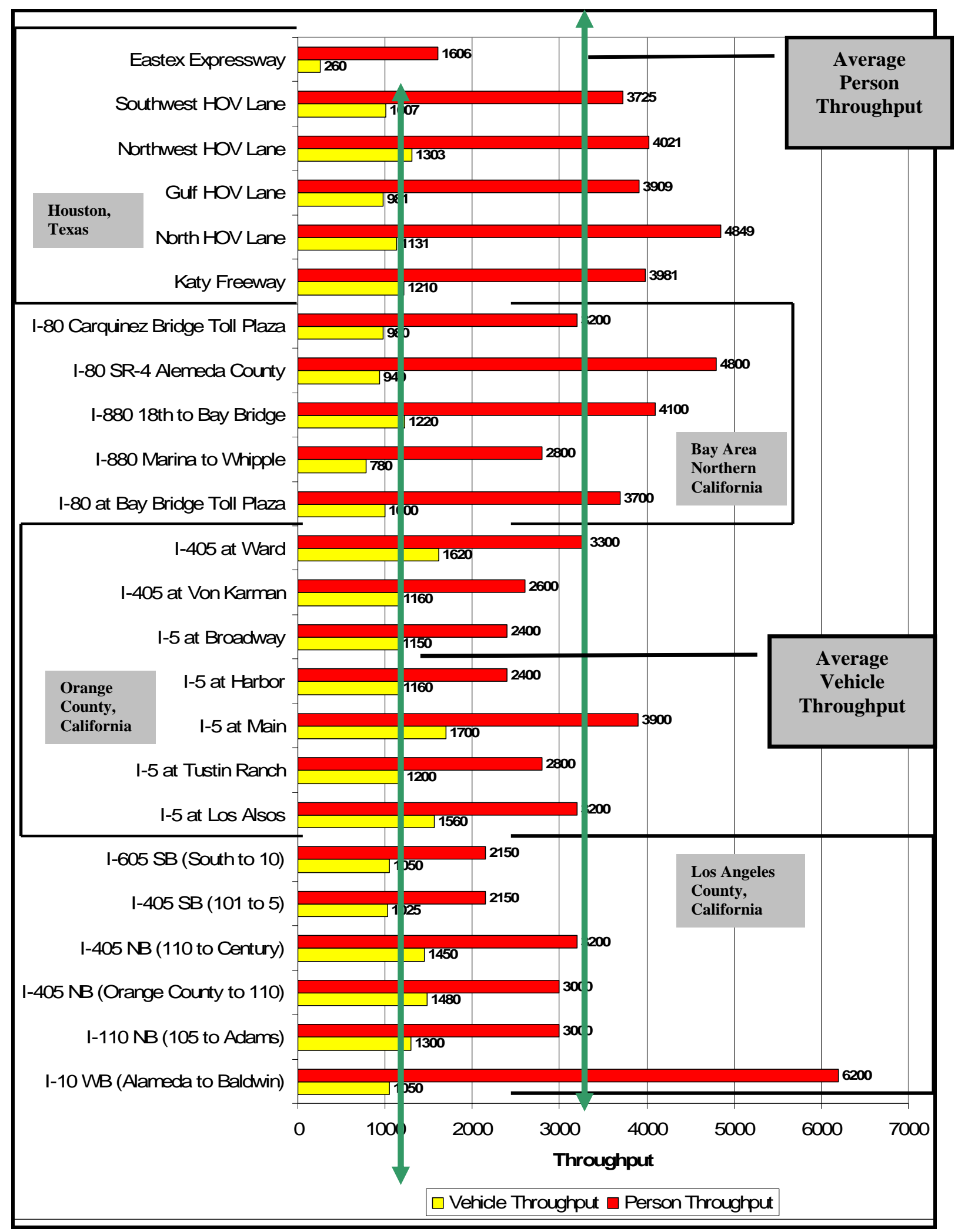

Figure 2.37 Vehicle and Person Throughput in Peak direction across various HOV Facilities

[Source: (Turnbull, 1992); (Fuhs \& Obenberger, 2002); (Skowronek et al., 2002); (Morrison \& Counts, 2005)] 


\subsubsection{Incident Handling/ Special Events on HOV Lanes}

Currently, most of the HOV lane facilities are being operated as a single HOV lane in each direction. An incident may occur in an HOV lane or in a mixed flow lane. The occurrence of a incident on the HOV lane may block the flow of traffic on the HOV lane unless the HOV lane vehicles are diverted to the GP lane. This could adversely affect the level of service on the general purpose lanes as well as the overall safety on the freeway corridor.

On the other hand, any major incident on the GP lane can prompt the authorities to open the HOV lanes to all traffic. If the incident has occurred on the mixed flow lane, the opening of HOV lane to mixed flow traffic can be considered depending upon the impact of the incident on the traffic conditions in the general purpose lanes. In case of major incidents that affect the traffic flow on multiple general purpose lanes the opening of HOV lanes to mixed flow traffic can be allowed. Such use of a barrier separated reversible HOV lane facility by general purpose lane traffic should be approached with caution as it may lead to safety concerns as vehicles try to enter or leave the HOV lane.

Therefore, it is necessary to ensure that the incident detection and handling capabilities for HOV facilities are carefully designed. For example, barrier-separated HOV facilities present different operational problems and possibilities as compared to other types of HOV facilities, for handling incidents both in the HOV lane and in the general purpose lane. Barrier-separated HOV facilities have very restrictive access points and hence generally should not be used for incident management unless the incident is of extended duration [Caltrans, 2003].

\subsubsection{Ridership Programs}

The development of ridership strategies is crucial in inducing the people to carpool. One of the reasons of failure of the HOV lanes in New Jersey was because no ridership strategies were implemented to encourage people to carpool. On the other hand, successful HOV facilities have implemented several ridership strategies. For example, in Houston the Metropolitan Transit Organization of Harris County (METRO) offers the following rideshare services through its website and other media.

\section{a) Free Ride-Matching}

Free ride-matching helps the travelers in the formation of carpools by helping them find other travelers who are willing to carpool. METRO website maintains a database of travelers interested in carpooling with data such as contact information, preferred time(s) of travel, etc. and therefore helps bring together people with similar travel patterns.

\section{b) METROVan}

The METROVan service was launched specifically for the people who live outside the zone of transit service. METROVan serves an eight-county region by leasing vans to a group (seven-fifteen people) of riders. METRO helps in the formation of these groups using the Free-Ride Matching service. Each group decides its primary driver. The primary driver is responsible for coordinating the morning and evening pickup arrangements, in addition to fueling and cleaning the van and conducting daily safety checks. The driver or any other designated rider is responsible for maintaining ridership logs, receive and distribute the monthly incentive report and inform METRO of any changes in ridership. The total cost of vanpooling is calculated based on mileage, number of passengers and 
the size of the van. The average cost per passenger is in the range of $\$ 2-\$ 4$ per day. The costs are further reduced if an employer provides additional ride sharing incentives.

\section{c) Corporate Discounts}

METRO encourages corporate businesses to promote the concept of ride sharing amongst the employees thereby helping in reducing congestion not only on the road but also in the company's parking lot. The employer incentives can be in the form of:

- $\quad$ Reduced investment on parking lots

- Improved work atmosphere

- $\quad$ Employees arriving at work on time

- Recruiting workers from outlying areas who would not prefer the company otherwise

- Increased productivity

- $\quad$ Reduction in the payroll taxes

- $\quad$ Retaining top talent by providing transportation benefits

METRO helps the companies in launching their rideshare program. It analyzes the travel pattern of the employees by zip code density maps and employee transportation surveys. The employees are then assisted in starting a vanpool or carpool through ride matching and custom trip planning.

RideFinders, a Central Virginia regional ride share agency maintains a database of carpoolers. RideFinders has implemented an employer-based marketing to encourage carpool programs within regional businesses. The agency has also started supporting an Emergency Ride Home program which is designed to allow the carpoolers to get back to home when an emergency or unscheduled overtime forces them to miss their pool.

In State of Washington, ride matching services are most frequently operated by transit/ridesharing agencies who maintain large databases of interested commuters in order to coordinate potential rideshares. Several sophisticated rideshare services such as Ridematch and Ridequest have been established in the central Puget Sound Region with interactive capabilities. Maps of employee home locations are also available from these services. WSDOT's CommuteMate software is available to assist in the setup of ridematching database. Three fundamental ways of organizing a vanpool have been found to be most common:

Owner Operated Vans: The van is owned or leased directly by an individual. The owner is completely responsible for organizing the vanpool, bearing financial arrangements, maintenance etc.

Employer Sponsored Vanpools: The employer purchases or leases the van for it's employees. The riders are charged a nominal fees for the operation and capital cost of the vehicle. The driver is either exempted from the fee or is allowed personal use of the van.

Third Party Vanpools: In this case, a third party which could be a transit agency, a private vendor or a non profit organization leases the vans for use by the carpoolers. The cost of leasing the van depends upon the cost of the vehicle, maintenance cost and fuel and insurance cost. The administration costs may or may not be included in the cost of leasing the van. In Houston, METRO transit provides this kind of service. In Central Virginia, the regional rideshare agency, RideFinders, does this job. 


\subsection{TRENDS OF HOV IMPLEMENTATION IN US}

High Occupancy Vehicle (HOV) lane facilities have been implemented in the US over the past three decades. Many of the early HOV lane projects began as demonstration projects to improve the operational effectiveness of the mass transit. For example, the first HOV system, implemented on I-395, Shirley Highway in Northern Virginia, involved a temporary bus only lane created through the construction work zone during the reconstruction of I-395 in 1969. Several other early HOV lane projects started as busways. Many of these gradually evolved to HOV systems through incremental extension and expansion. Most of the projects contain two lane miles for each route mile since HOV lanes exist in both directions. Currently, more than 2500 lane-miles of HOV lanes are operational in the country. Figure 2.38 shows the growth in route miles of the freeway HOV facilities in US since 1969.

Most of the HOV systems are in the largest metropolitan areas and within freeway corridors where traffic congestion is typically severe. Many of the initial HOV projects were limited in length and were implemented in corridors that served the CBDs because of the potential for transit service on these corridors. However, as congestion expanded into the suburbs and increasingly into the non-radial routes that connected suburbs to suburbs, a large number of HOV projects were implemented to cater to the potential carpool markets on these corridors [Fuhs and Obenberger, 2002] as shown in Figure 2.38. A large number of the non-radial corridors exist in southern California where there is a significant demand for the HOV lanes.

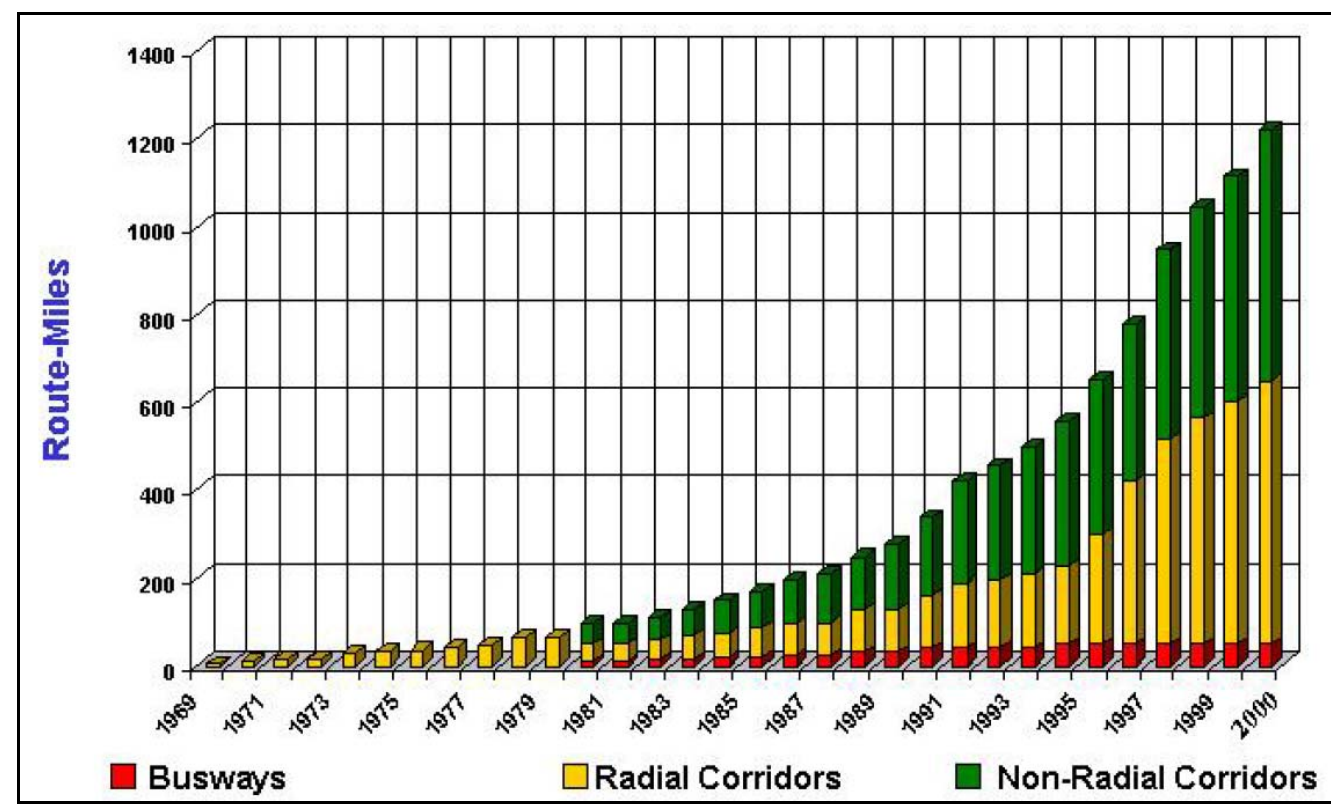

Figure 2.38: Route Miles of Freeway HOV Facilities in the US [Fuhs and Obenberger, 2002]

The buffer-separated HOV lane has emerged as the most popular approach for HOV facility implementation on freeways over the last two decades. Figure 2.39 presents the growth of the various types of HOV facilities in the country. In 2001, 48\% of all HOV route mileage comprised of buffer separated concurrent lanes and $28 \%$ of all route mileage comprised of non-buffer separated HOV lanes. 


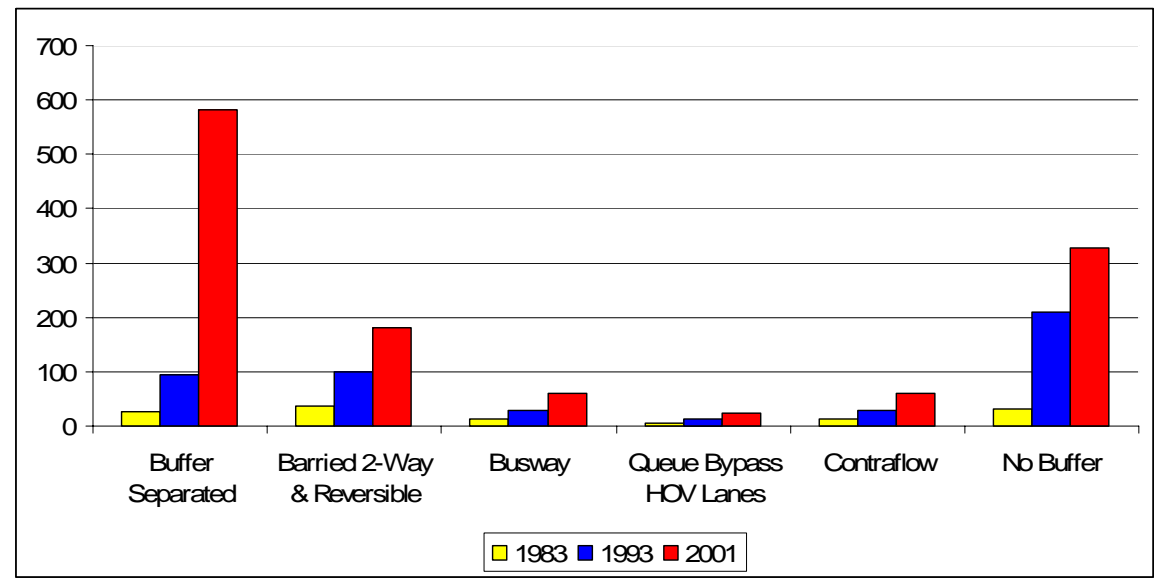

Figure 2.39: Growth Trends in Different Types of Freeway HOV Facilities [Fuhs and Obenberger, 2002]

Figure 2.40 shows the distribution of the various types of HOV facilities in 2004. The buffer-separated concurrent flow lane HOV facilities constitute $47 \%$ of the HOV system. The non-separated concurrent flow HOV lanes constituted $37 \%$ of the HOV system. Concurrent flow HOV lanes constitute $84 \%$ of the HOV system.

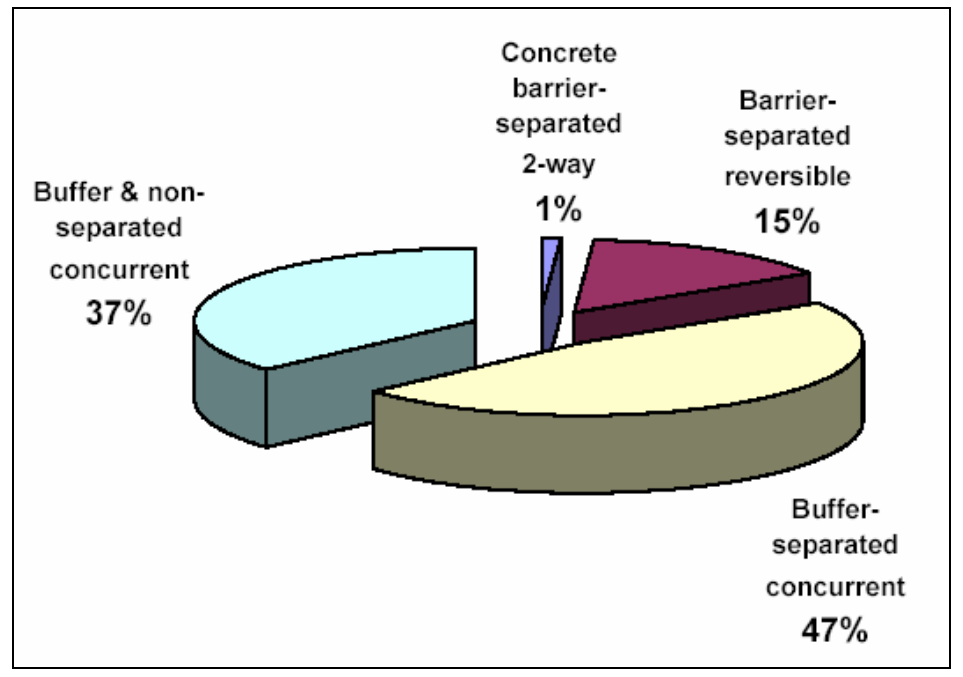

Figure 2.40: U.S. Total HOV Highway Miles by type [Markkula, 2004]

Figure 2.41 shows the various locations where HOV projects have been implemented. Currently, about $50 \%$ of the HOV projects are in California. Over 70\% of all HOV lane miles in California are located in southern California in the counties of Los Angeles, Orange, San Bernardino San Diego and Riverside. More than 50\% of these HOV facilities are operated for 24 hours a day and seven days a week. 86\% of these HOV lanes operate with a 2+ occupancy requirement. HOV Lanes also exist on a number of arterials inside many cities, and most of these lane 
treatments were designed to facilitate bus movements, typically in the vicinity of CBDs. The last HOV lane facility that was terminated was in New Jersey on I-80 and I-287 in 1998. Prior to this a HOV facility was closed in 1991 on the Dulles Toll Road in Northern Virginia, where a lane was constructed and initially opened to general purpose traffic, and then it was converted into an HOV lane.

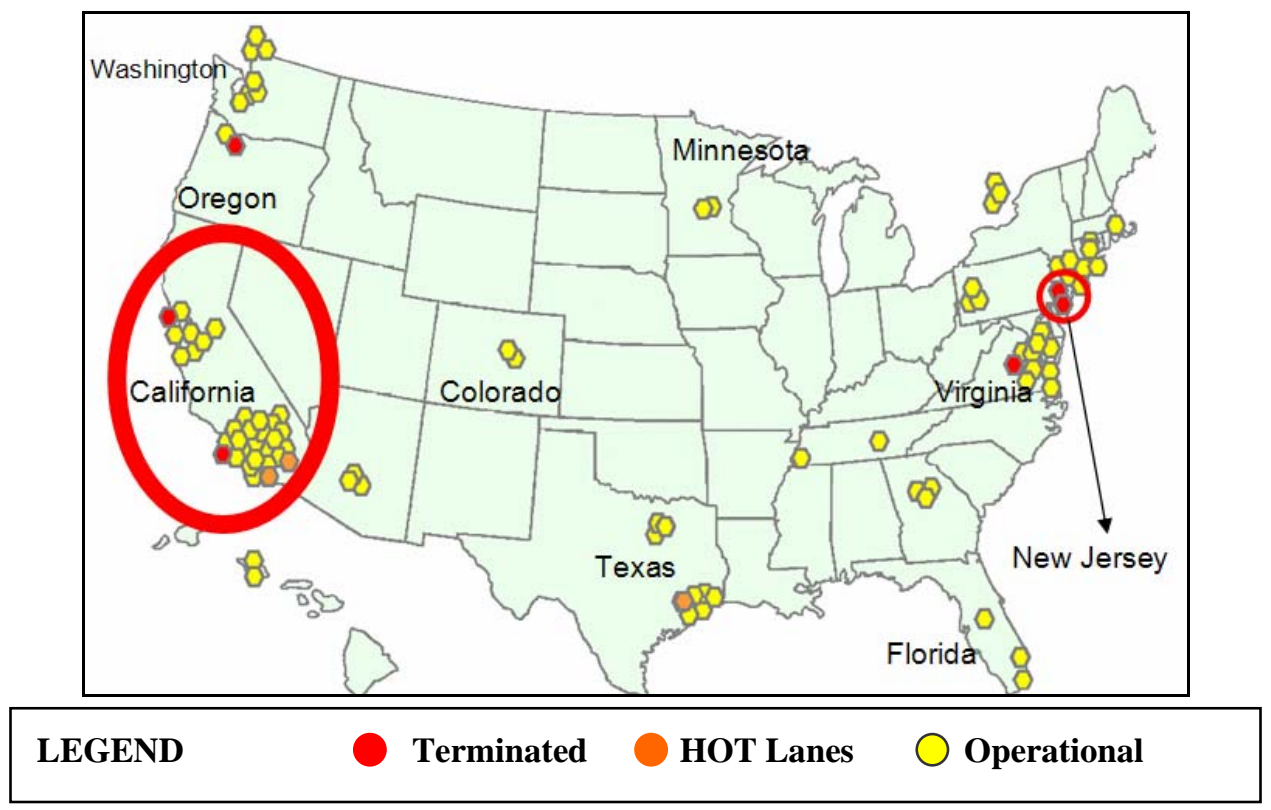

Figure 2.41: Distribution of HOV Facilities in the US [Fuhs and Obenberger, 2002]

The distribution of the average length of the HOV lane depending upon the type of the HOV facility is shown in Figure 2.42. The average length of a HOV lane varies in the range of eight to twelve miles.

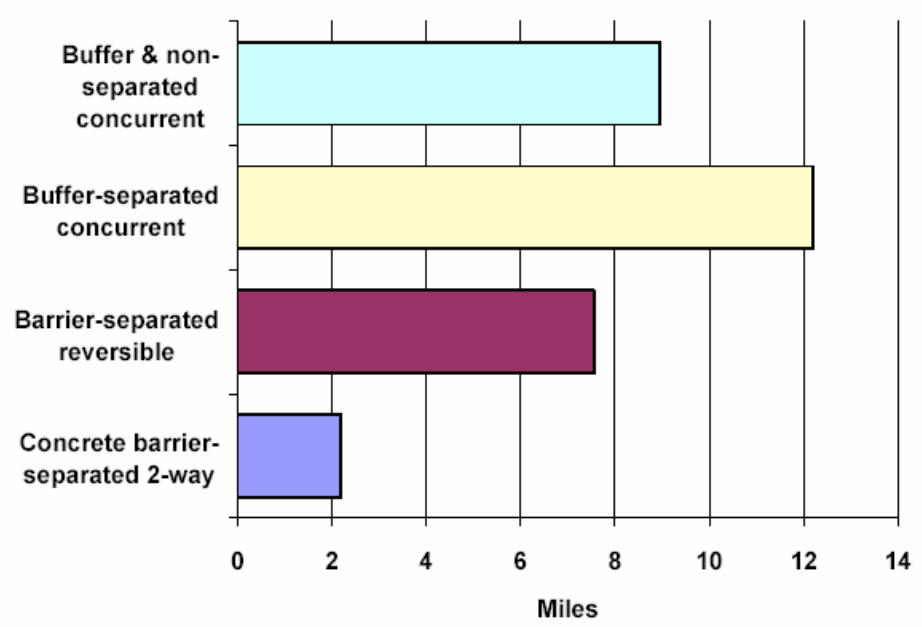

Figure 2.42: Average Mile Length of U.S. HOV Lanes by Type [Markkula, 2004] 


\section{$2.5 \quad$ HOV SYSTEM COST ESTIMATION}

The cost of the HOV system depends upon what physical components have been included in the system and hence can vary from one location to another. The cost can vary significantly depending upon the number and size of parkand-ride lots, direct access ramps, enforcement areas and the approach used for the construction of the lane. The cost of the projects can also vary depending upon whether they are implemented separately or as part of a bigger project. HOV lanes have been around for more than two decades and a lot of the projects have been implemented as a part of a bigger project. A synthesis of the costs of HOV lane projects at various places has been presented in this section. The HOV system has grown with time at most of these places and hence the costs may not reflect the net worth of the entire facility. However, the objective was to be able to estimate the cost of the HOV facility based upon the trends.

\subsubsection{HOV Facility Cost - Past Trends}

This section presents the total cost of the HOV facility at various places depending upon the type of the HOV facility. The data has been obtained from CUTS (FTA, 1992) and converted to 2005 dollars using the FHWA construction price index.

\subsubsection{Exclusive 2-Directional HOV Facility}

The capital cost of the Exclusive two-directional HOV facility in San Bernandino (LA) was \$77.04 million per route mile in 2005 dollars. The high cost of the project was primarily due to the purchase of additional right of way required for the implementation of the HOV lanes.

\subsubsection{Exclusive Reversible HOV Facility}

Capital costs of several barrier separated exclusive reversible HOV facilities are shown in Table 2.12. The average capital cost per lane mile was found to be approximately \$6 m (2005 dollars).

Table 2.12: Capital Cost of Exclusive Reversible Lane HOV Facilities (2005 Dollars) [Source: FTA, 1992]

\begin{tabular}{|c|c|c|c|c|c|c|}
\hline Location & $\begin{array}{c}\text { Construction } \\
\text { Year }\end{array}$ & $\begin{array}{l}\text { Route } \\
\text { Miles }\end{array}$ & $\begin{array}{c}\text { Freeway Lanes } \\
\text { Striped/Operated } \\
\text { as HOV Lane }\end{array}$ & $\begin{array}{l}\text { Total Capital } \\
\text { Cost (\$) }\end{array}$ & $\begin{array}{l}\text { Capital Costs/ } \\
\text { Lane mile }\end{array}$ & $\begin{array}{c}\text { Average } \\
\text { Capital } \\
\text { Costs/Lane } \\
\text { mile }\end{array}$ \\
\hline I45N Houston & 1988 & 9.1 & 1 & $\$ 48,310,300$ & $\$ 5,308,824$ & \multirow{5}{*}{$\$ 6,229,557$} \\
\hline I45S Houston & 1988 & 6.5 & 1 & $\$ 45,478,317$ & $\$ 6,996,664$ & \\
\hline I10 Houston & 1989 & 11.5 & 1 & $\$ 52,763,454$ & $\$ 4,588,126$ & \\
\hline US290 Houston & 1988 & 9.5 & 1 & $\$ 73,298,386$ & $\$ 7,715,620$ & \\
\hline I-15 San Diego California & 1988 & 8 & 1 & $\$ 52,308,394$ & $\$ 6,538,549$ & \\
\hline
\end{tabular}

* FHWA CPI used to convert construction year costs to the year 2005

The total cost of seventy-one miles of HOV lanes in Texas along the North, KATY, Gulf, Northwest, and Southwest Freeways was reported equal to $\$ 525$ million in 1987, which translates to approximately $\$ 7.4$ million per 
route mile. The total cost of ninety-one miles of HOV lanes in Houston was reported equal to \$643 million in 1990, i.e., $\$ 7$ million per mile. About $70 \%$ of cost was for the construction of HOV lanes and ramps. The Houston HOV system comprises of ten direct access HOV ramps connecting park-and-ride facilities or transit centers to the HOV lane. The HOV system in Houston consists of thirty-two park-and-ride facilities.

\subsubsection{Concurrent Flow/ Buffer Separated HOV Facility}

Cambridge Systematics (1992), reported that the capital cost per route-mile of a concurrent flow lane HOV facility is approximately $\$ 1.2 \mathrm{~m}$ (2005 dollars). The capital cost per route mile (2005 Dollars) of a few concurrent flow lane HOV projects is shown in the Table 2.13. The average cost is approximately $\$ 1.2 \mathrm{~m}$. However, the variation in the costs is quite large (\$70,000 - \$6 million), which can be attributed to different physical components of these HOV systems. The cost of the HOV system will be determined by taking into account each component of the system, so as to account for this variation, in section 2.5.2. Concurrent flow lane HOV facilities are the most common HOV facilities in the country comprising of $84 \%$ of the route-miles in the country.

Table 2.13: Capital Cost of Concurrent Flow Lane HOV Facilities (2005 Dollars) [FTA, 1992]

\begin{tabular}{|c|c|c|c|c|c|c|}
\hline Location & $\begin{array}{c}\text { Construction } \\
\text { Year }\end{array}$ & $\begin{array}{c}\text { Route } \\
\text { Miles }\end{array}$ & $\begin{array}{c}\text { Freeway Lanes } \\
\text { Striped/Operated } \\
\text { as HOV Lane }\end{array}$ & $\begin{array}{c}\text { Total Capital } \\
\text { Cost }\end{array}$ & $\begin{array}{c}\text { Capital Costs/ } \\
\text { Lane mile } \\
\text { Average } \\
\text { Capital Costs/ } \\
\text { Lane mile }\end{array}$ \\
\hline Route 91 (Los Angeles) & 1984 & 8 & 1 & $\$ 575,320$ & $\$ 71,915$ \\
\hline Route 51 (Orange County) & 1984 & 11 & 1 & $\$ 767,093$ & $\$ 69,736$ \\
\hline I-4 (Orlando, Florida) & 1980 & 30 & 2 & $\$ 25,577,654$ & $\$ 426,294$ \\
\hline Montague (Santa Clara) & 1985 & 5 & 2 & $\$ 2,611,500$ & $\$ 261,150$ \\
\hline San tomas (Santa Clara) & 1985 & 11 & 2 & $\$ 6,093,500$ & $\$ 276,977$ \\
\hline $\begin{array}{c}\text { I-5 North (Seattle, } \\
\text { Washington) }\end{array}$ & 1985 & 6 & 2 & $\$ 13,231,600$ & $\$ 1,102,633$ \\
\hline SR520 (Seattle, Washington) & 1973 & 2.8 & 1 & $\$ 417,840$ & $\$ 149,229$ \\
\hline $\begin{array}{c}\text { I405 (Seattle, Washington), } \\
\text { Ranton to I90 }\end{array}$ & 1986 & 6 & 2 & $\$ 17,916,285$ & $\$ 1,493,024$ \\
\hline Route 405 (Orange County) & 1988 & 14 & 1 & $\$ 89,957,111$ & $\$ 6,425,508$ \\
\hline
\end{tabular}

\subsubsection{Contraflow HOV Facility}

According to Cambridge Systematics, the capital cost/route mile of a contra-flow lane HOV facility (converted to 2005 dollars) is approximately $\$ 286,000$. Table 2.14 shows the capital cost of contraflow HOV projects as reported by the Federal Transit Administration.

Table 2.14: Capital Cost of Contra-Flow Lane HOV Facility (2005 Dollars) [FTA, 1992]

\begin{tabular}{|c|c|c|c|c|c|c|}
\hline Location & $\begin{array}{c}\text { Construction } \\
\text { Year }\end{array}$ & $\begin{array}{c}\text { Route } \\
\text { Miles }\end{array}$ & $\begin{array}{c}\text { Lanes Modified } \\
\text { During } \\
\text { Construction }\end{array}$ & $\begin{array}{c}\text { Total Capital } \\
\text { Cost }\end{array}$ & $\begin{array}{c}\text { Capital Cost/ } \\
\text { Lane Mile }\end{array}$ & $\begin{array}{c}\text { Average Capital } \\
\text { Cost/ Lane Mile }\end{array}$ \\
\hline $\begin{array}{c}\text { Lincoln Tunnel- New } \\
\text { Jersey }\end{array}$ & 1970 & 2.5 & 2 & $\$ 2,546,344$ & $\$ 509,269$ & \\
\cline { 1 - 5 } \multirow{\text{LongIslandExpressway}}{19}{} & 1971 & 2.2 & 2 & $\$ 1,942,910$ & $\$ 441,571$ & \\
\hline Gowanus Expressway & 1980 & 0.9 & 2 & $\$ 730,790$ & $\$ 405,995$ & \\
\hline I45N (Houston) & 1979 & 9.6 & 2 & $\$ 3,738,568$ & $\$ 194,717$ & \\
\hline
\end{tabular}




\subsubsection{Cost Estimation by HOV System Components}

A new HOV lane can be added by restriping the shoulders, by median reconstruction or by purchase of new right of way on the freeway. The construction of the HOV lane also includes the installation of signs, pavement markings, slip ramps, enforcement area and barrier/buffer installation. The cost of a HOV facility constructed on a separate right of way is significantly higher than that implemented on the freeway right of way. The cost of barrier separated HOV facilities is generally considerably higher than the cost of contiguous HOV facilities mainly because of the added right of way purchase costs. This section presents an estimate of the cost of each component of the HOV system. The total cost of the HOV facility can be estimated by based on these unit costs depending upon the components included in the system.

\subsubsection{Right of Way Cost}

The construction of the HOV lane by add-a-lane approach may require the acquisition of right of way at some places. The cost of the right of way can vary from one location to another depending upon the land costs and whether the right of way is being purchased in a built-up area or an outlying area. Table 2.15 shows the right of way costs for different types of highways [FTA, 1992]. The right of way cost for constructing additional lanes on freeways in built-up areas is $\$ 764,000$ per lane-mile and in outlying areas is $\$ 304,000$ per lane-mile. In cases where right of way is already available this cost does not have to be included in the overall system cost.

Table 2.15: Right of Way Cost for Additional lanes (2006 Dollars*) [FTA, 1992]

\begin{tabular}{|c|c|c|c|c|c|c|}
\hline & \multicolumn{2}{|c|}{$\begin{array}{c}\text { Freeways/ } \\
\text { Expressways }\end{array}$} & \multicolumn{2}{c|}{ Other Divided Highways } & \multicolumn{2}{c|}{ Undivided Highways } \\
\hline & $\begin{array}{c}\text { Built-Up } \\
\text { Areas }\end{array}$ & $\begin{array}{c}\text { Outlying } \\
\text { Areas }\end{array}$ & $\begin{array}{c}\text { Built-Up } \\
\text { Areas }\end{array}$ & $\begin{array}{c}\text { Outlying } \\
\text { Areas }\end{array}$ & $\begin{array}{c}\text { Built-Up } \\
\text { Areas }\end{array}$ & $\begin{array}{c}\text { Outlying } \\
\text { Areas }\end{array}$ \\
\hline $\begin{array}{c}\text { Right-of-Way for } \\
\text { Additional Lanes }\end{array}$ & $\$ 764,000$ & $\$ 304,000$ & $\$ 684,000$ & $\$ 275,000$ & $\$ 617,000$ & $\$ 250,000$ \\
\hline
\end{tabular}

* Costs were adjusted to 2006 dollars using the FHWA CPI.

\subsubsection{HOV Lane Addition}

The cost of road widening per lane-mile varies depending upon whether the entire facility is reconstructed with changes in pavement structure or whether the widening is limited to addition of through lanes in each direction. Table 2.16 shows the cost of road construction and widening depending upon the type of improvement. These costs were extracted from the CUTS report [FTA, 1992] for various highway functional classes.

Major widening refers to the addition of lanes or dualization of an existing facility where the existing pavement is salvaged. Minor widening refers to the widening of the lanes or shoulders of an existing facility without addition of through lanes. Resurfacing refers to placement of additional surface material over the existing roadway to improve serviceability or to provide additional strength. Reconstruction refers to the construction on approximate alignment of an existing route where the old pavement structure is substantially removed and replaced. Such reconstruction may include addition of lanes, dualization, revising interchanges, replacing other highway elements such as grade separation. 
For High Occupancy Vehicle systems, the addition of HOV lanes can be done in several ways. A lane can be added by removing the median, or by reducing the lane width of the existing mixed flow lanes combined with shoulder resurfacing or by simply adding a 11-12 ft wide lane in each direction which may or may not involve the purchase of right of way. This analysis assumes an average widening cost of $\$ 1.3 \mathrm{~m} / \mathrm{lane}$-mile (2006 dollars) for adding a HOV lane on freeways based on the average of major and minor widening cost in built-up areas (Table 2.16). The taking away of an existing mixed flow lane for HOV lane operation does not involve any major construction and hence will be considered negligible.

Table 2.16: Cost of HOV Lane Addition in thousands of 2006 Dollars [FTA, 1992]

\begin{tabular}{|l|c|c|c|c|c|c|}
\hline & \multicolumn{2}{|c|}{$\begin{array}{c}\text { Freeways/ } \\
\text { Expressways }\end{array}$} & Other Divided Highways & \multicolumn{2}{c|}{ Undivided Highways } \\
\hline & $\begin{array}{c}\text { Built-Up } \\
\text { Areas }\end{array}$ & $\begin{array}{c}\text { Outlying } \\
\text { Areas }\end{array}$ & $\begin{array}{c}\text { Built-Up } \\
\text { Areas }\end{array}$ & $\begin{array}{c}\text { Outlying } \\
\text { Areas }\end{array}$ & $\begin{array}{c}\text { Built-Up } \\
\text { Areas }\end{array}$ & $\begin{array}{c}\text { Outlying } \\
\text { Areas }\end{array}$ \\
\hline $\begin{array}{l}\text { Construction for } \\
\text { Additional Lanes }\end{array}$ & $\$ 3,049$ & $\$ 2,566$ & $\$ 2,746$ & $\$ 2,306$ & $\$ 2,468$ & $\$ 2,074$ \\
\hline $\begin{array}{l}\text { Total Reconstruction } \\
\text { with More Lanes }\end{array}$ & $\$ 3,808$ & $\$ 2,869$ & $\$ 3,430$ & $\$ 2,582$ & $\$ 3,086$ & $\$ 2,323$ \\
\hline $\begin{array}{l}\text { Reconstruction with } \\
\text { Wider Lanes }\end{array}$ & $\$ 2,796$ & $\$ 2,018$ & $\$ 2,519$ & $\$ 1,817$ & $\$ 2,267$ & $\$ 1,634$ \\
\hline $\begin{array}{l}\text { Pavement } \\
\text { Reconstruction }\end{array}$ & $\$ 1,954$ & $\$ 1,759$ & $\$ 1,765$ & $\$ 1,585$ & $\$ 1,591$ & $\$ 1,428$ \\
\hline Major Widening & $\$ 1,560$ & $\$ 1,252$ & $\$ 1,404$ & $\$ 1,128$ & $\$ 1,262$ & $\$ 1,014$ \\
\hline Minor Widening & $\$ 1,128$ & $\$ 865$ & $\$ 1,014$ & $\$ 778$ & $\$ 912$ & $\$ 701$ \\
\hline $\begin{array}{l}\text { Resurfacing with } \\
\text { Shoulder Improv. }\end{array}$ & $\$ 532$ & $\$ 466$ & $\$ 480$ & $\$ 420$ & $\$ 433$ & $\$ 377$ \\
\hline Resurfacing & $\$ 232$ & $\$ 214$ & $\$ 210$ & $\$ 190$ & $\$ 188$ & $\$ 174$ \\
\hline
\end{tabular}

\subsubsection{HOV Lane Signing \& Pavement Marking}

HOV lane signs include the preferential lane signs, the guide signs that lead the traffic to the preferential only lane and reversible lane signs for reversible HOV lanes. The signs can be static or changeable message signs. The static and the changeable message signs can be either ground mounted or overhead. The Manual on Uniform Traffic Control Devices (MUTCD) provides guidelines on the placement and design of signs.

The cost of signing depends upon the number of direct access ramps, slip ramps, enforcement areas, HOV lane length and the number of HOV lanes. Signs have to be placed at each support facility as well as along the length of the HOV lane. Based on MUTCD guideline on placement of signs and the unit cost of signs, it was determined that the cost of HOV lane signing can vary from $\$ 20,000$ to $\$ 40,000$ per lane-mile. The cost of signing is a small component of the total HOV facility cost when park-and-ride facilities, enforcement areas, direct access ramps and other support facilities are implemented. However, when the HOV lane is implemented by taking away a mixed flow lane and no support facilities are constructed the cost of signing becomes a major component of the total capital cost. The cost of signing also varies from one region to another depending upon the unit cost of sign overhead and ground-mounted signs. 
According to an assessment of the total project costs made by the Dearborn County in Indiana, pavement marking accounts for approximately $2 \%$ of the total cost of adding a lane [Dearborn, 2004], where the total costs include the cost of earthwork, pavement construction, drainage and erosion control, signing and pavement markings, maintenance of traffic and other miscellaneous costs. The cost assessment made by the Dearborn County was for rural two lane roads. Using the unit cost of major and minor widening from Table 2.16, the cost of pavement marking is expected to be approximately in the range of $\$ 20,000$ - $\$ 30,000$ per lane mile. However, pavmenet marking on the HOV lanes may prove to be a slightly more expensive because of the HOV symbol markings and

buffer separation. For the purpose of economic evaluation, the analysis in this study assumes that the pavement marking cost varies in the range of $\$ 30,000$ - $\$ 50,000$ per lane mile.

\subsubsection{Cost of Park-and-Ride Facilities / Transit Centers}

The land, construction, operation and maintenance costs are the major components of the cost of a park-and-ride facility. The cost of the park-and-ride lots can constitute a significant fraction of the total HOV capital costs. The construction of the park-and-ride lots can also be scheduled after the implementation of the HOV facility, during the course of its operation, depending upon the growth in demand of the HOV facility. The parking facilities can be owned by the DOTs, other public agencies or by the private owners like shopping malls. For example, the King County Metro leases most of their park-and-ride lots from churches at a rate of $\$ 2.50-\$ 4.00$ per month per parking space.

The cost of the parking facility can be approximately in the range of $\$ 5000-\$ 10,000$ per parking space inclusive of the right of way costs in 2005 dollars [Fuhs, 2005(1)]. The number of parking spaces provided per HOV facility depends upon the number of carpools and the number of passengers using the HOV lanes. A sample of surface park-and-ride lots constructed by WSDOT’s Northwest Region averaged around $\$ 9,000$ per parking space inclusive of engineering, acquisition and construction costs in 2005 dollars [Fuhs, 2005(1)]. Leasing space is considerably cheaper. Table 2.17 shows the costs of various types of parking facilities. A parking space generally requires 150-200 sq. $\mathrm{ft}$ of land. Off street parking requires driveways that connect the parking lot to a road and access lanes to provide circulation within the parking lot. Therefore, approximately 300-400 sq. $\mathrm{ft}$ of land is generally required for a parking space [VTPI, 2005], allowing 100-150 spaces per acre.

A discount rate of $7 \%$ was used to discount the construction and land costs to annualized total capital cost over a twenty year analysis period. The number of parking spaces per acre of land area was assumed to be 110, 120 and 130 for suburban, urban and CBD areas respectively. It was assumed that the parking facility is in used for twenty days of a month in the suburban and urban areas and for twenty-five days in a month in central business districts (CBD) [VTPI, 2005].

Table 2.18 shows the variation in construction cost of a parking facility. The costs of construction of a parking facility can increase by $30-40 \%$ if the project design, planning and other related costs are included. The construction costs increase significantly for structured parking. Hence, the choice of structured parking involves a trade off between construction and land costs. In general, the structured parking becomes cost-effective when land prices exceed about \$1 million per acre [VTPI, 2005]. 
Table 2.17: Cost of Typical Parking Facilities in 2005 Dollars [VTPI, 2005]

\begin{tabular}{|l||c|c|c|c|c|c|}
\hline \multicolumn{1}{|c|}{ Type of Facility } & Land Costs & $\begin{array}{c}\text { Land } \\
\text { Costs }\end{array}$ & $\begin{array}{c}\text { Construction } \\
\text { Costs }\end{array}$ & $\begin{array}{c}\text { O \& M } \\
\text { Costs }\end{array}$ & Total Cost & Daily Cost \\
\hline & Per Acre & Per Space & Per Space & $\begin{array}{c}\text { Annual, } \\
\text { Per Space }\end{array}$ & $\begin{array}{c}\text { Annual, } \\
\text { Per Space }\end{array}$ & Per Space \\
\hline Suburban, On-Street & $\$ 50,000$ & $\$ 200$ & $\$ 2,000$ & $\$ 200$ & $\$ 408$ & $\$ 1.36$ \\
\hline Suburban, Surface, Free Land & $\$ 0$ & $\$ 0$ & $\$ 2,000$ & $\$ 200$ & $\$ 389$ & $\$ 1.62$ \\
\hline Suburban, Surface & $\$ 50,000$ & $\$ 455$ & $\$ 2,000$ & $\$ 200$ & $\$ 432$ & $\$ 1.80$ \\
\hline Suburban, 2-Level Structure & $\$ 50,000$ & $\$ 227$ & $\$ 10,000$ & $\$ 300$ & $\$ 1,265$ & $\$ 5.27$ \\
\hline Urban, On-Street & $\$ 250,000$ & $\$ 1,000$ & $\$ 3,000$ & $\$ 200$ & $\$ 578$ & $\$ 1.93$ \\
\hline Urban, Surface & $\$ 250,000$ & $\$ 2,083$ & $\$ 3,000$ & $\$ 300$ & $\$ 780$ & $\$ 3.25$ \\
\hline Urban, 3-Level Structure & $\$ 250,000$ & $\$ 694$ & $\$ 12,000$ & $\$ 400$ & $\$ 1,598$ & $\$ 6.66$ \\
\hline Urban, Underground & $\$ 250,000$ & $\$ 0$ & $\$ 20,000$ & $\$ 400$ & $\$ 2,288$ & $\$ 9.53$ \\
\hline CBD, On-Street & $\$ 2,000,000$ & $\$ 8,000$ & $\$ 3,000$ & $\$ 300$ & $\$ 1,338$ & $\$ 4.46$ \\
\hline CBD, Surface & $\$ 2,000,000$ & $\$ 15,385$ & $\$ 3,000$ & $\$ 300$ & $\$ 2,035$ & $\$ 6.78$ \\
\hline CBD, 4-Level Structure & $\$ 2,000,000$ & $\$ 3,846$ & $\$ 15,000$ & $\$ 400$ & $\$ 2,179$ & $\$ 7.26$ \\
\hline CBD, Underground & $\$ 2,000,000$ & $\$ 0$ & $\$ 25,000$ & $\$ 500$ & $\$ 2,645$ & $\$ 8.82$ \\
\hline
\end{tabular}

Table 2.18: Typical Parking Facility Construction Costs in 2000 Dollars [VTPI, 2005]

\begin{tabular}{|l||c|c|c|}
\hline & $\begin{array}{c}\text { Small Site } \\
(30,000 \mathrm{sf})\end{array}$ & $\begin{array}{c}\text { Medium Site } \\
(60,000 \mathrm{sf})\end{array}$ & $\begin{array}{c}\text { Large Site } \\
(90,000 \mathrm{sf})\end{array}$ \\
\hline Area Per Space & $350 \mathrm{sf}$ & $325 \mathrm{sf}$ & $315 \mathrm{sf}$ \\
\hline Surface Parking & $\$ 1,838$ & $\$ 1,706$ & $\$ 1,654$ \\
\hline Ground + 1 level & $\$ 7,258$ & $\$ 6,143$ & $\$ 5,705$ \\
\hline Ground + 2 level & $\$ 8,085$ & $\$ 6,767$ & $\$ 6,284$ \\
\hline Ground + 3 level & $\$ 8,407$ & $\$ 6,996$ & $\$ 6,491$ \\
\hline Ground + 4 level & $\$ 8,747$ & $\$ 7,269$ & $\$ 6,747$ \\
\hline Ground + 5level & $\$ 8,973$ & $\$ 7,451$ & $\$ 6,918$ \\
\hline Ground + 6 level & $\$ 9,135$ & $\$ 7,581$ & $\$ 7,040$ \\
\hline Ground + 7 level & $\$ 9,256$ & $\$ 7,678$ & $\$ 7,132$ \\
\hline Ground + 8 level & $\$ 9,351$ & $\$ 7,754$ & $\$ 7,203$ \\
\hline
\end{tabular}

The total cost of the park-and-ride lots per lane-mile can be calculated as follows:

PRCost Per Lane - Mile $=\frac{1}{N \times L} \times\left[P R_{-}\right.$Spaces $\left.\times P R \times U_{P R}\right]$

where, $\quad P R=$ Number of Park-and-ride/Transit facilities constructed in the HOV system

PR_Spaces $=$ Average Number of Parking Spaces per parking facility

$\mathrm{U}_{\mathrm{PR}}=$ Unit cost of park-and-ride facility per parking space (\$10,000 per space)

$\mathrm{L}=$ Length of the HOV facility

$\mathrm{N}=$ Number of HOV lanes

\subsubsection{Cost of Direct Access Ramps}

The cost of direct access ramps can range from $\$ 5 \mathrm{~m}$ - \$20 m per location depending upon the type of direct access ramp and the region where it is being implemented [Fuhs, 2005(1)]. Slip ramps on the other hand are constructed 
during the construction of HOV lane and are comparatively less expensive than the direct access ramps. The construction of the direct access ramps can also be planned at strategic stages in course of HOV lane operation. For example, a direct access ramp on US 290 in Houston was completed in 1998 although the facility had been in operation since 1984.

The construction of direct access ramps for part-time HOV lane facilities where the benefits of HOV lane are limited to a smaller fraction of the AADT may depend on the decision of the local authorities. Nevertheless, the cost per lane-mile of the direct access ramps, for any type of HOV facility can be computed as follows:

$$
\text { DRCost Per Lane }- \text { Mile }=\frac{1}{N \times L} \times\left[D R \times U_{D R}\right]
$$

Where,

DRCost per lane-mile $=$ Cost of construction of direct access ramps per lane mile

$\mathrm{U}_{\mathrm{DR}}=$ Average construction cost of a direct access ramp

$\mathrm{DR}=$ Number of direct access ramps constructed

$\mathrm{L}=$ Length of the HOV facility

$\mathrm{N}=$ Number of HOV lanes

\subsubsection{Enforcement Area}

Enforcement areas can either be directional or bidirectional depending upon the HOV lane operation and HOV lane separation from the general purpose lanes. A minimum width of $4.2 \mathrm{~m}$ [Caltrans, 2003] and a minimum length of $300 \mathrm{~m}$ is recommended for the enforcement area to ensure the safety of the officer. Since the enforcement areas are paved, the unit cost of lane construction (\$1.0 m per lane-mile) [Dearborn, 2004] was used to calculate the cost of directional and bidirectional enforcement areas. Typically, bidirectional enforcement areas are $800 \mathrm{~m}$ in length and 7 $\mathrm{m}$ wide whereas directional enforcement areas $400 \mathrm{~m}$ in length and $7 \mathrm{~m}$ wide. Therefore, the estimated cost of a bidirectional enforcement area is approximately $\$ 1.0 \mathrm{~m}$ and that of a directional enforcement area is approximately $\$ 0.5 \mathrm{~m}$. The total cost associated with the construction of enforcement areas along the HOV facility length can be computed as follows:

$$
\text { EACost Per Lane }- \text { Mile }=\frac{1}{N \times L} \times\left[\left(E A_{D} \times U_{E A}^{D}\right)+\left(E A_{B D} \times U_{E A}^{B D}\right)\right]
$$

where,

EACost per lane-mile $=$ Cost of Enforcement Area Construction per lane-mile

$E A_{D}=$ Number of directional enforcement areas

$\mathrm{EA}_{\mathrm{BD}}=$ Number of bi-directional enforcement areas

$U_{E A}^{D}=$ Unit cost of directional enforcement area ( $\$ 0.5 \mathrm{~m}$ per lane-mile)

$U_{E A}^{B D}=$ Unit cost of bi-directional enforcement area (\$1.0 m per lane-mile)

$\mathrm{L}=$ Length of the HOV facility

$\mathrm{N}=$ Number of HOV lanes 


\subsubsection{Cost Estimation by HOV Facility Type}

The total cost of the HOV facility depends upon the selection of the physical components of the HOV system. The total capital cost per lane-mile of HOV facility can be calculated using equation 2.4.

$$
\begin{aligned}
\text { TotalCapitalCost }= & \text { ROWCost }+ \text { LaneCost }+ \text { SignCost }+ \text { PMCost } \\
& + \text { DRCost }+ \text { PRCost }+ \text { EACost }
\end{aligned}
$$

Total Capital Cost $=$ Total Capital Cost per lane-mile

ROW Cost $=$ Right of way cost per lane-mile (\$0.8 m per lane-mile)

Lane Cost $=$ HOV lane addition cost per lane-mile (\$1.3 m per lane-mile)

Sign Cost $=$ HOV lane signing cost per lane-mile $(\$ 20,000$ - \$40,000 per lane-mile $)$

PM Cost $=$ HOV lane pavement marking cost per lane-mile (\$30,000 - \$50,000 per lane-mile)

PR Cost $=$ Cost of Park and ride lots per lane-mile (from equation 2.1)

DR Cost $=$ Cost of Direct Access Ramps per lane-mile (from equation 2.2)

EA Cost $=$ Cost of Enforcement areas per lane-mile (from equation 2.3)

\subsubsection{Application of the Cost-Estimation Methodology}

The total cost of the HOV facility can be estimated approximately for the purpose of economic evaluation using the estimates of the individual physical components as described in the previous sections. For example, Table 2.19 shows the estimated total capital cost of four types of hypothetical concurrent flow HOV lane facilities. The number of park-and-ride lots, slip ramps, size of the park-and-ride lots and number of enforcement areas was varied to estimate the total cost of HOV facilities in this example. Hence the variation in the capital cost of the various concurrent flow lane HOV facilities that was observed in section 2.5.1 can be explained.

\begin{tabular}{|c|c|c|c|c|}
\hline & Concurrent 1 & Concurrent 2 & Concurrent 3 & Concurrent 4 \\
\hline Right of Way Cost & $\$ 764,000$ & $\$ 304,000$ & $\$ 0$ & $\$ 0$ \\
\hline HOV Lane Cost & $\$ 1,300,000$ & $\$ 1,300,000$ & $\$ 532,000$ & $\$ 0$ \\
\hline Signing Costs & $\$ 27,017$ & $\$ 18,467$ & $\$ 21,317$ & $\$ 24,167$ \\
\hline Pavement Markings & $\$ 26,000$ & $\$ 26,000$ & $\$ 26,000$ & $\$ 26,000$ \\
\hline Direct Access Ramps & $\$ 0$ & $\$ 0$ & $\$ 0$ & $\$ 0$ \\
\hline Parking Facilities / Transit Centers & $\$ 150,000$ & $\$ 100,000$ & $\$ 150,000$ & $\$ 0$ \\
\hline \multirow[t]{2}{*}{ Enforcement Area Construction } & $\$ 100,000$ & $\$ 50,000$ & $\$ 100,000$ & $\$ 0$ \\
\hline & $\$ 2,367,017$ & $\$ 1,798,467$ & $\$ 829,317$ & $\$ 50,167$ \\
\hline \multicolumn{5}{|c|}{ Assumptions-Default Values } \\
\hline Number of Park-and-ride facilities & 3 & 1 & 2 & 0 \\
\hline Number of Direct Access Ramp & 0 & 0 & 0 & 0 \\
\hline Number of Slip Ramps/legal access points & 5 & 2 & 3 & 4 \\
\hline Number of Spaces per park and Ride lot & 100 & 200 & 150 & 250 \\
\hline Number of Designated HOV Lanes & 2 & 2 & 2 & 2 \\
\hline Number of Bidirectional Enforcement Areas & 2 & 1 & 2 & 0 \\
\hline Number of Directional Enforcement Areas & 0 & 0 & 0 & 0 \\
\hline
\end{tabular}

Table 2.19: Capital Cost Estimation for a Hypothetical 10-mile Concurrent Flow Lane HOV Facility 


\subsubsection{Operation, Maintenance and Enforcement Costs}

This cost depends upon factors such as the size of the HOV facility (length and number of lanes), the number of daily deployments and the level of enforcement. Table 2.21 shows the operation, maintenance and enforcement cost of some of the HOV facilities in the country. The annual enforcement and maintenance cost for most of the concurrent flow lane HOV facilities is approximately in the range of $\$ 20,000-\$ 30,000$ per route-mile in 2006 dollars [FTA, 1992]. Contra-flow lane HOV facilities generally have higher operating and maintenance costs compared to exclusive flow lane HOV facilities. Choocharukul and Sinha (2000) used the CUTS data [FTA, 1992] to estimate the annual operation and maintenance cost as a function of the number of daily deployments. The following adjusted functional form of the model can be used to obtain the costs in 2006 dollars:

$$
Y=34,227 * e^{0.5911^{*} X} \quad \mathrm{R}^{2}=0.9742
$$

Where, $\quad Y=$ Estimated Annual Operation and Maintenance Cost (2005 Dollars)

$$
\mathrm{X}=\text { Number of Daily Deployments (persons) [t-statistic }=13.73 \text { ] }
$$

This equation can be used to estimate the annual operation and maintenance cost when the number of daily deployments (number of enforcement personnel) is in the range of zero to six persons.

Cambridge Systematic (2001), developed an estimate of the annual operation, maintenance and enforcement costs depending upon the type of HOV facility. The cost estimates prepared are shown in Table 2.20. These cost estimates indicate that the maintenance and operation of a barrier separated HOV facility are going to be significantly higher than the maintenance costs on a concurrent flow lane HOV facility. The costs also indicate that the maintenance and operation costs associated with a contraflow HOV facility are more than any other type of HOV facility because of the frequent installation and removal of lane separation equipment such as a movable barrier or pylons.

Table 2.20: Adjusted Annual Operation, Maintenance and Enforcement Costs for a HOV Lane (2006 Dollars)

\begin{tabular}{|c|c|c|c|c|}
\hline & Bus-way & $\begin{array}{c}\text { Barrier- } \\
\text { separated }\end{array}$ & Concurrent Flow & Contraflow \\
\hline $\begin{array}{c}\text { Annual Operation and } \\
\text { Maintenance Cost }\end{array}$ & $\$ 32,240$ & $\$ 161,220$ & $\$ 64,490$ & $\$ 322,435$ \\
\hline $\begin{array}{c}\text { Annual Police } \\
\text { Enforcement Cost }\end{array}$ & $\$ 161,220$ & $\$ 64,490$ & $\$ 64,490$ & NA \\
\hline
\end{tabular}

Source: Cambridge Systematics (2001)

The annual operation and maintenance costs of park-and-ride facilities includes lighting, maintenance repairs, security services, cleaning, access control (entrance gates), fee collection (where parking is charged), enforcement, insurance, labor, administration and snow removal. The annual operation cost can hence range from $\$ 200$ per space to $\$ 800$ for a facility with toll booth attendants [VTPI, 2005]. 
Table 2.21: Adjusted Annual Operation and Maintenance Costs (2005 Dollars) [FTA, 1992]

\begin{tabular}{|c|c|c|c|c|c|}
\hline \multirow[t]{2}{*}{ HOV Facility } & \multicolumn{2}{|c|}{$\begin{array}{c}\text { Daily Deployment } \\
\text { (At time of reporting) }\end{array}$} & \multirow[t]{2}{*}{$\begin{array}{l}\text { Surveillance and } \\
\text { Control System }\end{array}$} & \multirow[t]{2}{*}{$\begin{array}{l}\text { Adjusted Annual } \\
\text { Operation and } \\
\text { Maintenance Cost }\end{array}$} & \multirow[t]{2}{*}{ Status } \\
\hline & Procedures & Persons & & & \\
\hline \multicolumn{6}{|c|}{ Barrier Separated Separate ROW } \\
\hline $\begin{array}{c}\text { South Busway, East } \\
\text { Busway } \\
\text { Pittsburgh, PA } \\
\end{array}$ & None & 0 & No & $\$ 99,680$ & Operational \\
\hline \multicolumn{6}{|c|}{ Barrier Separated Freeway ROW (Exclusive Reversible/ Exclusive 2-directional) } \\
\hline $\begin{array}{l}\text { Houston, TX, I-10, I-45, } \\
\text { US } 290\end{array}$ & $\begin{array}{c}\text { Manual gates, signs } \\
\text { and Lane Controls }\end{array}$ & 5 & Yes & $\$ 690,080$ & Operational \\
\hline Los Angeles, CA, I-10 & $\begin{array}{l}\text { Manual Control, } \\
\text { gates and signs }\end{array}$ & 0 & Yes & \$53,670 Maintenance & Operational \\
\hline Virginia, I-395 & $\begin{array}{l}\text { Remote Control, } \\
\text { gates and signs }\end{array}$ & 2 to 5 & Yes & $\$ 766,750$ & Operational \\
\hline San Diego, CA, I-15 & $\begin{array}{l}\text { Remote Control, } \\
\text { gates and signs }\end{array}$ & 2 & Yes & - & Operational \\
\hline \multicolumn{6}{|c|}{ Buffer Separated Freeway ROW/Concurrent Flow Lane Facilities } \\
\hline Los Angeles, CA, Rte-91 & None & 0 & Yes & \$15,340 Maintenance & Operational \\
\hline $\begin{array}{l}\text { Orange County, CA, Rte. } \\
55\end{array}$ & None & 0 & No & $\$ 23,000$ Maintenance & Operational \\
\hline Orlando, FL, I-4 & None & 0 & No & $\$ 314,370$ & Operational \\
\hline Seattle, WA, I-5 & $\begin{array}{l}\text { License Plates } \\
\text { Identified, HERO } \\
\text { Program } \\
\end{array}$ & 0 & Yes & $\$ 27,600$ & Operational \\
\hline SR 520 (Seattle) & $\begin{array}{c}\text { Automatic Signs, } \\
\text { License Plates } \\
\text { Identified and } \\
\text { HERO Program }\end{array}$ & 0 & Yes (Television) & $\$ 11,500$ & Operational \\
\hline $\mathrm{I}-405$ & None & 0 & Yes & $\$ 27,600$ & Operational \\
\hline \multicolumn{6}{|c|}{ Contraflow, Freeway ROW } \\
\hline $\begin{array}{c}\text { Honolulu, HI, Kalaniaole } \\
\text { Hwy }\end{array}$ & Cones and Signs & - & No & $\$ 76,680$ Operation & \\
\hline $\begin{array}{c}\text { New Jersey, Rte. } 495 \\
\text { (Lincoln Tunnel) }\end{array}$ & Cones and Signs & 6 & Yes & $\begin{array}{c}\$ 406,380 \text { without } \\
\text { enforcement }\end{array}$ & Operational \\
\hline $\begin{array}{l}\text { New York, Long Island } \\
\text { Exxpressway }\end{array}$ & $\begin{array}{l}\text { Cones and Remote } \\
\text { Control Signs }\end{array}$ & 5 to 6 & No & $\begin{array}{l}\$ 383,380 \text { without } \\
\text { enforcement }\end{array}$ & Operational \\
\hline Gowanus Expressway & $\begin{array}{l}\text { Cones and Remote } \\
\text { Control Signs }\end{array}$ & 2 to 3 & No & $\begin{array}{c}\$ 128,810 \text { without } \\
\text { enforcement }\end{array}$ & Operational \\
\hline Marin County, California & Cones and Signs & 5 to 6 & No & $\begin{array}{c}\$ 460,050 \text { without } \\
\text { enforcement }\end{array}$ & $\begin{array}{c}\text { Terminated } \\
1985 \\
\end{array}$ \\
\hline Houston, TX, I-45N & $\begin{array}{c}\text { Cones, Manual } \\
\text { Signs and Lane } \\
\text { Control } \\
\end{array}$ & 10 to 12 & No & $\begin{array}{l}\$ 920,100 \text { without } \\
\text { enforcement }\end{array}$ & $\begin{array}{c}\text { Terminated } \\
1984\end{array}$ \\
\hline \multicolumn{6}{|c|}{ Queue Bypass HOV Lane } \\
\hline $\begin{array}{l}\text { San Francisco, CA, I-80 } \\
\text { (Bay Bridge) }\end{array}$ & Change Signs & 0 & No & Minimal & Operational \\
\hline
\end{tabular}




\subsection{HOV LANE SAFETY}

The CUTS crash data in Table 2.22 (FTA, 1992), indicates that depending upon the type of HOV facility, there can be a reduction or increase in the number of crashes per million VMT due to the implementation of the HOV lane. In Seattle, Washington the HOV lanes experienced a 177\% higher crash rate in the buffer separated HOV lanes than in the general purpose lanes. In Los Angeles, on the other hand, the crash rate on the barrier separated HOV lanes on I10 had a 64\% lower crash rate than the adjacent mixed flow lanes.

Based on the crash rates data from CUTS (FTA, 1992), it seems that the barrier separated HOV facilities are safer than the buffer or non-separated HOV facilities. For example, the HOV lanes on the freeway corridors in Dallas have seen an increase in the injury crash rate due to buffer separation of concurrent flow HOV lanes. The IH35E north corridor experienced a 56\% increase in the injury crash rate due to the implementation of HOV lanes. The IH-635 corridor experienced a 41\% increase in the injury crash rate [Skowronek et al. 2002]. The Dallas research team attributed the increase in the crash rate to the speed differential between the HOV lane and the GP lanes. The general purpose lanes experience congestion during the peak periods, while the HOV lanes usually operate at the speed limit. A greater cross-section width for buffer separated concurrent flow HOV lanes was recommended to lessen the influence of the speed differential. It was recommended for these sections that the width of the inside shoulders and the painted buffer should be increased to increase the width of the cross-section. The higher number of crashes in the HOV lane was also attributed to vehicles weaving in/out of the HOV lane. The crash data on a movable barrier separated contraflow lane HOV facility on IH-30 did not show an increase in the crash rate which further strengthens the fact that the barrier separated HOV facilities are safer than those with buffer-separation or no separation.

Table 2.22: Comparison of HOV and Adjacent Lane Crash Rates (1990) [FTA, 1992]

\begin{tabular}{|c|c|c|}
\hline \multirow{2}{*}{ HOV Facility } & \multicolumn{2}{|c|}{ Number of Accidents per million VMT } \\
\cline { 2 - 3 } & HOV Lanes & $\begin{array}{c}\text { Adjacent Mixed Flow } \\
\text { Lanes }\end{array}$ \\
\hline \multicolumn{2}{|c|}{ Barrier Separated Facilities } \\
\hline I-10 Houston & 1 & 2.4 \\
\hline I-45 Houston & 2 & 2.4 \\
\hline I-10 Los Angeles & 0.4 & 1.1 \\
\hline I-395 Virginia & 2.3 & NA \\
\hline Buffer Separated and Non Separated Facilities \\
\hline I-5 Median Lane (Seattle) & 3.2 & 2.1 \\
\hline I-405 Outside Lanes (Seattle) & 3.6 & 1.3 \\
\hline I-10 Los Angeles & 3.6 & 1.4 \\
\hline US 101 (Marin County) & 2.4 & 2 \\
\hline I-95 Miami & 1.9 & 3.6 \\
\hline
\end{tabular}

The geometric design of the HOV lanes, type of separation, buffer width and the design near the ingress/egress ramps requires in depth analysis and the crash data from the HOV facilities implemented in the country can add to the information. 


\subsection{CASE STUDIES OF HOV SYSTEM SUCCESSES AND FAILURES}

Proper planning, design and implementation of all the physical and operational components of the HOV system at various places in the US has proved that the HOV facilities can offer travel time advantages, predictable trips, alternatives for improved personal mobility, incentives to rideshare and more efficient use of the transportation infrastructure. This section summarizes the results of the case studies of successful and failed HOV systems undertaken as part of this synthesis study. The first subsection presents the achievements of the HOV lanes nationwide in context of their goals and objectives while the second subsection discusses some of the HOV systems in context of the infrastructure developed and cost effectiveness achieved.

\subsubsection{Nationwide HOV Lane Achievements}

\subsubsection{Induced Carpools and Bus Riders}

The primary objective of the HOV lanes is to induce people to carpool thereby increasing the average vehicle occupancy and reducing the number of vehicles on the highways (reducing congestion). Table 2.23 shows the percentage of HOV lane carpoolers who were solo riders before the implementation of HOV lanes at some of the HOV facilities in the US. The numbers are based on a survey of carpoolers at the respective HOV facilities. The 1974 survey on the Shirley highway was conducted when the vehicle occupancy requirement was $4+$. This probably explains the lower percentage of carpoolers who previously drove alone for this highway. In general, all these HOV facilities witnessed that more than $30 \%$ of the HOV lane carpoolers were solo riders before HOV lane implementation.

Table 2.23: Percentage of HOV lane carpoolers who previously drove alone [Turnbull, 1992]

\begin{tabular}{|l|c|c|c|c|}
\hline \multicolumn{1}{|c|}{ HOV Facility } & Description & Occupancy Restriction & Survey Year & Percentage \\
\hline I-10 Katy Freeway, Houston & 1 Reversible HOV Lane & $2+$ & 1990 & $36 \%$ \\
\hline I-394, Minnesota & Concurrent Flow Lane & $2+$ & 1986 & $43 \%$ \\
\hline I-395, Shirley Highway & 2 Reversible HOV Lanes & $4+$ & 1974 & $23 \%$ \\
\hline I-45 North, Houston & 1 Reversible HOV Lane & $2+$ & 1990 & $39 \%$ \\
\hline US 290 Houston & 1 Reversible HOV Lane & $2+$ & 1990 & $46 \%$ \\
\hline I-45 South Houston & 1 Reversible HOV Lane & $2+$ & 1989 & $38 \%$ \\
\hline San Bernardino Freeway, LA & Exclusive 2-Directional & $2+$ & 1977 & $46 \%$ \\
SR 237, Santa Clara County & & & 1988 & $56 \%$ \\
\hline
\end{tabular}

In Houston, the HOV lane (barrier-separated exclusive reversible) carried 1000-1300 carpools per peak hour per peak direction in 2001. The extent of reduction in congestion on the general purpose lanes due to the implementation of the HOV lane can be estimated in terms of the number of SOVs lost by the general purpose lane to the HOV lane. The percentage of people who would shift from SOVs to carpooling can be estimated using the survey results shown in Table 2.24 for the respective HOV facility. Such estimation will be an underestimate of the actual number of SOVs moving to HOV lanes because carpooling in Houston has been on a rise after HOV implementation. The Houston HOV system has grown since 1990 with the construction of new direct access ramps and increase in the length of the HOV system. Because of this infrastructure growth the Texas freeway corridors with HOV lanes have experienced an increase in carpooling of $100 \%$ or greater during the last two decades even 
though carpooling has declined nationally by an average of 30\% [Stockton et al., 1999]. This approach can be utilized to estimate the minimum number of vehicles that have been removed from the general purpose lanes due to HOV lane implementation.

Table 2.24: Estimated Reduction in the Number of SOVs in the GP Lane Due to Carpooling

\begin{tabular}{|c|c|c|c|}
\hline HOV Facility & $\begin{array}{c}\text { Percentage } \\
\text { (Survey Year) }\end{array}$ & $\begin{array}{l}\text { March } 2001 \text { HOV } \\
\text { Carpools } \\
\text { (Carpool } \\
\text { Occupancy) }\end{array}$ & $\begin{array}{c}\text { Number of SOVs that Changed to HOVs } \\
\text { (2+ Carpools) } \\
\text { in Peak Hour Peak Direction }\end{array}$ \\
\hline \multicolumn{4}{|c|}{ AM Peak Hour (Inbound towards CBD) } \\
\hline I-10 Katy Freeway, Houston & $36 \%(1990)$ & $1,055(2.22)$ & $(1055 \times 0.36) \times 2.22=844 \mathrm{vph}$ \\
\hline I-45 North, Houston & $39 \%(1990)$ & $1,368(2.09)$ & $(1368 \times 0.39) \times 2.09=1,115 \mathrm{vph}$ \\
\hline US 290 Houston & $46 \%(1990)$ & $1014(2.05)$ & $(1014 \times 0.46) \times 2.05=956 \mathrm{vph}$ \\
\hline I-45 South Houston & $38 \%(1989)$ & $1,384(2.08)$ & $(1384 \times 0.38) \times 2.08=1,094 \mathrm{vph}$ \\
\hline \multicolumn{4}{|c|}{ PM Peak Hour (Outbound from CBD) } \\
\hline I-10 Katy Freeway, Houston & $36 \%(1990)$ & $1,145(2.12)$ & $(1145 \times 0.36) \times 2.12=874 \mathrm{vph}$ \\
\hline I-45 North, Houston & $39 \%(1990)$ & $1,065(2.05)$ & $(1065 \times 0.39) \times 2.05=852 \mathrm{vph}$ \\
\hline US 290 Houston & $46 \%(1990)$ & $1,267(2.05)$ & $(1267 \times 0.46) \times 2.05=1,195 \mathrm{vph}$ \\
\hline I-45 South Houston & $38 \%(1989)$ & $912(2.13)$ & $(912 \times 0.38) \times 2.13=738 \mathrm{vph}$ \\
\hline
\end{tabular}

It has been observed that for some of the HOV facilities as many as $66 \%$ of the HOV lane carpoolers are new carpoolers [Stockton et al., 1999]. However, the number of new carpools formed can vary from one location to another depending upon the marketing and ridesharing programs, number and size of park-and-ride lots and travel pattern (length of trip, trip purpose, etc.) in the region. A research study conducted for the evaluation of operational effectiveness of HOV lanes in the Dallas area (I-635 LBJ Freeway, I-35E north (Stemmons Freeway) bufferseparated concurrent flow HOV lanes; I-30 RL Thornton Freeway Contraflow HOV Lane) showed that there was a significant increase in the number of two-or-more person (2+) carpools in the region after the implementation of the HOV Facility. The percent increase in carpools due to the implementation of the HOV facility ranged from $88 \%$ on EB I-635 to 238\% on I-35E North [Skowronek et al., 2002]. Figure 2.43 shows the increase in the number of 2person carpools after the implementation of the HOV facility.

The reduction in the number of vehicles on the general purpose lanes due to HOV implementation is not only due to the formation of new carpools. Implementation of express bus services on the HOV lanes can also attract SOV drivers. The number of passengers traveling in buses has increased at several places after buses started using the HOV lanes. In fact most of the HOV facilities were started as bus-only lanes. In Houston according to a survey conducted in 1990 the percentage of bus passengers who were solo riders before ranged between $35 \%-50 \%$. Table 2.25 shows the percentage of the HOV lane bus riders who previously drove alone. The reduction in the number of SOVs in the general purpose lane due to the SOV drivers changing to buses is estimated in Table 2.26 for the 2001 AM and PM peak hour traffic. 


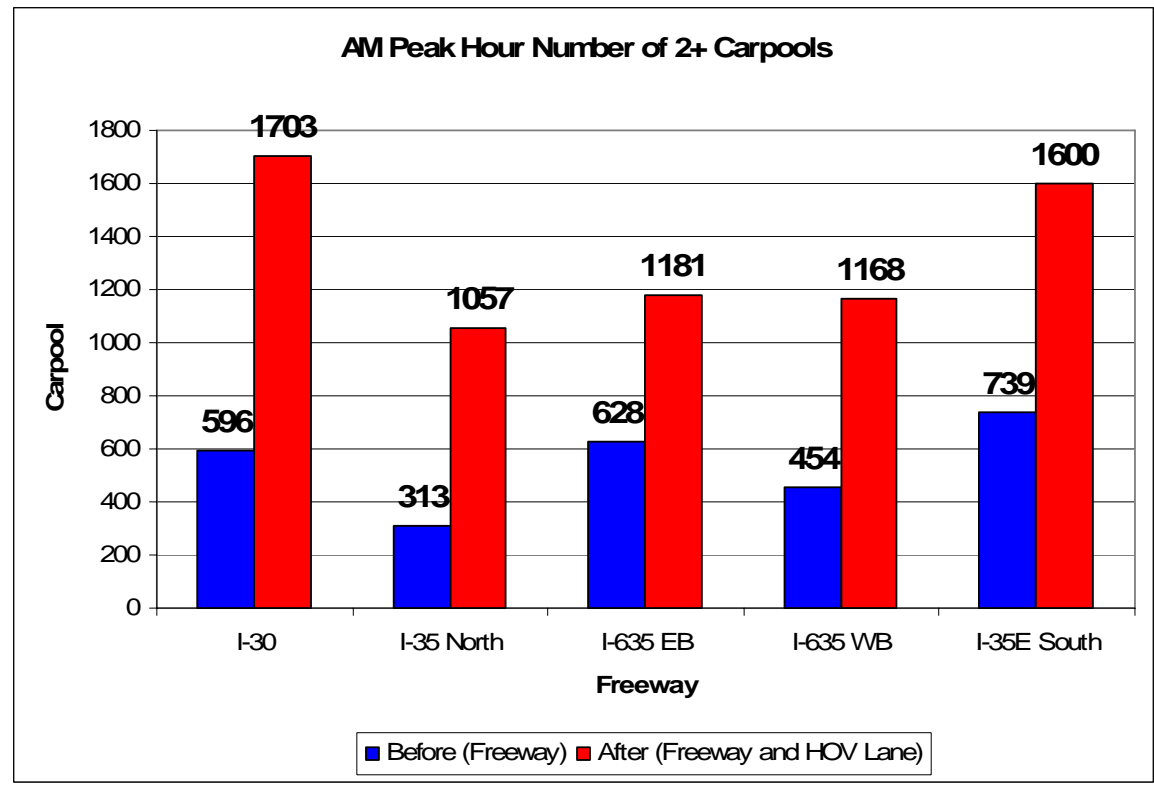

Figure 2.43: Change in number of carpools after HOV implementation in Dallas [Skowronek et al., 2002]

Table 2.25: Percentage of HOV Lane Bus Riders who previously Drove Alone [Turnbull, 1992]

\begin{tabular}{|l|c|c|c|c|}
\hline \multicolumn{1}{|c|}{ HOV Facility } & Description & $\begin{array}{c}\text { Occupancy } \\
\text { Requirement }\end{array}$ & Survey Year & Percentage \\
\hline Katy Freeway & 1 Reversible HOV Lane & $2+$ & 1990 & $36 \%$ \\
\hline I-395, Shirley Highway & 2 Reversible HOV Lanes & $4+$ & 1974 & $49 \%$ \\
\hline I-45 North, Houston & 1 Reversible HOV Lane & $2+$ & 1990 & $39 \%$ \\
\hline US 290 Houston & 1 Reversible HOV Lane & $2+$ & 1990 & $46 \%$ \\
\hline I-45 South Houston & 1 Reversible HOV Lane & $2+$ & 1989 & $38 \%$ \\
\hline $\begin{array}{l}\text { San Bernardino Freeway, Los } \\
\text { Angeles }\end{array}$ & Exclusive 2-Directional & $2+$ & 1977 & $50 \%$ \\
\hline
\end{tabular}

Table 2.26: Estimated Reduction in Number of SOVs in GP Lane Due to Buses in HOV lane, Houston

\begin{tabular}{|l|c|c|c||}
\hline \multicolumn{1}{|c|}{ HOV Facility } & $\begin{array}{c}\text { Percentage } \\
\text { (Survey Year) }\end{array}$ & $\begin{array}{c}\text { March 2001 } \\
\text { Bus Ridership }\end{array}$ & $\begin{array}{c}\text { Number of SOV Dirvers that moved } \\
\text { to buses } \\
\text { in Peak Hour Peak Direction }\end{array}$ \\
\hline \multicolumn{3}{|c||}{ AM Peak Hour (Inbound towards CBD) } \\
\hline I-10 Katy Freeway, Houston & $36 \%(1990)$ & 1,955 & $1,955 \times 0.36=703 \mathrm{vph}$ \\
\hline I-45 North, Houston & $39 \%(1990)$ & 2,555 & $2,555 \times 0.39=996 \mathrm{vph}$ \\
\hline US 290 Houston & $46 \%(1990)$ & 1,155 & $1,155 \times 0.46=531 \mathrm{vph}$ \\
\hline I-45 South Houston & $38 \%(1989)$ & 1,530 & $1,530 \times 0.38=581 \mathrm{vph}$ \\
\hline & $36 \%(1990)$ & 1,405 & $1,405 \times 0.36=506 \mathrm{vph}$ \\
\hline I-10 Katy Freeway, Houston & $39 \%(1990)$ & 2,595 & $2.595 \times 0.39=1,012 \mathrm{vph}$ \\
\hline I-45 North, Houston & $46 \%(1990)$ & 1,350 & $1,350 \times 0.46=621 \mathrm{vph}$ \\
\hline US 290 Houston & $38 \%(1989)$ & 1,745 & $1,745 \times 0.38=663 \mathrm{vph}$ \\
\hline I-45 South Houston
\end{tabular}


The HOV lanes in Houston were added in the freeway median without taking away a mixed flow lane. The reduction in the number of vehicles using the mixed flow lane due to formation of new carpools or because of SOV drivers changing to buses led to a significant reduction in congestion on the general purpose lane. Table 2.27 shows the estimated total reduction in the number of vehicles on the mixed flow lanes during the am/pm peak hour in the peak direction. The estimated reduction in the number of vehicles on the mixed flow lanes in Houston varies from 1,380 - 2,111 vph and would have been enough to justify conversion of a mixed flow lane to HOV lane. However such an approach would not have improved the level of service on the mixed flow lanes to the same extent as it has with the addition of a median HOV lane.

Table 2.27: Estimated Reduction in the Number of SOVs in GP Lane Due to Buses in HOV lane, Houston

\begin{tabular}{|l|c|c|}
\hline \multirow{2}{*}{ HOV Facility } & \multicolumn{2}{c|}{ Reduction in traffic on the Mixed Flow Lanes* } \\
\hline & AM Peak Hour & PM Peak Hour \\
\hline I-10 Katy Freeway, Houston & $844+703=1,547 \mathrm{vph}$ & $874+506=1,380 \mathrm{vph}$ \\
\hline I-45 North, Houston & $1,115+996=2,111 \mathrm{vph}$ & $852+1,012=1,864 \mathrm{vph}$ \\
\hline US 290 Houston & $956+531=1,487 \mathrm{vph}$ & $1,195+621=1,816 \mathrm{vph}$ \\
\hline I-45 South Houston & $1,094+581=1,675 \mathrm{vph}$ & $738+663=1,401 \mathrm{vph}$ \\
\hline
\end{tabular}

*Calculations based on estimated reduction in number of SOVs in Table 2.24 and Table 2.26

The increase in the number of carpools and bus ridership has led to an increase in the overall average vehicle occupancy on freeways with HOV lanes. Table 2.28 shows the increase in the average vehicle occupancy on HOV implemented freeways in Houston, Dallas, California, Washington and Northern Virginia. These numbers show that HOV implementation has improved the average vehicle occupancy on freeways compared to the national average vehicle occupancy of 1.14. The HOV lanes in the Dallas region have increased the overall average vehicle occupancy on the freeway corridor by 8-12\% [Skowronek et al., 2002]. 
Table 2.28: Average Vehicle Occupancy of some HOV Projects [Stockton et al., 1999; Skowronek et al., 2002]

\begin{tabular}{|c|c|c|c|c|}
\hline Freeway & Description & $\begin{array}{c}\text { Occupancy } \\
\text { Requirement }\end{array}$ & $\begin{array}{c}\text { Average Vehicle } \\
\text { Occupancy }\end{array}$ & \\
\hline & & & Before (Freeway) & $\begin{array}{l}\text { After (Freeway } \\
+ \text { HOV Lane) }\end{array}$ \\
\hline Houston, Katy Freeway & 1 Lane Exclusive Reversible & $2+$ & \multirow{8}{*}{$\begin{array}{c}1.14 \\
\text { (National } \\
\text { Average Vehicle } \\
\text { Occupancy ) }\end{array}$} & 1.42 \\
\hline Houston, Northwest Freeway & 1 Lane Exclusive Reversible & $2+$ & & 1.41 \\
\hline Houston, Gulf Freeway & 1 Lane Exclusive Reversible & $2+$ & & 1.32 \\
\hline Houston, I-45N & 1 Lane Exclusive Reversible & $2+$ & & 1.36 \\
\hline $\begin{array}{l}\text { Los Angeles, San Bernardino } \\
\text { Freeway }\end{array}$ & $\begin{array}{l}\text { Barrier Separated 2-Way - } 24 \\
\text { hours }\end{array}$ & $3+$ & & 1.7 \\
\hline I-5, Seattle, Washington & $\begin{array}{l}1 \text { Concurrent Flow Lane in } \\
\text { Each Direction-24 hours } \\
\text { Operation }\end{array}$ & $3+$ & & 1.6 \\
\hline $\begin{array}{l}\text { Shirley Highway, Washington } \\
\text { D.C, Northern Virginia }\end{array}$ & $\begin{array}{l}1 \text { Concurrent Flow Lane Each } \\
\text { Direction - } 8 \text { hrs Operation }\end{array}$ & $3+$ & & 2.28 \\
\hline I-15 Salt Lake City, Utah & $\begin{array}{l}\text { Buffer Separated Exclusive 2- } \\
\text { directional-24 hours } \\
\text { Operation }\end{array}$ & $2+$ & & 1.34 \\
\hline I-30, R. L. Thornton, Dallas & $\begin{array}{l}\text { Contraflow HOV Lane } \\
\text { 6-9 am 3:30 - 5:00 pm }\end{array}$ & $2+$ & 1.15 & 1.25 \\
\hline $\begin{array}{l}\text { I-35 North Stemmons Freeway, } \\
\text { Dallas }\end{array}$ & $\begin{array}{l}\text { Buffer-separated concurrent } \\
\text { flow HOV lane } \\
24 \text { hour }\end{array}$ & $2+$ & 1.09 & 1.22 \\
\hline I-635 LBJ Freeway EB, Dallas & $\begin{array}{l}\text { Concurrent Flow } \\
24 \text { hour }\end{array}$ & $2+$ & 1.15 & 1.26 \\
\hline I-635 LBJ Freeway WB, Dallas & $\begin{array}{l}\text { Concurrent Flow } \\
24 \text { hour }\end{array}$ & $2+$ & 1.18 & 1.27 \\
\hline I-35E South, Dallas & $\begin{array}{l}\text { Reversible Flow (6-9 am and } \\
3: 30-7: 00 \mathrm{pm})\end{array}$ & $2+$ & 1.11 & 1.20 \\
\hline
\end{tabular}

\subsubsection{Person Movement Capacity}

HOV lane implementation can improve the person movement capacity of the freeway. Figure 2.44 compares the HOV lane peak hour peak direction person trips with the GP lane at various locations in Orange County, Los Angeles County and Dallas, Texas. It was found that the HOV lane on all these freeways carried more people per peak hour in the peak direction than the general purpose lane. The general purpose lanes on an average carry approximately 1,900 passengers per peak hour in the peak direction. On the other hand, the average HOV lane(s) person throughput is approximately 3300 person-trips during the peak hour in the peak direction.

The HOV lane person throughput increases significantly if the freeway has an efficient bus service along the corridor. For example: the I-395 Shirley Highway, I-10 Orange County and San Bernardino freeway HOV lanes carry more than 6000 people in the HOV lane because of the excellent bus service on these corridors. However, even if the corridors with bus service are not taken into consideration while estimating the average person throughput, the remaining freeways will still carry an average of 2,774 passengers per hour. The total number of vehicles on the HOV lane varies between 800-1400 vphpl at most of these HOV facilities.

However, it is not difficult to find HOV lanes where the person throughput is less than the adjacent general purpose lanes. Therefore, it can be concluded that HOV lanes are capable of carrying more people than the general purpose lanes even while operating at less than two-thirds of their capacity (1600-1700 vphpl). 


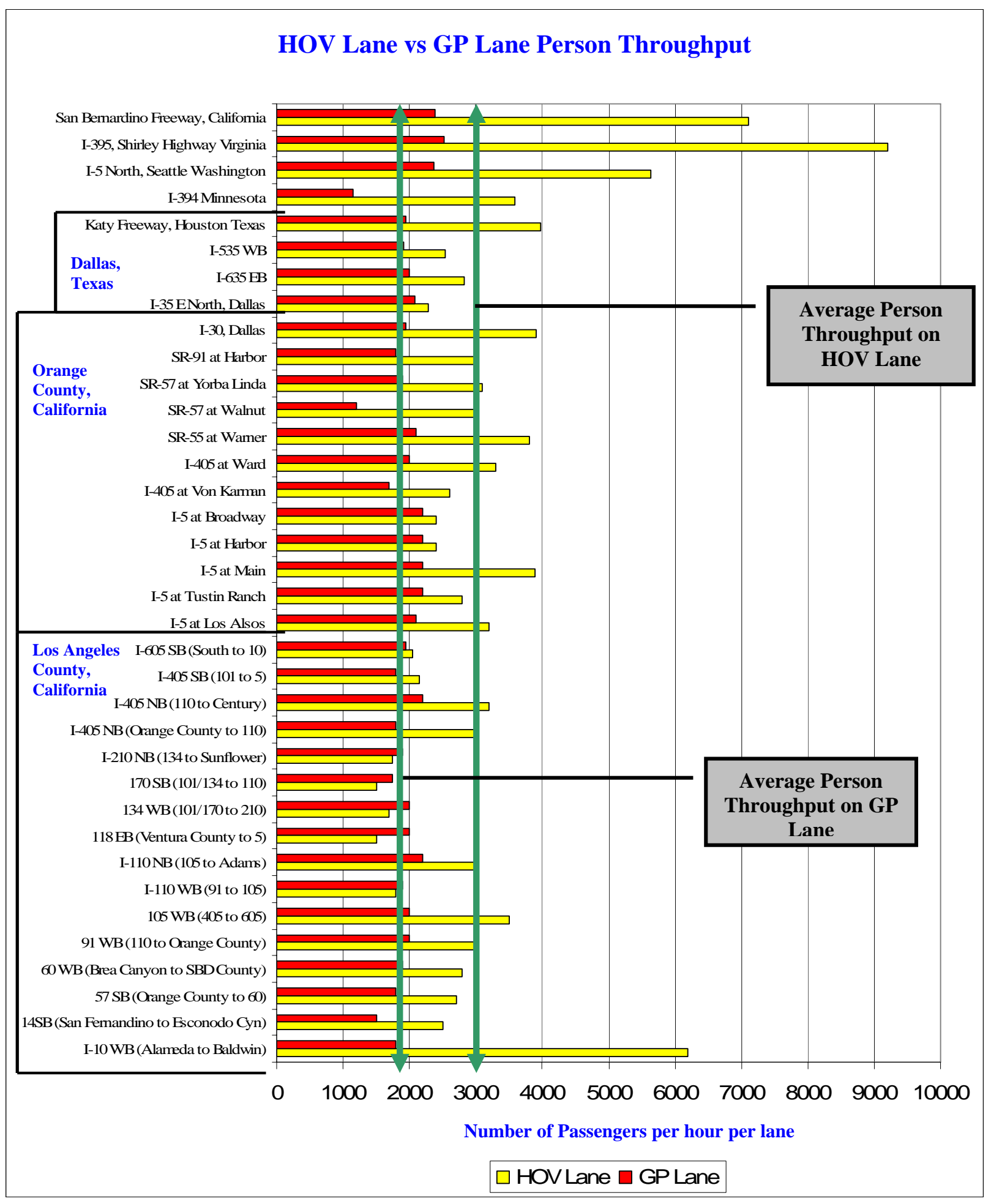

Figure 2.44: Person Movement Efficiency of HOV Lane vs GP Lane

[Source: Turnbull, 1992; Fuhs and Obenberger, 2002; Skowronek et al., 2002; Morrison \& Counts, 2005] 


\subsubsection{Travel Time Savings and Trip Reliability}

The average speed of travel on the HOV lane has been found to be considerably higher than the adjacent general purpose lanes on most freeways. For example, an evaluation study in Dallas, Texas found that the average speed on the HOV lane across five freeways was in the range of 53-58 mph [Skowronek et al., 2002] which was significantly higher than the speed on the general purpose lanes (24-37 mph). Further it was observed that the opening of the HOV lanes did not reduce the speed of travel on the general purpose lanes. Hence the level of service on the general purpose lane did not change due to the opening of the HOV lane. Similar results were seen on the Houston HOV lanes. Figure 2.45 compares the improved speed on the HOV lane to the speed on the GP lanes before and after the HOV facility implementation. The high speed (53-58 mph) on the HOV lane provided the commuters with valuable travel time savings compared to when they were traveling in the GP lanes (at 20-30 mph). Moreover, it was observed that the speed on the GP lanes after the HOV facility implementation did not reduce significantly. The speed in the GP lane on I-30 and I-35E were found to increase after HOV implementation. This increase is likely due to a large number of SOVs moving into the HOV lane from the GP lanes. Hence, travel time savings on the GP lane can also be expected at some locations.

Similar observations have been made at several other locations where HOV lanes have been implemented. The estimated travel time savings during the peak hour at these locations, along with the length of the HOV facility are presented in Figure 2.46.

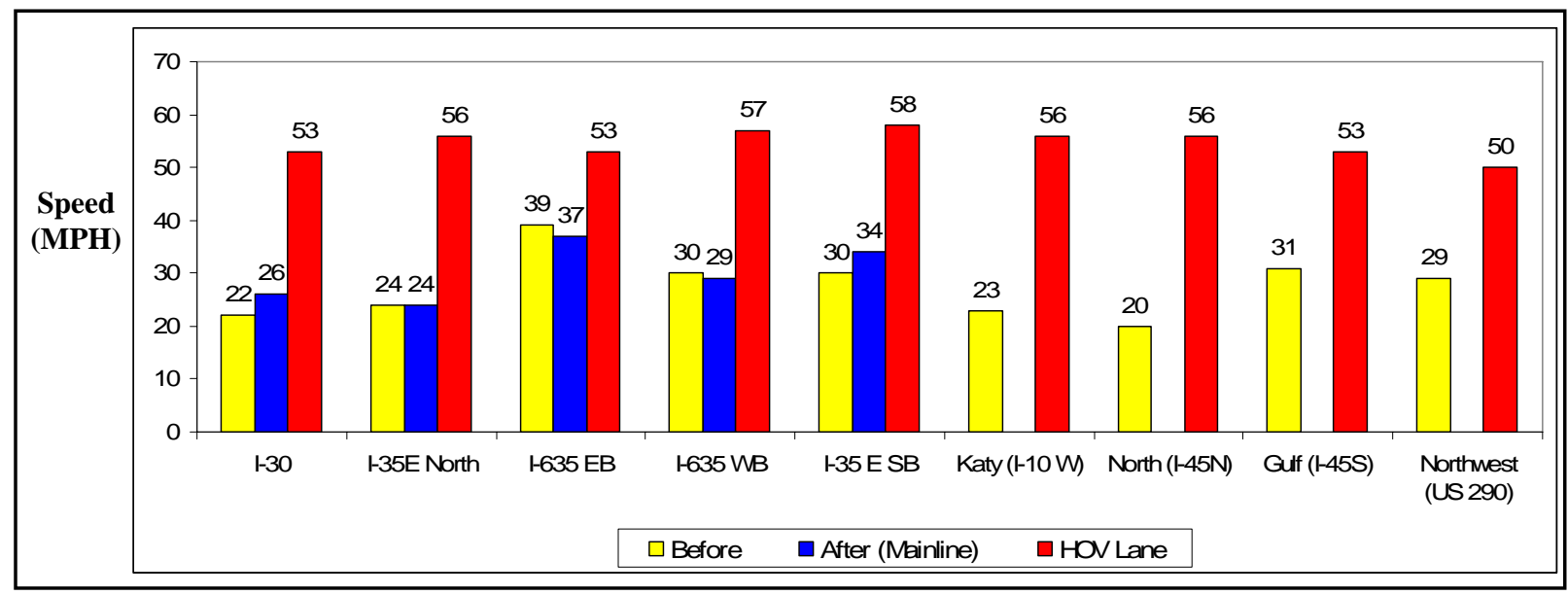

Figure 2.45: AM Peak Hour Operating Speeds on HOV and GP lanes Before and After HOV Facility Implementation in Texas [Skowronek et al., 2002; Turnbull, 1992] 


\section{HOV LANE TRAVEL TIME SAVINGS}

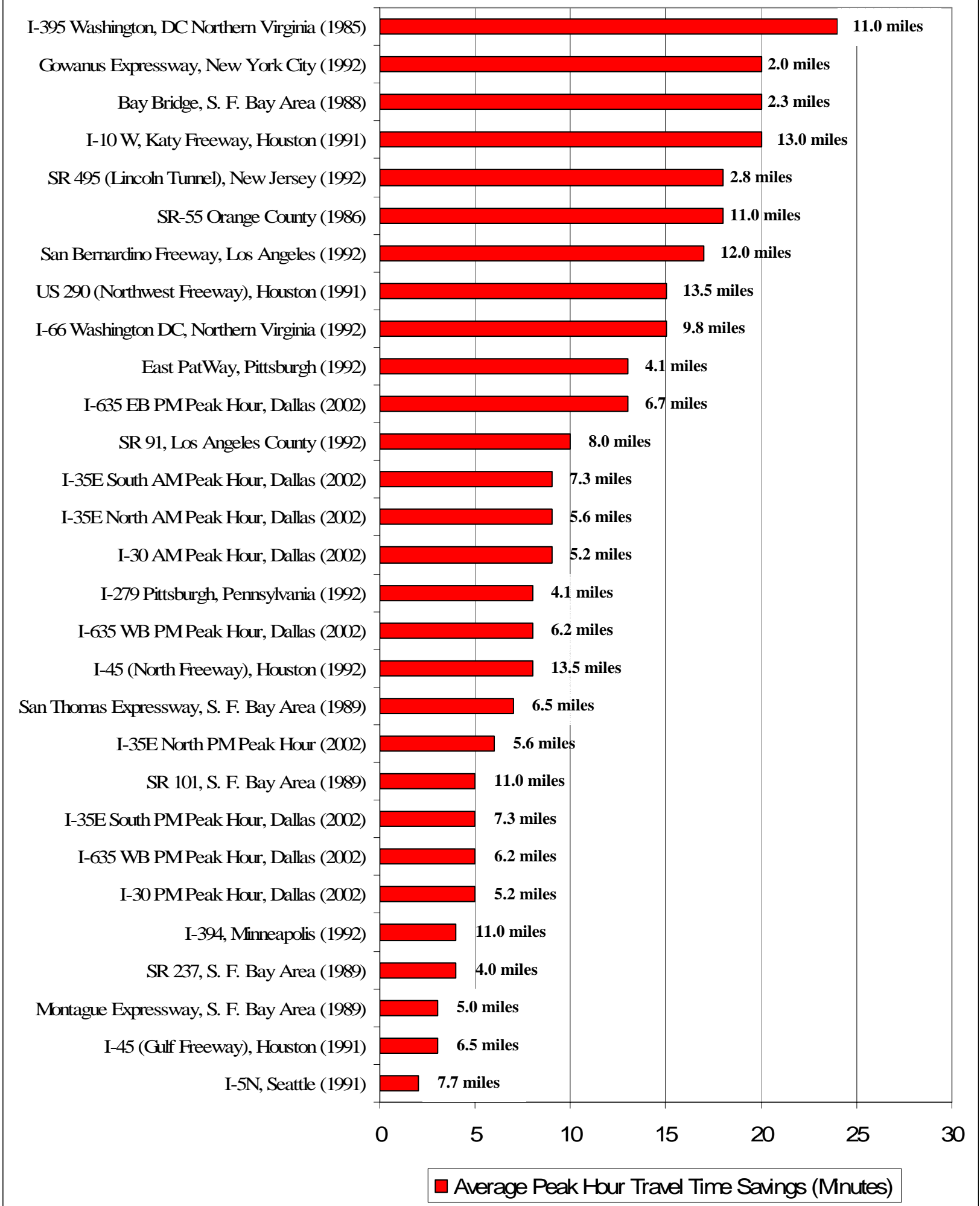

Figure 2.46: Average Peak Hour Travel Time Savings of HOV lanes on Freeways

[Source: Turnbull, 1992; Fuhs and Obenberger, 2002; Skowronek et al., 2002; Morrison \& Counts, 2005] 


\subsubsection{HOV Lane Facilities in States}

\subsubsection{California}

The HOV lanes in California have been in existence since 1985. California accounts for approximately 45\% (1112 lane miles in 2005) of the HOV lane miles in the country. These comprise the largest and one of the most successful HOV system in the country. Approximately $70 \%$ of the HOV projects in California are located in the five counties of the Los Angeles metropolitan area. These counties are located in Southern California and include Los Angeles County (with more than 425 HOV lane miles), Orange County (200 HOV lane miles), Riverside County, San Diego and San Bernardino County. About 90\% of the HOV facilities in California are Buffer Separated Exclusive twoDirectional or Concurrent Flow Lane HOV facilities. An exclusive 2-directional, buffer separated, full time, limited ingress/egress HOV facility with a 2+ occupancy requirement was implemented at most of the places in Southern California because the congestion on these freeways extended to 13-14 hours/ day before HOV implementation. The HOV facilities in Northern California are mostly concurrent flow lane HOV facilities operating part time during the peak periods, mostly 2+, unlimited access. Congestion on the freeways in Northern California occurred only during the peak period for 3-4 hours in the morning and evening. Hence a concurrent flow lane HOV operation was preferred in this region. One lane was added in each direction on almost all the freeways and operated as an HOV lane in the peak period. The lane is open to all traffic in the off-peak period.

The HOV systems in the state of California comprises of several direct connector ramps, direct local access

ramps, ramp meter bypass lanes, toll plaza bypass lanes and approximately 450 park-and-ride lots across the entire state. The system was setup with a large scale coordination involving several agencies such as FHWA, Caltrans, EPA, California Environmental agency, transit and other agencies. Overall, the HOV system in California is considered a success with the following characteristics/achievements:

- The systems carry roughly 2518 passengers per hour during the peak period substantially more than a congested mixed flow lane (about 2000 person trips) and roughly the same number of people as a typical mixed flow lane operating at maximum capacity (2500 person trips).

- On an average, approximately 1095 vehicles (two-thirds of the HOV lane capacity) use HOV lane in California. This has ensured a high level of service in the HOV lanes with an average travel time saving of 0.5 minutes per mile. Figure 2.47 shows the average number of vehicles in the HOV lane at various HOV locations in California. Consistent with the air quality enhancement goals of its program the state allows low-emission vehicles to use HOV lanes. 


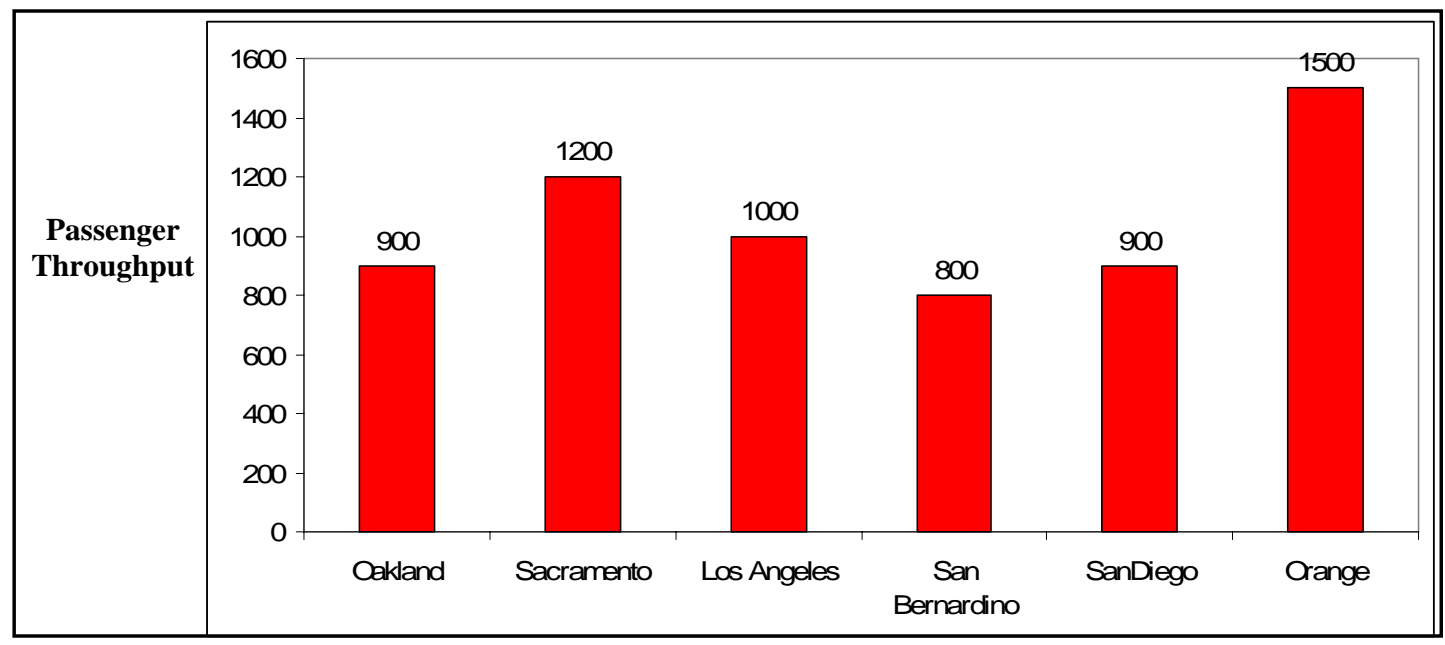

Figure 2.47: Average flow by of HOV lane vehicles by Caltrans District [Parsons, 2002]

\subsubsection{Houston, Texas}

The Houston HOV system has HOV lanes implemented on 6 freeways with over 100 lane-miles of HOV lanes (Figure 2.48). The HOV facility is implemented as an exclusive reversible barrier separated lane (20.5 feet wide) on over 90 lane-miles. In addition to the reversible HOV operation, Katy freeway has a 6.6-mile concurrent flow lane HOV facility and US 290 Northwest freeway has a small section where an exclusive two-directional HOV facility is implemented. The reversible HOV lane is operated 5:00 am - 12:00 pm in the morning peak and 2:00 pm - 9:00 pm in the afternoon peak. The HOV lanes are operated with a 2+ occupancy requirement for most of the time on these freeways. The only exceptions are the Katy and the Northwest freeway that operate the HOV lanes with a 3+ occupancy requirement from 6:45 am- 8:00 am in the morning and 5:00 pm - 6:00 pm in the afternoon. This period is referred to as the "peak of the peak" period.

The HOV system has 28 park-and-ride lots and 4 park-and-pool lots, direct access ramps (T-ramps, wishbone ramps), slip ramps and median HOV lanes. 10 out of the 32 parking facilities are connected to the HOV lanes by direct access ramps. The HOV lanes are managed by the TranStar HOV management center which is hightech traffic and emergency management center. The center is a facility metropolitan area. The HOV lanes are controlled by this facility through a series of variable message signs. Express bus service is provided by Metro with approximately 1000 buses operating on the six HOV corridors on a daily basis. METRO provides several ridesharing, corporate ride-sponsor programs and ride-matching services.

Since 1984 when it was first implemented the Houston HOV system has expanded with time. For example, some of the direct access ramps were completed in 1998 on I-45 North and I-10 Katy HOV lanes. Due to its incremental and evolutionary development, data on the overall cost of Houston's HOV implementation is difficult to obtain. A 1995 study estimated the total capital cost of 71 miles of the HOV lanes (operational in 1990) as \$643 million (1990 dollars). This approximates to $\$ 7.0$ million per lane-mile (1990 Dollars). It is estimated that about $70 \%$ of this money was spent on the construction of HOV lanes, enforcement areas, ramps and signs and markings. 


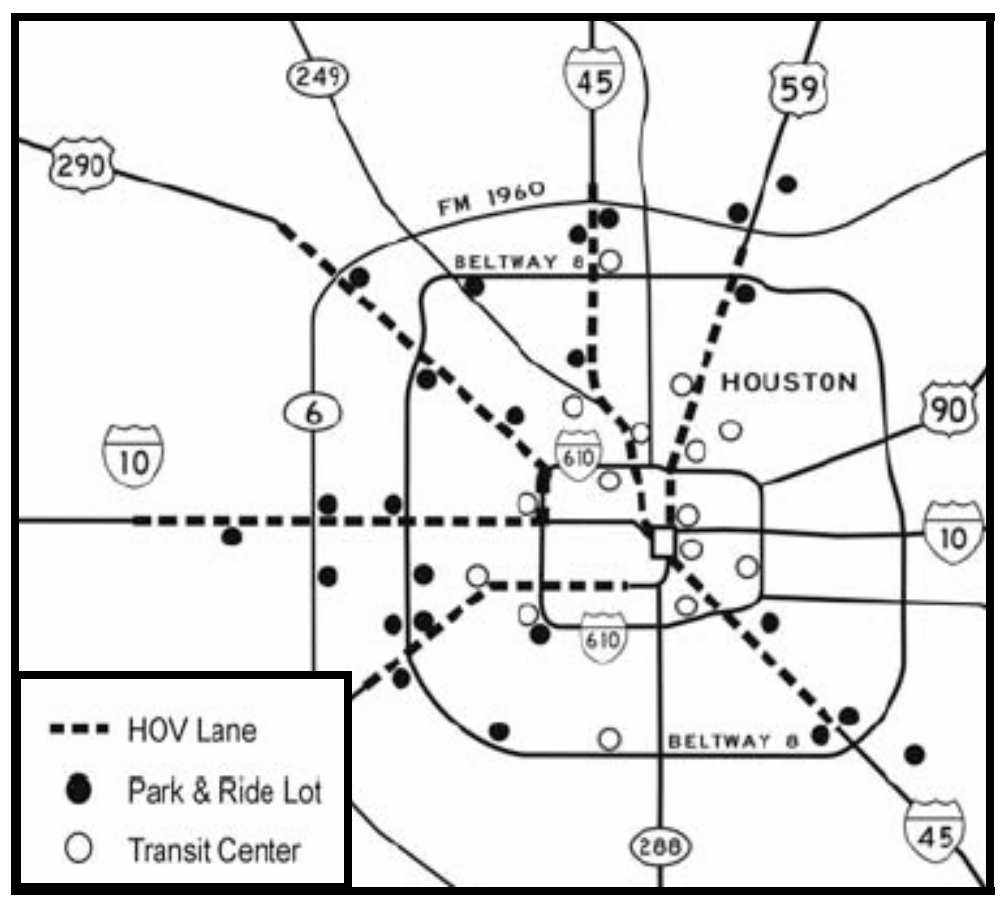

Figure 2.48: Houston HOV System in 2003 [Turnbull, 2003]

Several studies have been performed to determine the effectiveness of the Houston HOV system and the following conclusions have been made for five of the HOV corridors excluding Eastex Freeway:

- The crash rate did not increase on any of these corridors after the implementation of barrier separated exclusive reversible HOV lanes.

- The construction of median HOV lanes in Houston did not lead to a reduction of speeds on the GP lane.

- $\quad$ All the five HOV lane facilities are cost-effective. The benefit-to-cost ratio for all the facilities exceed one.

- The HOV lane implementation has increased the bus speeds by more than 50\% in all the Houston corridors

- The number of new carpools have increased by at least $25 \%$ due to the implementation of the HOV lanes on all the corridors

- The peak hour average vehicle occupancy has increased by 10-15\% on Katy, North and North-west freeways. The Gulf and Southwest Freeways have a lower percentage increase in their vehicle occupancy.

- An average of $65 \%$ of non-HOV users surveyed in Houston and Dallas believe that HOV lanes are good transportation improvements

- $\quad$ Travelers on the HOV lanes in Texas save 2-18 minutes of travel time in the morning rush hour.

- Carpooling has declined nationally by an average of $30 \%$ in the past two decades. However, the Texas freeway corridors with HOV lanes have experienced an increase in carpooling of $100 \%$ or greater during the same period.

- Air Quality Impacts: The results of the air quality analysis study conducted for the Katy freeway HOV lane, based on 1991 travel volumes are shown in Figure 2.49. Similar analysis was planned for other HOV lanes in Houston. This analysis utilized a freeway simulation computer model (FREQ). Using the FREQ model the 
operation on both the freeway general purpose lanes and the HOV lane was simulated during the morning peak period from 6 am to 12:00 pm in the peak direction on the Katy freeway exclusive reversible HOV lane.

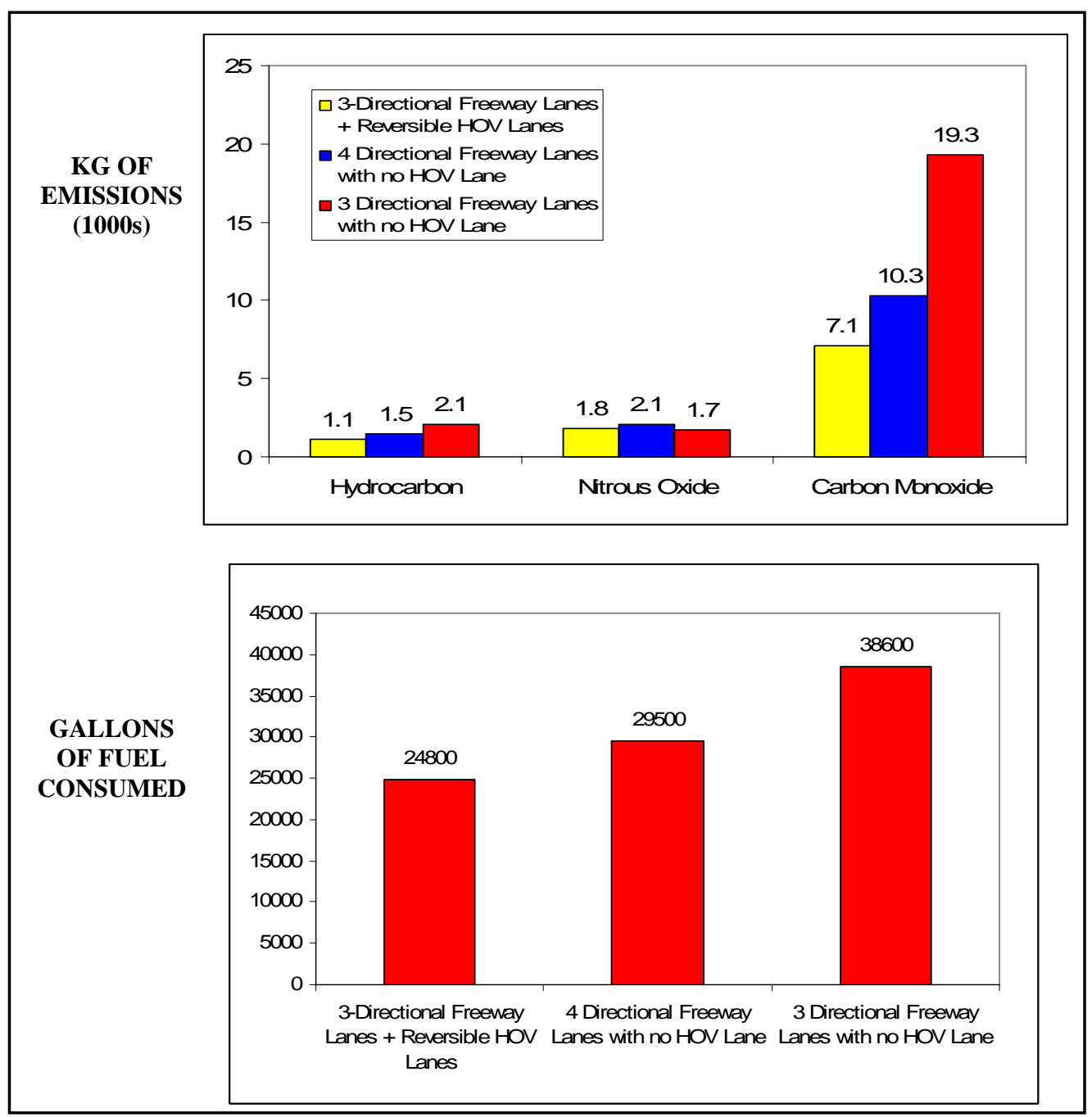

Figure 2.49: Air Quality and Energy Impacts of HOV Lanes in Houston [Turnbull, 1992]

The 1991 demand, expressed in passenger miles, was held constant across the alternatives and the average vehicle occupancy was adjusted between the alternatives as necessary to reflect the observed impacts of the HOV facility on vehicle occupancy. However, the implementation of the HOV lanes might increase the VMT (induced traffic) and hence the air quality and energy impacts. However the analysts argued that the analysis focused on asking the question, "What is the most effective means of serving the travel demand that is expected to occur and what are the air quality and energy impacts of the alternatives?” Therefore, instead of varying the demand across the alternatives the analysis assumed a constant demand and determined the best alternative that is capable of serving this demand. The analysis approach was undertaken based on the realization that implementing an HOV lane does not necessarily reduce vehicular volumes on the freeway, but rather allows more persons to use the HOV facility 
without increasing congestion in the freeway general purpose lanes. The results showed that HOV lanes are capable of reducing the emissions and fuel consumption on a freeway.

- Transit Efficiency: In Houston, surveys conducted in 1988, 1989, and 1990 found that 54-76\% of the bus riders using the HOV lanes responded that the opening of the HOV lanes was very important in their decision to ride a bus. Approximately 22 - 39\% of the respondents in these surveys indicated that they would not be riding the bus if the HOV lane had not been opened Table 2.29 shows the effect of HOV lanes on bus speeds on the Houston HOV lanes. The increase in bus operating speeds resulted in significant reduction in bus schedule time (Figure 2.50). The pre-HOV lane bus schedule times were estimated on the basis of the freeway operating speeds.

Table 2.29: Increase in Average Peak Hour Bus Speed on Houston HOV Lanes [Turnbull, 1992]

\begin{tabular}{|l|c|c|c|}
\hline \multirow{2}{*}{ HOV Facility } & \multicolumn{2}{c|}{$\begin{array}{c}\text { Bus Operating Speed } \\
\text { (MPH) }\end{array}$} & \multirow{2}{*}{ Increase } \\
\cline { 2 - 3 } & Before HOV & Current & \\
\hline Katy (I-10 W) & 23 & 56 & $143 \%$ \\
\hline North (I-45 N) & 20 & 56 & $180 \%$ \\
\hline Gulf (I-45 S) & 31 & 53 & $71 \%$ \\
\hline Northwest (US 290) & 29 & 50 & $72 \%$ \\
\hline Unweighted Average & 26 & 54 & $107 \%$ \\
\hline
\end{tabular}

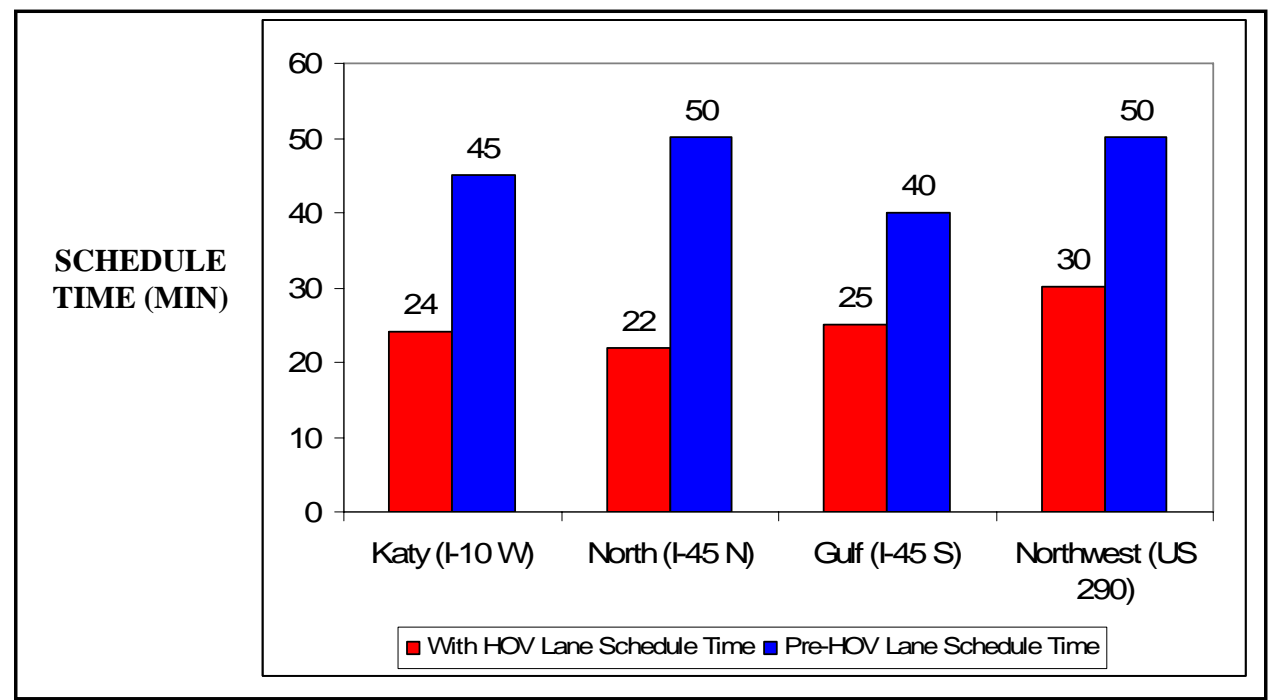

Figure 2.50: Bus Schedule Time, AM Peak Hour Service to Downtown Houston [Turnbull, 1992]

In 1992, METRO conducted a preliminary operational analysis of the impact of enhancements made to the HOV system in Houston. The study [Turnbull, 1992] examined the impacts during the first two years of operation, following enhancements. The benefits obtained were summarized by METRO (Table 2.30). 
Table 2.30: Bus Operating Impacts of Improvements to Houston HOV System [Turnbull, 1992]

\begin{tabular}{|c|c|c|c|c|c|c|}
\hline \multirow{2}{*}{$\begin{array}{c}\text { HOV } \\
\text { Facility }\end{array}$} & \multirow[t]{2}{*}{ Bus Route } & \multicolumn{2}{|c|}{ Schedule Time } & \multicolumn{3}{|c|}{ Bus Operating Impacts } \\
\hline & & Before & After & $\begin{array}{c}\text { Bus-Hours } \\
\text { Saveedd }\end{array}$ & $\begin{array}{c}\text { Equivalent } \\
\text { Buses Saved }\end{array}$ & $\begin{array}{c}\text { Annual Cost } \\
\text { Savings }\end{array}$ \\
\hline $\begin{array}{c}\text { North west } \\
\text { (US 290) }^{1}\end{array}$ & Route 214 & 44 & 30 & 14.9 & 4 & $\$ 85,000^{4}$ \\
\hline \multirow{3}{*}{$\begin{array}{c}\text { North (I- } \\
45 \mathrm{~N})^{2}\end{array}$} & Route 204 & 40 & 28 & - & - & - \\
\hline & Route 207 & 31 & 23 & - & - & - \\
\hline & Combined & - & - & 20 & 5 & $\$ 115,000$ \\
\hline $\begin{array}{c}\text { Katy (I- } \\
10 W)^{3}\end{array}$ & Route 228 & 30 & 24 & 6.4 & 2 & $\$ 117,000$ \\
\hline \multicolumn{7}{|c|}{${ }^{1}$ The improvement is a ramp from a park and ride lot to the HOV lane } \\
\hline \multicolumn{7}{|c|}{${ }^{2}$ The improvement is the reopening of a 3.8 mile section of the HOV lane } \\
\hline \multicolumn{7}{|c|}{${ }^{3}$ The improvement is a 1.5 mile extension to the HOV lane } \\
\hline
\end{tabular}

\subsubsection{I-15 Salt Lake City, Utah}

The HOV facility on I-15 was constructed as part of a larger project which was the reconstruction of I-15. The reconstruction project widened I-15 (from three general purpose lanes in each direction) by adding one general purpose lane and one HOV lane in each direction. After construction there were four general purpose lanes and one HOV lane in each direction. In addition to road widening, the reconstruction project also constructed interchanges at $400 \mathrm{~S}$ and $600 \mathrm{~N}$ (Figure 2.51) for improved downtown access.

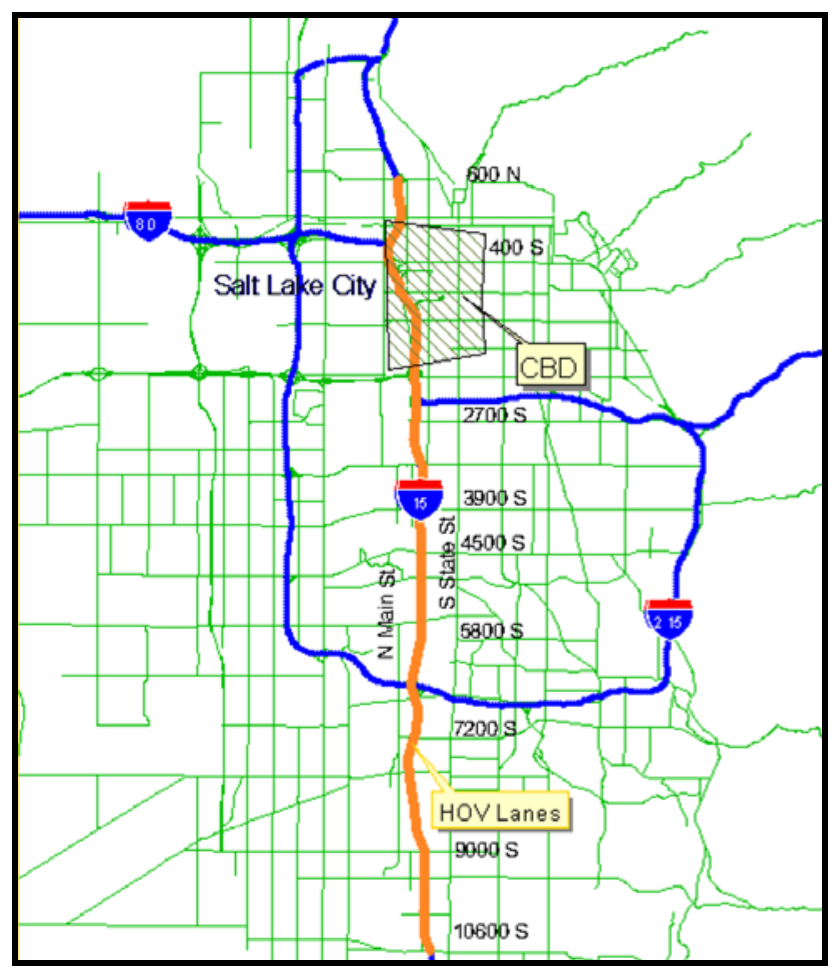

Figure 2.51: HOV lanes along I-15 in Salt Lake City 
The 16-mile buffer-separated (single solid white strip) exclusive two-directional HOV lanes were opened to traffic in May 2001 with a 2+ occupancy requirement. The HOV lanes provided open access to all general purpose lane traffic along the entire facility. The facility extends from $600 \mathrm{~N}$ to $10600 \mathrm{~S}$ with one HOV lane access ramp at 400 S near the CBD (Figure 2.51). Congestion on the freeway was mainly due to the work trips originating from the southern residential suburbs and ending in the dense employment district in the downtown area. The traffic volume profile on the HOV and GP lanes is shown in Figure 2.52. The following observations were made [Martin, 2002]:

a) PM Peak Period: 4-6 pm SB

- The HOV Lane carries the same number of people as each of the GP lane

- The HOV lane carries fewer vehicles than each GP Lane.

- The HOV lanes are operating at $44 \%$ of their capacity during the PM peak period

- HOV lanes provide $30 \%$ travel time savings compared to the adjacent general purpose lanes

- There is Less congestion in HOV lanes compared to general purpose lanes

- Traffic volumes in some of the GP lanes approached $2200 \mathrm{vphpl}$

(b) AM Peak Period : 6:30 am - 8: 30 am NB

- The HOV lane provide $13 \%$ travel time savings

- Traffic volume on the HOV lane is uniform throughout the day in the NB direction from 7 am to 7 pm

(c) Rest of the Day

- The HOV lane moves fewer people than its GP lane counterparts throughout the rest of the day, during times of little or no congestion.
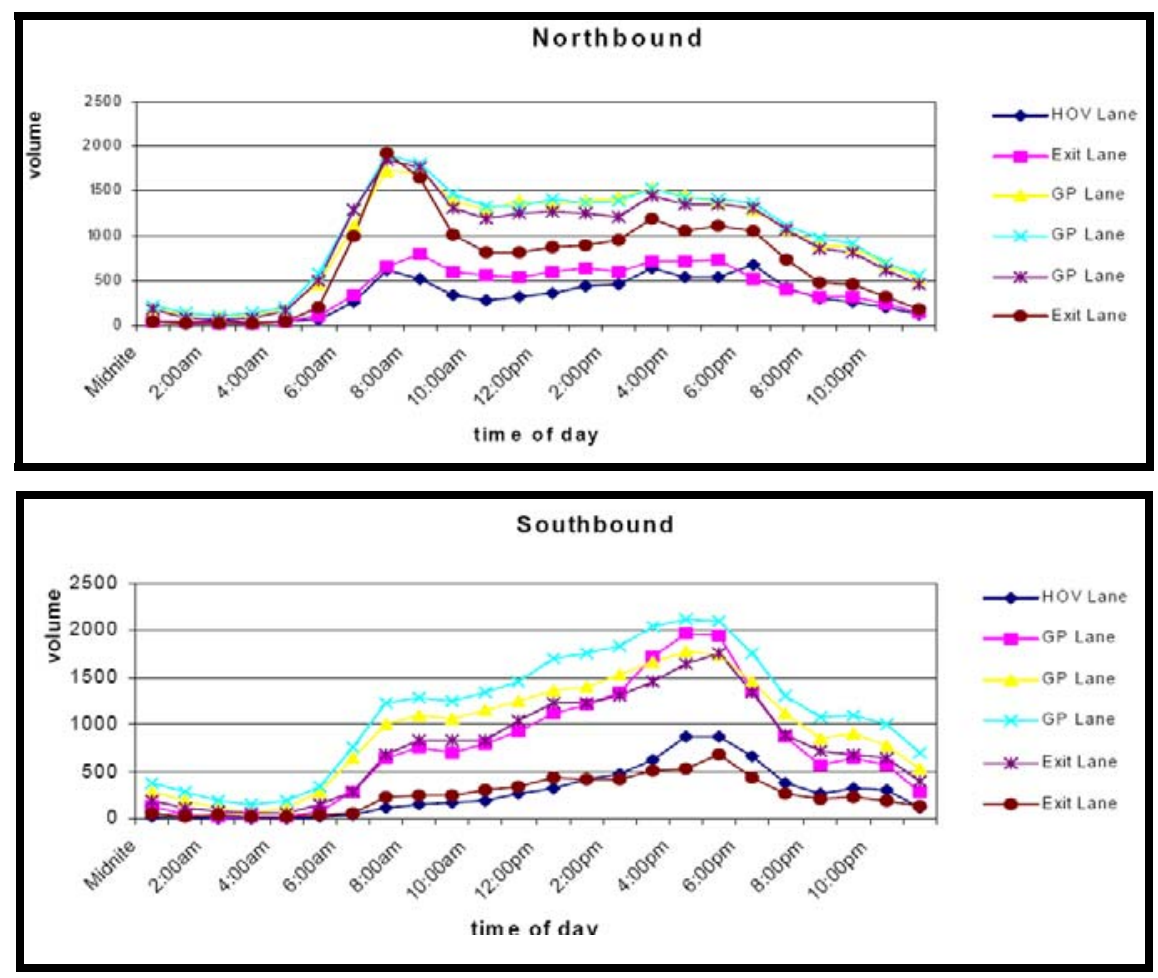

Figure 2.52: Traffic Volume Profile on HOV and GP Lanes on I-15 Salt Lake City, Utah [Martin, 2002] 
Throughout the day, it was observed that the average speed at the HOV lane was higher than that at the general purpose lanes (Figure 2.53). More importantly, the speed on the HOV lanes remained stable because of less congestion and fewer incidents thereby enhancing the reliability of travel on the HOV lanes. Table 2.31 shows the comparison of average travel speed on the HOV lanes in the northbound and southbound direction during the am/pm peak period.

Table 2.31: Speed Comparison of HOV and GP Lanes on I-15, Salt Lake City [Martin, 2002]

\begin{tabular}{|c|c|c|c|c|c|c|}
\hline & \multicolumn{2}{|c|}{ Morning Peak (NB) } & \multicolumn{2}{c|}{ Afternoon Peak (SB) } & \multicolumn{2}{c|}{ Off-Peak } \\
\hline & HOV & GP & HOV & GP & HOV & GP \\
\hline Mean & 74 & 65.7 & 63.6 & 51.5 & 74.2 & 68.4 \\
\hline $\begin{array}{c}\text { Standard } \\
\text { Deviation }\end{array}$ & 3.3 & 4 & 10.8 & 16.7 & 2.6 & 3.8 \\
\hline $\begin{array}{c}\text { Percentage } \\
\text { < 45 MPH }\end{array}$ & 0 & 0 & $10.30 \%$ & $31.00 \%$ & 0 & 0 \\
\hline
\end{tabular}

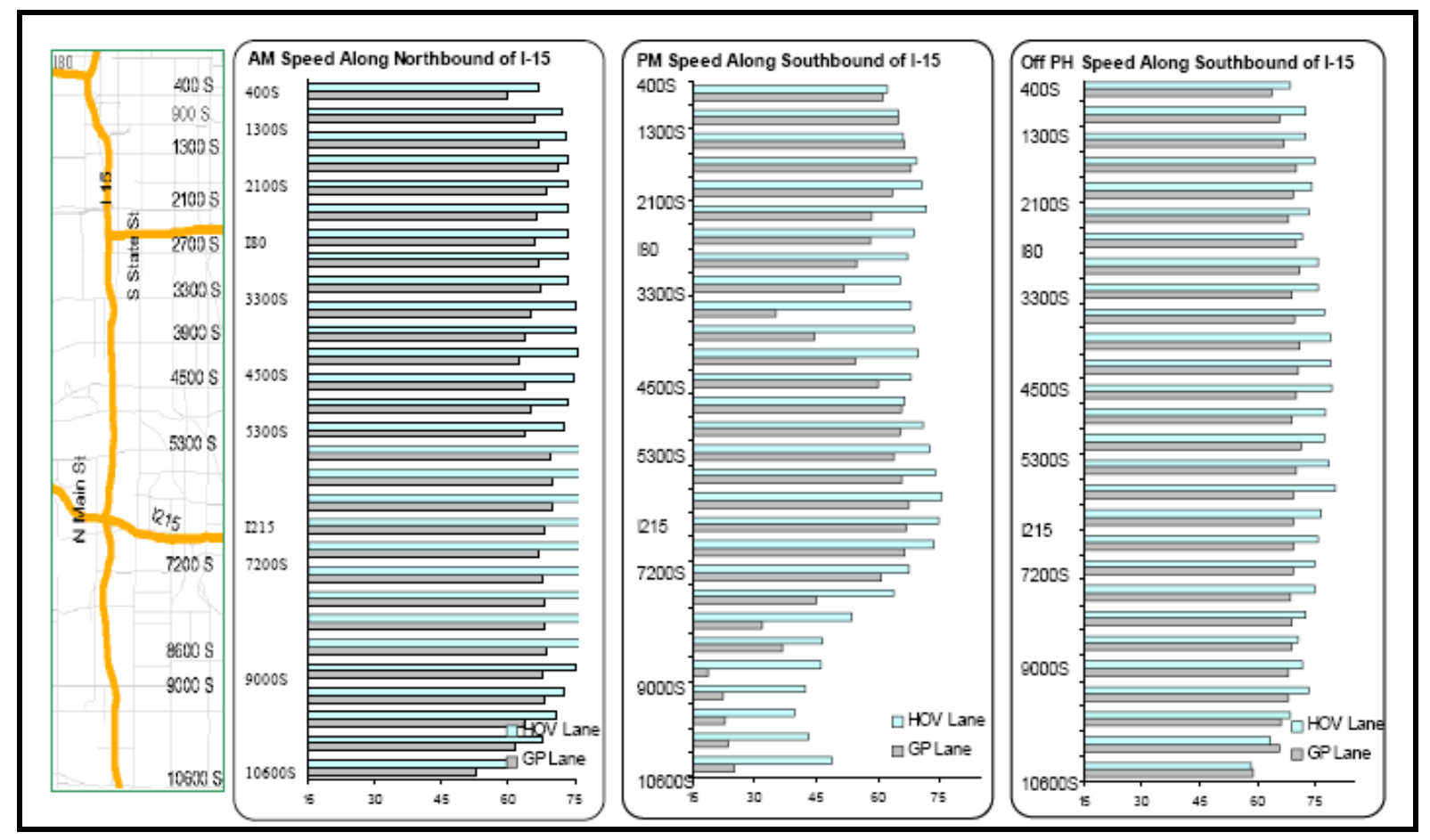

Figure 2.53: Variation of Speed along the I-15 HOV and GP Lanes [Martin, 2002]

The modal split and the person-trips by each mode on the HOV and GP lane is shown in Figure 2.54. Buses carried $27.5 \%$ of the people in HOV lanes. These readings were taken during the peak periods at the $3900 \mathrm{~S}$ highway. The average vehicle occupancy on the freeway improved by $20 \%$ from 1.1 to 1.3 (18\% increase) after the reconstruction of I-15 and implementation of the HOV lanes. This increase was considered significant because the reconstruction of I-15 could have increased congestion on the freeway due to induced traffic (enhanced capacity). The increase in average vehicle occupancy was attributed to the implementation of the HOV lanes on the freeway. 
The average vehicle occupancy on the HOV lanes was more than two (2+ occupancy requirement). The average vehicle occupancy at other freeway corridors in Salt Lake City where HOV lanes were not implemented (I-215W, I215E, 3100S, 4500S, I-15 and 600N) remained the same as earlier. Figure 2.55 shows the change in average vehicle occupancy for freeways before and after the HOV lane implementation in Salt Lake City.
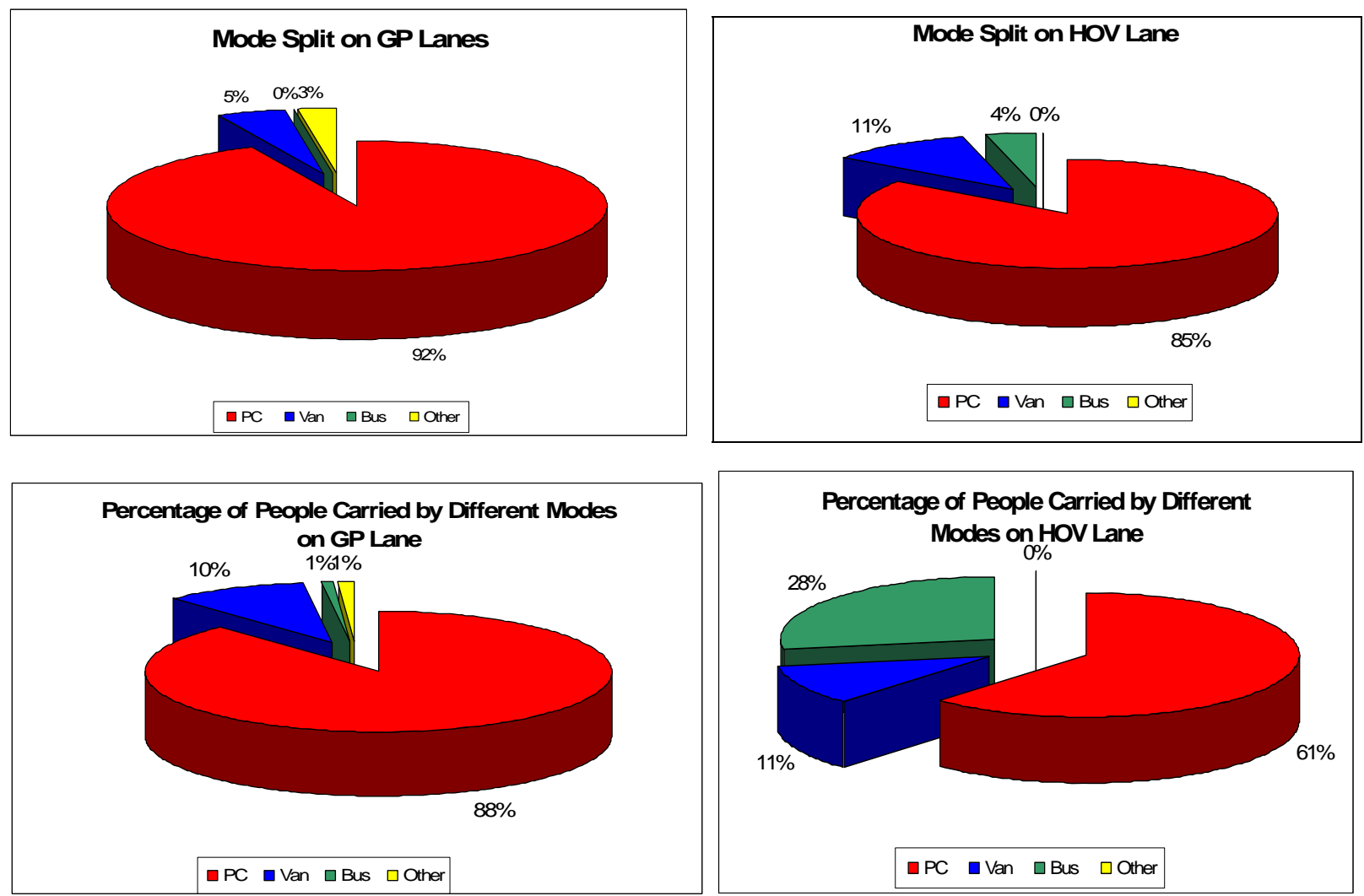

Figure 2.54: Modal Split in the HOV and GP Lane [Martin, 2002]

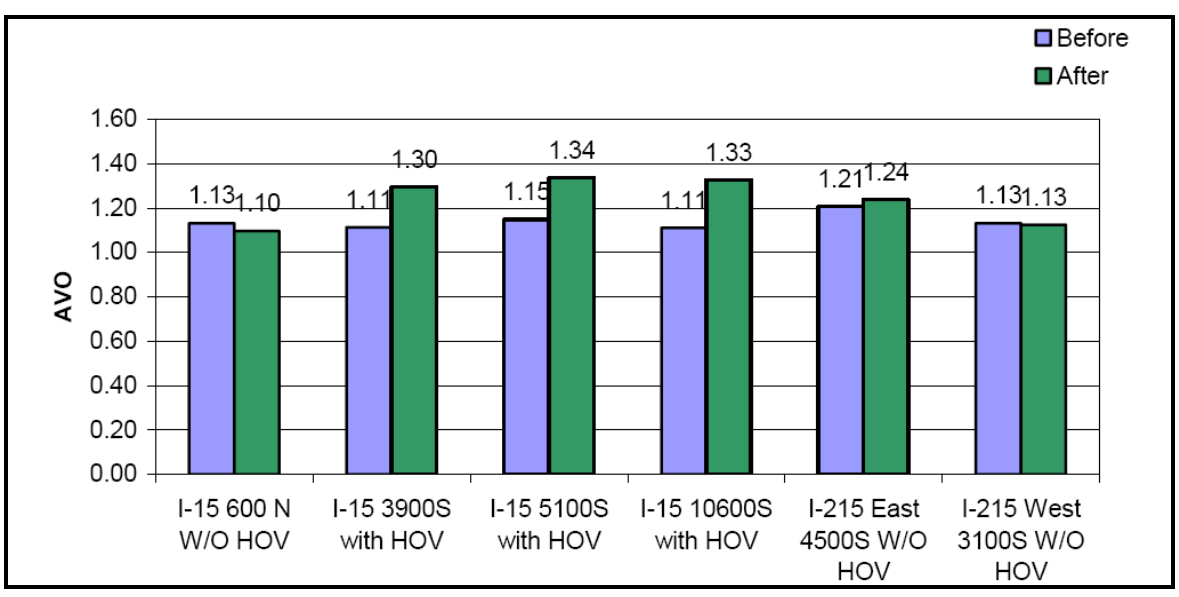

Figure 2.55: Change in Average Vehicle Occupancy in Salt Lake City with and without HOV [Martin, 2002] 
Open access to HOV lanes from GP lanes provided flexibility to HOV users. On the other hand the violation rate increased along the corridor. The recorded violation rate of $15 \%$ was marginally higher than the national average of $10 \%$. In general, it was observed [Martin, 2002] that the violation rate tends to be higher during congestion on the freeway because the commuters were willing to take a risk in exchange for the benefits derived from HOV lane use. According to Martin (2002), "the violation rates were particularly high near points where HOV lanes merged with GP lanes (for e.g. at 400S) and HOV ramps, as some people tend to believe that getting into the HOV lane "just a little early" is not really a violation, and the short time spent in the HOV lane limits the chances that they will be observed by a highway patrol officer”. The most dramatic change in violation rates occurred during the early stages of violation. The violation was approximately $50 \%$ in the first month and thereafter decreased to $24 \%$ and eventually to $18 \%$ one year later (Figure 2.56 ). This decrease was due to the increased HOV lane use due to highway patrol enforcement.

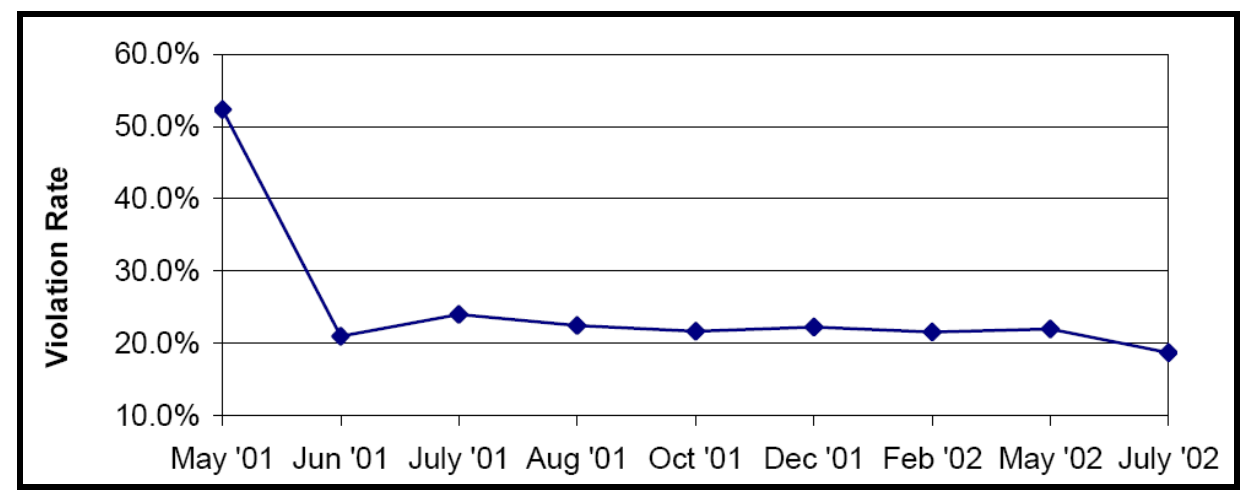

Figure 2.56: Violation Rates at 400S HOV Ramp [Martin, 2002]

The evaluation study concluded that the HOV system in Salt Lake City was successful in increasing the average vehicle occupancy, reducing travel times, increasing travel speed, improving trip reliability and in carrying more people in HOV lanes during the afternoon peak period. However, relative to other urban areas where HOV lanes have been installed, Salt Lake City has relatively lower congestion and therefore lower need for HOV facilities. As the congestion increases the benefits of the HOV lane should also increase. This study concluded that the benefits from the HOV lanes can be significant for significantly congested areas. The study also recommended consideration of inside ramps for the HOV lanes as HOV users in the PM peak had to cross four congested GP lanes to exit the freeway and therefore many potential users were not using the HOV facility for short freeway trips or in more congested southern portion of the freeway. Atlanta, Seattle and LA have all incorporated direct HOV ramps for freeway-to-freeway connectors and arterial connections resulting in increased utilization of HOV lanes.

\subsubsection{Northern Virginia}

The HOV system in Northern Virginia (Figure 2.57) is one of the most successful HOV programs in the country and is the single most important element in the transportation network of that region. The HOV lanes carry more freeway passengers than the conventional freeway lanes, bus systems, metro rails or Virginia Railway Express 
(VRE). It has been suggested that none of these modes can function properly without the state's HOV system [Morrison \& Counts, 2005]. The goals achieved by the HOV lanes in Virginia are:

- Congestion Management: average vehicle occupancy of 2.28 on the freeway in 1990

- Attainment of Clean Air goals

- Time savings incentive for people to rideshare

The HOV lane users received significant travel time savings over the same trip in the general purpose lanes. Table 2.32 shows HOV lane travel time savings at the I-395 Shirley Highway and I-66 HOV lanes.

Table 2.32: Travel Time Savings from HOV Lanes in Northern Virginia [Morrison \& Counts, 2005]

\begin{tabular}{|c|l|l|c|c|}
\hline Facility & Start Point & End Point & $\begin{array}{c}\text { HOV Lane Travel } \\
\text { Time }\end{array}$ & $\begin{array}{c}\text { Non-HOV } \\
\text { Lane Travel } \\
\text { Time }\end{array}$ \\
\hline I-95/395 & Quantico Creek & 14th Street and C Street & $29 \mathrm{~min}$ & $64 \mathrm{~min}$ \\
\hline I-66 & Route 234 & 23 rd and Constitution & $63 \mathrm{~min}$ & $94 \mathrm{~min}$ \\
\hline
\end{tabular}

This section presents two HOV lane corridors in Northern Virginia (Figure 2.57). Both these corridors served the trips going to the central business district in Washington D.C.

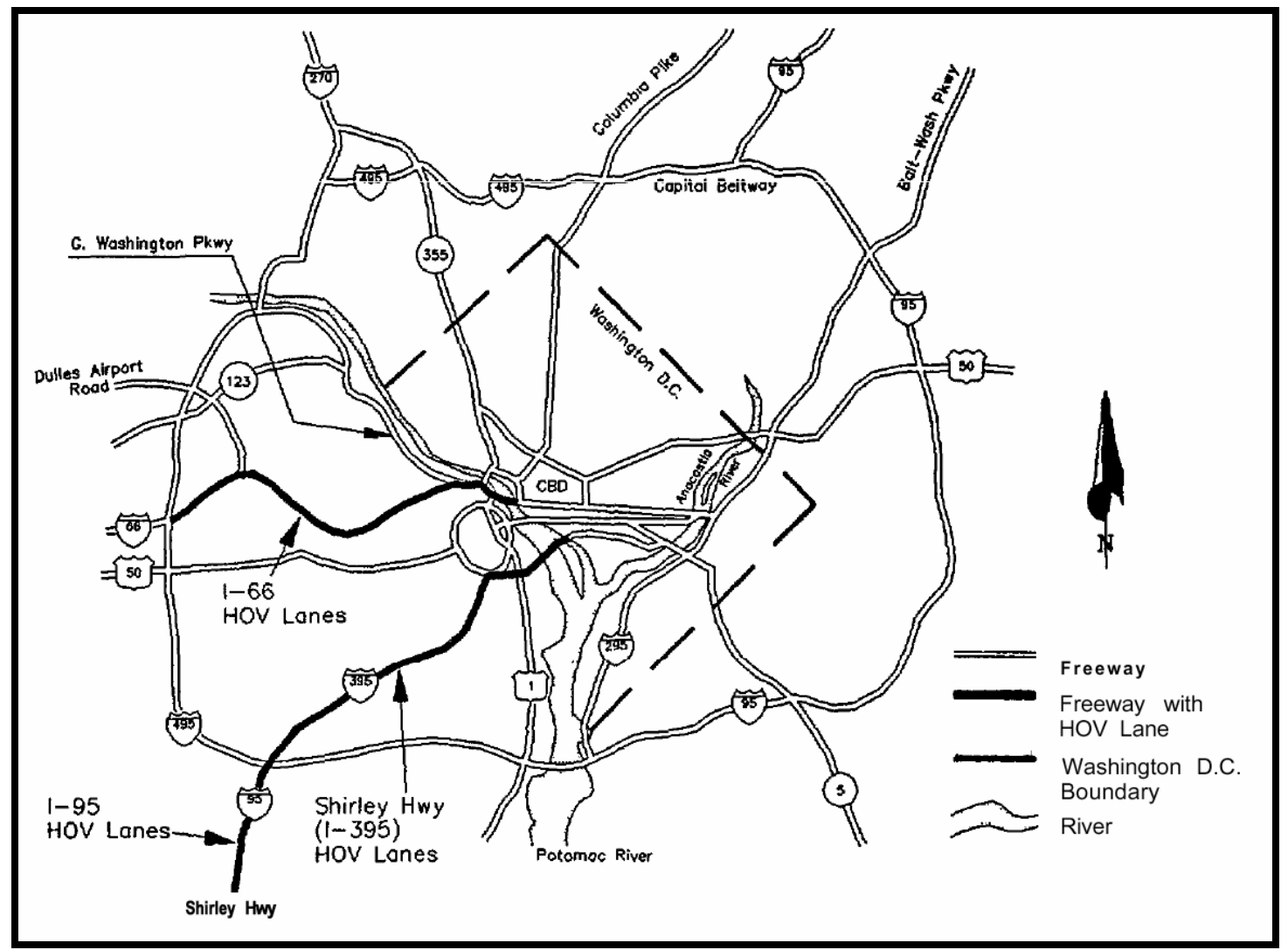

Figure 2.57: HOV System in Northern Virginia [Morrison \& Counts, 2005] 


\section{(a) I-395 Shirley Highway}

In 1969, a temporary bus-only lane was created through the construction work-zone during the reconstruction of I365 Shirley Highway corridor in suburban northern Virginia. In 1973, the final roadway alignment was opened as two reversible lanes for HOVs with four or more persons per vehicle. In each direction the HOV lanes are separated from the two general purpose lanes by a concrete barrier. The occupancy rules and hour of operation have since been modified, but the Shirley Highway Corridor currently continues to serve as a key HOV link in the region's HOV lane network. A 3+ occupancy requirement was implemented in 1989 and has not been changed since then. The HOV lanes were operated from 11:00 am - 11:00 pm inbound and 1:00 pm - 8:00 pm in the outbound direction until 1985. The operation hours were changed to 6:00-9:00 am in the inbound direction and 3:30-6:00 pm in the outbound direction in 1985. The lanes are opened to all traffic for the remaining portion of the day except when they are closed to reverse the direction of flow. The park and ride lots and direct access ramps are located at strategic points along the corridor. Figure 2.58, shows the AM peak hour utilization of the HOV lanes on Shirley highway. The average vehicle occupancy in Jan 1991 is 6.63 (18,406/2773) because of the large of number of buses traveling on the Shirley highway [Turnbull, 1992]

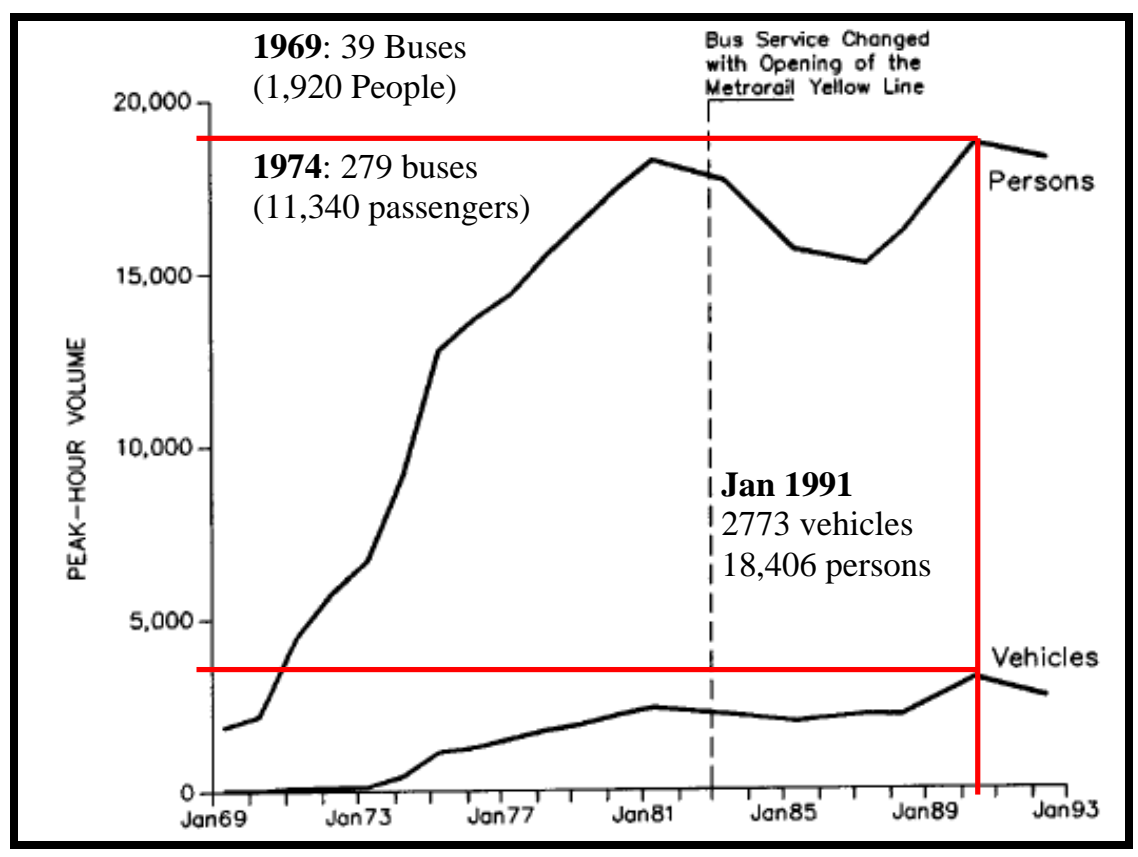

Figure 2.58: I-395 Shirley Highway HOV lanes AM Peak Hour Utilization [Turnbull, 1992]

In 2002, from 6:30 am - 9:30 am, Shirley Highway’s two HOV lanes carried a total of 31,650 people in 8,635 vehicles $(\mathrm{AVO}=3.66)$ compared to the four general purpose lanes which carried 23,510 people in 21,310 vehicles $(\mathrm{AVO}=1.10)$ [Morrisson, 2005]. The DC Metro transit's Blue and Yellow lines in this corridor carried 
16,700 people in the same time period. (Figure 2.59). The drastic increase in the number of vehicles on the HOV lanes over a period of 10 years was due to the 1989 reduction of HOV lane occupancy restriction to 3+.

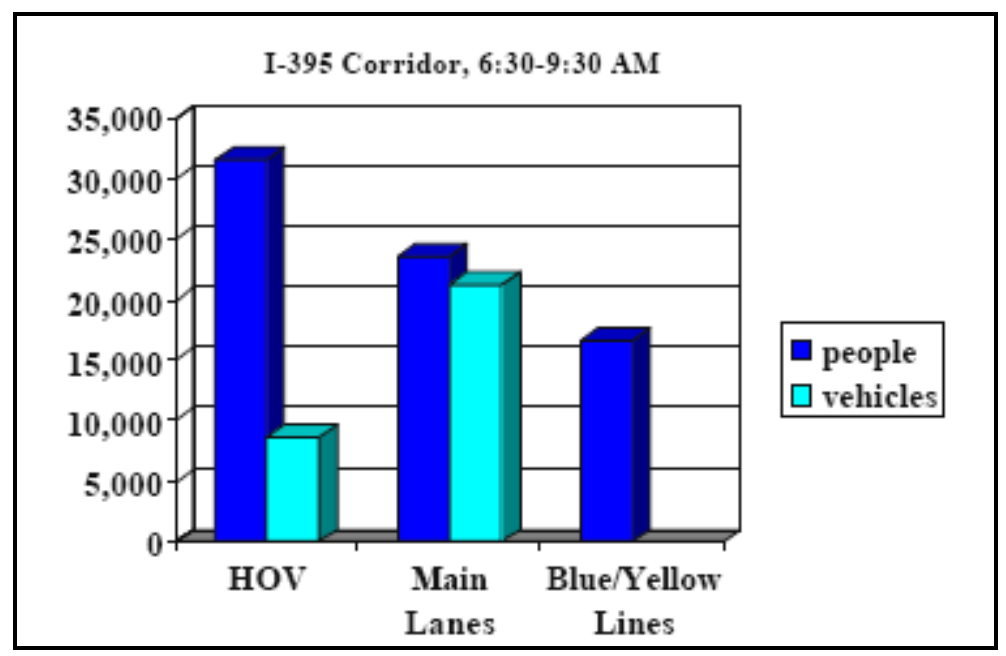

Figure 2.59: HOV vs GP Lane, Vehicle and Person Throughput on I-395 (2002) [Morrison \& Counts, 2005]

\section{(b) I-66 HOV Lanes}

In Northern Virginia, I-66 extends west from downtown Washington, D.C (Figure 2.60). The HOV lane was initially opened with a $3+$ occupancy requirement which was later changed to a $2+$. This led to a $60 \%$ increase in ridership, to 1700 vphpl in the HOV lanes. The I-66 HOV lanes carried a total of 20,940 people (in 9,825 vehicles) in 2002 between 6:30 am and 9:30 am from Virginia to the core areas. The Dulles toll road HOV carried 5800 people in 3220 vehicles many of which also use I-66 inside the beltway. In comparison, the Orange line of the DC metro rail transit carried 24,600 people from Virginia to the core areas of Arlington and DC and beyond (Figure 2.57).

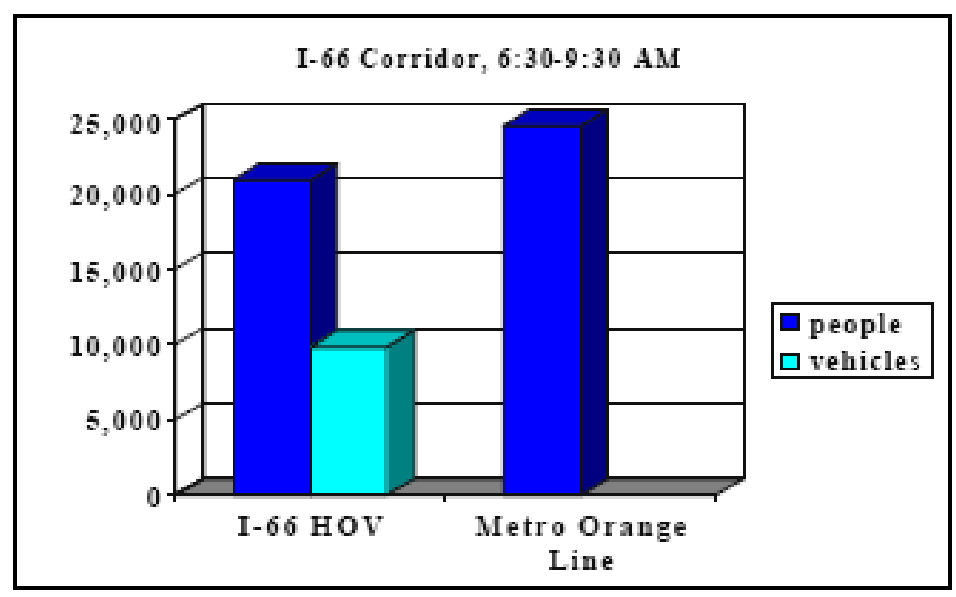

Figure 2.60: HOV Lane vs GP Lane vehicle and person throughput on I-66 (2002) [Morrison \& Counts, 2005] 


\subsubsection{Seattle, Washington}

The HOV system in Seattle, Washington comprised of approximately 205 lane-miles of HOV lanes in 2002. Most of the HOV facilities in the region were operated as a concurrent flow HOV lane 24 hours and seven days a week. The concurrent flow HOV lanes are separated from the GP lanes by a single solid white painted stripe. Therefore, the lanes have continuous access from the GP lanes. This section discusses the I-5N freeway HOV lanes in the Puget Sound region. HOV lanes have also been implemented on I-405, I-90 and SR-520 in this region (Figure 2.61). Table 2.33 presents a description of the HOV facilities in this region.

Table 2.33: HOV System in Washington [Nee, 2002]

\begin{tabular}{|c|c|c|c|c|}
\hline $\begin{array}{c}\text { HOV Corridors } \\
\text { (Opening Year) }\end{array}$ & Facility Type \{Length\} & Number of Lanes & $\begin{array}{c}\text { Operating } \\
\text { Hours }\end{array}$ & $\begin{array}{c}\text { Occupancy } \\
\text { Requirement }\end{array}$ \\
\hline I-5 North (1983) & $\begin{array}{c}\text { Concurrent Flow } \\
\text { \{7.7 mi SB and 6.2 mi NB }\end{array}$ & 1 each direction & $24 \mathrm{hr}$ & $2+$ \\
\hline I-405 (1986) & Concurrent Flow Lane & 1 each direction & $24 \mathrm{hr}$ & $2+$ \\
\hline I-90 (1988) & Concurrent Flow & 1 each direction & $24 \mathrm{hr}$ & $2+$ \\
\hline SR-520 (1988) & Concurrent Flow & 1 each direction & $24 \mathrm{Hr}$ & $\begin{array}{c}2+(\mathrm{EB}) ; \\
3+(\mathrm{WB})\end{array}$ \\
\hline SR-167 & Concurrent Flow & 1 each direction & $24 \mathrm{Hr}$ & $\begin{array}{l}2+(\mathrm{EB}) ; \\
3+(\mathrm{WB})\end{array}$ \\
\hline
\end{tabular}

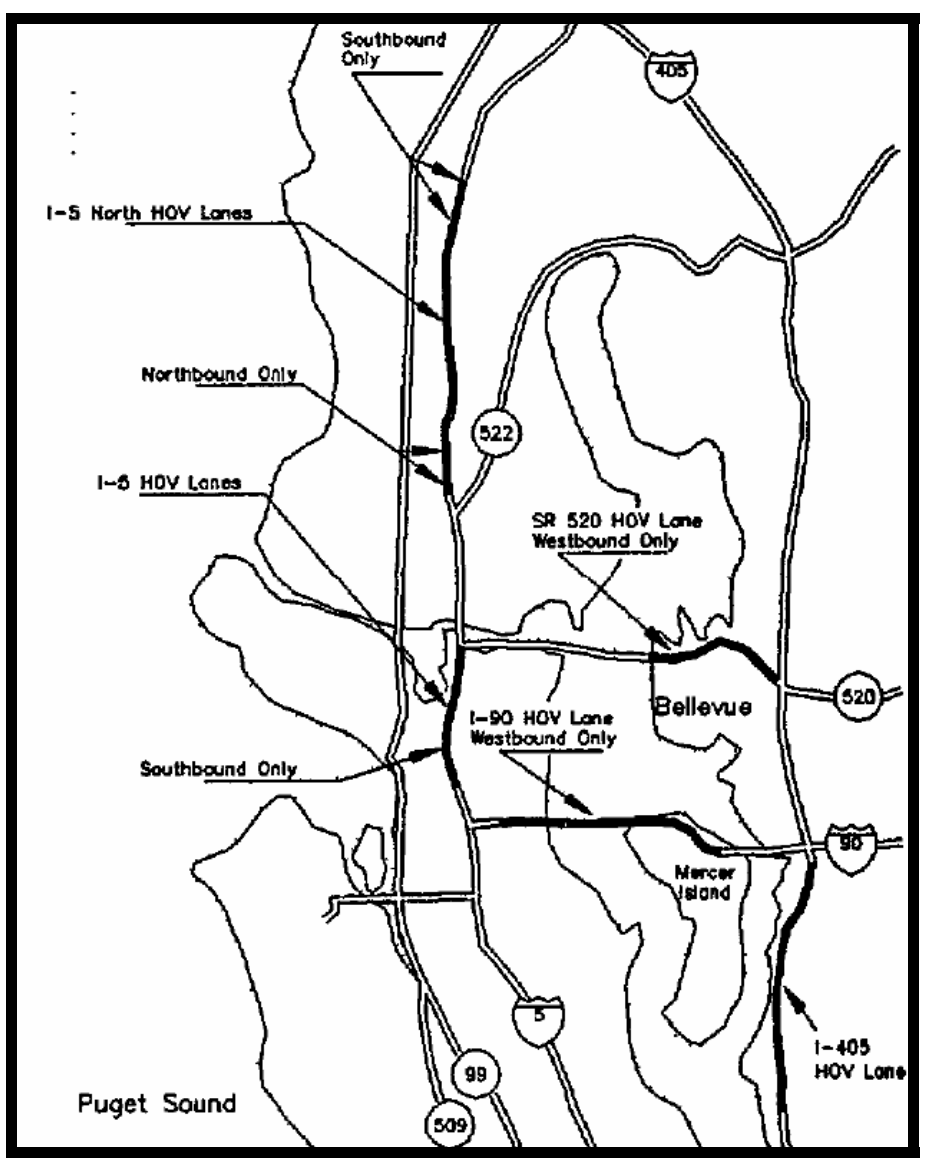

Figure 2.61: HOV Lane Facilities in Puget Sound Region, Seattle, Washington [Turnbull, 1992] 
The concurrent flow HOV lanes on Seattle’s I-5N were implemented in 1983 with a 3+ occupancy requirement and were operated as such until July 1991 when the occupancy requirement was lowered to 2+. The vehicle and person throughput on the I-5 HOV lanes since their implementation in 1983 is shown in Figure 2.62. There was a significant increase in the number of vehicles using the HOV facility after the occupancy requirement was lowered to 2+. The average hourly traffic profiles (in year 2002) on I-5 HOV and GP lanes are shown as Figure 2.63. The number of vehicles using the HOV lane reduces drastically to about 500 vphpl after the peak period. However the GP lanes are not congested (about $1500 \mathrm{vphpl}$ ) during the off-peak period and hence the passenger throughput on the HOV lane is almost the same as that at the general purpose lanes. The modal share of transit in Seattle exceeds $45 \%$. The HOV lane on SR-520 carries more people in buses than at all adjacent freeway lanes combined. Recent surveys of randomly selected drivers in the Seattle area found that $72 \%$ of single occupant drivers and 95\% or HOV drivers indicated that “HOV lanes are a good idea” [Fuhs and Obenberger, 2002]. A 1995 study in the Seattle area found that an HOV lane, operating at 20-25\% of its capacity, carried up to $15 \%$ more people than a conventional non-HOV lane [Johnston et al., 1995].

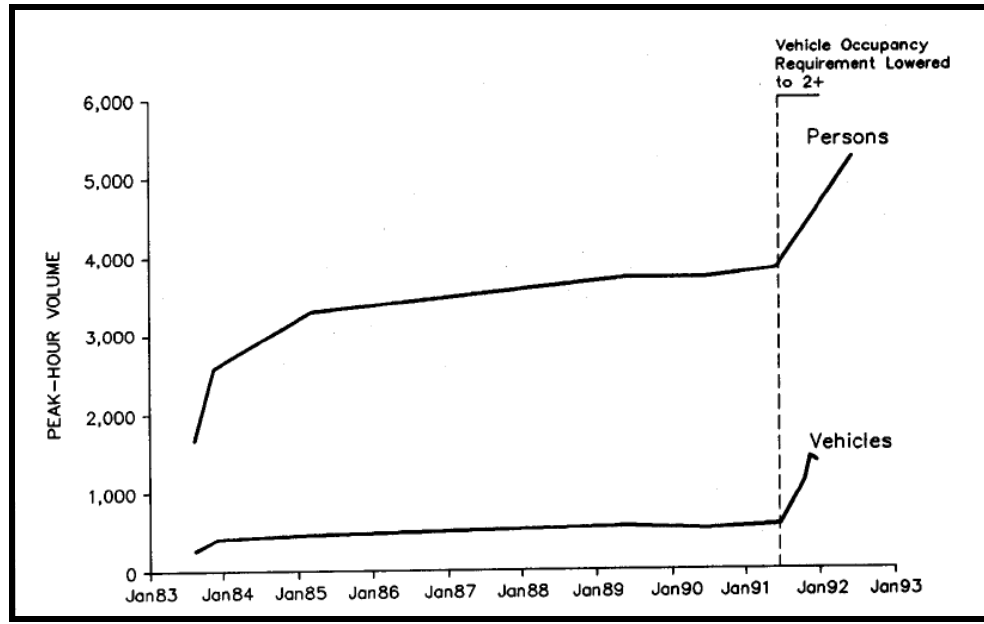

Figure 2.62: Person and Vehicle Throughput on the I-5 HOV lanes in Seattle, Washington [Turnbull, 1992]

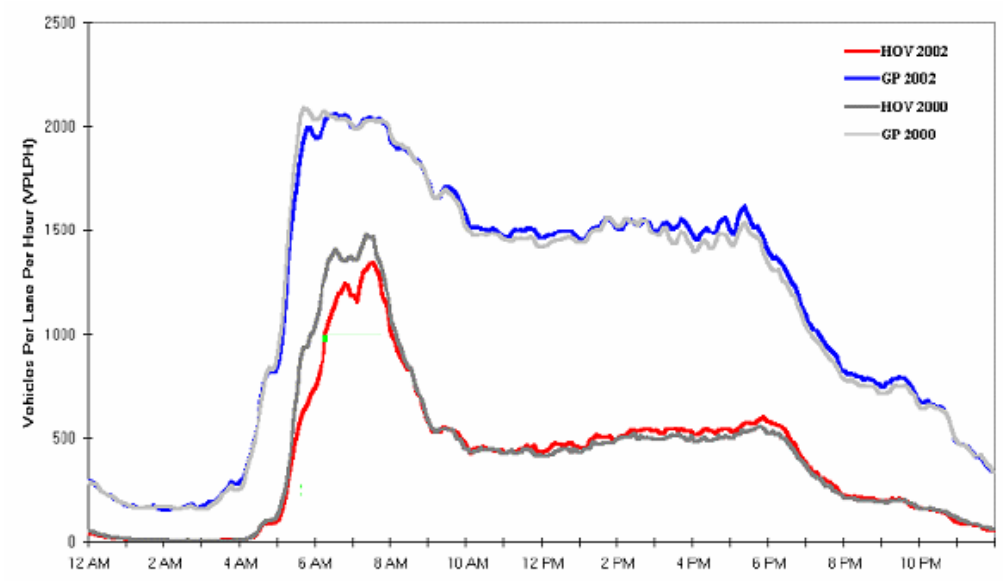

Figure 2.63: Average Hourly Traffic Profile on HOV Lane and GP Lanes on I-5 in 2002 [Nee, 2002] 


\subsubsection{New Jersey - HOV Failure}

In New Jersey, the implementation of the HOV lanes was initiated to promote and sustain transit ridership. In 1969, exclusive bus lane (XBL) was added on the Route 495 approach to Lincoln tunnel in New Jersey. It was a 2.5-mile lane "borrowed" from the off-peak direction traffic lanes. The project was implemented at an initial cost of less than $\$ 200,000$. It served over 700 buses and more than 30,000 passengers during the peak hour and continues to move approximately the same number into Manhattan each weekday morning.

The HOV lanes on two corridors (I-80 and I-287) in New Jersey were discontinued and were opened to all traffic in 1998. The closure of the HOV lanes on these corridors significantly affected the image of HOV lanes in New Jersey and raised questions about their effectiveness in countering congestion at several other places in the country as well. The HOV lanes on these freeways were closed in response to adverse public reaction and their inability to fulfill objectives (induce carpool) that were set forth.

The HOV lanes on I-80 were opened in 1994 with the objective of increasing the number of carpools and reducing congestion. One lane was added in each direction on the I-80 interstate and operated as a concurrent flow HOV lane in the morning (6:00 am - 9:00 am) and afternoon (3:00 pm - 7:00 pm) peak periods with 2+ occupancy requirement. I-80 served as a major radial corridor for commuters and commercial vehicles entering or leaving the New York metropolitan area. The commute trips were expected to have originated from communities in Morris County and from as far west as Pennsylvania. Hence the travel pattern in the corridor was conducive to being served by carpools, vanpools and buses. Before HOV implementation, in 1991, the number of lanes at the I-80 segments varied from two to four lanes. The construction of an additional lane and its usage as an HOV lane during the peak periods was expected to generate the following results [Parsons, 2000]:

- $\quad 900$ - 1,100 eligible vehicles carrying 2,250 - 2,750 passengers in EB direction; Morning Peak

- 1,300 - 1,500 vehicles with 3,250 - 3,750 passengers in WB direction, Afternoon Peak Hour

- $\quad$ 12-14 mins per trip travel time savings were expected

- $\quad$ 220-360 vehicles on the HOV Queue Bypass lanes

The facilities and programs that were recommended in a pre-HOV lane implementation study were [Turnbull, 2000]

- Park-and-Ride Facilities: New park-and-ride lots with 20-30 spaces were recommended. Trip origins were identified but no specific recommendations regarding park-and-ride facilities were made.

- Marketing Strategies: Also recommended to deal with the diverse trip patterns of the potential users.

However, the pre implementation study did not provide any specific guidelines on how to implement the supporting infrastructure. The importance of the support facilities was identified and although many of the components of the successful HOV facility were implemented, some of the critical factors were missing [Turnbull, 2000]. Only one park and ride facility was opened in on I-80 with 50 spaces. From 1994 to 1998 I-80 HOV lanes were operated with HOV traffic volumes consistently in the range of 900-1400 vehicles during the peak period. The average vehicle occupancy on the freeway increased from $1.23-1.30$ during this period. The violation rate ranged from 4.1-21.5\% which was marginally higher than the national average (10-15\%). However, I-80s HOV lanes were closed in 1998 because of the following reasons [Turnbull, 2000]: 
- The HOV lane implementation did not induce any new carpools on the freeway. The HOV traffic volumes observed on the freeway represented spatial shifts from adjacent facilities.

- The HOV lanes were implemented with an objective of carrying at least 700 vehicles per hour and the same number of people in the HOV lane as in the GP lanes. This objective was achieved but mainly because of carpoolers coming from other facilities.

- The HOV lanes were expected to be able to reduce congestion or at least maintain the same level of congestion in the GP lanes. However this objective was not achieved.

- The political pressure built-up due to the closure of I-287 HOV lanes just 10 months after their opening in January 1998 also contributed to the closure of the HOV lanes on I-80. I-287 HOV lanes were closed because the lanes did not induce carpooling. The absence of a significant job base at destination, absence of adequate park-and-ride lots and ride sharing programs were some of the factors associated to the failure of HOV lanes in inducing carpooling.

Before closing the HOV lanes on I-287, a marketing program was launched for informing people about the importance, goals, objectives and the success of HOV lanes at other places. However, the marketing failed to turn the tide in favor of HOV lanes due to the adverse public opinions formed because of media reports. The HOV facilities on both these corridors was a concurrent flow HOV lane constructed by adding a lane to the freeway, and operating in the peak periods with a 2+ occupancy requirement. The proposed shuttle services were not started on these corridors and the bus service was also not significant enough to generate the kind of success it did at some of the other places. The New Jersey DOT concluded that these facilities are good enough to eliminate congestion for two to four years but are not effective over the long term. After the closure of the HOV lanes, a 2002 report found that the facilities were still congested. I-80 was forecasted to reach a failure point by 2009. Vehicles were able to get to the ramps quicker because of the removal of the HOV lanes and as a result there was queuing on the ramps.

\subsubsection{Massachusetts}

The monitoring data collected in the summer of 2004, indicated that on the I-93 North HOV lane (southbound,) between 6:00 am-10:00 am, the HOV travel time was approximately three minutes whereas general purpose lane travel time ranged from three to eight and one-half minutes. The travel times on the HOV and the GP lane before 6:30 am were almost identical.

On the Southeast Expressway HOV facility, travel time on the northbound HOV lanes was approximately between five and eight and one-half minutes during the morning peak period (6-10 am). The travel time on the general-purpose lanes on the other hand ranged from approximately nine minutes to over 14 minutes. In the southbound direction, between 3:00 pm-6:00 pm, average travel time of less than seven minutes on the HOV lanes was reported compared to a travel time between nine to more than 14 minutes in general-purpose lanes. 


\subsection{HOV IMPLEMENTATION}

\subsubsection{Incentives for using a HOV Facility}

The primary incentives of using the HOV lane are travel time savings, trip reliability, reduced congestion, reduced fuel consumption, lower vehicle operating costs and improved air quality. However all these benefits arise primarily due to the formation of new carpools on the freeway. The implementation of the HOV facilities in Texas led to several important experiences [Martin, 2002]. It was observed that these facilities attracted travelers particularly from amongst the young, educated and white collar professionals. It was concluded that people with such socioeconomic backgrounds are more likely to use HOV system because of the following reasons:

- Save time,

- Avoid driving in congested traffic,

- Have time to relax,

- Have a reliable trip time,

- Public perception of HOV lanes being effective at serving their dispersed trip destinations, such as suburban office complexes and that the they are better than the general purpose lanes for a long distance commute.

However, many states (For example, California, Washington, Texas) have offered several other incentives to the HOV lane users in order to ensure the formation of new carpools. The implementation of ridesharing programs and park-and-ride lots ensures that travelers consider the HOV lane as an alternative while making a mode choice. The ridership programs ensure comfort to the HOV users in terms of ease with which the HOV facility can be accessed. However, more incentives such as reduced parking cost, parking availability and tax incentives have also been offered to the HOV lane users so as to encourage them to use the HOV lane.

\section{1) Parking Incentives}

Preferential parking can be made available for high occupancy vehicles at their destinations. This could in the form of reduced parking charges or availability of more parking spaces than for the single occupancy vehicles. The cost of single parking space in an urban area in California was approximately of the order of $\$ 15,000$ [Legislative Analyst's Office, California, 2000]. The variation in the cost is primarily because of the variation in land costs and type of parking facility from one location to another. An underground parking space in a central business district could run as high as $\$ 20,000$. Construction of a 300,000 square-foot downtown building might cost $\$ 4$ to $\$ 5$ million for parking spaces. Those costs are reduced when transit and ridesharing incentives or pedestrian amenities make parking spaces unnecessary. Operating an organized ridesharing program can reduce employee parking demand by an average of 22\%. Reducing just 10 spaces in a two-level underground parking structure could justify an annual expenditure of up to $\$ 4,000$ on a ridesharing program. Moreover, developers accrue higher returns on investment from increased floor space available for lease, as well as reduced daily operating costs for parking areas. 


\section{2) Financial Incentives (TEA-21 1998 Amendment)}

The 1998 amendment to the Transportation Equity Act for the $21^{\text {st }}$ century (TEA-21) created financial incentives related to commuter benefits for employers and employees. At least one of the following systems could be established as an incentive for the establishment of ride-sharing programs:

a) Employer-Paid Transportation Benefits

Here, employers could pay for their employees to commute via transit, carpool or vanpool. The employees do not pay taxes on the value of this benefit. Thus the employees are able to derive benefits in the form of reduced taxes. Employers also get a tax deduction for their expenses on the commuting services. This provides a significant saving to the employer over providing a salary increase of the equivalent dollar value.

b) Shared Cost Transportation Benefits

In this case, employers could share with the employee the cost of transit, carpool or vanpool. The employer pays a portion of the total commuting cost of the employee and gives them a tax-free benefit on this portion. Therefore the employees do not have to pay tax on this benefit. The employee pays the remaining portion of the commute cost using the pre-tax dollars. Hence, he employee does not have to pay tax even on the remaining portion of commute cost. Furthermore, the employer still gets tax deduction on the money spent to pay for commuting costs.

c) Pre-Tax Transportation Benefits

Employers pay for the commute cost for the employee and deduct an equivalent amount from the salary. The taxable income of employees is reduced as they have used his pre-tax dollars to pay for the commute. The employers do not have to pay payroll taxes on the amount deducted to pay for the commute costs.

- California encourages van-pooling through the Ridesharing Vanpool Revolving Loan Fund and Grant Fund by providing loans or grants to people to purchase or lease vanpool vehicles

- Connecticut is considering eliminating registration fees for vanpool vehicles

In addition flex-time policies could be considered at work places where several agencies in the downtown CBD can coordinate to start their offices at different times during the morning. The flex time policies can be complemented with a percent ridesharing goal for private and state employees at their respective work places. For example, California allows a tax credit to employers who purchase or lease certain vehicles for an employersponsored ridesharing incentive program Other states are also considering tax incentives for those who purchase or lease certain vehicles. California also allows a tax credit to employers for the costs of providing subsidized transit passes for employees [Legislative Analyst's Office, California, 2000].

Another proposed regulatory incentive includes highway user fees, or "congestion pricing". This strategy would establish toll roads on which single-occupant vehicles would be charged an increased price during peak commuter periods. The opening of high occupancy vehicle lanes to the SOVs can also be considered provided the SOVs are made to pay for using the facility. This concept of a High Occupancy Toll Lane has been implemented at several locations in California. 


\subsubsection{Implementation Guidelines}

Over $130 \mathrm{HOV}$ projects have been implemented in about 30 cities in the country comprising of more than 2500 lane miles. As discussed in the previous sections, various supporting facilities are implemented in conjunction with the HOV lanes in order to ensure success of the HOV facility. Express bus services, ingress/egress ramps, park-and-ride

lots, rideshare programs, HOV bypass lanes at freeway ramp meters, enforcement areas and policies, marketing programs and the other physical and operational components play an important role in the overall success of the project. Most of the HOV facilities across the country have provided travel time benefits, reduced congestion, increased average vehicle occupancy, reduced fuel consumption, improved air quality and enhanced transit operations. HOV projects are capable of significantly reducing congestion and providing other benefits to travelers on a freeway. However, a systematic approach with proper planning, design, implementation and coordination from various local transit and transportation agencies, enforcement personnel and other agencies is required. This section presents a set of guidelines based upon the synthesis study that can be used to determine the economic feasibility of HOV lanes and can help in planning the implementation of HOV lanes on congested freeways.

\subsubsection{Existing Traffic Analysis}

The first step, before implementation of the HOV facility is considered, is to analyze the existing traffic conditions on the freeway. HOV projects are congestion dependent. Commuters are reluctant to carpool or ride a bus if they do not see a significant difference in terms of travel time and speed between HOV and GP lane. The presence of recurrent congestion on the freeway with recurring peak hour speeds of $30 \mathrm{mph}$ or less can be considered as warrants for a successful HOV lane implementation. Significant congestion should exist on the freeway for at least 1 hour of morning and evening peak periods. However, the traffic volume in the HOV lane should be predicted before the implementation of the HOV lane. The hourly traffic volume along the freeway corridor should be analyzed in order to determine the directional nature, magnitude (v/c ratio), hours and origin of congestion.

The Texas Department of Transportation recommends that freeway corridors with an average daily traffic of at least 25,000 vehicles per lane should be considered as an HOV lane candidate. The Washington DOT found that the HOV lanes are well used during the off-peak periods when congestion exists, which increasingly extends beyond the traditional peak travel periods. The average number of people in each car during the peak period was found to be more than the expected number of people during the off-peak periods, especially on the weekends.

A Seattle study established that 30-60 percent of the weekend traffic is HOV eligible and when congestion occurs these vehicles use the HOV lanes. Hence existence of congestion can induce people to change to HOVs thereby resulting in a successful HOV implementation. Unless severe congestion exists daily on the freeway, HOV lanes are probably not a viable alternative.

\subsubsection{Travel Pattern}

The likelihood of achieving success increases significantly if the HOV lanes are implemented on the freeways where the travel pattern is conducive to being serviced by rideshare alternatives such as carpool, vanpool or buses. More than $50 \%$ of the existing HOV facility route miles have been implemented on the radial freeway corridors that are 
mainly used for work trips from residential suburbs to densely developed activity centers such as a CBD. Most of the non-radial HOV lane corridors are located in Southern California where there is a significant HOV lane demand. However agencies that are implementing the HOV facility for the first time should ensure (by starting with a radial corridor HOV lane implementation) that the travel pattern on the corridor is favorable unless significant HOV lane demand already exists on the corridor.

For example, in Houston, exclusive reversible HOV lane facilities are implemented on I-10, I-45N, I-45S, US-290 and Eastex freeways because all these routes lead the traffic to the downtown areas of work. The existence of a job base at the end of an HOV facility has proved to be very crucial in the success of the Houston HOV system. The bus service operating on the Houston HOV corridors operates in the radial direction from the downtown CBD to the residential suburbs thereby giving a good option of a single mode travel to work in less time. The success of a bus service on HOV lanes is dependent on the travel pattern in the region. If there is not a significant job base beyond the HOV lanes along with severe roadway congestion during the peak periods it will be difficult for the HOV lanes to attract riders.
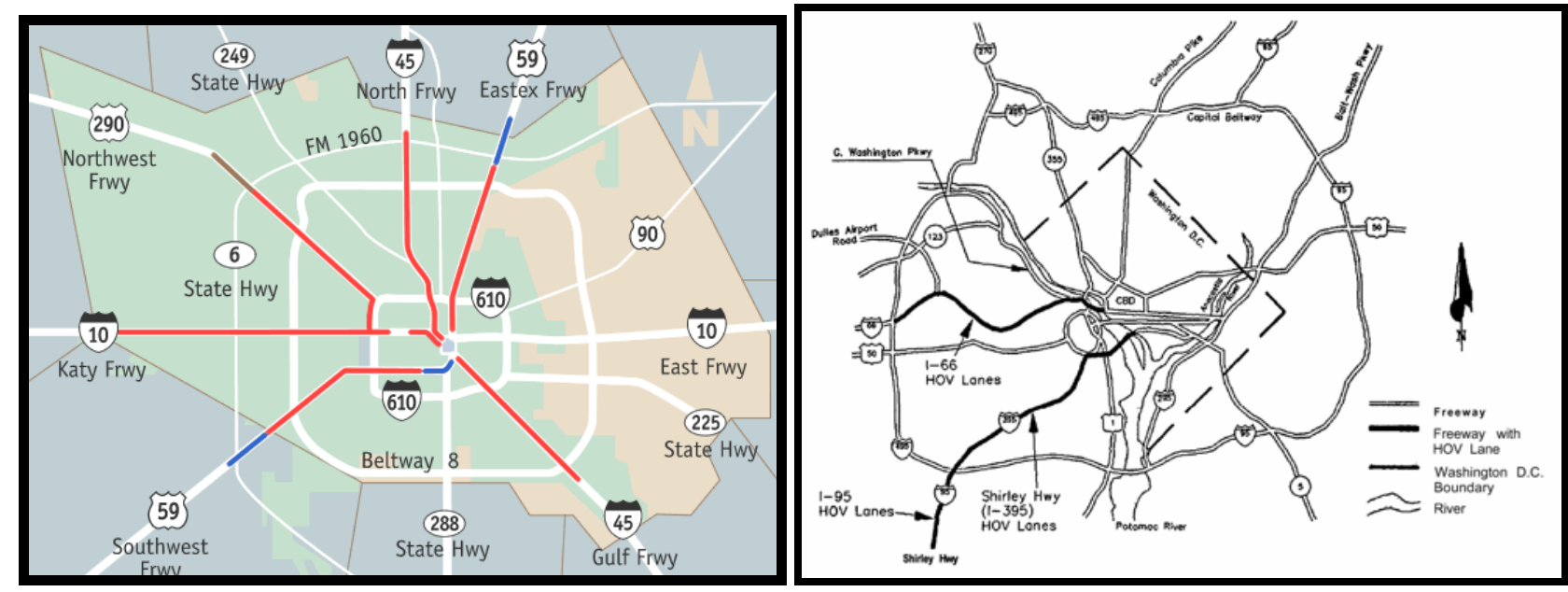

Figure 2.64: HOV System in Houston and Northern Virginia with CBD as the Destination

The HOV system in Northern Virginia is another example of a very successful HOV system where HOV lanes serve the CBD as the destination. As of 2005, approximately 190,000 people travel inbound on transit or in autos to the core areas of Arlington and the CBD during the morning rush hours of 6:30 am - 9: 30 am which is only slightly different from the HOV restricted times. Figure 2.64 shows the map of the Houston HOV system serving the CBD as the destination.

Most of the other HOV projects implemented in the country have also been constructed on freeways that were primarily used for work trips and where congestion occurred because of a significant number of vehicles heading to/from work. Route 55, in California serves as a heavily traveled link between the residential areas in eastern Orange and river-side counties and the employment centers in central Orange County. The 11-mile HOV stretch was opened in 1985 as a concurrent flow lane HOV facility with one HOV lane in each direction. The facility 
was open on a 24-hour basis with 2+ occupancy requirement. The HOV lanes on Interstate 15 in Salt Lake City, Utah also connect the suburban residential areas to the downtown CBD. The 16 mile HOV facility is provided with only one direct access ramp near the downtown CBD to provide direct access to and from arterials into the HOV lane.

The goal of the HOV lanes is to induce people to carpool, which is difficult if the trip purpose is not the same for most of the traffic on the freeway. The HOV lanes should be able to carry the people from the origin to the destination using only one mode and without making stops that have a waiting time. It is unreasonable to expect the commuters to make several stops on their trip at park-and-ride lots waiting for the formation of carpools. A study of the travel pattern on the freeway hence plays a major role in the success of the HOV facility. Turnbull and DeJohn (2000) identified that the regional population should be at least 1.5 million for the successful implementation of the HOV facility.

\subsubsection{HOV Lane Type}

The decision on the type of the HOV lane that should be implemented depends on the level of congestion on the freeway. Based on the synthesis study, several trends were observed in the selection of the type of HOV lane. For example, if recurrent congestion exists on the freeway for two to three hours in each direction, the implementation of a concurrent flow lane HOV facility with operation during the peak periods only can be considered. On the other hand if congestion extends more than ten to twelve hours in each direction, an exclusive 2-directional HOV facility could be considered. If congestion is present for five to six hours separately in each direction and the directional split is more than $66 \%$ an exclusive reversible HOV lane can be constructed in the freeway median. For example, the exclusive barrier separated reversible HOV lanes in Houston operate for five hours in the morning and five hours in the afternoon in each direction. If the congestion in each direction occurs for two to three hours only and the directional split during the peak periods is more than $66 \%$, a contraflow lane HOV facility can be considered. These numbers are based on the trends observed in the implementation of the HOV lanes. An economic evaluation of one or more HOV lane types should be performed to justify the economic feasibility. The guidelines provided above are a good starting point to select the alternatives that should be evaluated.

The approach that will be used for the construction of the HOV lanes is also important. There are two ways of constructing the HOV lane: add-a-lane approach and take-a-lane approach. Almost all the HOV projects implemented in the country over the last three decades have been based on the add-a-lane approach. While the takea-lane approach might prove to be economically feasible, the implementation has often not been supported by the various sectors of the society. The add-a-lane approach may involve the addition of a new HOV lane by either purchasing the right of way or by utilization of the existing median and shoulders along with a reduced lane width. The construction of enforcement areas and slip ramps should also be considered in estimating the right of way required. In the past, the add-a-lane approach has often been the preferred one because of fear of public opposition and political pressure. In 1976, a "take-a-lane” approach based HOV project on Santa Monica Freeway in California was closed because of adverse effect on traffic in GP lane and public criticism. Most of the HOV lane projects 
implemented in California since then were based on add-a-lane approach. Most of the other states have also followed the add-a-lane approach for the construction of the HOV facility.

The addition of a lane on the freeway could require the purchase of the right of way and hence could result in significantly higher costs. However the cost of right of way can be minimized or can be eliminated completely if the lane is added in a freeway median or additional space is made for the incorporation of HOV lane by re-striping of shoulders. The construction of enforcement areas and slip ramps should also be considered in estimating the right of way required.

In addition to the operation hours and HOV lane type, occupancy requirement on the HOV lane also has to be decided. According to Caltrans (2003), the occupancy requirements for HOV facilities should be based on the following considerations:

- Maximizing the person per hour throughput.

- Allowing for HOV growth and increased usage of HOV facility.

- Maintaining a free-flow condition, preferably a level of service C.

- Conforming to the occupancy requirements of the region, particularly connecting HOV routes.

- Completion of a region's HOV system or adjacent HOV facilities could redistribute the HOV traffic, thereby making occupancy adjustments unnecessary.

The occupancy requirement on the HOV lanes should be such that the traffic volume in the HOV lane is sufficiently large so that the HOV lanes do not appear empty. For example, California uses a threshold of atleast 800 vehicles per hour in the HOV lane. The guidelines based on current occupancy levels, as shown in Table 2.34, are considered a good starting point for determining the qualifying occupancy criterion.

Table 2.34: Occupancy Restriction Based on Current Average Occupancy (JHK and Associates, 1990)

\begin{tabular}{|c|c|}
\hline Current Average Occupancy & Occupancy Restriction \\
\hline$<1.2$ & $2+$ \\
$>1.2$ & $3+$ \\
$>1.4$ & $4+$ \\
\hline
\end{tabular}

\subsubsection{Support Facilities}

The implementation of support facilities requires the following considerations:

a) Enforcement Areas \& Policies

The construction of enforcement areas is required in the absence of technology that can be used to detect violators in the HOV lane. The number of the enforcement areas, location and the design of each enforcement area are the variables that need to be considered. The number of enforcement areas required for a HOV facility depends on the HOV lane length, separation from general purpose lane, number of ingress/egress points. Caltrans (2003) recommends the following design guidelines for the enforcement areas:

- Continuous paved median $4.2 \mathrm{~m}$ or wider in both directions for the length of the HOV facility. If space is available, additional enforcement areas may be built in conjunction with the $4.2 \mathrm{~m}$ median. 
- When 4.2 m continuous paved medians shoulders are not possible, paved bidirectional enforcement areas with 2-3 miles spacing should be built. A separation in the median barrier should be provided for motorcycle officers to patrol the facility in both directions.

- Where median width is limited, some combination of the above two configurations should be provided.

- Paved directional enforcement areas with 2-3 miles spacing and staggered configuration should be the next alternative when space limitations do not allow any of the above considerations.

- When space is limited, directional enforcement areas should be located wherever right of way is available.

Figure 2.65 shows typical enforcement areas for various median configurations that are used by Caltrans. The typical length of the enforcement area is around $400 \mathrm{~m}$ with a minimum set at $300 \mathrm{~m}$. The minimum thresholds are set to ensure the safety of the patrolling officer. Therefore, Caltrans (2003) recommends that enforcement areas should be avoided at ingress/egress points for Buffer/ Barrier-separated facilities, at curves, and should not be placed near over crossings, so as to prevent officers from thrown or falling objects. Caltrans also recommends that the right shoulder should not be sacrificed for the construction of enforcement area in the median except for extreme circumstances and only with necessary approvals and that the buffer should be carried full width adjacent to the enforcement area for buffer-separated HOV facilities.

Enforcement areas can be designed separately for low speed and high speed zones. The implementation of slow speed enforcement areas is generally considered at access points to the HOV lane where the vehicle speeds are usually below $45 \mathrm{mph}$. Cothron (2003) recommends the following geometric design features for low speed enforcement areas:

- $\quad$ The enforcement area should be at least 100 feet (30 meters) in length and preferably up to 200 feet (60 meters) on high-volume facilities, not including approach and departure tapers.

- $\quad$ The enforcement area should be at least a width of 14 to 15 feet (4.3 to 4.6 meters).

- $\quad$ The enforcement area should have an approach taper of 2:1 or 30 feet (9.1 meters).

- The enforcement area should have a departure taper of 10:1 or 150 feet (45.7 meters) to allow for vehicle acceleration into the lane.

High speed enforcement areas are generally considered along the HOV facility length at facilities that have multiple at-grade access points or that are not physically separated from the general purpose lanes. Cothron (2003) suggests the following geometric design guidelines for the implementation of high speed enforcement areas:

- The length of a high-speed monitoring area should be at least 100 feet (30 meters), not including the approach and departure tapers. For monitoring and apprehension, the preferable length is 1300 feet (396 meters).

- $\quad$ The enforcement area should be at least 14 to 15 feet (4.3 to 4.6 meters) in width.

- The enforcement area should have an approach taper of 20:1 and a departure taper of 80:1 or higher, or it may be controlled by general freeway criteria as required to fit in the design for proper acceleration to the design speed.

- Enforcement areas should be provided at a minimum interval of 2 to 3 miles (3.2 to $4.8 \mathrm{~km}$ ) along the mainline managed lane facility. 


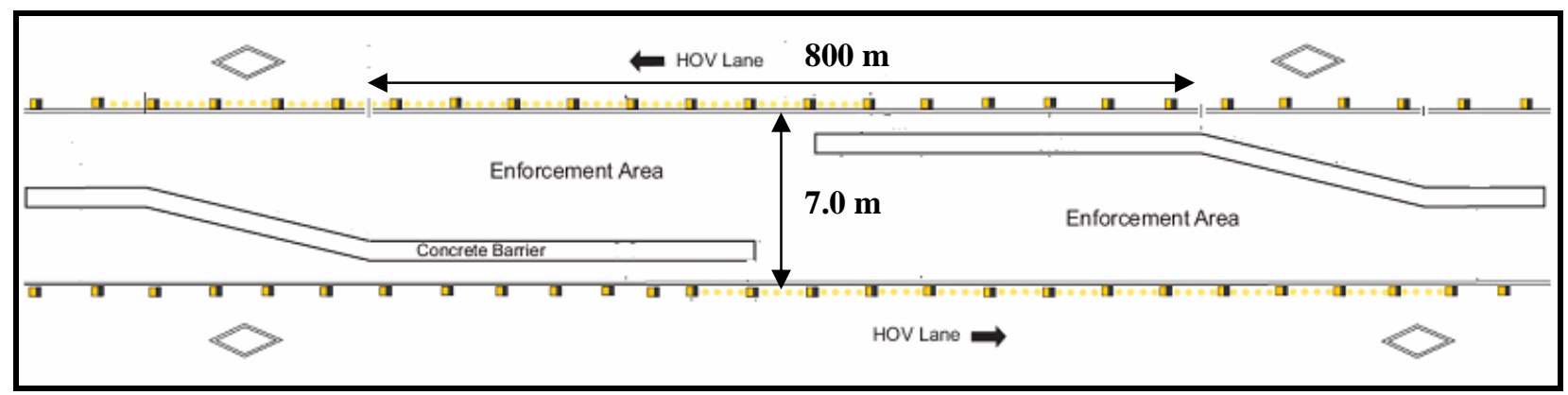

(a) Bi-directional Enforcement Area for 7.0 Medians

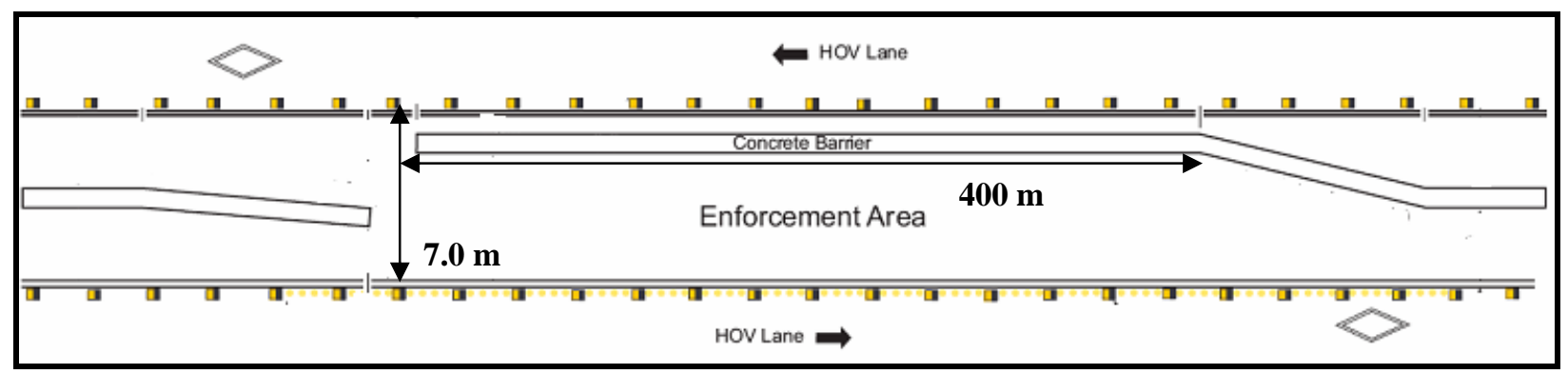

(b) Directional Enforcement Area for 7.0 m Medians

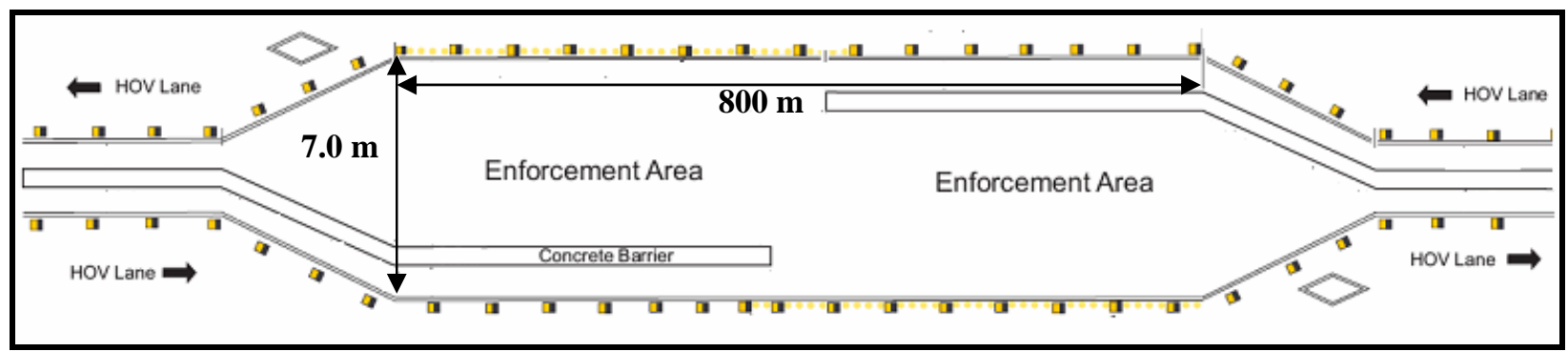

(d) Bi-Directional Enforcement Area for Medians Less than 7.0 m

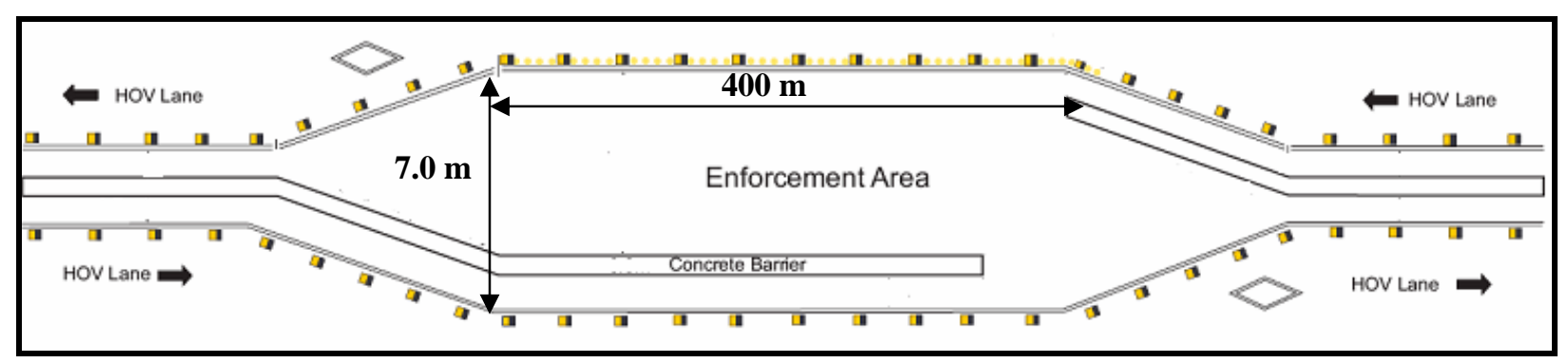

(c) Directional Enforcement Area for Medians Less than $7.0 \mathrm{~m}$

Figure 2.65: Directional and Bi-directional Enforcement Area For Different Median Widths [Caltrans, 2003] 
Enforcement of occupancy requirements can be greatly facilitated by appropriate physical design. Providing adequate shoulder length can allow police officers to monitor and to pull over the violators. The design of enforcement policies should consider the hours of enforcement, decide between random and fixed schedule enforcement, number of police deployments during the enforcement hours and the fines that shall be imposed on violators in the HOV lane. Self enforcement policies such as the HERO program in Seattle Washington, can also be implemented. ITS techniques for identifying violators in the HOV lane have not yet been accepted as a reliable enforcement technique [Parsons, 2005]. While the automatic occupancy detection approaches are being evaluated, the construction of enforcement areas is essential to regulate the violation rate.

\section{b) Park-and-ride lots / Transit Centers}

The estimated of demand and size of park-and-ride lots is a major challenge. The location, number and the size of the park-and-ride lot required for supporting the HOV facility may vary from one location to another depending upon the travel pattern on the freeway. The construction of park-and-ride lots and transit centers should be considered at locations where HOV traffic enters the freeway. Park-and-ride facilities may be strategically located near the direct access ramps and slip ramps or in between them. The location of the park-and-ride lots can also be considered at places adjacent to the freeways that are connected to the freeway by frontage roads. The provision of parking at the private shopping parking lots should be explored to minimize the costs of construction of a park-andride lot. The strategic location and the number of park-and-ride lots play a very important role in inducing carpooling and forming a public opinion about the HOV lanes. A long ride to the parking facility and from the parking facility to the HOV lane can reduce the tendency of the people to carpool.

\section{c) Direct Access Ramps/ Slip Ramps}

Direct access ramps are grade-separated HOV lane access ramps and are generally the most expensive component of the HOV system. The construction of direct access ramps for part-time HOV facilities is not considered often, unless they provide significant travel time and safety benefits or when it is estimated that a large number of carpools will use the HOV lane. When direct access ramps are not constructed, slip ramps are used to provide access to the HOV lane. The construction of direct access ramps for exclusive HOV facilities may be justified, given the hours of HOV lane operation, the percentage of the annual average daily traffic using the HOV lane and the reduction in the number of conflicts and crashes during merging/diverging into/from the HOV lane.

The location and the number of slip ramps for ingress/egress depends on the number of HOVs formed in a region, the point of their origin and the average trip length of a high occupancy vehicle on the freeway. For example, Caltrans (2003) guidelines for the implementation of the HOV facilities specify that selection of locations for Barrier and Buffer-Separated HOV facilities should be based on the following criteria:

- When adjacent to park and ride facilities

- To serve ramps with high number of carpools

- To serve high volume ramps 
- To serve every freeway to freeway connection

- To support and encourage ride sharing programs (HOV demand/usage)

- To assist in the modification of local commute patterns (may be at local request)

- When requested by transit districts

- To help balance and optimize interchange operational level of service within a local jurisdiction within a corridor or within a region

Closely spaced ingress/egress locations can increase violation rate and adversely affect the operation of HOV lanes. On the other hand large spacing between these openings can prevent short freeway trips from using the HOV facility. For example, in the case of I-15 freeway in Salt Lake City, it was observed that HOV vehicles exiting the freeway during the PM peak hour in South bound direction had to change 4 GP lanes after getting out of HOV lane. This discouraged short freeway trips from using the HOV facility. Consideration of inside ramps for HOV lanes was recommended in the evaluation study in order to increase the utilization of the HOV lanes.

The spacing between the ramps has to be decided in an optimal manner. Closely spaced ramps could lead to situations in which merging from or into the HOV lane may create queuing in the HOV or GP lane. For example, ingress/egress openings provided near ramp locations on a freeway that has many closely spaced ramps in a bottleneck section could create conflicts in the flow of both the HOV lane and the mainline facilities thereby reducing the level of service and increasing the number of crashes. On the other hand large spacing between these openings can prevent short freeway trips from using the HOV facility.

\section{d) Signing and Pavement Marking}

The Manual of Uniform Traffic Control Devices (MUTCD, 2003) provides guidelines on the placement and types of HOV lane signs. Additional guidelines on the placement of signs can be set by the respective state transportation agencies if required. Caltrans (2003), provides the following guidelines for HOV lane signing and pavement marking:

- The design and placement of HOV signs and markings should indicate whether they are intended for vehicles in the HOV lane or the mixed flow lane

- Are able to convey a clear message about the hours of HOV lane operation

- Provide clear directions for ingress/egress areas

- Provide Information about violation fines and occupancy requirements should be clearly displayed

- Minimize the impact of differential speed between the HOV lane and general purpose lane, lack of passing opportunities in the HOV lanes (if any) and frequent weaving and merging actions

\section{e) Ridership Programs}

Some of the ridership programs that have been implemented across the HOV facilities in the country were discussed in Section 2.3. The presence of such ridership programs and ride-matching services can facilitate the formation of carpools. The ridership program should be developed depending upon the scope of HOV implementation in the region and in coordination with the transit agencies and employers at the destination of the HOV facility. A zone by 
zone analysis of the freeway travel demand combined with traveler surveys can help in the identification of the type of ridership programs that should be implemented in the region. California and Washington maintain databases of riders who are interested in carpooling and lease vans to groups of riders to encourage carpooling. Such ridership programs can enhance the effectiveness of the HOV lanes. The implementation of ridership programs should be considered before the implementation fo the HOV facility so that a significant number of vehicles use the HOV lane once they are implemented.

\section{e) Bus Service}

The passenger throughput and the level of service in the HOV lane can be significantly enhanced if more number of buses use the HOV lane. The reduction in the number of single occupancy vehicles in the GP lane will increase thereby improving the level of service in the GP lane. The presence of an efficient bus service can also affect the number of carpools formed. People might prefer traveling in the buses instead of carpooling on the HOV lanes. For example, in Houston, about $16 \%$ of the HOV lane bus passengers were carpoolers and shifted to buses because of efficient operations.

\section{f) Incident Management}

The architecture of the incident management and response system should be developed to ensure that the performance of HOV lanes is not significantly affected by incidents in the HOV and the general purpose lane. A set of guidelines should be developed that clearly define the scenarios when the opening of the HOV lane to the general purpose lane traffic would be considered and vice versa depending upon the number of general purpose or HOV lanes blocked during an incident.

\section{g) Carpooling Incentives}

The number of carpools formed can be enhanced by providing carpooling incentives in addition to the travel time savings and improved level of service. Incentives such as reduced parking cost at destination, parking availability at destination and tax incentives have been offered to the HOV lane users in order to provide them with more incentives to travel in a HOV lane. For example, California encourages van-pooling through the Ridesharing Vanpool Revolving Loan Fund and Grant Fund by providing loans or grants to people to purchase or lease vanpool vehicles. Further, California allows a tax credit to employers who purchase or lease certain vehicles for an employer-sponsored ridesharing incentive program. California also allows a tax credit to employers for the costs of providing subsidized transit passes for employees [Legislative Analyst's Office, California, 2000]. The provision of such incentives or other user incentives could significantly increase the HOV lane use and reduce congestion.

\section{h) HOV Project Marketing \& Stated Preference Surveys}

An effort to determine the views of the public on the HOV project should be made before the construction of the facility. This can be done in the form of a survey where people can be informed about the infrastructure that will be developed as part of the HOV project, the cost of the project and the expected benefits that they are likely to derive 
from the project. The survey can be used to ask the people about how they feel about the HOV lanes. The survey can also be used to determine the kind of marketing programs that should be launched so that the travelers are informed about the goals and objectives of HOV lanes and how they are better than the construction of additional freeway lanes.

For example, a WSDOT HOV lane community perception study was conducted in September 2001 before the implementation of HOV lane on I-5 in Vancouver. Approximately 202 households were surveyed with a margin of error of $6.89 \%$. Ninety-six percent of those surveyed drove or carpooled on I-5, traveling one-way for 25.4 minutes on an average. The following conclusions were drawn from the survey [Parsons, 2001]:

- Overall support for the WSDOT HOV lane was found to be 58\%, with $31 \%$ stating that HOV lane is an excellent idea and about $27 \%$ stating that it is a good idea. Approximately $50 \%$ of the residents who generally drive alone supported the HOV lane.

- The reasons that were most often cited for the support of the HOV lane facility were as follows:

o Encourages carpooling/ benefits carpoolers

o Less traffic tie ups/ less cars

o Get there faster/save time

o Traffic moves better/ faster

- The reasons most often cited for opposition of permanent HOV lane adoption were:

o Would cause more delays/ worsen the problem

o Not fair to single drivers

o Not used enough/ waste capacity of lane

- It was concluded that pre-opening public perception of the HOV lane was positive in general. The support for the HOV lane was highest in Vancouver and Hazel Dell/ Salmon Creek area and somewhat lower in Battle ground and North Clark County areas.

- Approximately $48 \%$ of the respondents felt that the HOV lane should be permanently adopted while $36 \%$ felt that it should not be adopted permanently. About $16 \%$ of the respondents were undecided. Fifty-six percent of the Vancouver residents and $48 \%$ of the residents of Salmon Creek/ Hazel Dell zip code cluster supported permanent adoption of the HOV lane. However, 48\% of the residents in Battle Ground and 46\% in North Clark County opposed permanent adoption of the HOV lane.

- It was found that citizens in the Battle Ground and North Clark County typically drive alone ( $80 \%$ and $73 \%$ of their populations respectively). On the other hand, $37 \%$ of the Vancouver residents were found to drive or ride with someone else.

The survey also helped in the identification of areas where the support for HOV lanes was not good. Such information can be used to direct and develop the HOV lane marketing programs depending upon the requirements in the region. The reasons that are most often cited for the support of the HOV lane facility and that are cited in opposition of the HOV lane adoption can also help in the development of the marketing strategy for HOV lane.

Table 2.35 summarizes the guidelines for the implementation of the support facilities. 
Table 2.35: Factors to be considered in the Implementation of Support Facilities

\begin{tabular}{|c|c|}
\hline Support Facility & Factors To Be Considered \\
\hline \multirow{4}{*}{ Enforcement Areas and Policies } & Type of Enforcement Policy, Enforcement Hours \\
\hline & Daily Deployments, Fines \\
\hline & Number of Enforcement Areas, Location \& Design \\
\hline & Technology Based Enforcement \\
\hline \multirow[t]{4}{*}{ Park and Ride Lots } & Number of Park and Ride Lots Required \\
\hline & Number of Spaces in each Parking lot \\
\hline & Location of the Park and Ride Lots \\
\hline & Parking Facility Ownership and Costs \\
\hline \multirow[t]{2}{*}{ Transit Centers } & Number of Transit Centers \\
\hline & Location of Transit Centers \\
\hline \multirow[t]{3}{*}{ Direct Access Ramps/ Slip Ramps } & Number and Location of Access Ramps \\
\hline & Purpose of Access Ramps \\
\hline & Safety Benefits, Travel Time Benefits, Cost-effectiveness \\
\hline \multirow[t]{2}{*}{ Signing and Pavement Marking } & Placement and Location of Signs \\
\hline & HOV lane Separation from GP lane, Buffer markings \\
\hline \multirow[t]{2}{*}{ Ridership Programs } & Types of Programs that will be Implemented \\
\hline & Scope and Cost of each Program \\
\hline \multirow[t]{3}{*}{ Bus Service } & Number of Buses Using the HOV Lane \\
\hline & Bus Schedules \\
\hline & Cost of New Buses/Staff/Administration \\
\hline Incident Management & System Architecture and Response \\
\hline \multirow[t]{4}{*}{ Marketing Strategies } & Types of Strategies and Scope \\
\hline & Cost of Strategy Implementation \\
\hline & Public Information Programs \\
\hline & Marketing Schedule \\
\hline \multirow[t]{4}{*}{ Carpooling Incentives } & Tax Incentives and Policies \\
\hline & Incentives For Employers and Employees \\
\hline & Parking Cost and Availability at Destination \\
\hline & Other \\
\hline
\end{tabular}

\subsubsection{HOV Lane Traffic Estimation}

The most important step in the economic evaluation of any transportation project is the determination of traffic volume before and after the implementation of the project. A corridor with a large number of carpools is a good candidate for HOV lane implementation from the point of view of economic feasibility. The estimation of the HOV lane traffic volume depends on the number of carpools formed and on the estimation of the percentage of these carpools that will eventually use the HOV lane.

The HOV demand can be predicted using demand models when they are available for the region under study. The tendency to car-pool depends upon the trip characteristics such as travel time, trip length; trip makers attributes such as household size, income, auto availability, workers per household; and trip end descriptors such as employment density, employer incentives, ridership programs and parking programs. A unique demand model should be developed for each region as the analysis of each HOV lane project is unique. The demand models that are 
borrowed from other locations do not represent the trip maker's attributes and the trip end descriptors of the region under study and hence the HOV lane traffic volume projections are not reliable. The calibrated parameters in such demand models also change over time and hence result in inaccurate predictions.

The demand models can be divided into two categories depending upon the scope of their application. Region-wide demand models are essentially multinomial logit models. These multinomial logit models are used to determine the modal split given the vehicle volumes in the region. These models are capable of predicting the HOV demand in a corridor by taking into consideration the transportation network of the entire region. They can take into account the carpools diverted to the HOV lane from the adjacent parallel routes as well as the new induced carpool volume. Hence, they are specific to the region for which they are calibrated and cannot be carried over from one region to another. Another disadvantage in using these models is that they are data intensive. Some of the region wide corridor models are shown in Table 2.36.

Corridor demand models focus on predicting the demand on the HOV lane in a single corridor usually ignoring the impact of the HOV facility on the regional network. Methodologies include both multinomial logit models and quick-response regression relationships that compute HOV lane demand as a function of travel time savings or some other measure of congestion. These models can differ significantly depending upon the field of vision within the corridor. They can be further classified into three types namely, the parallel route models, single route models and critical point route models.

Parallel route models take into account two or more parallel routes and the interactions between them in order to obtain better estimates of diversion and spatial interaction. Single route models focus only on a single route and hence are not able to capture diversion effects adequately. Critical point models focus on a particular point in the study corridor (usually the most congested point in the segment considered) and compute the performance characteristics for the entire segment based on the characteristics of this congested point. Though this method reduces data requirements significantly, it is usually at the expense of accuracy. Table 2.37 shows some of the corridor demand models.

The number of HOVs in the traffic stream can also be estimated using the average vehicle occupancy on the freeway. Alexiadis, (1996) developed the following equations for estimation of number of HOVs based on the average vehicle occupancy. The equations were developed based on the data collected from twenty-seven HOV lane facilities in the country.

$$
\begin{aligned}
& \% \text { SOV }=[(-0.80 * \text { Average Vehicle Occupancy })+1.80] * 100 \\
& \% H O V 2=[0.667 * \text { Average Vehicle Occupancy })-0.667] * 100 \\
& \% H O V 3+=[100-\% \text { SOV }-\% H O V 2]
\end{aligned}
$$

The number of carpools present in the traffic stream before and after the HOV lane implementation can be determined using these equations. The economic feasibility of HOV lane implementation can be determined depending upon the expected growth in average vehicle occupancy after HOV lane implementation. This methodology is particularly useful when region specific or corridor specific demand models are not available and a sensitivity analyses with respect to growth in number of carpools has to be conducted. 
Table 2.36: Region-wide HOV Demand Models

\begin{tabular}{|c|c|c|c|c|c|c|}
\hline \multirow[b]{2}{*}{ Model/Area } & \multirow[b]{2}{*}{ Reference } & \multicolumn{2}{|c|}{ Mode Split Process } & \multirow{2}{*}{$\begin{array}{l}\text { Model Type } \\
\text { Model Type }\end{array}$} & \multicolumn{2}{|c|}{ Variables } \\
\hline & & First Stage & $\begin{array}{l}\text { Second } \\
\text { Stage }\end{array}$ & & $\begin{array}{c}\text { Trip } \\
\text { Descriptors }\end{array}$ & $\begin{array}{l}\text { Socio- } \\
\text { Economic }\end{array}$ \\
\hline $\begin{array}{l}\text { Metropolitan } \\
\text { Washington COG }\end{array}$ & $\begin{array}{l}\text { Barton } \\
\text { Aschman } 1986 \\
\text { Ecosometrics }\end{array}$ & $\begin{array}{l}\text { Drive Alone } \\
\text { Transit Carpool }\end{array}$ & $\begin{array}{l}\text { Pool (2) } \\
\text { Pool (3) } \\
\text { Pool (4+) }\end{array}$ & $\begin{array}{l}\text { Nested } \\
\text { Multinomial } \\
\text { Logit Model }\end{array}$ & $\begin{array}{l}\text { Time, Cost, } \\
\text { HOV Savings }\end{array}$ & $\begin{array}{l}\text { Household, } \\
\text { Auto } \\
\text { Ownership }\end{array}$ \\
\hline $\begin{array}{l}\text { Southern } \\
\text { California } \\
\text { Association of } \\
\text { Governments } \\
\end{array}$ & $\begin{array}{l}\text { SCAG } 1986 \\
\text { Barton } \\
\text { Aschman } 1987\end{array}$ & Transit Auto & $\begin{array}{l}\text { Walk } \\
\text { Access } \\
\text { Drive } \\
\text { Access } \\
\end{array}$ & $\begin{array}{l}\text { Nested } \\
\text { Multinomial } \\
\text { Logit Model }\end{array}$ & $\begin{array}{l}\text { Time, Cost, } \\
\text { Income }\end{array}$ & $\begin{array}{l}\text { Auto/House, } \\
\text { Drivers/HH, } \\
\text { Workers/HH, } \\
\text { Income }\end{array}$ \\
\hline $\begin{array}{l}\text { Network } \\
\text { Performance } \\
\text { Evaluation Model }\end{array}$ & $\begin{array}{l}\text { Carnegie } \\
\text { Melon, Oak } \\
\text { Ridge, Janson } \\
\text { et. al. } 1987\end{array}$ & $\begin{array}{l}\text { Auto } \\
\text { Transit } \\
\text { Pool (2) } \\
\text { Pool (3+) }\end{array}$ & $\begin{array}{l}\text { Pool } \\
\text { Access } \\
\text { Drive } \\
\text { Alone } \\
\text { Pool }(2 / 3+)\end{array}$ & $\begin{array}{l}\text { Multinomial } \\
\text { Logit Iterative } \\
\text { Assignment }\end{array}$ & Time, Cost & $\begin{array}{l}\text { Income, Zonal } \\
\text { Laned Area }\end{array}$ \\
\hline $\begin{array}{l}\text { San Franscisco } \\
\text { Metropolitan } \\
\text { Transportation } \\
\text { Commission }\end{array}$ & $\begin{array}{l}\text { Kollo, } 1987 \\
\text { Pulvis } 1988\end{array}$ & $\begin{array}{l}\text { Drive Alone } \\
\text { Transit Pool (2) } \\
\text { Pool (3+) }\end{array}$ & & $\begin{array}{l}\text { Multinomial } \\
\text { Logit }\end{array}$ & Time, Cost & $\begin{array}{l}\text { Auto/HH, } \\
\text { Workers/HH, } \\
\text { Employment } \\
\text { Desity, Income }\end{array}$ \\
\hline $\begin{array}{l}\text { North Central } \\
\text { Texas COG }\end{array}$ & NCTCOG, 1990 & $\begin{array}{l}\text { Drive Alone } \\
\text { Pool (2) } \\
\text { Pool (3+) } \\
\text { Transit(Walk) } \\
\text { Transit (Drive) }\end{array}$ & & $\begin{array}{l}\text { Multinomial } \\
\text { Logit }\end{array}$ & Time, Cost & $\begin{array}{l}\text { CBD } \\
\text { Attraction, } \\
\text { Autos/Person, } \\
\text { Choice/No } \\
\text { Choice } \\
\text { Quadrants } \\
\end{array}$ \\
\hline
\end{tabular}

Table 2.37: Corridor Demand Models

\begin{tabular}{|c|c|c|c|c|c|}
\hline \multirow{2}{*}{ Model/Area } & \multirow{2}{*}{ Reference } & \multirow{2}{*}{ Mode Split Process } & \multirow{2}{*}{ Model Type } & \multicolumn{2}{|c|}{ Variables } \\
\hline & & & & Trip Descriptors & Socio-Economic \\
\hline $\begin{array}{l}\text { Cambridge } \\
\text { Systematics }\end{array}$ & CSI, 1977 & $\begin{array}{l}\text { Drive Alone Transit } \\
\text { Carpool }\end{array}$ & $\begin{array}{l}\text { Multinomial } \\
\text { Logit, Pivot } \\
\text { Point }\end{array}$ & $\begin{array}{l}\text { Change in travel } \\
\text { time and cost by } \\
\text { mode }\end{array}$ & $\begin{array}{l}\text { Location, Income, } \\
\text { Auto Availability }\end{array}$ \\
\hline UC Berkeley & $\begin{array}{l}\text { Kruger et. al. } \\
\text { 1977, Small, } \\
1977 \text { Cilliers, } \\
1978\end{array}$ & $\begin{array}{l}\text { Non-Carpool Carpool } \\
(2+\text { and } 3+) \\
\text { Bus (walk) Bus (Drive) }\end{array}$ & $\begin{array}{l}\text { Multinomial } \\
\text { Logit }\end{array}$ & $\begin{array}{l}\text { Time and Cost, } \\
\text { Walk and Wait } \\
\text { time Bus } \\
\text { travellers }\end{array}$ & $\begin{array}{l}\text { Income, Age, Length } \\
\text { of Residence, No. of } \\
\text { Children }\end{array}$ \\
\hline $\begin{array}{l}\text { I-580, San } \\
\text { Francisco }\end{array}$ & Talvitite, 1978 & $\begin{array}{l}\text { Drive Alone Shared } \\
\text { Ride } \\
\text { Bus }\end{array}$ & $\begin{array}{l}\text { Multinomial } \\
\text { Logit }\end{array}$ & $\begin{array}{l}\text { Access Time } \\
\text { Line Haul time }\end{array}$ & $\begin{array}{l}\text { Household } \\
\text { Characteristics }\end{array}$ \\
\hline $\begin{array}{l}\text { Metropolitan } \\
\text { Washington } \\
\text { COG }\end{array}$ & Mann, 1983 & $\begin{array}{l}\text { Car Occupancy } \\
\text { Distributions }\end{array}$ & $\begin{array}{l}\text { Regression } \\
\text { Nomograph }\end{array}$ & $\begin{array}{l}\text { HOV Time } \\
\text { Savings }\end{array}$ & None \\
\hline $\begin{array}{l}\text { Charles River } \\
\text { Associates }\end{array}$ & $\begin{array}{l}\text { Parody CRA, } \\
1984\end{array}$ & $\begin{array}{l}\text { Drive Alone } \\
\text { Pool (2) / (3+) } \\
\text { Transit }\end{array}$ & $\begin{array}{l}\text { Pivot Point } \\
\text { Regression }\end{array}$ & $\begin{array}{l}\text { Change in travel } \\
\text { time by mode }\end{array}$ & None \\
\hline Orange County & $\begin{array}{l}\text { Wessmann, } \\
1987\end{array}$ & $\begin{array}{l}\text { HOV Formation (\% of } \\
\text { Base) }\end{array}$ & $\begin{array}{l}\text { Pivot Point } \\
\text { Table Look-up }\end{array}$ & $\begin{array}{l}\text { HOV Time } \\
\text { Savings, Trip } \\
\text { Length }\end{array}$ & None \\
\hline $\begin{array}{l}\text { Texas } \\
\text { Transitway }\end{array}$ & TTI, 1988 & $\begin{array}{l}\text { Drive Alone } \\
\text { Transit } \\
\text { Pool }\end{array}$ & Trip Table & Modal Time & $\begin{array}{l}\text { Destination } \\
\text { Attractions }\end{array}$ \\
\hline $\begin{array}{l}\text { Riverside } \\
\text { County } \\
\end{array}$ & DKS, 1990 & $\begin{array}{l}\text { Drive Alone } \\
\text { Pool }\end{array}$ & $\begin{array}{l}\text { Non Linear } \\
\text { Function }\end{array}$ & $\begin{array}{l}\text { HOV Time } \\
\text { Savings }\end{array}$ & $\begin{array}{l}\text { Hard Core Drive } \\
\text { Alone }\end{array}$ \\
\hline Dallas & $\begin{array}{l}\text { Poe et. al., TTI, } \\
1994\end{array}$ & $\begin{array}{l}\text { HOV Lane Use as a \% } \\
\text { of AADT }\end{array}$ & Regression & $\begin{array}{l}\text { Congestion } \\
\text { Level } \\
\text { (ADT/Lane) }\end{array}$ & None \\
\hline
\end{tabular}


The prediction of HOV lane demand is also important from the point of view of public perception, so that the public does not perceive the implementation as a waste of resources. The prediction of HOV lane usage should be done using both the $2+$ and $3+$ occupancy requirements. If the predicted HOV lane volumes using a 3+ occupancy requirement are less, then the HOV facility should be implemented with a 2+ occupancy requirement. However, if congested conditions prevail in the HOV lane with the 2+ occupancy restriction, then the occupancy requirement should be increased. Some of the other issues that need to be considered while predicting the HOV lane demand are:

- $\quad$ Factors Affecting HOV Demand

The tendency to car-pool:

- increases with increase in travel time on mixed flow lane,

- increases with trip length,

- $\quad$ increases with household size,

- increases as income drops,

- increases as parking charges are levied at the workplace,

- $\quad$ is only weakly related to age,

- decreases with one's education level.

- Short Freeway Trips that are Eligible for HOV Lane Use

The distance between the ingress/egress ramps and the number of lane changing maneuvers required to enter or leave the HOV lane can affect the HOV demand. Short freeway trips may prefer to use the GP lane. Studies [Alexiadis, 1996] suggested that a maximum of about $80-90 \%$ of the eligible carpools should be assumed as moving into the HOV lanes for the estimation of HOV lane traffic volume.

- Induced Demand (SOVs and HOVs) / Diverted HOVs from other Facilities

An estimate of the number of vehicles that will be diverted/ induced from adjacent facilities is also required to determine the HOV lane usage. A multinomial logit model uses the existing number of vehicles on the freeway to decide the modal split. The induced demand must be estimated and added to the predicted number of HOVs that is determined by the logit model.

- Effectiveness of Ride Sharing Programs and Marketing strategies

The multinomial logit model will assign the number of vehicles using the HOV lane based on travel time savings. However, despite the travel time benefits people may still decide to travel in the general purpose lanes if the carpool formation is not made easy through ride sharing programs and construction of parking facilities. Marketing strategies can also affect the number of HOV eligible people that will eventually use the HOV lanes.

- $\quad$ Bus Service

The presence of an efficient bus service can affect the number of carpools formed. People might prefer traveling in the buses instead of carpooling on the HOV lanes. In Houston, about $16 \%$ of the HOV lane bus passengers were carpoolers before but shifted to buses because of efficient operations. Hence 
transit should be considered as one of the modes of travel apart from the SOVs and the HOVs in the multinomial choice logit model.

\subsubsection{HOV Lane Safety}

The safety of the geometric design of HOV lane should be assessed before the implementation of the HOV lane. It has been observed that the number of crashes increase when the HOV lanes are not physically separated from the general purpose lanes. Barrier-separated HOV facilities on the other hand have reduced the crash rate at several places. Separation of HOV lanes by using a wide buffer may also reduce the crashes. The contraflow HOV lane facility, if implemented with barrier separation, has reduced the number of crashes. Any modifications required in terms of more lane width, inadequate shoulders etc., should be dealt with in the design phase.

\subsubsection{Cost Estimation}

The capital cost estimate of the HOV lane project depends upon the physical components incorporated and the length of the HOV facility. The number of park and ride lots, direct access ramps and enforcement areas constructed can significantly affect the total capital cost of the project. While the cost estimation is important from the point of view of determining funding opportunities and allocation of funds, it is also important for the cost-effectiveness evaluation of the HOV facility. A detailed estimated of the capital, operation, maintenance and enforcement costs should therefore be prepared. A methodology for an approximate estimation of the costs for the purpose of economic evaluation was described in Section 2.5. A construction schedule could also be prepared for the various components of the HOV facility. The construction and opening of some of the park-and-ride lots or direct access ramps can be postponed for several years depending upon the forecasted HOV demand and its estimated growth.

\subsubsection{Benefits Estimation and Cost-Effectiveness Analysis}

A comprehensive economic evaluation should be carried out before the implementation of the HOV facility. The impact of HOV lane implementation on freeway travel time, speed, congestion level, person and vehicle throughput and average vehicle occupancy should be determined at various levels of forecasted HOV traffic. An estimate of the dollar value of the travel time savings, vehicle operating cost savings, crash savings and emission savings based on the prevalent unit cost values should be made and the overall cost-effectiveness of the project should be determined over an analysis period.

The following performance measures should be computed before the implementation of the HOV facility. These performance measures help in estimating the expected benefits from the implementation of the HOV lanes.

(i) Travel Time savings

The implementation of an HOV lane should be considered only when it offers travel time reduction to the HOV lane users. The existence of travel time savings plays a crucial role in determining the success of HOV lane. According to the guidelines set forth by North Carolina DOT (NCDOT), an approximate saving of at least one minute per mile over a typical trip from origin to destination is required of any HOV project. An overall saving of four minutes is considered a minimum and a saving of 8 minutes is considered desirable over a typical trip on 
the HOV lane. According to the Washington State DOT, to be effective HOV lanes must operate at $45 \mathrm{mph}$ or more during the peak hour at least $90 \%$ of the time.

(ii) Person Throughput

According to North Carilina DOT (NCDOT) guidelines, the number of people projected to use the lane should exceed the average number of persons carried in an adjacent mixed flow lane in the same direction. The NCDOT relaxes this criterion during the initial period of HOV operation and allows the use of locally accepted thresholds for minimum person throughput. It states that if the HOV facility can move to within $20 \%$ of the number of passengers carried by a mixed flow lane then this criterion is satisfied and the HOV lanes can be implemented.

(iii) Vehicle Throughput

According to Caltrans [Caltrans, 2003], HOV lane candidates must be predicted to carry atleast $800 \mathrm{vphpl}$ during the peak hour. Houston uses a minimum requirement of 400-800 vphpl depending upon the type of the HOV facility. In order to avoid public perception of "empty lane syndrome", NCDOT recommends that the HOV lane should carry at least 400-800 vehicles per hour per lane during the initial years of its operation. A lower volume can be accepted if the number of buses operating in the HOV lane is significant so that the person throughput of the HOV lane justifies the implementation. NCDOT recommends that a peak hour bus volume of 30-45 vehicles when combined with other HOVs is sufficient.

(iv) Cost Effectiveness

HOV lanes should be considered for implementation only if they can be proved to be cost effective. Cost effectiveness can be measured in terms of the Benefit to Cost ratio or the Net Present Value. Benefits comprise of travel time savings, vehicle operating cost savings, emission savings, and crash savings converted into dollar values. The costs mainly encompass construction, operation, enforcement and maintenance of the HOV system.

(v) Impact on GP Lane

The impact of HOV lane implementation on the GP lane should be determined. The induced traffic in the GP lane due to the construction of a new lane on the freeway and due to the reduction in the number of SOVs should be determined. The speed in the HOV lane should also be determined to determine if the level of service has improved or become worse.

\subsubsection{Development of Warrants and Implementation Criteria}

A set of warrants and implementation criteria should be prepared by the agency that justifies the implementation of the HOV facility from the point of view of social equity and other issues. For example, according to the guidelines set forth by North Carolina DOT (NCDOT), an approximate saving of at least one minute per mile over a typical trip from origin to destination is required of any HOV project. An overall saving of four minutes is considered a minimum and a saving of eight minutes is considered desirable over a typical trip on the HOV lane.

The Washington state DOT stipulates that HOV lanes must operate at $45 \mathrm{mph}$ or more during the peak hour at least $90 \%$ of the time to be effective. NCDOT stipulates that the number of people projected to use the lane should exceed the average number of persons carried in an adjacent mixed flow lane in the same direction. 
However, NCDOT relaxes this criterion during the initial period of HOV operation and allows the use of locally accepted thresholds for minimum person throughput. It states that if the HOV facility can move to within $20 \%$ of the number of passengers carried by a mixed flow lane then this criterion is satisfied and the HOV lanes can be implemented.

Caltrans (2003) requires its HOV lane candidates carry atleast 800 vphpl during the peak hour. Houston uses a minimum requirement of 400-800 vphpl depending upon the type of the HOV facility. In order to avoid public perception of "empty lane syndrome", NCDOT recommends that the HOV lane should carry at least 700 vehicles per hour per lane during the initial years of its operation. A lower volume can be accepted if the number of buses operating in the HOV lane is significant so that the person throughput of the HOV lane justifies the implementation. NCDOT recommends that a peak hour bus volume of 30-45 vehicles when combined with other HOVs is sufficient. The Texas department of transportation recommends that the average daily traffic on the freeway should be greater than 25,000 vehicles per lane to justify the consideration of a HOV lane. The average speed in a mixed flow lane drops below $35 \mathrm{mph}$ at this level of traffic and hence the Texas warrant essentially ensures that the HOV lanes are considered only under severely congested scenarios.

The development of such criteria and warrants can help the agencies in ensuring that the HOV lanes are well received after their implementation. The economic feasibility will justify the implementation of the HOV lane from the point of view of cost-effectiveness. The guidelines are summarized in Table 2.38. 
Table 2.38: Guidelines for HOV Lane Implementation

\begin{tabular}{|c|c|c|}
\hline Step & Item & Description \\
\hline 1 & Congestion Level & $\begin{array}{l}\text { Hourly Traffic Data Analysis on the Freeway in both directions. } \\
\text { Number of Peak Hours and the location of the peak period should be } \\
\text { determined. } \\
\text { Speed of travel in the peak period peak direction should be estimated }\end{array}$ \\
\hline 2 & Travel Pattern & Travel Pattern on the Freeway Corridor \\
\hline 3 & HOV Lane Type & $\begin{array}{l}\text { The number of HOV lanes, operations hours occupancy requirements and } \\
\text { the type of operation (reversible, concurrent, contraflow) should be decided } \\
\text { here. } \\
\text { The construction of the HOV lane can be done using add-a-lane approach or } \\
\text { take-a-lane approach. The congestion level on the general purpose lane after } \\
\text { HOV facility implementation should be determined using both the } \\
\text { approaches. }\end{array}$ \\
\hline 4 & Support Facilities & $\begin{array}{l}\text { The design of the support facilities described in Table } 3.1 \text { should be done at } \\
\text { this stage to ensure that the predicted HOV lane demand is achieved. The } \\
\text { design of the support facilities determines the public perception of the HOV } \\
\text { lane and hence park and ride programs, ride sharing services, parking } \\
\text { facilities and other travel incentives should be given due consideration. The } \\
\text { enforcement policies should also be formulated at this stage. }\end{array}$ \\
\hline 5 & $\begin{array}{l}\text { HOV Lane Traffic } \\
\text { Estimation }\end{array}$ & $\begin{array}{l}\text { The demand on the HOV lane can be estimated using logit models. The } \\
\text { design of the support facilities plays a major role in inducing carpooling. } \\
\text { An estimate of the number of vehicles that will be attracted from the } \\
\text { adjacent facilities to use the HOV lane and the GP lane after the HOV } \\
\text { facility implementation should be made. }\end{array}$ \\
\hline 6 & Safety Analysis & $\begin{array}{l}\text { The safety analysis of the geometric design of the proposed HOV facility } \\
\text { should be done and the crash reduction factor should be estimated. }\end{array}$ \\
\hline 7 & Cost Estimation & $\begin{array}{l}\text { An estimate of the cost of the HOV facility based on the type of the facility } \\
\text { and design of the support facilities (step 7) should be done at this stage. A } \\
\text { construction schedule should be prepared. }\end{array}$ \\
\hline 8 & $\begin{array}{l}\text { Benefits Estimation \& } \\
\text { Cost-Effectiveness } \\
\text { Analysis }\end{array}$ & $\begin{array}{l}\text { An evaluation of each type of HOV system (HOV facility types selected in } \\
\text { step } 3+\text { Support Facilities) should be done where travel time savings, crash } \\
\text { cost savings, emission reductions and user cost savings are determined. A } \\
\text { sensitivity analysis should also be performed at this stage to determine the } \\
\text { best and worst case scenario }\end{array}$ \\
\hline 9 & $\begin{array}{l}\text { Warrants and } \\
\text { Implementation } \\
\text { criteria }\end{array}$ & $\begin{array}{l}\text { The construction of the HOV System can be started once it is ascertained } \\
\text { that the marketing programs have been successful in developing a favorable } \\
\text { public response. }\end{array}$ \\
\hline
\end{tabular}




\subsection{Summary}

HOV lanes are an effective tool for managing congestion along heavily traveled corridors. However they are not suitable in every situation. They have to be well planned and the success depends largely on how well the system components have been implemented. If right corridors are selected and the guidelines are followed, the HOV lanes can prove to be a significant congestion mitigation strategy. The HOV lanes work on the principle of demand management combined with transportation infrastructure improvements in order to mitigate congestion and hence can prove to be far more effective than projects that are solely based on infrastructure improvements such as road widening. This chapter discussed the various physical and operational components of the HOV system, presented case studies of the various HOV facilities in the country and provided guidelines that should be followed for the implementation of a HOV facility in a region and that can be used to determine the economic feasibility of the HOV lane. 


\section{Chapter 3}

\section{Ramp Metering}

\subsection{INTRODUCTION}

The principal causes of congestion on a freeway are:

- Incidents and crashes,

- Queues from exiting vehicles that spill over onto the mainline,

- Bottlenecks,

- Freeway entering demand that exceeds exiting demand, and

- Mainline flow disrupted by platoon entering demand.

One solution to tackle the problem of congestion without constructing additional lane-miles is to implement ramp metering. Ramp metering essentially involves a traffic signal located at the entrance of a freeway ramp in order to achieve the following objectives:

- Reduce mainline freeway congestion by controlling the number of vehicles entering the freeway,

- Ease ramp merging operation by breaking up a platoon of vehicles entering the freeway

A secondary incentive of ramp metering is to introduce controlled delay to the vehicles wishing to enter the freeway, and as a result, reduce the incentive to use the freeway for short trips. By regulating ramp access to the mainline, ramp metering aims to eliminate, or at least reduce, operational problems resulting from (3), (4), and (5). The predominant goal of most, if not all, ramp metering applications is to prevent, alleviate, or reduce congestion on freeways due to traffic entering from the ramps. This chapter discusses the different types of ramp metering strategies, warrants for considering implementation as well as costs, benefits and impacts of ramp metering.

\subsection{DEFINITION AND DESCRIPTION OF SYSTEMS}

Ramp metering is the use of traffic signals at freeway on-ramps to control the flow of traffic entering a freeway by strategically allowing vehicles to merge into the traffic stream at appropriate points in time (typically when gaps permit). Ramp metering is advantageous because it can be implemented fairly readily, requiring only installation of stoplights and extended lanes on entrance ramps and coordination of these lights and freeway sensors by computers and telemetry. The signals can be set for different metering rates to optimize flow and minimize congestion on the freeway. The metering rate is calculated based on the specific strategy being used [Kachroo and Ozbay, 2003]. The application of signal timing algorithms and real-time data from mainline loop detectors is often included in ramp metering operations to enhance the effectiveness of such systems [O’Brien, 2000].

Ramp metering is one of the most commonly used congestion control measures for freeway networks. Typically, the rationale behind ramp metering stems from the fact that freeway congestion is often attributable to controllable factors such as freeway bottlenecks, the excess of entering vehicles over exiting vehicles, and disruption of the freeway traffic flow by platoon entering demand. In practice, ramp metering systems have been considered 
very successful in reducing congestion and increasing safety. Most ramp metering systems have resulted in higher mainline throughput with lower congestion, significant travel time savings, less accidents, and enhanced reliability of travel time. However, the impacts on energy use and air quality have been mixed: the reduced congestion on the freeway allows for greater fuel efficiency and reduced emissions for vehicles on the mainline, but those queued at ramp meters have increased rates of fuel consumption and emissions [Pearson et al., 2001].

Various forms of ramp control were implemented in the late 1950's and throughout the 1960's in large metropolitan areas such as Chicago, Los Angeles, and Detroit as well as other cities around the world. In Indiana however, the use of ramp metering has been non-existent to date. This section describes the various metering strategies, types of ramp metering systems and warrants for consideration of ramp metering.

\subsubsection{Ramp Metering Control Systems}

Ramp Metering Systems can be categorized based on the type of control, as follows:

\subsubsection{Operator Controlled Metering}

Operator controlled metering is implemented by using cameras and/or other sensing and detection methods in order for the vehicle operator at the control station to monitor and control the on-ramps. For example, in the State of Washington, ramp meters are monitored remotely by traffic specialists at the Traffic Systems Management Center. Hence, although the ramp meters are programmed by computers, the operators staffing the center can override the computer system at any time and manually set the ramp metering rates [WSDOT, 2005].

\subsubsection{Pre-Timed Ramp Metering}

This is the simplest form of metering in which the ramp metering rate is constant over a period of time during the day. Metering rates are preset for ramp traffic signal operation using historically averaged traffic data. The loop detectors are installed on the ramp to actuate and terminate the metering cycle but the metering rate is preset. No detectors are installed on the freeway mainline. This strategy is typically used where traffic conditions are predictable. Traffic signals operate at a predetermined cycle length, usually 4 seconds, which permits one vehicle per green. The cycle length is determined based on historical freeway and ramp traffic data. The advantage is the simplicity of the system in terms of hardware configuration and ease of implementation. Pre-timed ramp metering can be effective in addressing recurrent congestion. The disadvantage is that it does not respond to freeway traffic conditions, incidents and daily fluctuations in the traffic pattern and hence can often cause overload or underutilization of the freeway under certain conditions. However, fixed time metering can provide benefits associated with crash reductions from merging conflicts. The metering rate generally ranges from 4-15 seconds per vehicle or 900-240 vph for single lane applications. This is because metering rates less than four seconds will not allow the drivers to respond to the signal in time as the average move up time is two seconds for a typical driver. On the other hand, if the metering rate is set less than $240 \mathrm{vph}$, it would result in traffic signal violations at the ramp. 


\subsubsection{Traffic Responsive Metering}

Unexpected incidents or fluctuations in the demand on the freeway could be dealt with by traffic responsive ramp metering systems. Traffic responsive ramp metering system is a sophisticated approach to ramp metering where real time traffic data is fed into an algorithm that selects the appropriate metering rate. Traffic data is obtained from the mainline loop detectors. Figure 3.1 shows a schematic diagram for a local traffic responsive ramp metering system. Traffic responsive systems can be based on local or system-wide conditions.

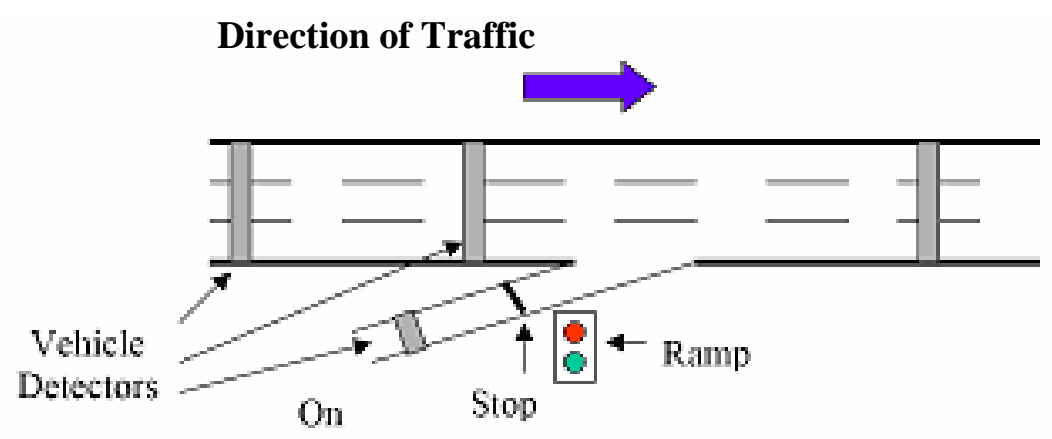

Figure 3.1: Local Traffic Responsive Ramp Metering System [Clark and Scherer, 2000]

\section{Local Traffic Response Systems}

Detectors are placed on the ramp and the freeway region in the vicinity of the ramp (one or two miles). Metering rate is based on the inputs of ramp and prevailing freeway traffic conditions in the vicinity of the on-ramp. Hence, the local ramp meters act independently of all other ramp meters when determining their metering rate. The hardware requirements for local traffic responsive operation are similar to the pre-timed operation, with the addition of required mainline detectors upstream of the ramp. The advantage is the relative simplicity of the system. Since metering rates are not based on optimizing the overall system performance, ineffective operations can result when there are incidents on the freeway. The main criticism of traffic responsive algorithms is that they are reactive, and adjust metering rates after mainline congestion has already occurred. Traffic predictive algorithms such as ALINEA [Clark and Scherer, 2000] have been developed to anticipate operational problems before they occur.

Local ramp metering may result in diversion of traffic entering from the ramps on the surface streets when ramp traffic volumes are large. This may result in public opposition of ramp metering due to increased delay on the ramps as well as due to the increased delay due to diversion. In such a scenario, ramp metering can be stopped at times when ramp traffic volume is high and exceeds ramp storage capacity. This is referred to as flushing and it significantly reduces the benefits of ramp metering. Hence, flushing of vehicles from the ramp disregards the traffic conditions on the freeway. However, it does not take care of the excess waiting times on the ramp due to ramp metering. Therefore, a system-wide ramp metering approach can be considered to minimize the delay on the ramps in the system and achieve optimality. 


\section{Coordinated (System-Wide) Traffic Responsive Systems}

System wide traffic responsive ramp metering operation seeks to optimize a multiple-ramp section of highway, often with the control of a bottleneck as the ultimate goal. System wide ramp meters communicate with vehicle detectors and other ramp meters outside of the local ramp area. The metering rate at each ramp is determined by taking into consideration the traffic conditions throughout the freeway Detectors are located throughout the freeway and the metering rate at other ramps. Typically a centralized computer supervises numerous ramps and implements control features which override local metering instructions. All the detectors (freeway \& ramps) transmit traffic conditions to the management center, where algorithms are applied to identify the best system-wide ramp metering strategy based on optimizing a predefined set of performance measures. Thus the metering rate is altered on a realtime basis. Dynamic traffic management systems are therefore responsive to incidents on freeways and the daily fluctuations in traffic. . The hardware requirements for this mode of operation are the most complex, requiring detectors upstream and downstream of the ramp, as well as a communication medium and central computer linked to the ramps. Hence, the coordinated or system wide traffic responsive systems are the most expensive and sophisticated systems.

\subsubsection{Ramp Metering Algorithms}

Ramp metering algorithms play an important role in the success of ramp metering. The hardware requirements of the system are governed by the type of algorithm that is implemented for the operation of ramp meters. Several ramp metering operational strategies or algorithms are available for implementation. Some of them are discussed in this section. Table 3.1 shows a two by two matrix which displays available ramp metering algorithms for each class of ramp meter. The algorithms can broadly be classified into two types of categories based upon their operation.

Table 3.1: Available Ramp Metering Algorithms [Clark and Scherer, 2000]

\begin{tabular}{|c|c|c|}
\hline & Local Feedback Algorithms & \multirow{2}{*}{ System-wide Feedback Algorithms } \\
\hline \multirow{3}{*}{ Pre timed } & Clock-time & System-wide Clock-time \\
\hline \multirow{4}{*}{ Traffic Responsive } & Open Loop Algorithms: & Closed Loop Algorithms: \\
\cline { 2 - 3 } & Demand Capacity Control & Bottleneck \\
\cline { 2 - 3 } & Speed Control & Fuzzy-Logic Algorithms \\
\cline { 2 - 3 } & Upstream Occupancy Control & Predictive \\
\cline { 2 - 3 } & Gap Occupancy Control & Neural Networks \\
\cline { 2 - 3 } & Closed Loop Algorithms: & \\
\cline { 2 - 3 } & ALINEA & \\
\hline
\end{tabular}

\subsubsection{Open Loop Algorithms}

In the Open-loop ramp control algorithms the control input (metering rate) is independent of the system output (volume, capacity, gap). That is, the metering rate is independent of the operations of the other metered ramps along the freeway corridor. Traffic inputs from the ramp and the freeway in the immediate vicinity are processed to 
generate the timing plan for the meter. Such systems do not employ system-wide conditions for generating the metering output.

\section{a) Speed Control}

Real time speed data collected from vehicle detectors is utilized by this algorithm to operate the ramp meter [Clark and Scherer, 2000]. Generally, speed measurements from the immediate upstream detector are used to decide the metering rate. However, the metering rate can also be decided based upon speed data obtained from the downstream detectors. These speed measurements obtained are used with a preset speed look up table to decide the metering rate. One such example of a speed look-up table is presented in Table 3.2. The speed measurements made are compared to the values in this table and the appropriate metering rate is selected. The metering rate can be interpolated if the speed measurement falls in between the intervals.

Table 3.2: Sample Speed Control Lookup Table [Clark and Scherer, 2000]

\begin{tabular}{|l|l|}
\hline Speed $(\mathbf{m p h})$ & Metering Rate (Seconds per vehicle) \\
\hline$\geq 60$ & 4 \\
\hline $50-59$ & 6 \\
\hline $40-49$ & 8 \\
\hline $35-39$ & 10 \\
\hline$\leq 35$ & 12 \\
\hline
\end{tabular}

\section{b) Demand Capacity Control}

Demand Capacity algorithm is used when the traffic volumes downstream of the ramp have to be regulated such that they are less than the capacity (mitigating congestion downstream). The difference between the upstream volume and the downstream capacity is utilized to determine the metering rate. If the upstream volume exceeds the downstream capacity, the minimum metering rate is applied [Kachroo and Ozbay, 2003]. The basic idea is to ensure that congestion does not occur downstream. Hence the upstream traffic volume which is a function of the metering rate is adjusted. The upstream volume can be determined using the freeway mainline detectors (traffic responsive) or using historically available peak hour traffic volume data (pre timed ramp metering). For example if the downstream capacity is 5,400 vehicles per hour and the upstream volume is 4,800 vehicles per hour then the meter will release traffic at the rate of 600 vehicles per hour. The metering rate is set within a range of 240-900 vehicles per hour. A lower bound of 240 vehicle per hour is used to ensure that the vehicles on the ramp do not become impatient and start proceeding through red light. A maximum metering rate is selected because any metering rate that is set higher than this value will make it difficult for the vehicles to keep up with the signal.

\section{c) Upstream Occupancy Control}

Upstream occupancy control uses the real-time upstream occupancy of the on-ramp in order to determine the metering rate. Hence this type of control is similar to the speed control algorithm except that here upstream detector occupancy measurements are used instead of the speed measurements. The upstream occupancy is first measured and then a predetermined metering rate is selected based on the upstream occupancy. Hence with this strategy the 
focus is to reduce the traffic congestion at the upstream end by keeping a constant check on the upstream occupancy level. In order to determine the upstream occupancy level in real time a traffic responsive ramp metering strategy has to be adopted. Table 3.3 shows an example of the occupancy control look-up table. The metering rate increases with increase in upstream detector occupancy.

Table 3.3: Sample Occupancy Control Lookup Table [Clark and Scherer, 2000]

\begin{tabular}{|l|l|}
\hline Occupancy (\%) & Metering Rate (Seconds per vehicle) \\
\hline$\leq 10$ & 4 \\
\hline $11-16$ & 6 \\
\hline $17-22$ & 8 \\
\hline $23-29$ & 10 \\
\hline$\geq 29$ & 12 \\
\hline
\end{tabular}

\section{d) Gap Acceptance Control}

Gap-acceptance control uses the occupancy measurements which are taken upstream of the ramp. The signal turns green when there is an available gap in the merging lane on the freeway. This method does not account for lane changes and the acceleration behavior of vehicles, which closes the gaps originally measured by the detectors.

\subsubsection{Closed Loop Control Systems}

Unlike, open-loop control strategies, closed-loop local control strategies have the system output fed back and then the input can be modified in order to maintain the output close to the set value. Closed loop control systems, use inputs from throughout the system to generate an optimal metering plan for the entire system. There is a predefined set of objectives for the entire system. Based on the inputs from across the system the algorithm generates an optimal timing plan that maximizes the performance goals. Some of the closed loop algorithms are as follows:

\section{a) ALINEA}

Asservissement Lineaire d'entrée Autoroutiere (ALINEA) [Clark and Scherer, 2000] is one of the most commonly used local feedback (closed-loop) algorithms. The algorithm tries to maintain an optimal occupancy on the freeway mainline. This occupancy is referred to as the critical occupancy. Unlike most traditional metering algorithms, ALINEA uses the occupancy measurement as well as the metering rate in the previous period when calculating the metering rate in the current period. This allows ALINEA to respond smoothly to large differences and react to small fluctuations in the occupancy measurement.

\section{b) Bottleneck Algorithm}

Unlike ALINEA this is a system wide closed loop ramp metering algorithm [Clark and Scherer, 2000]. Multiple meters are controlled at the same time with the objective of optimizing the traffic flow through a downstream bottleneck. Hence this algorithm looks beyond the local ramp area. Many different control equations can be developed in order to achieve the above objective but the aim of all these equations is to ensure that the traffic 
entering the bottleneck area does not exceed the capacity. The number of vehicles released from the upstream entrance ramps added to the upstream mainline demand must be less than the capacity of the bottleneck. This algorithm often causes upstream meters to have more restrictive metering rates than they would if a local metering algorithm was used.

\section{c) Fuzzy Logic Ramp Metering Algorithms}

Fuzzy logic techniques use linguistic variable resembling human reasoning and rules which incorporate the experience of the operator [Kachroo and Ozbay, 2003]. A fuzzy logic ramp-metering algorithm was developed to maximize the total distance traveled and to minimize total travel time and vehicle delays while also maintaining reasonable ramp queues. Researchers found that compared to other strategies, the fuzzy logic had the highest speed and the least delays. [Taylor et al, 1998].

\subsubsection{Single Lane vs. Dual Lane Ramp Metering}

Each of the ramp metering systems and algorithms discussed in the previous section can be implemented using a single lane or multiple lane ramp metering. Chaudhary and Messer (2000) identified the following types of metering strategies that are currently in deployment in various parts of the country.

\subsubsection{Single Lane One-Car per Green}

This strategy allows one car per cycle. The cycle length of 4 seconds is split as one second of green, 1 second of yellow and 2 seconds of red, with one vehicle being allowed into the freeway every cycle. Thus the meter capacity is about 900 vph. However, field observations have shown that a 4-second cycle may be too short to achieve the requirement that each vehicle must stop before proceeding. Also, any hesitation on the part of a driver may cause the consumption of two cycles per vehicle. The report suggests that a more reasonable cycle is around 4.5 seconds, obtained by increasing the red time to 2.5 seconds. This increase in red would result in a lower meter capacity of 800 vph.

\subsubsection{Single Lane Multiple Cars per Green}

Also known as platoon metering and bulk metering, this strategy allows for two or more vehicles to enter the freeway during each green indication. The most common form of this strategy is to allow two cars per green. Allowing three or more cars is feasible, however, it would counter an objective of establishing ramp metering, viz., breaking up large platoons. The study reports that bulk metering does not provide significant increase in capacity beyond the single car per green case because bulk metering requires longer green and yellow times which in turn increase the cycle length, because of which there are fewer cycles per hour. Typically two cars per green strategy results in cycle lengths of 6-6.5 seconds with a metering capacity of 1100 to $1200 \mathrm{vph}$. Thus it can be seen that bulk metering does not double capacity. 


\subsubsection{Dual Lane Metering}

Dual lane metering requires two lanes in vicinity of the merge of the ramp with the freeway, but eventually necks down to one lane at the merge. In this strategy, separate signal heads and cycles are used for the two lanes. However, the cycles are synchronized such that green never occurs simultaneously on both lanes. Synchronization also ensures that there is a constant headway between successive vehicles in both lanes. An important advantage of dual lane metering is that it provides extra queuing space for vehicles on the ramp. Dual lane meters have a metering capacity of 1600-1700 vph. Figure 3.2 shows photographs of ramps with single and dual lane meters.
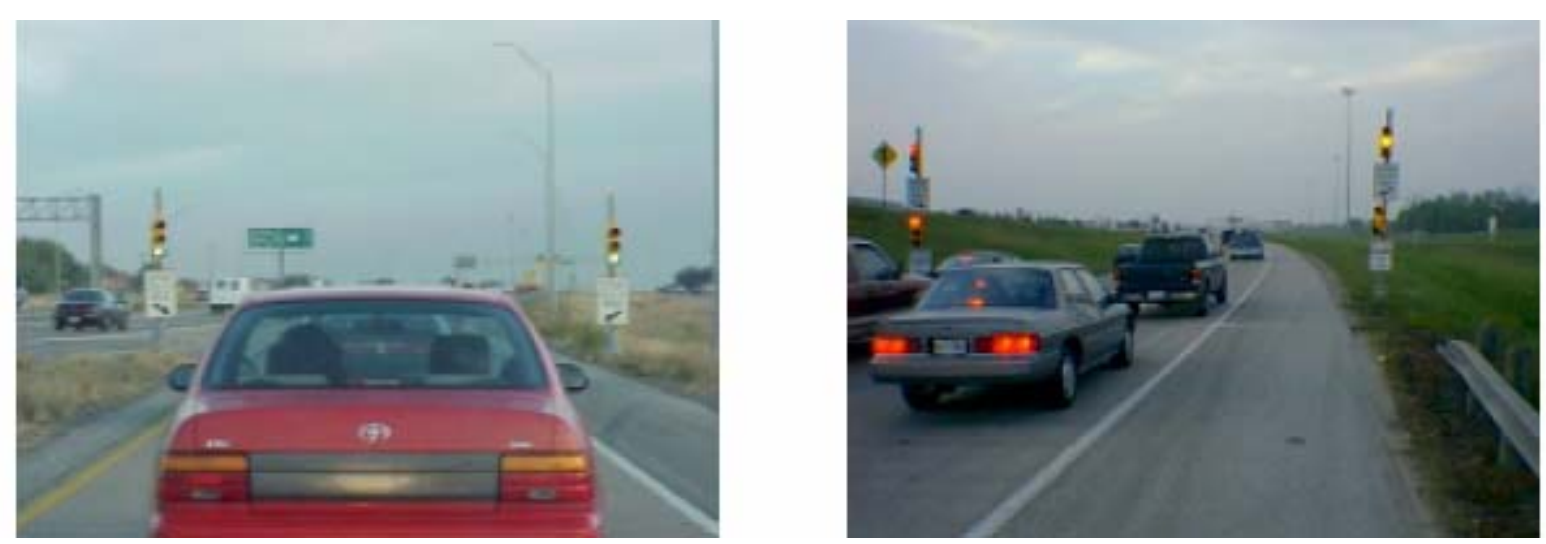

Figure 3.2: Single Lane \& Dual Lane Meters [Chaudhary and Messer, 2000]

\subsubsection{Quality of Ramp Metering: Single Lane vs. Dual Lane}

The quality of the single lane and dual lane ramp metering strategies is measured on the basis of the performance measure, metering availability, which is the percent of time for which the signal is metered. [Chaudhary and Messer, 2000] derived the following information about the quality of single and dual-lane metering from Figure 3.3:

- Good quality ramp metering (metering availability of $80 \%$ or more) can be achieved with single lane ramps if the ramp demand is less than $1200 \mathrm{vph}$.

- Single-lane ramp metering should not be used when ramp demands are higher than $1400 \mathrm{vph}$. The quality of single lane ramp metering is fair when ramp demand is between 1200-1400 cph

- Dual-lane ramp metering provides good quality ramp metering for ramp demands up to $1650 \mathrm{vph}$

Hence based on Figure 3.3, the following guidelines were proposed by Chaudhary and Messer (2000):

1. If ramp volume is less than $1200 \mathrm{vph}$, design a single-lane ramp

2. If ramp volume is more than $1200 \mathrm{vph}$, design a dual-lane ramp

The California Department of Transportation, (Caltrans) stipulates $900 \mathrm{vph}$ as the cut-off point that determines the choice of single or dual lane ramp [Caltrans, 2000]. 


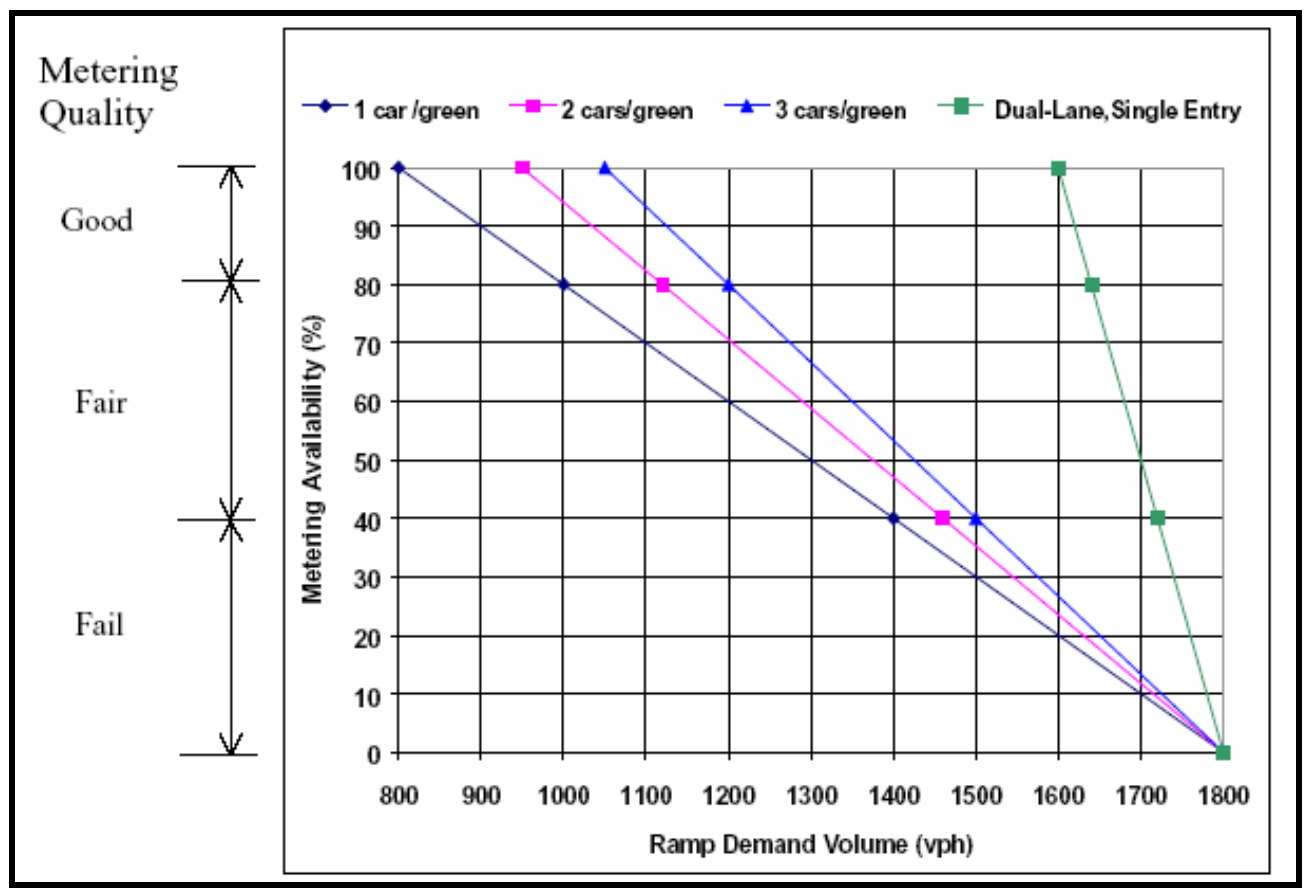

Figure 3.3: Quality of Metering Strategies [Chaudhary and Messer, 2000] 


\subsection{GEOMETRIC DESIGN AND LAYOUT}

\subsubsection{Ramp Metering Hardware}

Ramp metering system consists of various components. Often these components are elements within a larger freeway management architecture. The hardware requirements for ramp metering systems are described below. [Caltrans, 2000]

\subsubsection{Signal Heads and Standards}

The signal is typically located to the drivers left, or on both sides of the ramp. For one lane ramps with one car per green a two-section lower head (200 mm lenses) should be used. For two lane ramps a three section head must be used (300 mm lenses) with standards on both sides of the ramp. Signal standards are not required for non-metered HOV lanes. For three lane ramps, three section heads should be installed on mast arm standard located on the right side of the ramp approximately $21 \mathrm{~m}$ downstream of the limit line (stop line on the ramp).

\subsubsection{Detector Loops}

Figure 3.4 presents an overall detector layout. The following types of detector loops are typically installed for an effective operation of the overall ramp metering system.

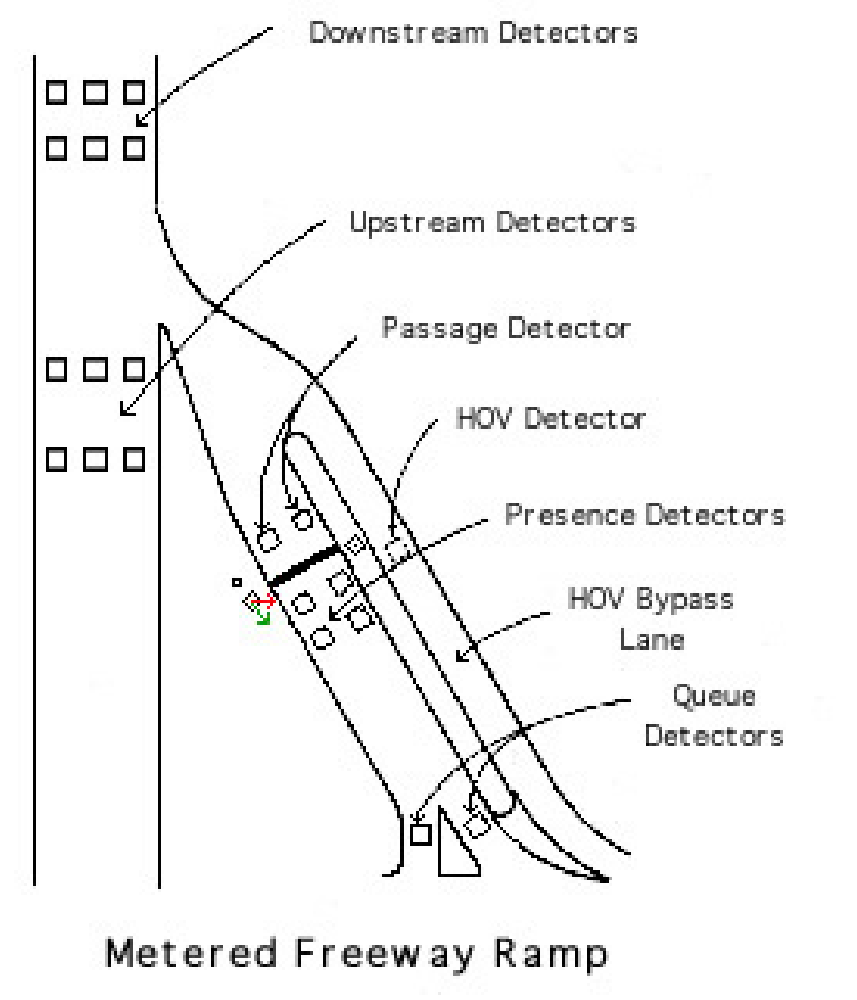

Figure 3.4: Overall Detector Layout for a Typical Ramp Meter [Chien, 2001] 


\section{a) On-Ramp Loop Detectors}

The check-in, or demand detector is located upstream of the ramp metering cordon line. These detectors are placed upstream of the limit line to detect vehicles approaching the meter on the ramp. The check-in detector notifies the controller that a vehicle is approaching and activates the green interval. Generally, two or more demand detectors per lane are utilized to avoid situations where a vehicle that stopped just upstream of the detector is not recognized by the controller and the ramp meter fails to switch to green.

The passage loop detectors or check out detectors are placed downstream of the limit line to detect passing vehicles. The check-out detector notifies the controller that a vehicle has passed through the ramp meter and that the signal should be returned to red. In this manner, one vehicle passes per green interval. Figure 3.5 shows the passage and the ramp demand loop detectors.

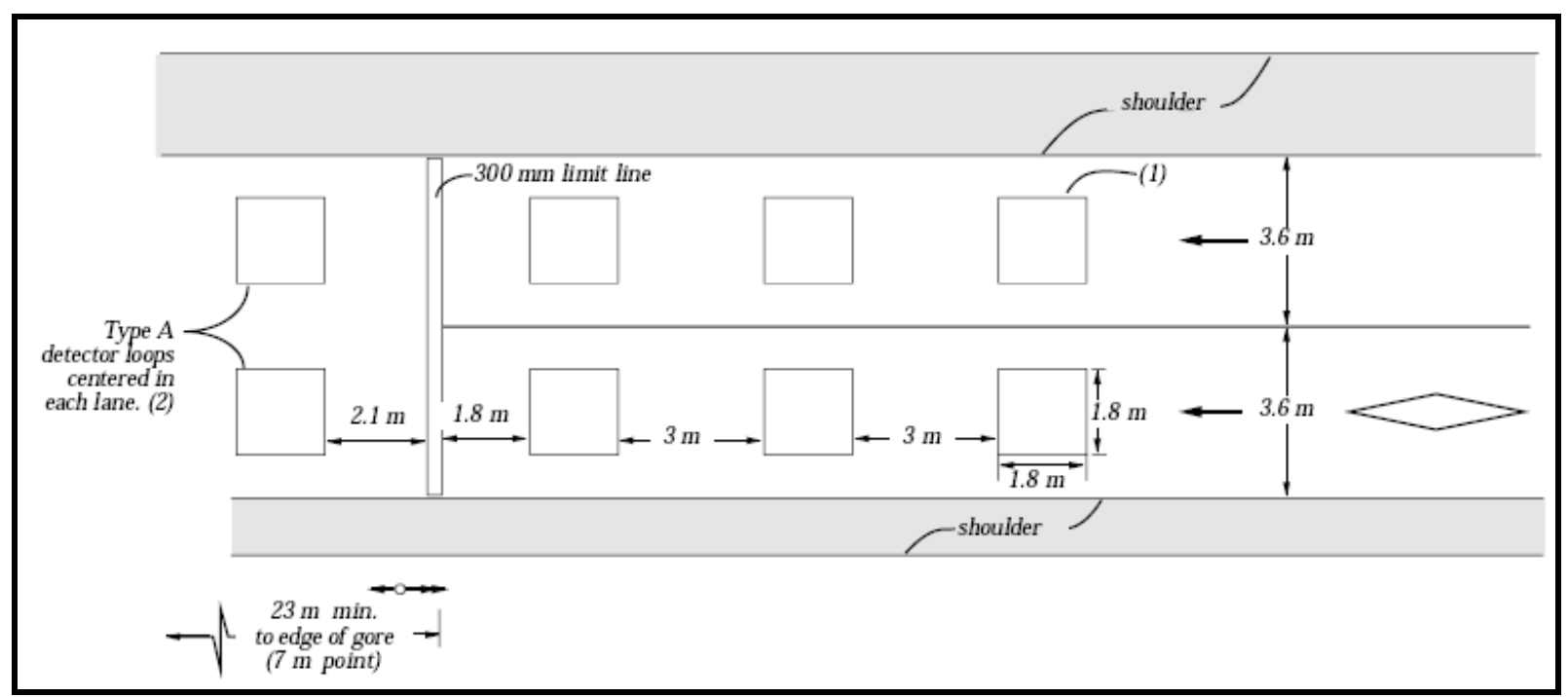

Figure 3.5: Ramp Detector Loop Layout [Caltrans, 2000]

b) Mainline Loop Detectors

For a traffic responsive ramp metering system, two loops should be installed on the mainline with a spacing of $6.1 \mathrm{~m}$ between leading edges. (Figure 3.6) Mainline loops should be located upstream of the entrance of the ramp nose opposite the limit line (stop line). Mainline detectors are sometimes also located on the downstream of the on-ramp. For isolated ramp metering applications, only the occupancy/flow registered from upstream detectors influences the ramp metering rate if the metering is adaptive (not preset), responding to traffic conditions. For ramp metering systems, data from both upstream and downstream detectors influence the metering rate. 


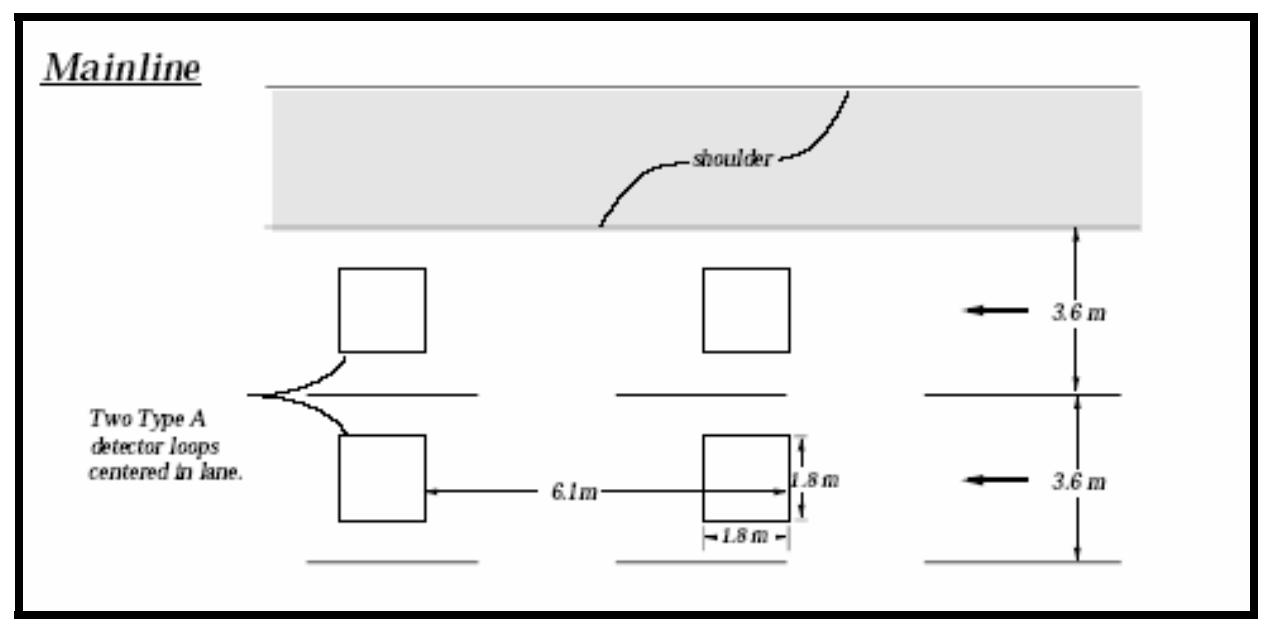

Figure 3.6: Freeway Mainline Detector Layout (Upstream) [Caltrans, 2000]

\section{c) Queue Detectors}

Queue detector loops should be installed (one per entrance lane) near the surface street in order to ensure that the queue on the ramp does not spill over to the surface street. Metering rates may have to be increased irrespective of traffic condition on the freeway if the queue on the ramp builds up to the surface street. Continued actuation of the queue detector with no actuation of the check-in detector indicates that the first queued vehicle has stopped in advance of the check-in detector, and the ramp metering signal should be turned to green to allow this vehicle to proceed.

\section{d) Exit Ramp Detectors}

Exit ramp detector loops must be installed (one per exit ramp) for data collection and loop calibration.

\section{e) Merge Detector}

The merge detector is an optional component which senses the presence of vehicles in the primary merging area of the ramp. To prevent queuing in the primary merging area, the controller holds a red indication if the merge detector indicates a vehicle within it's area. This prevents vehicles having to merge onto the freeway from a stopped position, requiring additional acceleration distance on the mainline and disrupting mainline vehicle speeds. This typically occurs when a timid motorist hesitates, impacting subsequent vehicles. In the case of single-entry metering, subsequent green intervals are preempted until the vehicle merges.

Figures 3.7 through 3.10 show the typical geometric design for single-lane and dual-lane freeway entrance ramps as recommended in the Ramp Meter Design Manual [Caltrans, 2000] prepared as a supplement to Highway Design Manual for the California Department of Transportation. The recommended geometric design for a three lane ramp meter is similar to the dual lane ramp design. 


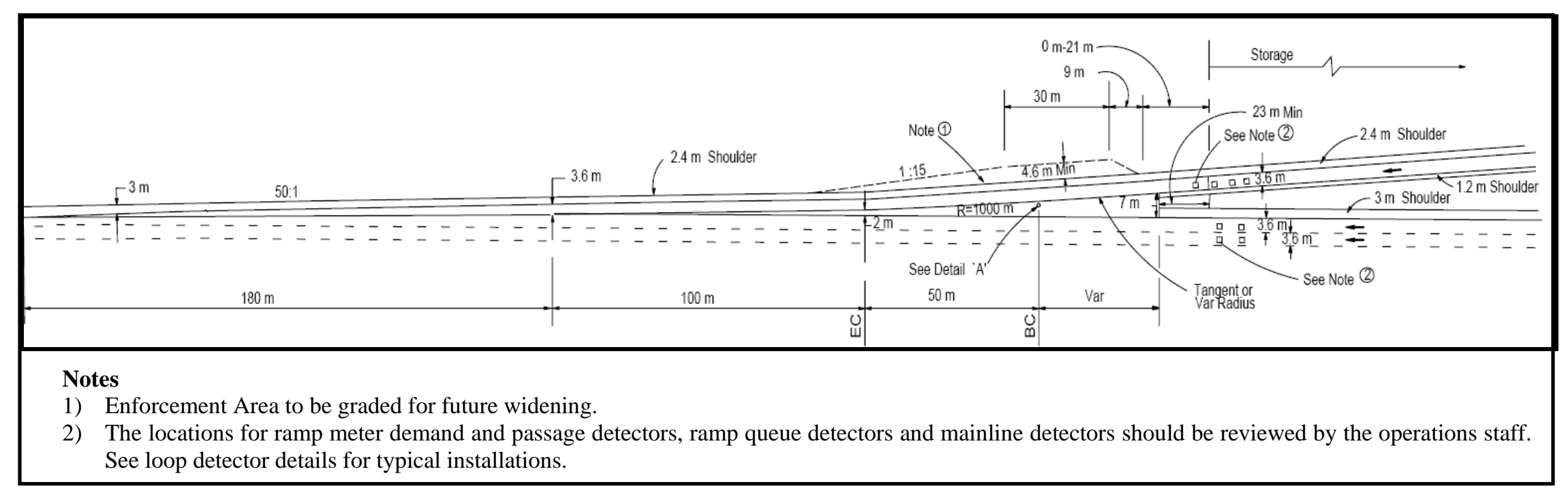

Figure 3.7: Typical Freeway Entrance with 1-Lane Ramp Meter [Caltrans, 2000] 


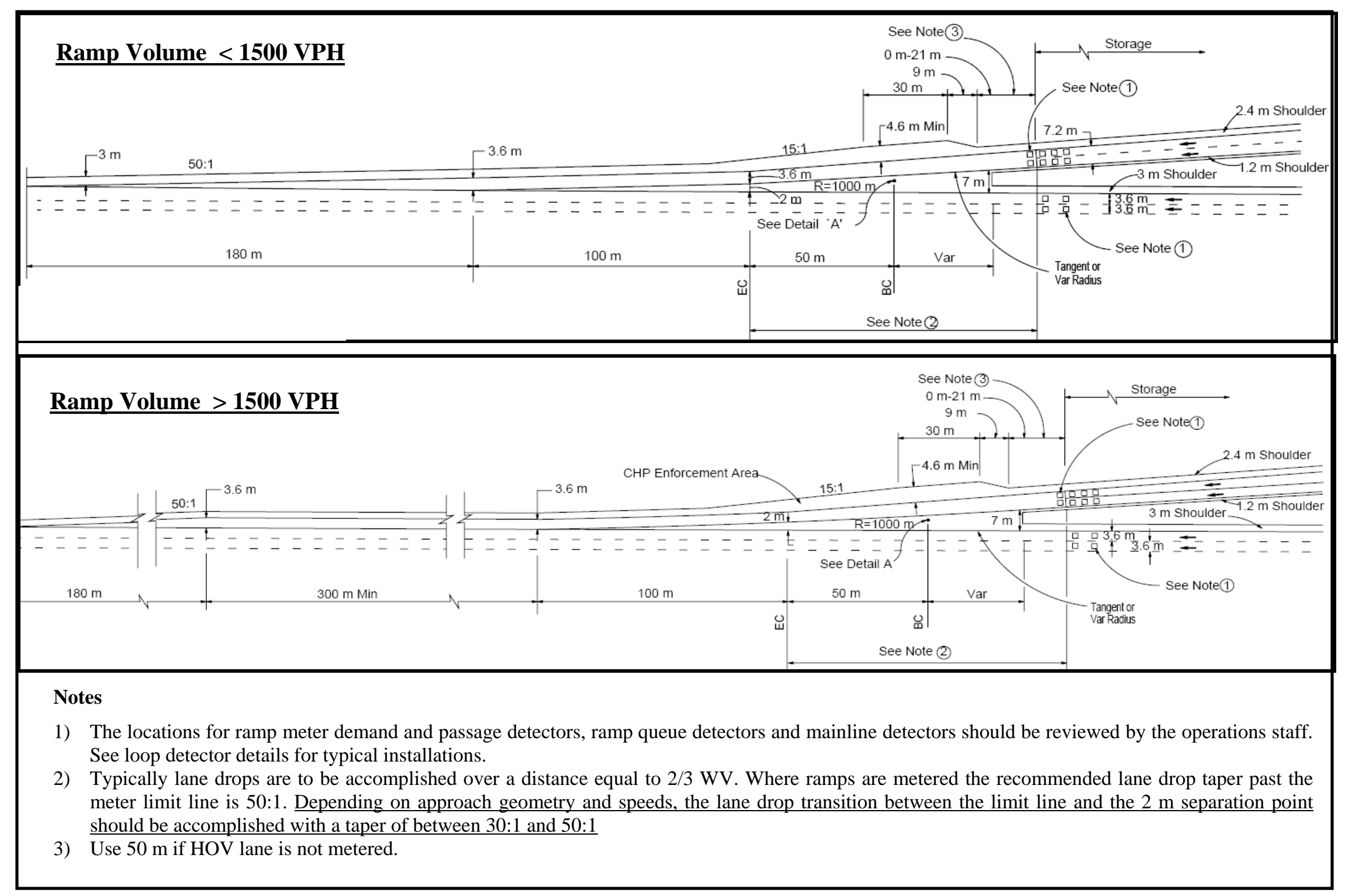

Figure 3.8: Typical Freeway Entrance with 2-Lane Ramp Meter [Caltrans, 2000] 


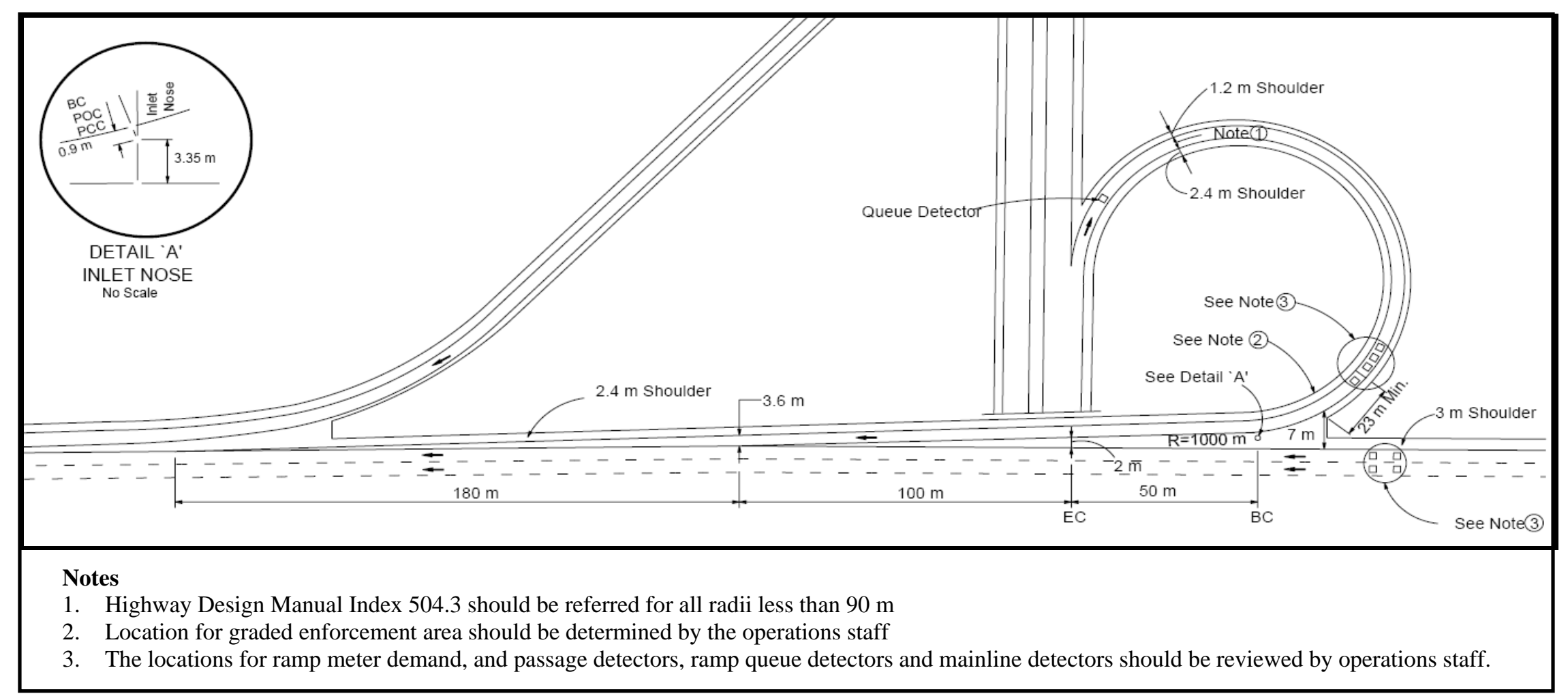

Figure 3.9: Typical Freeway Entrance Loop Ramp with 1-Lane Ramp Meter [Caltrans, 2000] 


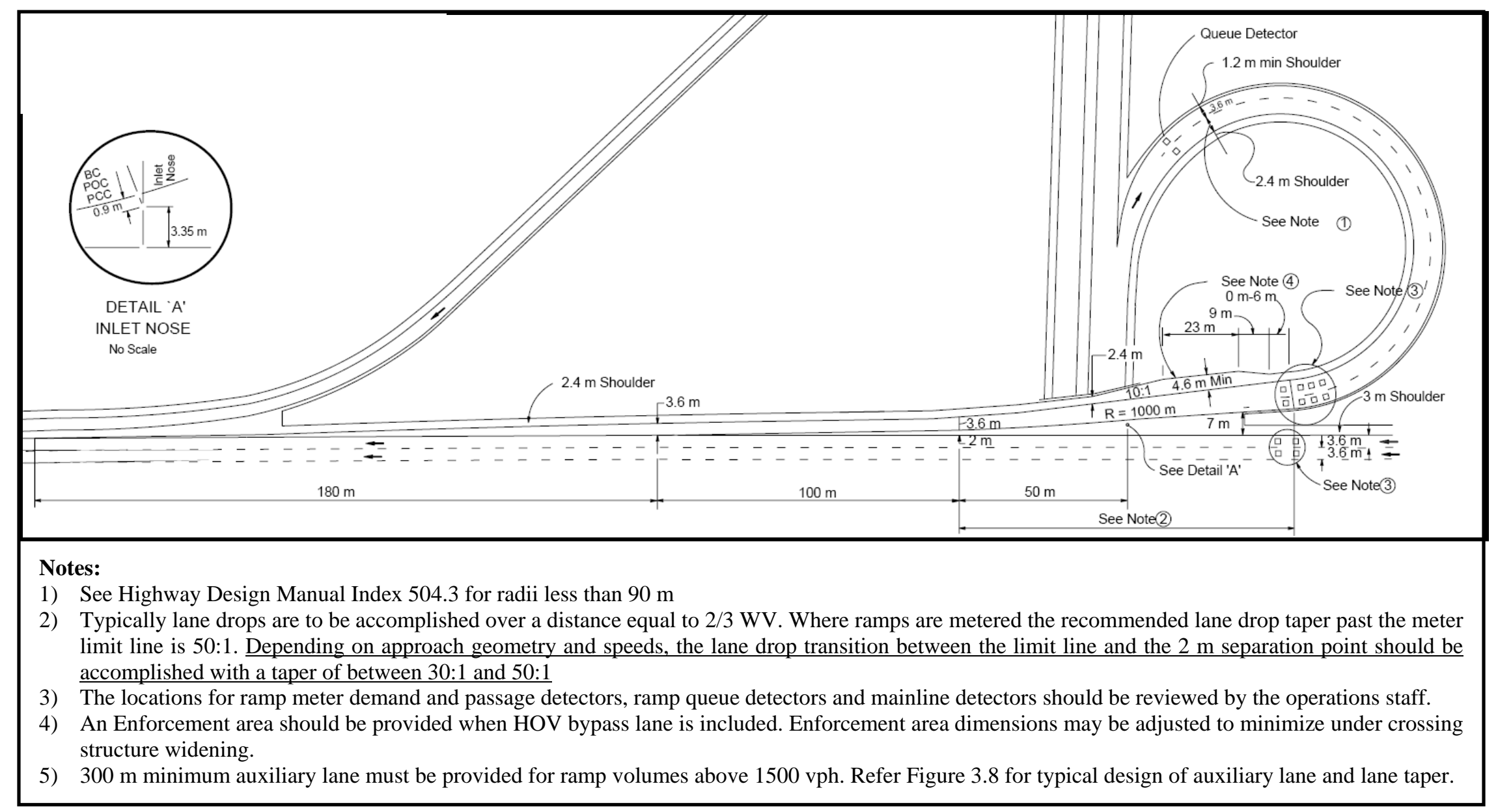

Figure 3.10: Typical Freeway Entrance Loop Ramp with 2-Lane Ramp Meter [Caltrans, 2000] 


\subsubsection{Controller Assembly}

Each ramp meter typically has one nearby weatherproof control cabinet which houses the controller, modem(s), and inputs for each loop. A multi-lane ramp meter is served with a single cabinet. The controller is set to a specified algorithm, which controls the ramp metering rate. A widely used controller is the Type 170 Controller (a microprocessor based device used to control ramp meter signals based on information from the loop detectors) developed jointly by the states of New York and California (to be upgraded to the Type 2070 controller with more functionality). The cabinet should be located at a safe distance from the ramps in order to minimize the possibility of collision of vehicles with it and to facilitate easy and safe access to maintenance personnel.

\subsubsection{Communications}

One telephone demarcation cabinet has to be installed for every telephone service point. If more than one entrance ramp is to be metered, a telephone bridge should be installed in the telephone demarcation cabinet or in the controller cabinet which is nearest to the telephone demarcation cabinet. Alternative communications technologies such as radio waves, fiber optics or microwaves can also be used.

\subsubsection{Advance Warning Signs:}

MUTCD (Manual of Uniform Traffic Control Devices) recommends one or two advance warning signs with flashing beacons indicating that ramp metering is active. Advance Warning Signs should be installed near the entrance of ramps facing each direction of traffic entering the ramp. This is especially important if the traffic signal or queue is not visible from the ramp meter entrance. A flashing beacon with "Signal Ahead" or "Meter On” sign (The Meter On sign is especially relevant when ramp metering is done on a part time basis) should be used. A "Prepare to Stop” sign should be installed about 120 to 180 meters downstream of the Meter On sign. (Figure 3.11) 

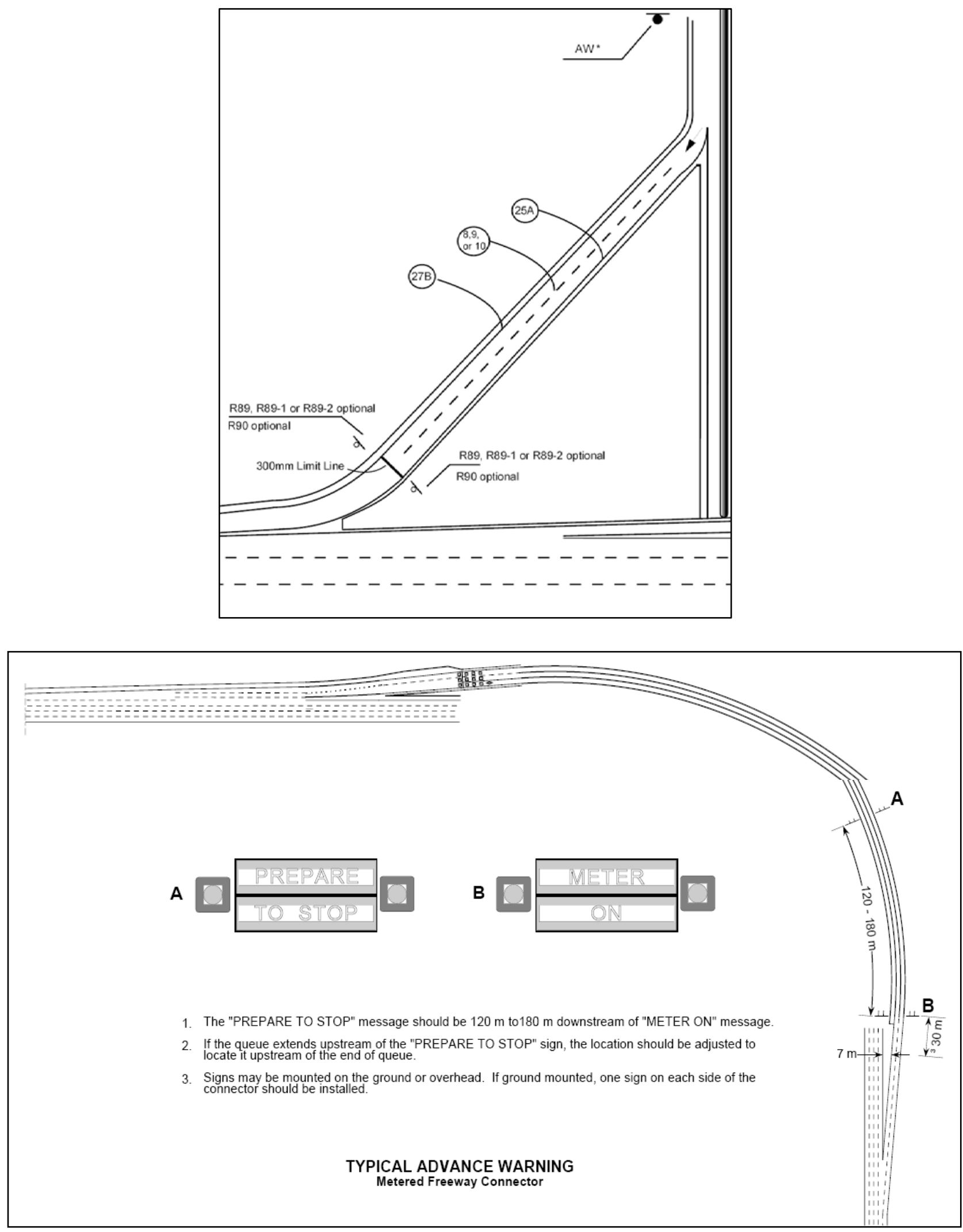

Figure 3.11: Location of Advance Warning Signs [Caltrans, 2000] 


\subsection{RAMP METERING USAGE IN THE U.S. AND ABROAD}

\subsubsection{Ramp Metering in United States}

Ramp metering was first introduced in 1963 on I-290 (Eisenhower expressway) in Chicago, Illinois. A police officer was stationed at the entrance of on-ramps, manually regulating traffic flow into the freeway. Over the past 40 years ramp metering has evolved considerably and is currently an important and effective congestion management strategy in several metropolitan areas including Los Angeles, Minneapolis, Seattle, Denver, Phoenix, Salt Lake City and Portland.

The ITS Deployment Study by the USDOT studied the use of ITS in several regions in North America. A total of 128 cities were surveyed including 78 large metropolitan areas, 30 medium-size cities, and 20 tourist cities. The data was gathered beginning in 1996 and continuing to 2002. The website contains the latest update to the data from a survey of over 2200 state and local agencies carried out in 2002 [USDOT, 2004].

Out of the agencies surveyed, 28 agencies reported having ramp metering. These agencies combined have a total of over 2100 ramp meters. Ramp metering is applied in cities such as Minneapolis/St. Paul, MN; San Diego, CA; and Phoenix, AZ. Figure 3.12 and 3.13 show the number of ramp meters deployed in each metropolitan area. Group 1 includes the metropolitan areas with as many as 400 ramp meters while Group 2 includes areas with no more than 60 ramp meters [USDOT, 2004]. Figure 3.14 shows the percent of ramps controlled by ramp meters in the United States [USDOT, 2004].

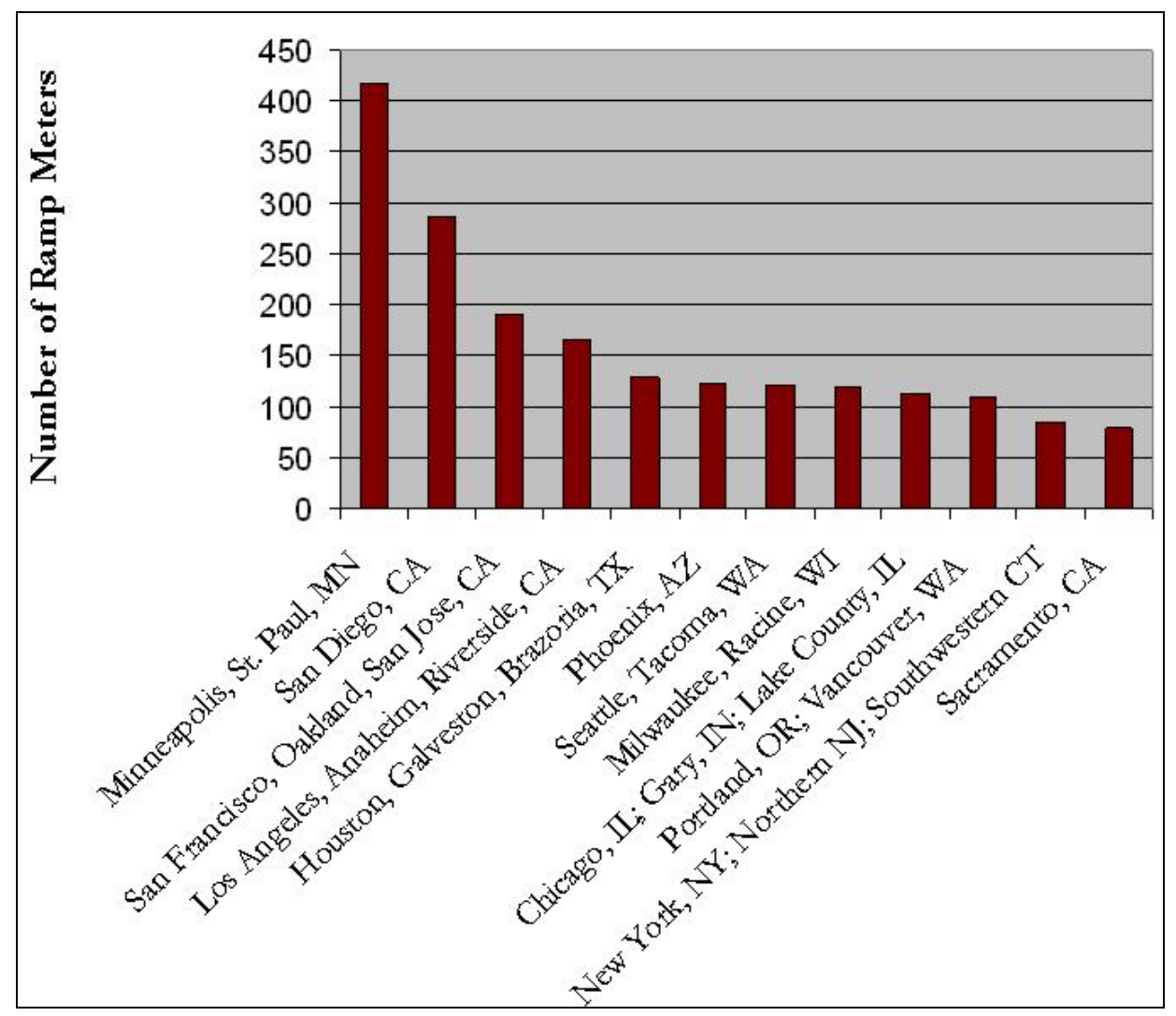

Figure 3.12: Ramp Metering Usage in the Metropolitan Areas in Group 1 


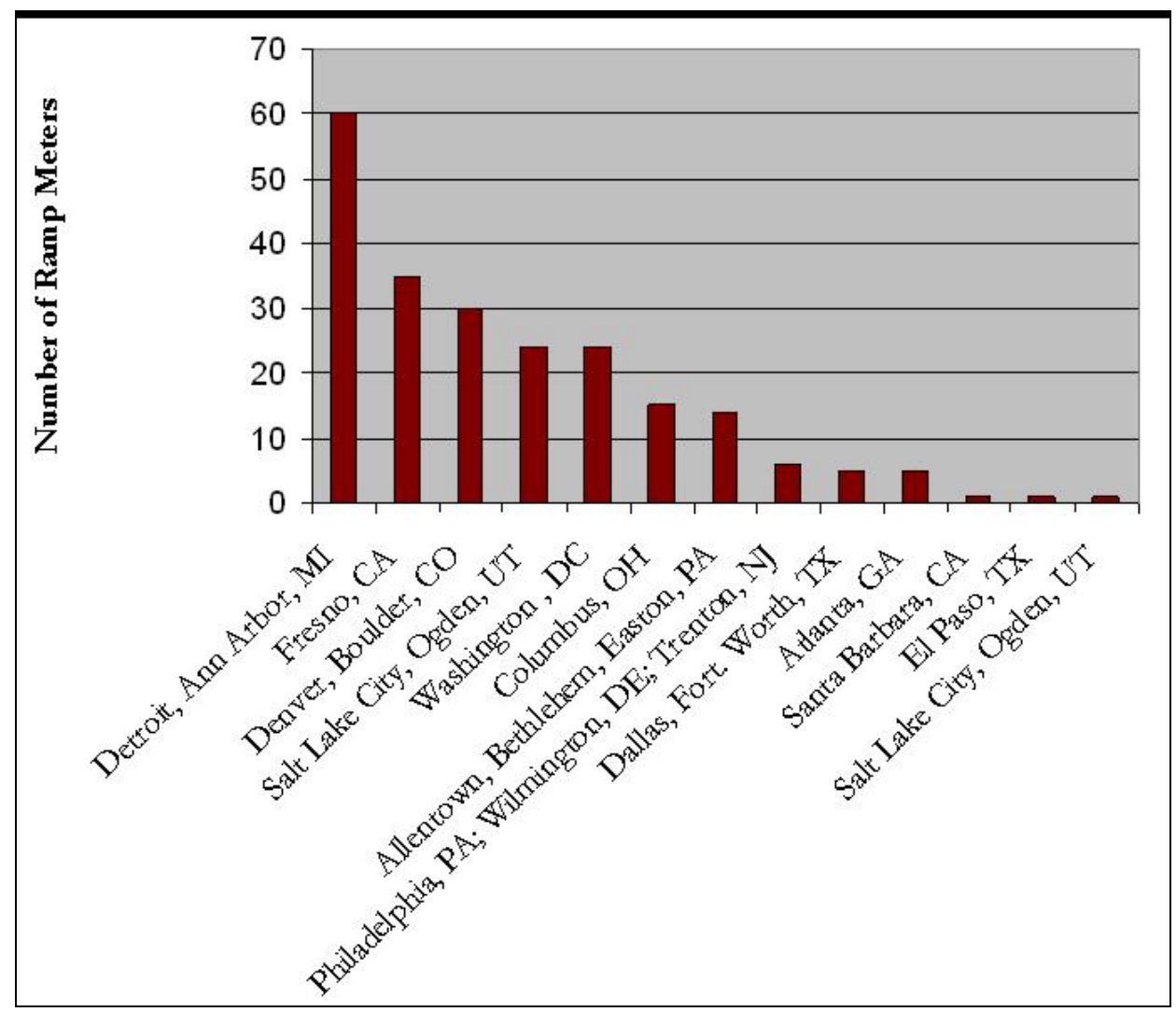

Figure 3.13: Ramp Metering Usage in the Metropolitan Areas in Group 2

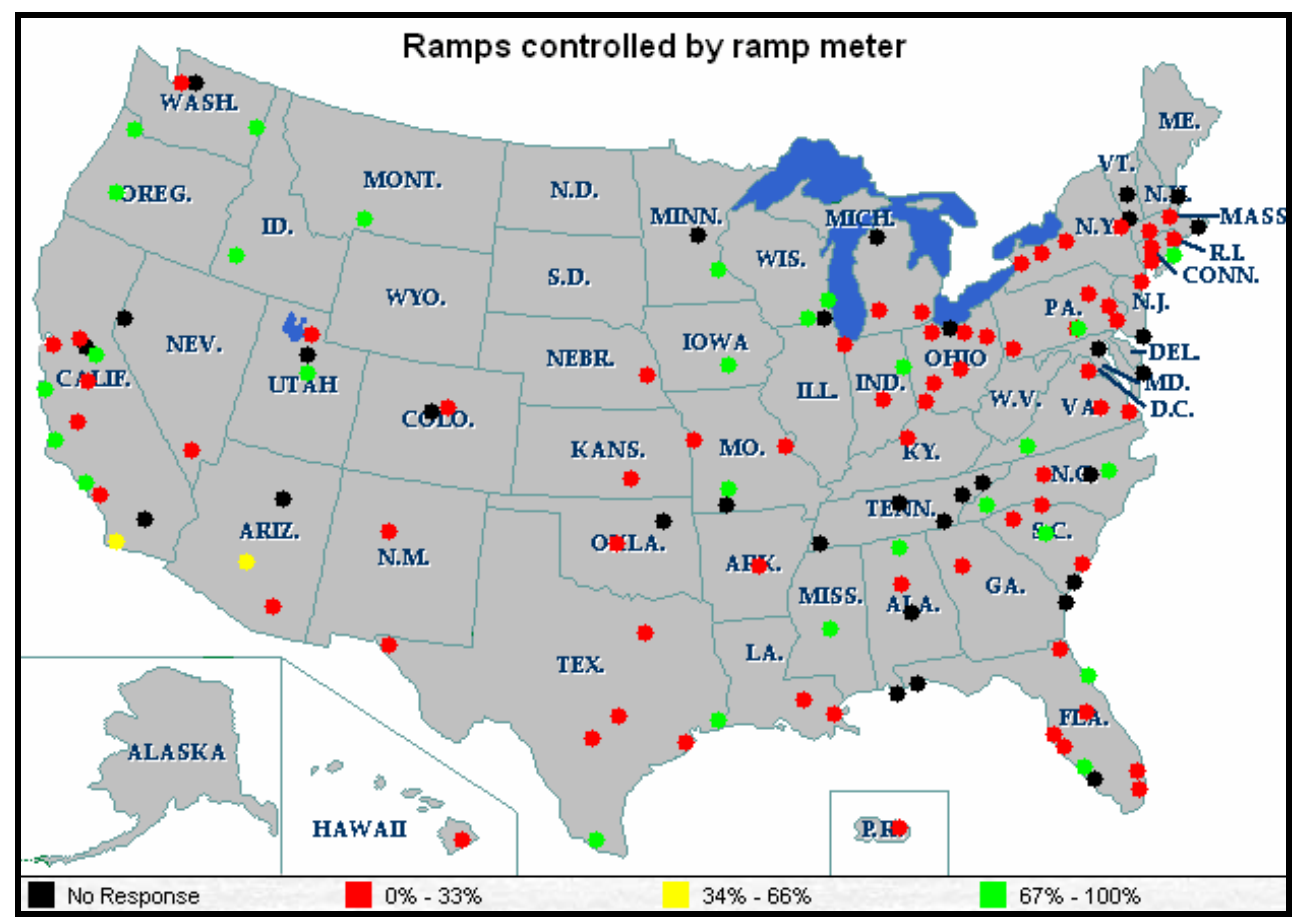

Figure 3.14: Ramps Controlled by Ramp Meter [ITS Deployment, 2003] 
There are over 450 pretimed ramp meters deployed in metropolitan areas, as shown in Table 3.4. Table 3.5 shows the number of traffic responsive meters by metropolitan area. Some metropolitan areas use both pretimed and traffic responsive meters [USDOT, 2004].

Table 3.4: Number of Pretimed Ramp Meters Deployed in Metropolitan Areas

\begin{tabular}{|l|c|}
\hline Metropolitan Area & Ramp Meters \\
\hline Los Angeles, Anaheim, Riverside, CA & 147 \\
Portland, OR; Vancouver, WA & 110 \\
New York, NY; Northern New Jersey, NJ; SW Connecticut, CT & 86 \\
Phoenix, AZ & 60 \\
Salt Lake City, Ogden, UT & 23 \\
Allentown, Bethlehem, Easton, PA & 14 \\
Philadelphia, PA; Wilmington, DE; Trenton, NJ & 6 \\
Milwaukee, Racine, WI & 6 \\
Atlanta, GA & 5 \\
San Diego, CA & 3 \\
Santa Barbara, CA & 1 \\
Beaumont-Port Arthur, TX & 1 \\
El Paso, TX & 1 \\
Salt Lake City, Ogden, UT & 1 \\
\hline \hline Total & 464 \\
\hline \hline
\end{tabular}

Table 3.5: Number of Traffic Responsive Ramp Meters Deployed in Metropolitan Areas

\begin{tabular}{|l|c|}
\hline Metropolitan Area & Ramp Meters \\
\hline Minneapolis, St. Paul, MN & 419 \\
San Diego, CA & 277 \\
San Francisco, Oakland, San Jose, CA & 191 \\
Los Angeles, Anaheim, Riverside, CA & 147 \\
Seattle, Tacoma, WA & 120 \\
Chicago, IL; Gary, IN; Lake County, IL & 113 \\
Milwaukee, Racine, WI & 107 \\
Sacramento, CA & 80 \\
Detroit, Ann Arbor, MI & 60 \\
Houston, Galveston, Brazoria, TX & 58 \\
Fresno, CA & 35 \\
Denver, Boulder, CO & 30 \\
Washington, DC & 24 \\
Columbus, OH & 15 \\
Phoenix, AZ & 12 \\
\hline \hline Total & 1688 \\
\hline
\end{tabular}


Tables 3.6 through 3.8 describe different types of ramp meters deployed in metropolitan areas. Table 3.6 lists the six agencies that reported having freeway-to-freeway ramp meters [USDOT, 2004].

Table 3.6: Number of Freeway-to-Freeway Ramp Meters

\begin{tabular}{|l|c|}
\hline Metropolitan Area & Ramp Meters \\
\hline Minneapolis, St. Paul, MN & 32 \\
Denver, Boulder, CO & 30 \\
San Diego, CA & 12 \\
San Francisco, Oakland, San Jose, CA & 10 \\
Milwaukee, Racine, WI & 5 \\
Portland, OR; Vancouver, WA & 1 \\
\hline \hline Total & 90 \\
\hline
\end{tabular}

Table 3.7: Number of Centrally Controlled Ramp Meters

\begin{tabular}{|l|c|}
\hline Metropolitan Area & Ramp Meters \\
\hline Minneapolis, St. Paul, MN & 419 \\
Seattle, Tacoma, WA & 120 \\
Chicago, IL; Gary, IN; Lake County, IL & 113 \\
Portland, OR; Vancouver, WA & 105 \\
Houston, Galveston, Brazoria, TX & 102 \\
New York, NY; Northern New Jersey, NJ; Southwestern Connecticut, CT & 83 \\
Sacramento, CA & 80 \\
Phoenix, AZ & 63 \\
Denver, Boulder, CO & 30 \\
Washington, DC & 24 \\
Columbus, OH & 15 \\
Atlanta, GA & 5 \\
Fresno, CA & 2 \\
El Paso, TX & 1 \\
\hline \hline Total & 1,162 \\
\hline
\end{tabular}

There are 14 agencies which reported having centrally controlled ramp meters, as shown in Table 3.7 and 12 agencies reported using HOV bypass lanes at ramp meters as shown in 3.8 [USDOT, 2004]. 
Table 3.8: Number of HOV Bypass Lanes at Ramp Meters

\begin{tabular}{|l|c|}
\hline Metropolitan Area & Ramp Meters \\
\hline San Diego, CA & 161 \\
Minneapolis, St. Paul, MN & 85 \\
Seattle, Tacoma, WA & 85 \\
San Francisco, Oakland, San Jose, CA & 66 \\
Milwaukee, Racine, WI & 62 \\
Sacramento, CA & 33 \\
Salt Lake City, Ogden, UT & 12 \\
Phoenix, AZ & 10 \\
Los Angeles, Anaheim, Riverside, CA & 5 \\
New York, NY; Northern New Jersey, NJ; Southwestern Connecticut, CT & 5 \\
Denver, Boulder, CO & 5 \\
Portland, OR; Vancouver, WA & 2 \\
\hline \hline Total & 531 \\
\hline \hline
\end{tabular}

Table 3.9 shows the areas using isolated, or stand-alone, ramp meters and Table 3.10 shows the metropolitan areas with ramp meters providing priority for transit vehicles [USDOT, 2004].

Table 3.9: Number of Isolated Ramp Meters

\begin{tabular}{|l|c||}
\hline Metropolitan Area & Ramp Meters \\
\hline San Diego, CA & 280 \\
San Francisco, Oakland, San Jose, CA & 191 \\
Los Angeles, Anaheim, Riverside, CA & 147 \\
Phoenix, AZ & 40 \\
Fresno, CA & 35 \\
Salt Lake City, Ogden, UT & 23 \\
Allentown, Bethlehem, Easton, PA & 14 \\
Philadelphia, PA; Wilmington, DE; Trenton, NJ & 6 \\
New York, NY; Northern New Jersey, NJ; Southwestern Connecticut, CT & 2 \\
Santa Barbara, CA & 1 \\
Salt Lake City, Ogden, UT & 1 \\
New York, NY; Northern New Jersey, NJ; Southwestern Connecticut, CT & 1 \\
\hline \hline Total & 741 \\
\hline
\end{tabular}


Table 3.10: Number of Ramp Meters Providing Priority for Transit Vehicles

\begin{tabular}{|l|c|}
\hline Metropolitan Area & Ramp Meters \\
\hline New York State DOT-Long Island Region 10 & 4 \\
Oregon Department of Transportation & 1 \\
Caltrans District 11 & 161 \\
Caltrans District 4 & 66 \\
\hline \hline Total & 232 \\
\hline
\end{tabular}

None of the agencies reported having ramp meters which provided preemption for emergency vehicles. Thirteen agencies reported having no deployed ramp metering and no plans to do so by 2008, but they had conducted a feasibility study [USDOT, 2004]. These agencies are as follows:

- Baltimore, MD

- Des Moines, IA

- Orlando, FL

- New York, NY; Northern New Jersey, NJ; Southwestern Connecticut, CT

- Pittsburgh, Beaver Valley, PA

- New York, NY; Northern New Jersey, NJ; Southwestern Connecticut, CT

- New London, CT

- New Haven, Meriden, CT

- Hartford, New Britain, Middletown, CT

- New York, NY; Northern New Jersey, NJ; Southwestern Connecticut, CT

- Austin, TX

- Washington, DC

- Greensboro, Winston-Salem, High Point, NC

\section{Houston, TX}

The Houston TranStar is responsible for the planning, design, operations, and maintenance of transportation operations and emergency management operations within the Greater Houston Area. The components of Houston TranStar include a freeway management system, a freeway and arterial street incident management program, ramp meter signals, closed circuit television verification, changeable message signs, HOV lane system, a regional computerized traffic signal system, intelligent transportation systems programs, emergency management operations, and motorist assistance program. Flow signals provide a positive means for managing freeway demand and enhancing safety with 113 ramps operating in 2003. The location of flow signals by freeway is listed in Table 3.11 [TTI, 2004]. 
Table 3.11: Operating Flow Signals by Freeway in Houston, Texas

\begin{tabular}{|l|c|}
\hline Freeway & Number of Flow Signals \\
\hline IH 10 Katy & 19 \\
IH 45 North & 20 \\
US 290 Northwest & 20 \\
US 59 Southwest & 14 \\
IH 45 Gulf & 26 \\
IH 610 Loop & 14 \\
Total & 113 \\
\hline
\end{tabular}

\section{Denver, CO}

Currently there are 55 ramp meters in the Denver metropolitan area. Colorado DOT typically places ramps at twolane entrances so that when the meters are operating and queues form, there are 2 queues of cars. They utilize advance "signal ahead" signs along with "when flashing" plaques so that motorist know that a ramp meter is approaching. The meter for each of the two lanes turns green at the same time. On the south portion of I-25 in Denver, the meters run between about 6:30 a.m.-6:30 p.m. The hours vary at other meters in Denver [Salek, 2004].

\section{Washington}

The ramp meters in the State of Washington respond to freeway conditions using loop detectors and WSDOT's central computers at the Traffic Systems Management Center in Shoreline. The systems utilizes a fuzzy logic algorithm to calculate meter rates. Operators may override computers if necessary and if the ramp queue begins to back up onto local streets, the ramp meter rate automatically increases [WSDOT, 2005].

\section{Minneapolis/ St. Paul, MN}

MnDOT has been operating an extensive ramp metering program since 1970. The first ramp meters were tested along I-35E in St. Paul and these meters were implemented to optimize freeway safety and efficiency. Currently Minnesota has 419 ramp meters and 213 of these meters are able to operate during morning peak period and 266 are able to operate in the evening peak period. Minnesota DOT uses a Stratified Ramp Metering algorithm to balance the metering rates based on existing traffic conditions. In general, about $80 \%$ of the freeway entrance ramps have ramp meters and there are ramp meters at $30 \%$ of the HOV bypasses.

\section{Phoenix, AZ}

In Phoenix, Arizona there are both pre-timed and traffic responsive ramp meters. The pre-timed meters are timed according to the time of day. The ramp meters are placed either on 1-lane, 2-lane or at an HOV bypass. Table shows the types of ramp meters utilized in the Phoenix, Arizona area. Currently there are 170 freeway on-ramps which do not have any ramp metering equipment installed. 
Table 3.12: Phoenix-Area Ramp Meter Information, November 2004

\begin{tabular}{|llcccc|}
\hline \multicolumn{2}{l}{ Ramp Meter Installed (Operational) } & & & \\
Category & Type of Meter & 1-Lane & 2-Lane & HOV Bypass & Total \\
\hline FMS & Time of Day & 15 & 41 & 0 & 56 \\
FMS & Traffic Responsive & 7 & 23 & 1 & 31 \\
Non-FMS & Time of Day & 12 & 5 & 0 & 17 \\
& & & & & \\
\hline Ramp Meter Installed (Non-Operational) & 12 & 8 & 0 & 20 \\
FMS & - & 1 & 3 & 0 & 4 \\
Non-FMS & - & & & & \\
\hline
\end{tabular}

\section{Utah}

Utah Department of Transportation has 23 ramp meters. These meters are installed on I-15 between Draper and Farmington. The meters operate by time-of-day (TOD). This system uses a constant programmed rate that is based on time. Recently the rates were optimized. UDOT is considering a traffic-responsive system [Taylor, 2004].

\subsubsection{Ramp Metering Implementation outside of the United States}

Outside of the United States, ramp metering is used in various countries including Britain, Canada, France, Germany, and the Netherlands. Table 3.13 summarizes the number of ramp meters deployed in the countries outside the U.S. [TRANSCORE, 1999].

Table 3.13: Ramp Meters outside United States

\begin{tabular}{|l|l|c|}
\hline \multicolumn{1}{|c|}{ Country } & \multicolumn{1}{c|}{ Area } & Number of Ramps \\
\hline \multirow{2}{*}{ Britain } & Birmingham & 6 \\
\cline { 2 - 3 } & Glasgow & 1 \\
\hline Canada & Toronto & 10 \\
\hline France & Paris & 3 \\
\hline \multirow{2}{*}{ Germany } & Munich & 3 \\
\cline { 2 - 3 } & Duisburg & 28 \\
\hline \multirow{3}{*}{ Netherlands } & Coentunnel & 5 \\
\cline { 2 - 3 } & Amsterdam & 4 \\
\cline { 2 - 3 } & Zoetermeer & 9 \\
\hline
\end{tabular}

\subsection{EFFECTIVENESS OF RAMP METERING OPERATIONS}

Ramp metering has the potential to mitigate stop-and-go conditions on the freeway, improve freeway throughput and reduce accident rate. The potential benefits of ramp metering include efficient use of capacity, improved safety, reduced vehicle emissions on freeways, and travel time savings as summarized in Table 3.14. Measures of effectiveness vary from state to state and depend on the objectives of the system. Ramp meters are often implemented at the same time as other freeway improvement techniques such as HOV lanes, surveillance systems, and incident management programs. Studies show that ramp metering improves mainline traffic flow, increases travel speeds, and improves travel time reliability. Peak demands could normally cause the mainline flow to breakdown however with ramp metering; these peak demands can be smoothed out. Ramp metering also helps to reduce 
the number of crashes [Piotrowicz, 1995]. Table 3.15 presents a list of quantitative impacts of ramp metering. A discussion of impacts of experienced in various metropolitan areas is provided in the following.

Table 3.14: Estimated Benefits of Ramp Metering Systems

\begin{tabular}{|c|l|}
\hline Benefit & \multicolumn{1}{c|}{ Description } \\
\hline Efficient Use of \\
Capacity & $\begin{array}{l}\text { If there is excess capacity on surface streets, it may be worthwhile to divert traffic from } \\
\text { congested freeways to surface streets, and discourage trip paths with high societal costs. } \\
\text { A driver with a simple inexpensive alternative to a congested freeway should be } \\
\text { Ramp metering can also result in temporal diversion, where drivers shift ramp arrival } \\
\text { time. Empirical results show these shifts can results in up to l5\% reductions in } \\
\text { premetering volumes. Flow peaks are thus spread out over a longer period resulting in } \\
\text { better freeway capacity utilization. }\end{array}$ \\
\hline Improved Safety & $\begin{array}{l}\text { Reduced turbulence in merge zones can lead to reduced sideswipe and rear-end type } \\
\text { accidents which are associated with unmetered areas. Such turbulence is generated by } \\
\text { platoons of entering vehicles which disrupt mainline flow. Similarly, if metering prevents } \\
\text { a bottleneck, one can also expect safer conditions through the reduced variance in speed } \\
\text { distributions. }\end{array}$ \\
\hline Reduced Vehicle & $\begin{array}{l}\text { Smoother traffic flow resulting in less speed variation on a metered freeway can lead to } \\
\text { substantial reduction in emissions and fuel savings. }\end{array}$ \\
\hline Travel Time Savings & $\begin{array}{l}\text { If properly implemented metering can significantly increase peak speeds and reduce } \\
\text { positive. }\end{array}$ \\
\hline \hline
\end{tabular}

\section{Minneapolis/St. Paul, MN}

In a computer simulation study for the Minnesota DOT, it was shown that total travel time on the mainline decreased by $46 \%$ and $24 \%$ when ramp metering controls were used under typical traffic congestion conditions and heavy congestion conditions, respectively. There was substantial increase of total delays for vehicles on the ramp waiting to enter the freeway. However, overall system travel time and delay were reduced by $35 \%$ and $62 \%$, respectively. Under both traffic scenarios, it was found that higher speeds were achieved and flow was generally smooth throughout the freeway [ITS Sensor, 1999].

The Minnesota Department of Transportation (MnDOT) found similar benefits of ramp metering as those observed by WSDOT. A study was conducted [MnDOT, 2001] by Cambridge Systematics for the MnDOT where impacts associated with turning off, of all the ramp meters in the twin cities metro area were determined. The following observations were made:

- Freeway volume reduces by $9 \%$

- Freeway travel times increased by $22 \%$

- Freeway speeds reduced by $7 \%$ which contributed to the reduced travel times on the freeway.

- The reliability of travel time on the freeway reduced by $91 \%$.

- The total number of crashes increased by $26 \%$, with a $14.6 \%$ increase in rear end crashes, $200 \%$ increase in side swipe crashes, $60 \%$ increase in run-off the road crashes and an $8.6 \%$ increase in other types of crashes 
Table 3.15: Ramp Metering Impacts

\begin{tabular}{|c|c|c|c|c|c|c|c|}
\hline & Minnesota & Austin & Denver & Michigan & $\begin{array}{l}\text { New } \\
\text { York }\end{array}$ & Portland & Seattle \\
\hline $\begin{array}{c}\text { System Travel } \\
\text { Time }\end{array}$ & $-35 \%$ & & & & & & \\
\hline System Delay & $-62 \%$ & $\begin{array}{c}\text {-2875 veh- } \\
\text { hr daily }\end{array}$ & & & & & \\
\hline $\begin{array}{c}\text { Mainline } \\
\text { Travel Time }\end{array}$ & $-24 \%$ to $-46 \%$ & & & & lower & & $-47 \%$ \\
\hline $\begin{array}{c}\text { Mainline } \\
\text { Throughput }\end{array}$ & & $+8 \%$ & & $+14 \%$ & & & $+86 \%$ \\
\hline $\begin{array}{c}\text { Mainline } \\
\text { Speed }\end{array}$ & & $+60 \%$ & $+58 \%$ & $+8 \%$ & $+20 \%$ & $\begin{array}{c}\text { NB } \\
\text { speeds:Before: } \\
\text { 16 After: } 41 \text { mph } \\
\text { SB Speeds:3 } \\
\text { mph increase }\end{array}$ & \\
\hline Crash Rate & & & $-5 \%$ & $\begin{array}{l}-50 \% \text { total - } \\
71 \% \text { injury }\end{array}$ & lower & $\begin{array}{c}\text {-43\% (especially } \\
\text { rear-end and } \\
\text { sideswipe) }\end{array}$ & $-40 \%$ \\
\hline Emissions & & & $-24 \%$ & & & & \\
\hline
\end{tabular}

\section{Austin, TX}

In Austin, Texas, it was found that the installation of three ramp meters along northbound section of I-35 resulted in an $8 \%$ increase in throughput and a $60 \%$ increase in speeds [Pearson, 2001]. At Houston, where ramp meters were installed along the I-10 Katy Freeway in 1996, it was found that there was a daily savings of 2,875 vehicle-hours for 150 days every year, compared to pre-metered conditions [Parsons and TTI, 1997].

\section{Denver, CO}

In Denver, Colorado, five ramp meters installed on I-25 were evaluated in 1981/82. It was found that speeds increased significantly by $58 \%$, vehicle hours of travel decreased by $37 \%$, vehicle emissions dropped by $24 \%$, and accidents decreased by 5\%. Stop-and-go conditions on the freeway were completely eliminated, and the system was a public relations success, receiving accolades from the media. It was found that motorists shifted their ramp arrival times to avoid ramp delays, and flows on area arterials increased fourfold, resulting in virtually no degradation of surface street conditions. The Denver system was subsequently expanded to a centralized system with additional meters. 


\section{Michigan}

Ramp metering has been an important aspect of Michigan DOT's Surveillance and Driver Information System (SCANDI), and ramp meters were installed in 1982 with six ramps on eastbound I-94. It was determined that this investment yielded an 8\% increase in speeds, even though volumes increased from 5600 to $6400 \mathrm{vph}$. Also, the impact on safety was very substantial: the total number of crashes was reduced by $50 \%$, and the number of injury crashes dropped by $71 \%$.

\section{New York, NY}

The New York Department of Transportation installed sixty ramp meters on the eastbound Long Island Expressway and evaluated the impacts of this investment in 1987-90. It was found that mainline travel times decreased by 4 minutes, and an average motorists using a metered ramp saved $13 \%$ in travel time. There was no conclusive results with regard to impacts on throughput volume, and at some sections, there was reduction in travel speed. A public survey showed that equal numbers of users (40\%) viewed the system favorable and unfavorably [Pearson, 2001]. More recent studies demonstrate the effectiveness of ramp metering has increased mainline speed approximately by $20 \%$. It has also reduced travel time, congestion and crashes.

\section{Portland, OR}

In Portland, Oregon, ramp meters were installed along I-5 in 1981, and it was found that average northbound speeds increased from 16 to $41 \mathrm{mph}$. Pre-metered conditions were less severe in the southbound direction, as such average speeds increased only by $3 \mathrm{mph}$ (to $43 \mathrm{mph}$ ). Also, it was found that fuel consumption decreased by 540 gallons per weekday, and there was $43 \%$ reduction in peak period accidents, particularly rear-end and side-swipe crash types [ODOT, 1985].

\section{Seattle, WA}

According to Washington Department of Transportation (WSDOT), a major goal of ramp metering is to keep the freeway moving at a reasonable speed [WSDOT, 2005]. WSDOT found that ramp metering reduces congestion, collisions, and travel times while increasing freeway speeds, reliability and throughput.

The Washington DOT implemented ramp metering on I-5 north of the Seattle Central Business District. In a six-year evaluation period, it was found that travel time dropped from 22 minutes before metering to 11.5 minutes after, even though mainline volumes increased by $86 \%$. Also, the crash rate decreased by almost $40 \%$ [WSDOT, 1996]. Other studies for ramp metering have shown that such systems have reduced average trip times and increased freeway vehicle flows, both on the order of 10-15 percent [Johnston et al., 1995]. Ramp metering has reduced travel time (because delays occur at entrance ramps where they affect fewer motorist), improved travel time reliability, reduced fuel consumption and vehicle emissions, reduced crashes, increased driver satisfaction, and increased capacity. In another study, ramp metering alone was shown to reduce travel time by 13 to 60 percent and to reduce accidents by 24 to 50 percent [Dudek and Ullman, 1992]. 
Carpools, vanpools, bus, and HOV lanes are allowed to bypass the meters without stopping to save time. Figure 3.15 shows how ramp meters have been effective in eliminating stop and go conditions on SR-520 in the EB direction during the morning peak period. The stop-and-go traffic was limited to a total duration of about 15 minutes after the implementation of ramp metering. As a result congestion was reduced while increasing vehicle throughput and freeway speeds.

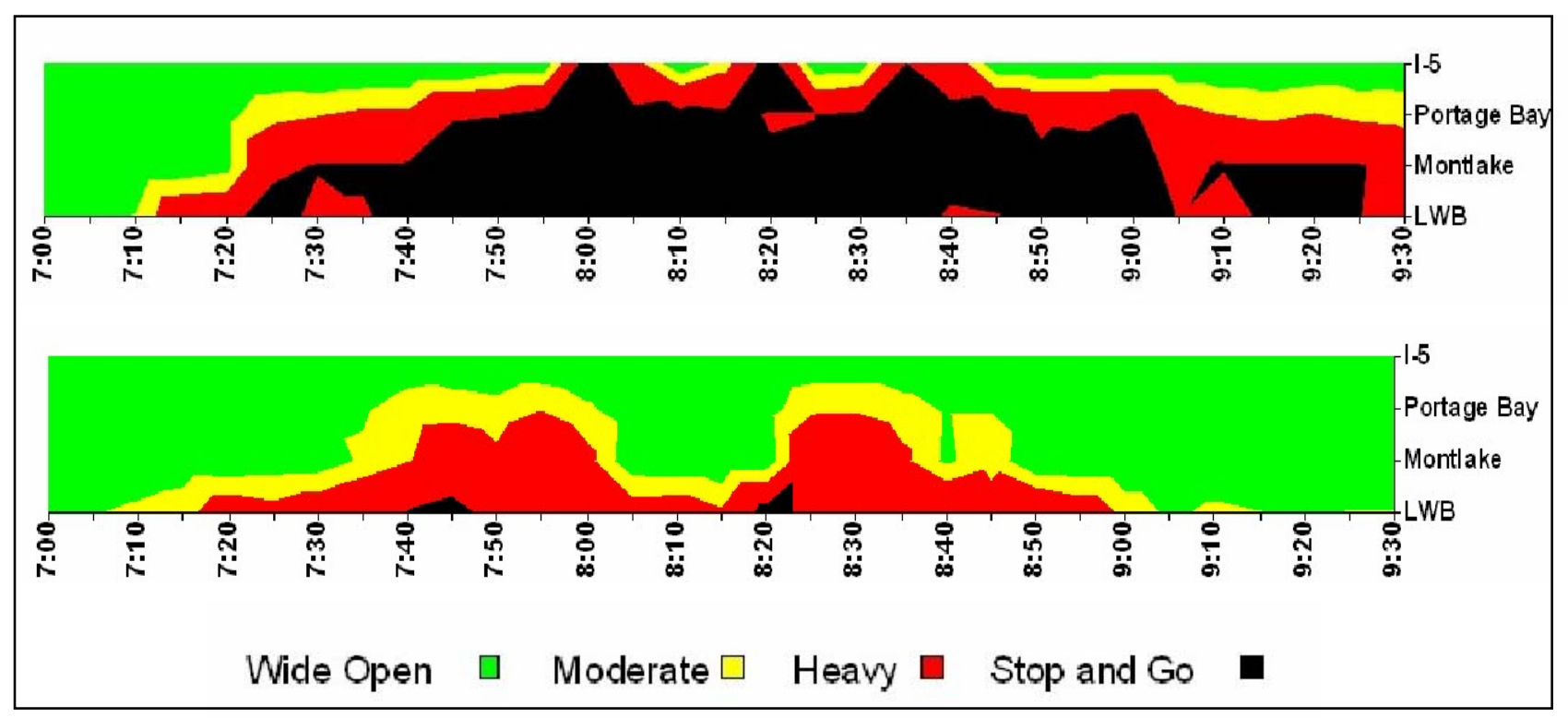

Figure 3.15: SR-520 EB Morning Congestion, I-5 to Lake Washington Blvd. in Sept. 2001 [WSDOT, 2005]

\section{Great Britain}

In Great Britain, a fixed time ramp and variable message sign were installed on M6 in an attempt to address severe congestion on that highway. This resulted in increased bottleneck capacity (by 3.2\%) and decreased total delay. Less than $5 \%$ of drivers were diverted to surface streets, even though motorists shifted their ramp arrival times to earlier periods. The system was found to be more effective in Summer than in Winter, as lower speed in the latter season made it difficult to prevent flow breakdown [Pearson, 2001]. 


\section{6}

\section{COSTS OF RAMP METERING FACILITIES}

Costs associated with ramp metering include the monetary cost of installation, operation \& maintenance along with the non-monetary costs of adverse impacts, equity and public reaction. Table 3.16 summarizes some of the possible costs of ramp metering systems.

Table 3.16: Possible Cost of Ramp Metering Systems [Deakin, 2002]

\begin{tabular}{|c|c|}
\hline Potential Cost & Description \\
\hline Diversion & $\begin{array}{l}\text { Diversion involves the diversion of trips from the freeway to alternate surface } \\
\text { network routes. Factors which influence diversion include O-D patterns, trip length, } \\
\text { ramp delays, and the quality of alternate routes. Conceptually, freeways were not } \\
\text { designed for short trips, so diversion may be desirable if surface streets are under } \\
\text { utilized. Even if alternate routes do not exist, experiences in Virginia, Chicago, and } \\
\text { Denver indicate that metering can still be effective. }\end{array}$ \\
\hline Equity & $\begin{array}{l}\text { Because ramp metering favors through traffic, metering benefits longer trips at the } \\
\text { expense of "local" motorists. Trips may be diverted to local surface streets, and } \\
\text { residents close to the CBD may be deprived of access given to suburban dwellers. In } \\
\text { Milwaukee, where equity proved to be a delicate subject, metering rates were adjusted } \\
\text { so that delay to the average motorist was the same on close-in ramps and on outlying } \\
\text { ramps. }\end{array}$ \\
\hline $\begin{array}{l}\text { Installation and } \\
\text { Maintenance Costs }\end{array}$ & $\begin{array}{l}\text { Depending on existing ramp configuration and the size of the system, capital and } \\
\text { maintenance costs can be sizable. Ramp metering systems typically have high costs } \\
\text { associated with the communication medium connecting the ramps to the control } \\
\text { center. }\end{array}$ \\
\hline On-Ramp Emissions & $\begin{array}{l}\text { Local emissions near the ramp may increase from stop-and-go conditions and vehicle } \\
\text { queuing on the ramp. }\end{array}$ \\
\hline Promotes Longer Trips & $\begin{array}{l}\text { There is evidence that metering results in longer trips replacing shorter trips, as those } \\
\text { trips taking up critical bottleneck capacity are also likely to use the long un congested } \\
\text { upstream or downstream freeway sections. Such catering to longer trips can have } \\
\text { negative feedback effects, encouraging rather than discouraging commutes from } \\
\text { further out. }\end{array}$ \\
\hline Ramp Delay and Spill Back & $\begin{array}{l}\text { Queues which back up onto adjacent arterial streets can adversely affect the surface } \\
\text { network. Those vehicles which use the ramp are delayed as they pass through the } \\
\text { meter. }\end{array}$ \\
\hline Public Opposition & $\begin{array}{l}\text { In addition to physical requirements of the ramp, the feasibility of implementing ramp } \\
\text { metering control is dependent on public acceptance of ramp metering. The issue of } \\
\text { public acceptance is critical, as the public is bound to be critical of a new installation. }\end{array}$ \\
\hline Transfer of Land Values & $\begin{array}{l}\text { Users who have been accustomed to ready freeway access may be rerouted in favor of } \\
\text { new users, which can cause land values to change. }\end{array}$ \\
\hline
\end{tabular}


The annual operation and maintenance cost of Minnesota DOT (MnDOT) ramp metering in fiscal year (FY) 2000 was $\$ 210,000$. This cost includes the staff needed to monitor and adjust meter settings, to conduct field reviews, and to respond to inquiries from the public and media [Staples, 2001]. The Arizona Department of Transportation estimated the construction cost of a two-lane ramp meter as $\$ 60,000$, maintenance costs $\$ 1,000$ per year and operation (electricity) costs $\$ 150$ per year [Maccubbin, 2003]. Each ramp meter site in Colorado had a cost of approximately $\$ 50,000$. This cost included the controller and approximately $15 \%$ mark-up for design. The cost did not include cost of communication infrastructure to the installation [Maccubbin, 2003].

A 2003 evaluation of Utah Commuter Link Advanced Transportation Management System (ATMS) was conducted in order to assess the benefits and costs of the system. The total capital cost of the ATMS was approximately \$106 million. Annual maintenance cost was \$377,800 and annual operational cost was \$2.3 million. The total capital cost for ramp metering was approximately $\$ 5.75$ million and the annual maintenance and operational costs were $\$ 13,800$ and approximately $\$ 8,000$ respectively. According to the National ITS Architecture Cost Analysis Study [1996], the cost of ramp meters for freeway control including the controller, power etc. ranged from $\$ 30,000$ to $\$ 50,000$ (1995 Dollars) with a life cycle of five years.

Table 3.17 shows the various cost components of ramp metering updated to the 2005 dollars using the FHWA construction price index.

Table 3.17: Ramp Metering Cost Components For Different Places in the US

\begin{tabular}{|c|c|c|c|c|c|c|}
\hline & Minnesota & Arizona & Colorado & TTI & CALTRANS & $\begin{array}{l}\text { National ITS } \\
\text { Architecture Study }\end{array}$ \\
\hline Construction & & $\$ 60,000$ & $\$ 50,000$ & $\$ 40,000$ & $\$ 65,000$ & $\$ 40,000$ to $\$ 60,000$ \\
\hline $\begin{array}{l}\text { Maintenance } \\
\text { (Annual) }\end{array}$ & & $\$ 1,000$ & & & & $\$ 1,500$ to $\$ 2,500$ \\
\hline $\begin{array}{l}\text { Operation } \\
\text { (Annual) }\end{array}$ & & $\begin{array}{l}\text { \$150 } \\
\text { (Electricity } \\
\text { only) }\end{array}$ & & & & \\
\hline $\begin{array}{l}\text { Maintenance and } \\
\text { Operation } \\
\text { (Annual) }\end{array}$ & $\begin{array}{l}\$ 210,000 \\
\text { (Systemwide) }\end{array}$ & & & & & \\
\hline
\end{tabular}


Clark and Scherer (2000) used the following rules to calculate the cost of ITS deployment schemes such as ramp metering. The costs were broken into three major categories: initial costs, installation costs, and maintenance and operation costs.

\section{a) Initial Costs}

The initial cost is the same regardless of the complexity of the deployment scheme.

- $\$ 10,000$ needed for engineering staff to perform traffic analysis and generate ramp metering system design.

- $\$ 3000$ required for publicity needed to educate the public about the meters

\section{b) Installation Costs}

The installation costs can be broken down into two types. Fixed installation costs are the same regardless of the complexity of the deployment scheme. Variable equipment costs depend on the amount of equipment deployed. The fixed installation cost comprises of the following components:

- Communication from detectors to meters (twisted pair wire): \$79,040

- Communication Hub: $\$ 100,000$

The variable installation costs comprise of the following components:

- Vehicle Detector: \$2,200 per loop (1 loop needed in each lane)

- 170 Series Processor: \$6,250 each (1 needed per detector group)

- $\quad$ Ramp Meter: \$35,000 per interchange (regardless of pre-timed or traffic responsive)

\section{c) Maintenance \& Operating Costs}

The annual operation and maintenance costs were estimated to be $10 \%$ of the total installation cost. These costs were calculated using a 5 year planning horizon. 


\subsection{WARRANTS FOR RAMP METERING}

\subsubsection{Manual of Uniform Traffic Control Devices (MUTCD)}

The 2003 edition of MUTCD (Chapter 4H) suggests that ramp metering is warranted if at least one of the following conditions exists:

A. Congestion recurs on the freeway because traffic demand is in excess of the capacity, or congestion recurs or a high frequency of crashes exists at the freeway entrance because of inadequate ramp merging area. A good indicator of recurring freeway congestion is freeway operating speeds less than $80 \mathrm{~km} / \mathrm{h}$ (50 mph) occurring regularly for at least a half-hour period. Freeway operating speeds less than $50 \mathrm{~km} / \mathrm{h}(30 \mathrm{mph})$ for a half-hour period or more would indicate severe congestion.

B. Controlling traffic entering a freeway assists in meeting local transportation system management objectives identified for freeway traffic flow, such as the following:

- Maintenance of a specific freeway level of service.

- Priority treatments with higher levels of service for mass transit and carpools.

- Redistribution of freeway access demand to other on-ramps.

C. Predictable, sporadic congestion occurs on isolated sections of freeway because of short-period peak traffic loads from special events or from severe peak loads of recreational traffic.

\subsubsection{Individual Warrants}

1. Recurring Congestion Warrant: Does the freeway operate at speeds less than $50 \mathrm{mph}$ for a duration of at least 30 minutes for 200 or more calendar days per year?

2. Collision History Warrant: Is there a high frequency of crashes (collision rate that exceeds in the subject metropolitan area) near freeway entrances due to inadequate merge area and congestion?

3. Freeway Level of Service: Will the ramp meter or system of ramp meters contribute to maintaining a specific level of service in the region’s transportation systems management plan?

4. Modal Shift: Will the ramp meter or system of ramp meters contribute to maintaining a higher level of vehicle occupancy through the use of HOV preferential treatments as identified in the region's transportation systems management plan?

5. Redistribution of Access: Will the ramp meter or system of ramp meters contribute to balancing demand and capacity at a system of adjacent ramps entering the same facility? 
6. Sporadic Congestion Warrant: Does the ramp meter or system of ramp meters mitigate predictable sporadic congestion on isolated sections of freeway because of short period peak loads from special events or severe peak loads of recreational traffic?

7. Total Volume Warrant: Is the ramp plus freeway volume greater than the tabulated (Table 3.18) criteria for the design hour?

Table 3.18: Threshold Volumes for Ramp Metering

\begin{tabular}{|c|c|}
\hline $\begin{array}{c}\text { Freeway lanes in one direction } \\
\text { including Auxiliary Lanes* }\end{array}$ & Criteria Volume=Ramp plus Freeway Volume \\
\cline { 2 - 2 } & Downstream of Gore in vph \\
\hline 2 & 2650 \\
\hline 3 & 4250 \\
\hline 4 & 5850 \\
\hline 5 & 7450 \\
\hline 6 & 9050 \\
\hline
\end{tabular}

*lanes that continue at least 1/3 miles downstream from ramp gore

8. Right Lane plus Ramp volume Warrant: Does the volume of the ramp plus freeway right lane exceed 2100 vph?

9. Geometric Warrant: Does the existing or proposed ramp geometry permit safe and effective ramp metering, and provide adequate merging distance with the freeway?

\section{Overall Ramp Metering Warrants}

10. Are any of warrants one, two, three, four, five or six satisfied? If yes to any go to step 2 . If no to all, stop, ramp metering is not warranted.

11. Are warrants seven or eight satisfied? If yes, go to step 3, else stop, ramp metering is not warranted.

12. An exception to the above two criteria is that ramp metering may be warranted solely due to current or anticipated high collision rates at a location. So in certain cases (at the discretion of ADOT) if warrant two is satisfied, ramp metering can be warranted even if both warrants seven and eight are not satisfied.

13. Is Warrant nine satisfied? If yes, ramp metering is warranted. If no, stop, ramp metering is not warranted. 


\subsection{RAMP METERING DESIGN AND IMPLEMENTATION CONSIDERATIONS}

This section discusses the various design and implementation considerations for ramp metering. These guidelines should be followed once it has been determined that ramp metering is warranted (using the warrants in Section 3.7).

\subsubsection{Caltrans Guidelines}

In 2000, a comprehensive supplement to the Highway Design Manual for the design and operation of Ramp Meters was prepared by the Traffic Operations Program in California, in cooperation with Design and Local Programs and Department of California Highway Patrol. The supplement states the following guidelines for ramp metering implementation.

- Ramp Characteristics: Ramps themselves must possess characteristics suitable for metering, namely the availability of vehicle storage space on the ramp, and adequate acceleration and merge distance downstream of the meter cordon line. Storage requirements to prevent queues from backing up onto the arterial network, can be estimated from the projected metering rate and ramp demand.

- Metered Single-Lane Entrance Ramps: Geometrics for a single lane ramp meter should be provided for volumes up to 900 vehicles per hour. When truck volumes ( 3 axle or more) are $5 \%$ or greater on ascending entrance ramps to freeways with sustained upgrades exceeding 3\% (i.e. atleast throughout the merge area), a minimum of $150 \mathrm{~m}$ length of auxiliary lane should be provided beyond the ramp convergence point.

- Metered Multi-Lane Entrance Ramps: A multilane entrance ramp is provided to increase the number of vehicles that can be stored in a given ramp length and/or to create a preferential lane for the HOVs. When entrance ramp volumes exceed $900 \mathrm{vph}$, and/or when an HOV lane is determined to be necessary, a 2 or 3 lane ramp segment should be provided.

- Ramp Pavement Width: Caltrans recommends a minimum lane width of $3.6 \mathrm{~m}$ per lane for 1 , 2 or 3 lane ramps. The inside shoulder width for 1 and 2 lane ramps is recommended as $1.2 \mathrm{~m}$ and the outside shoulder width is recommended as $2.4 \mathrm{~m}$.

- Metered Freeway to Freeway Connectors: Freeway to freeway connectors can also be metered if warranted. The need to meter a freeway to freeway connector ramp should be determined on individual basis. These freeway to freeway connector ramps connect two high speed facilities and hence drivers using these ramps do not expect to stop, nor do they expect to approach a stopped vehicle. The installation of ramp meters on connector ramps shall be limited to those facilities which meet or exceed the following geometric design criteria:

- Standard lane and shoulder widths

- "Tail Light” sight distance is provided for a design speed of $50 \mathrm{mph}$ (the control objects used for sight distance calculation on freeways are the tail lights of a passenger car)

The following factors should be considered before the implementation of ramp metering. Issue: queue backup onto surface streets. In order to address this problem, many ramp metering strategies automatically release vehicles into the freeway or an operator can override the preset rates and allow vehicles to enter the freeway. 


\subsubsection{Minnesota Department of Transportation Guidelines}

The Minnesota Department of Transportation report [Cambridge Systematics, 2002] lists several keys to a successful program. These recommendations are listed in Table 3.19.

\subsubsection{Washington Department of Transportation (WSDOT) Guidelines}

WSDOT engineer's analyze each ramp using traffic data and computer modeling techniques to determine if implementation of ramp metering will reduce congestion and improve level of service. The following factors are particularly considered by the engineers [WSDOT, 2005]:

- $\quad$ Ramp Volumes

- $\quad$ Physical Layout of the Ramps

- Mainline Traffic Volumes

Furthermore, WSDOT found that ramp meters are most effective when metering is started before congested conditions prevail on the highway [WSDOT, 2005]. Metering on the ramp is activated as soon as traffic volumes start to build on the mainline so that ramp meters can extend the free flow conditions for as long as possible. WSDOT found that if meters are turned on late, when the freeway has already become congested, the benefits of ramp metering are significantly reduced. In addition, it was found that the meters should not be turned off the instant, speeds rise on the mainline. The ramp meters should be programmed such that as the mainline clears, the metering rates increase accordingly to allow as much traffic from the ramp to enter the mainline as possible without causing congestion.

\subsubsection{Arizona DOT Guidelines}

The ADOT (Arizona Department of Transportation, Ramp Meter Design, Operations and Maintenance Guidelines, August 2003) prescribes a set of warrants for assessing the suitability of deploying ramp meters at a study location. This set of warrants has the following data requirements:

- Current traffic volumes for both freeway and the ramp (to be collected at a maximum of 15 minute intervals)

- Future traffic volumes for design year for both freeway and ramp

- Accident data for both freeway and ramp

- Freeway and Ramp Operating Speeds 
Table 3.19: Keys to a Successful Ramp Metering System, Minnesota Department of Transportation

\begin{tabular}{|c|c|}
\hline Select the right place & $\begin{array}{l}\text { In order to realize significant positive benefits of ramp metering, it is necessary to implement } \\
\text { ramp metering in freeway sections that actually need it. Appropriate locations typically have } \\
\text { the following characteristics: peak-period speeds less than } 30 \mathrm{mph} \text {, flow of } 1,200 \text { to } 1,500 \\
\text { vphpl, high accident rates, and significant merging problems. }\end{array}$ \\
\hline Secure funding & $\begin{array}{l}\text { Before embarking on a ramp metering program, make sure that the local politicians and city } \\
\text { officials are committed to funding the program. In some cases, public-private partnerships can } \\
\text { forge a more secure funding situation. }\end{array}$ \\
\hline $\begin{array}{l}\text { Start small and } \\
\text { simple }\end{array}$ & $\begin{array}{l}\text { Cities trying to implement ramp metering for the first time should start with a few ramps, with } \\
\text { a fixed-time control, adopting a more conservative strategy. }\end{array}$ \\
\hline $\begin{array}{l}\text { Excellent public } \\
\text { support }\end{array}$ & $\begin{array}{l}\text { All implementing cities believe that public education and support are critical to the success of } \\
\text { their ramp metering programs. }\end{array}$ \\
\hline $\begin{array}{l}\text { Ample storage } \\
\text { capacity }\end{array}$ & $\begin{array}{l}\text { Most cities would like to have longer and wider ramps, to prevent queues from extending } \\
\text { beyond the ramps, onto the arterials. If long queues with backups onto the arterials occur on a } \\
\text { consistent basis, good queue detection systems, and adopting a more conservative strategy } \\
\text { may be necessary. }\end{array}$ \\
\hline Synergy & $\begin{array}{l}\text { Use other forms of Intelligent Transportation Systems (ITS) to eliminate disadvantages found } \\
\text { in ramp metering alone (i.e., ramp delays or increases in arterial volumes). Agencies may } \\
\text { couple ramp metering with ramp queue wait time signs or an Advanced Traveler Information } \\
\text { System (ATIS) that can inform motorists of crowded ramps, or provide motorists with options } \\
\text { of different travel modes, times, or routes. }\end{array}$ \\
\hline $\begin{array}{l}\text { Avoid conflicting } \\
\text { solutions }\end{array}$ & $\begin{array}{l}\text { Mainline freeway HOV lanes and ramp meters are two freeway management solutions that } \\
\text { may not work well together. In some cases, mainline HOV lanes are believed to dilute the } \\
\text { benefits of ramp metering. Without HOV bypass lanes or direct HOV connectors, metering } \\
\text { may impose unnecessary delay to buses and carpools. }\end{array}$ \\
\hline $\begin{array}{l}\text { Eliminate technical } \\
\text { problems }\end{array}$ & $\begin{array}{l}\text { Make sure the system is free from technical breakdowns, to sustain high public trust and } \\
\text { compliance rates }\end{array}$ \\
\hline $\begin{array}{l}\text { Consistent } \\
\text { enforcement }\end{array}$ & $\begin{array}{l}\text { A study by Newman et al. showed that consistent police enforcement, though costly, is the } \\
\text { most effective enforcement strategy }\end{array}$ \\
\hline $\begin{array}{l}\text { Continuous } \\
\text { improvement }\end{array}$ & $\begin{array}{l}\text { Upgrade the fixed or traffic responsive controllers to central or fuzzy logic controllers. Central } \\
\text { control offers greater benefits because it can monitor an entire system, while fuzzy logic } \\
\text { controllers eliminates the possibility of processing and applying imprecise or erroneous traffic } \\
\text { data. }\end{array}$ \\
\hline
\end{tabular}




\subsection{SUMMARY}

The objective of this chapter was to identify the components of ramp metering and present guidelines and warrants that could be used in the implementing of ramp metering. A synthesis study was performed to study the ramps metering systems implemented at various places in the country, to study the benefits of ramp metering, and to summarize the guidelines and warrants that need to be satisfied for the implementation of ramp metering. The guidelines given by MUTCD, Caltrans and the Minnesota Department of Transportation were reviewed. Various types of ramp metering strategies, algorithms and geometric designs were also discussed along with the current status of ramp metering in the US. 


\section{$4 \quad$ I-70 Case Study}

\subsection{INTRODUCTION}

This chapter discusses the feasibility of implementation of HOV lanes and Ramp Metering on the east leg of I-70 between I-65 and I-465 in Indianapolis. The chapter presents the results of analyses of the travel pattern, hourly traffic volume, congestion level and level of service (speed) along the six-mile corridor. The economic feasibility of the HOV lanes and Ramp Metering has been determined separately. The economic feasibility has been determined based on the benefit-to-cost ratio. The benefits include the monetized travel time savings, vehicle operating cost savings and emission savings. The costs were estimated by summing up the capital, operation, maintenance and enforcement costs.

\subsection{I-70 CORRIDOR DESCRIPTION}

The schematic diagram of the east leg of I-70 between I-65 and I-465 is shown in Figure 4.1. The figure presents the location of the on-ramps and off-ramps in the EB and WB directions relative to the interchanges. The mileposts of the five interchanges along the six-mile stretch are also shown in the figure. The east leg of I-70 under study extends from Milepost 13.94 (Interchange 83) until Milepost 20.17 (Interchange 90). There are five interchanges on this sixmile section:

Interchange 83: I-70 and I-65 interchange (Milepost: 13.94)

Interchange 85: I-70 and N Rural St./ Keystone interchange (Milepost: 15.46)

Interchange 87: I-70 and Emerson Ave. Interchange (Milepost: 17.33)

Interchange 89: I-70 and Shadeland Ave. Interchange (Milepost: 19.60)

Interchange 90: I-70 and I-465 Interchange (Milepost: 20.17)

The analysis presented in this chapter is based on the ramp traffic and freeway traffic count data received from INDOT. The figure also shows the station ID of the traffic count stations. 


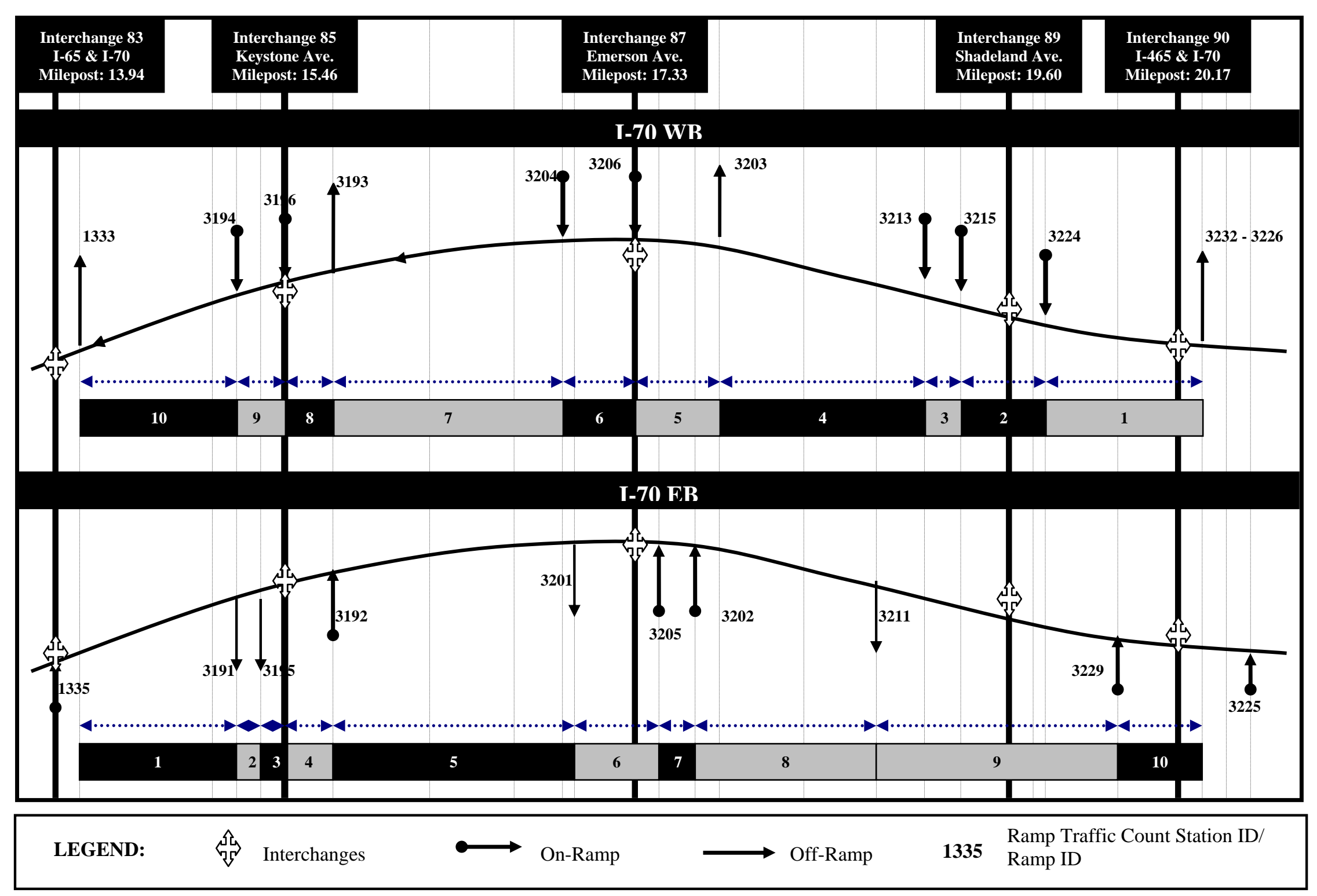

Figure 4.1: I-70 Corridor Description in the EB and WB Direction 


\subsection{ECONOMIC FEASIBILITY OF HOV FACILITY IMPLEMENTATION}

The economic feasibility of HOV lane implementation on the east leg of I-70 will be determined using the guidelines presented in Chapter 2.

\subsubsection{Travel Pattern}

The I-70 corridor between I-65 and I-465 is one of the most extensively used corridors in Indiana with commuters from parts of Hamilton, Madison, Hancock and Marion counties using the six-mile freeway section to access the center township and downtown in Indianapolis. The Indianapolis Metropolitan Planning Organization estimated that approximately 36,000 work trips are made in the morning peak period (6:00 A.M. - 9 A.M.) on I-70 between I-65 and I-465, by using the 2000 Census Transportation Planning Package (CTPP). Also, it was estimated that the average vehicle occupancy on I-70 is 1.07 [Roth, 2005]. The study of travel pattern along the I-70 corridor suggested that congestion would occur during the morning and afternoon commutes to/from work. The travel pattern on I-70 seemed conducive to carpooling as commuters travel to downtown places of work in Indianapolis.

\subsubsection{Hourly Traffic Data Analysis}

The hourly traffic data acquired from INDOT was analyzed to identify the peak periods and the sections on the freeway that are congested during the peak period. The hourly traffic counts along the freeway were available for the year 2002 (October) and were converted to October, 2006 (design year) traffic counts assuming a growth factor of $1 \%$. Following results were obtained from the analysis of the hourly traffic data.

\subsubsection{Congestion Level and Level of Service}

The level of congestion on the freeway can be measured using the $v / c$ ratio, where ' $v$ ' represents the hourly traffic volume in the peak period along the freeway and 'c' represents the capacity of the freeway. According to Highway Capacity Manual (HCM, 2000) the capacity under prevailing conditions is calculated by multiplying the capacity under ideal conditions with a set of adjustment factors. The ideal capacity of urban freeway is 2,300 vehicles per hour per lane. The actual capacity of the freeway was calculated as approximately 2,160 vehicles per hour per lane, using the following equation:

Actual Capacity $=$ Ideal Capacity $\times f_{w} \times f_{H V} \times f_{p}$

where, Ideal Capacity = Capacity under ideal conditions (2300 vphpl)

$f_{w}=$ Factor due to Lane Width and Shoulder Width (1.00) $\quad$ [For $12 \mathrm{ft}$ lanes \& $7 \mathrm{ft}$ shoulders]

$f_{H V}=$ Factor due to Heavy Vehicles (0.93) [Assuming 13\% Trucks; 0\% buses]

$f_{p}=$ Factor due to Driver Population (1.00)

The volume to capacity ratio and speed profile was analyzed over an analysis period of ten years (20072016) and it was determined that the I-70 corridor is congested in the WB direction. Figure 4.2 shows the profile of the estimated speed in the EB and WB direction along the six-mile corridor in the year 2006. The estimated speed in 
the WB direction varies in the range of 20-30 mph between Milepost 15.72 and 19.34 which suggests that the feasibility of HOV lane implementation should be evaluated in this direction.
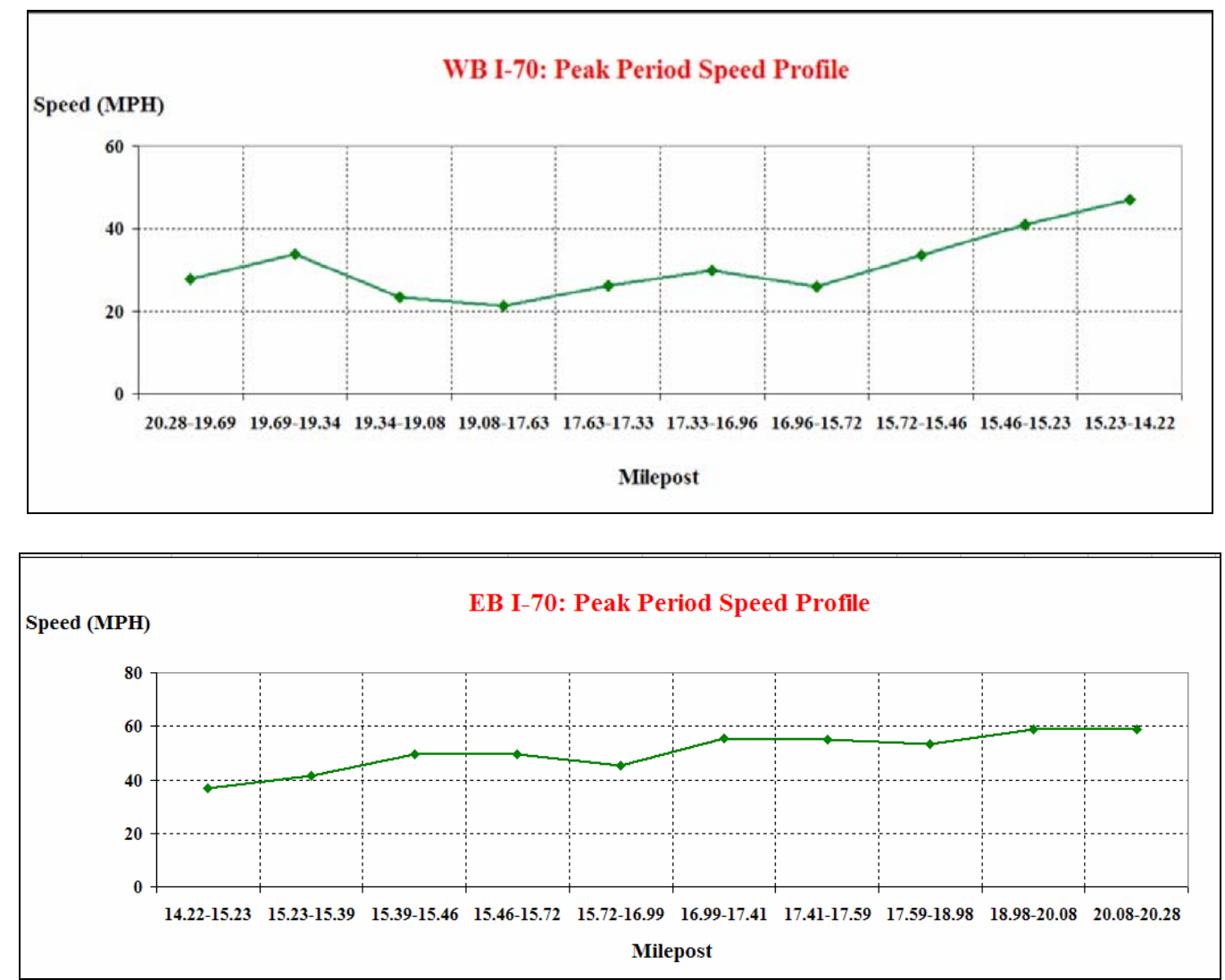

Figure 4.2: Estimated Speed Profile on I-70 in the year 2006 During the Peak Period

\subsubsection{Ramp Traffic Analysis}

The location and design of the support facilities such as the park-and-ride lots, transit centers, ingress/egress facilities depends upon the traffic volume at the on-ramps. The analyses presented in this section can be used to identify the location and number of park-and-ride lots, slip ramps/direct access ramps and enforcement areas. The implementation of these support facilities encourages the formation of new carpools, and the construction of enforcement areas will minimize the violation rate. Tables 4.1 and 4.2, show the AWDT and traffic volumes during the peak period on the ramps in the WB and EB direction respectively. The percentages of AWDT entering/exiting each ramp during the peak period are also shown in the table. Approximately $15-30 \%$ of the ramp traffic enters/exits the freeway during the peak period, from each ramp depending upon the ramp location. 
Table 4.1: Traffic Entering From the On-Ramps along I-70 WB

\begin{tabular}{|c|c|l|c|c|c|}
\hline $\begin{array}{c}\text { Milepost } \\
\text { (Miles) }\end{array}$ & $\begin{array}{c}\text { Ramp } \\
\text { Traffic } \\
\text { Count } \\
\text { Station }\end{array}$ & \multicolumn{1}{|c|}{ Description } & AWDT & $\begin{array}{c}\text { Total } \\
\text { Peak } \\
\text { Period } \\
\text { Traffic }\end{array}$ & $\begin{array}{c}\text { \% of } \\
\text { AWDT } \\
\text { During } \\
\text { Peak } \\
\text { Period }\end{array}$ \\
\hline 20.28 & $3232-3226$ & $\begin{array}{l}\text { Off-Ramp: To Shadeland Ave. Ramp 3232 } \\
\text { is I-70 WB traffic that took exit 89 along } \\
\text { with the I-465 NB traffic that took exit 44A }\end{array}$ & 1,995 & 636 & $31.9 \%$ \\
\hline 19.69 & 3224 & On Ramp: From I-465 SB & 25,489 & 8,098 & $31.8 \%$ \\
\hline 19.34 & $3215(\mathrm{~N})$ & On Ramp: From I-465 SB \& I-465 NB & 8,972 & 2,001 & $22.3 \%$ \\
\hline 19.08 & 3213 & $\begin{array}{l}\text { On Ramp: From Shadeland Ave. } \\
\text { Neighborhood }\end{array}$ & 12,336 & 1,936 & $15.7 \%$ \\
\hline 17.63 & 3203 & Off-Ramp: To NB and SB Emerson Ave & 6,849 & 1,362 & $19.9 \%$ \\
\hline 17.33 & 3206 & On-Ramp: From NB Emerson Ave. & 6,218 & 1,292 & $20.8 \%$ \\
\hline 16.94 & 3204 & On Ramp: From SB Emerson Ave. & 10,919 & 2,886 & $26.4 \%$ \\
\hline 15.72 & 3193 & $\begin{array}{l}\text { Off-Ramp: To NB/SB Keystone Way / N } \\
\text { Rural St) }\end{array}$ & 4,906 & 965 & $19.7 \%$ \\
\hline 15.46 & 3196 & On-Ramp: From NB N Rural St. & 4,395 & 730 & $16.6 \%$ \\
\hline 15.23 & 3194 & On-Ramp: From SB Keystone Way & 11,215 & 2,502 & $22.3 \%$ \\
\hline 14.22 & 1333 & $\begin{array}{l}\text { Freeway to Freeway Connector Off Ramp: } \\
\text { To I-65 }\end{array}$ & 35,958 & 9,824 & $27.3 \%$ \\
\hline
\end{tabular}

The ramp traffic data presented in Tables 4.1 and 4.2 was used to calculate and compare the number of vehicles entering/exiting from each interchange during the morning and afternoon peak periods. Table 4.3 presents the calculated number of vehicles entering/leaving from each interchange. For example, an estimated 3,232 vehicles enter from NB Rural St. (Ramp ID: 3196) and SB Keystone Avenue (Ramp ID: 3194), during the morning peak period (6:00 A.M. - 9.00 A.M.). In the evening, peak period an estimated 3,259 vehicles exit the I-70 freeway to enter these streets through off-ramps 3195 and 3191. Hence, it can be concluded that approximately 3,200 vehicles commuting to work will enter/exit from Interchange 85 in the design year (2006). Figure 4.3 shows the location of these ramps along the I-70 corridor.

Similarly, it was estimated that approximately 4,500 vehicles will be entering/exiting the I-70 corridor from Interchange 87 and approximately 12,000 vehicles will enter/exit the freeway through on- and off-ramps located near Interchange 89, during the peak period. Figure 4.3 shows the location of each of these on- and off-ramps along the I-70 corridor. Therefore, the total number of vehicles using the I-70 freeway corridor during the peak periods from Interchange 85, 87 and 89 is approximately 20,000 (Table 4.3) on an average weekday in 2006.

Based on the ramp traffic data analysis it can be concluded that support facilities in the form of park-andride lots, transit centers, ingress/egress facilities can be provided near Interchanges 85, 87 and 89. The location and the spacing of the slip ramps can be decided based on the location of the entry and exit points of the carpools. In section 4.3.3.2 it will be shown that if the average vehicle occupancy along the six-mile section is assumed to be constant at 1.07 [Roth, 2005], then the number of carpool vehicles entering from the on-ramps is approximately $6 \%$ of the total ramp traffic entering the freeway. 
Table 4.2: Traffic Entering from the On-Ramps along I-70 EB

\begin{tabular}{|c|c|l|c|c|c|}
\hline $\begin{array}{c}\text { Milepost } \\
\text { (Miles) }\end{array}$ & $\begin{array}{c}\text { Ramp } \\
\text { Traffic } \\
\text { Count } \\
\text { Station }\end{array}$ & \multicolumn{1}{|c|}{ Description } & AWDT & $\begin{array}{c}\text { Total } \\
\text { Peak } \\
\text { Period } \\
\text { Traffic }\end{array}$ & $\begin{array}{c}\text { \% of } \\
\text { AWDT } \\
\text { During } \\
\text { Peak } \\
\text { Period }\end{array}$ \\
\hline 13.94 & 1335 & $\begin{array}{l}\text { Freeway to Freeway Connector On Ramp: } \\
\text { From I-65 }\end{array}$ & 38515 & 10644 & 27.6 \\
\hline 15.23 & 3191 & Off-Ramp: To SB N Rural Street & 5112 & 944 & 18.5 \\
\hline 15.39 & 3195 & Off-Ramp: To NB N Rural Street & 9831 & 2315 & 23.5 \\
\hline 15.72 & 3192 & On-Ramp: From NB N Rural St. & 5317 & 1253 & 23.6 \\
\hline 16.99 & 3201 & Off-Ramp: To NB and SB Emerson Ave. & 17365 & 4921 & 28.3 \\
\hline 17.41 & $3205($ E) & $\begin{array}{l}\text { On-Ramp: From SB Emerson Ave. (over- } \\
\text { bridge) }\end{array}$ & 2409 & 504 & 20.9 \\
\hline 17.59 & $3202(B)$ & On-Ramp: From NB EmersonAve. & 3650 & 693 & 19.0 \\
\hline 18.9 & $3211($ A) & $\begin{array}{l}\text { Off-Ramp: To I-465 SB, I-465 NB, } \\
\text { Shadeland Ave. }\end{array}$ & 42639 & 11191 & 26.2 \\
\hline 20 & 3229 & $\begin{array}{l}\text { On-Ramp: From Shadeland Ave. to Bridge } \\
\text { 5711CDE to freeway }\end{array}$ & 1820 & 520 & 28.6 \\
\hline 20.46 & 3225 & On-Ramp: From I-465 SB & 10784 & 2964 & 27.5 \\
\hline 20.57 & 3222 & On-Ramp: From I465 NB & 10495 & 2354 & 22.4 \\
\hline
\end{tabular}

Table 4.3 Comparison of Traffic Volumes (2006) Entering I-70 WB During Morning Peak Period with Traffic Volume Exiting I-70 EB During Afternoon Peak Period

\begin{tabular}{|c|c|c|c|c|c|}
\hline \multirow{3}{*}{$\begin{array}{c}\text { Interchange } \\
\\
\text { Interchange } 85 \\
\text { (I-70 and N Rural } \\
\text { St./Keystone) }\end{array}$} & \multirow{2}{*}{$\begin{array}{l}\quad \begin{array}{l}\text { Travel Pattern } \\
\text { (Peak Period) }\end{array} \\
\text { Morning: } \\
\text { Vehicles Entering I-70 } \\
\text { WB } \\
\end{array}$} & \multicolumn{3}{|c|}{$\begin{array}{c}\text { Ramp Volume } \\
\text { (Ramp ID) } \\
\text { (Refer to Figure 6.4 For Location of } \\
\text { Ramps) } \\
\end{array}$} & \multirow{2}{*}{ 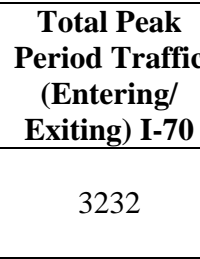 } \\
\hline & & $\begin{array}{c}730 \\
(3196)\end{array}$ & $\begin{array}{c}2502 \\
(3194)\end{array}$ & - & \\
\hline & $\begin{array}{l}\text { Evening: } \\
\text { Vehicles Exiting I-70 } \\
\text { EB }\end{array}$ & $\begin{array}{c}944 \\
(3191)\end{array}$ & $\begin{array}{c}2315 \\
(3195)\end{array}$ & - & 3259 \\
\hline \multirow{2}{*}{$\begin{array}{c}\text { Interchange } 87 \\
\text { (I-70 and Emerson } \\
\text { Ave.) }\end{array}$} & $\begin{array}{l}\text { Morning: } \\
\text { Vehicles Entering I-70 } \\
\text { WB }\end{array}$ & $\begin{array}{c}2886 \\
(3204)\end{array}$ & $\begin{array}{c}1292 \\
(3206)\end{array}$ & - & 4178 \\
\hline & $\begin{array}{l}\text { Evening: } \\
\text { Vehicles Exiting I-70 } \\
\text { EB }\end{array}$ & $\begin{array}{c}4921 \\
(3201)\end{array}$ & - & - & 4921 \\
\hline \multirow{2}{*}{$\begin{array}{c}\text { Interchange } 89 \\
\text { (I-70 and Shadeland } \\
\text { Ave.) }\end{array}$} & $\begin{array}{l}\text { Morning: } \\
\text { Vehicles Entering I-70 } \\
\text { WB }\end{array}$ & $\begin{array}{c}1936 \\
(3213)\end{array}$ & $\begin{array}{c}2001 \\
(3215)\end{array}$ & $\begin{array}{c}8098 \\
(3224)\end{array}$ & 12035 \\
\hline & $\begin{array}{l}\text { Evening: } \\
\text { Vehicles Exiting I-70 } \\
\text { EB }\end{array}$ & $\begin{array}{l}11191 \\
(3211)\end{array}$ & - & - & 11191 \\
\hline \multirow{2}{*}{\multicolumn{5}{|c|}{$\begin{array}{l}\text { Total Vehicles Entering I-70 WB During Morning Peak Period }=3229+4178+12035= \\
\text { Total Vehicles Exiting I-70 EB During Afternoon Peak Period }=3259+4921+11191=\end{array}$}} & 19,442 \\
\hline & & & & & 19,371 \\
\hline
\end{tabular}




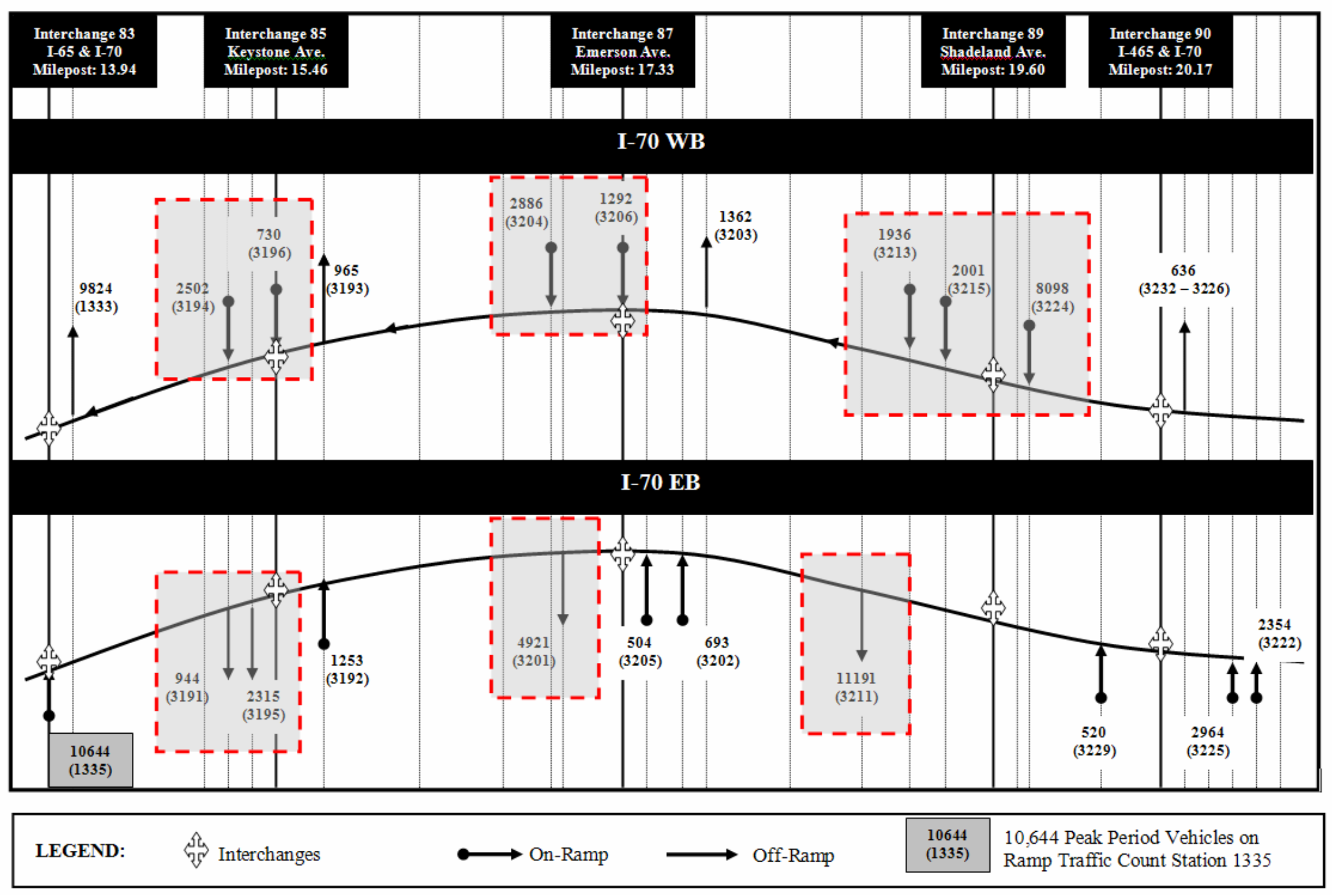

Figure 4.3: Travel Pattern on I-70 between I-65 and I-465 in the EB and WB direction 


\subsubsection{HOV Facility Type}

Based on the I-70 corridor description, travel pattern, hourly traffic data and ramp traffic analysis, it was determined that congestion occurs on I-70 during the morning peak period (6:00 A.M. - 9 A.M.) in the WB direction. Hence an exclusive HOV facility is not required on I-70. A part-time HOV facility such as a concurrent flow HOV lane or contraflow HOV lane may be considered for I-70 which operates in the WB direction in the morning peak period. The WB direction accounts for $60 \%$ of the traffic during the peak period on the section between Mileposts 14.22 and 18.98. Since the directional split is less than $66 \%$, based on the guidelines presented in Chapter 2, it was concluded that a contraflow HOV lane facility cannot be considered for I-70.

The concurrent flow HOV lane facility can be constructed using add-a-lane approach or take-a-lane approach. Both alternatives were evaluated and the cost-effectiveness was determined for the six-mile stretch on I70 in the WB direction. It was found that the volume to capacity ratio in the EB direction on I-70, exceeds the benchmark v/c ratio marginally in the year 2010, on a 1.5-mile stretch (between Mileposts 15.46 and 16.99), for one hour between 4:00 P.M -5:00 P.M. The v/c ratio increases after year 2010 in the EB direction but congestion does not extend beyond the 1.5-mile stretch. Therefore it was concluded that the EB direction is not severely congested and the HOV lane implementation was not considered in this direction. Hence, the economic feasibility of HOV lane implementation was determined for the WB direction only. The following alternatives were evaluated:

Alternative 1 - One lane is added in the WB direction between Mileposts 14.22 and 20.28. The added lane is operated as a concurrent flow HOV lane.

Alternative 2 - One lane is taken away from the existing set of lanes in the WB direction and the taken lane is operated as a concurrent flow HOV lane between Mileposts 14.22 and 20.28.

In addition to the above alternatives, the economic feasibility of adding one general purpose lane in the WB direction between Mileposts 14.22 and 20.28 was also evaluated and the results were compared with Alternative 1 to determine the fraction of benefits, corresponding to Alternative 1, that arise due to addition of lane on the freeway.

The concurrent flow HOV lane in each direction should be separated from the GP lanes using a wide painted buffer in order to ensure that the number of crashes do not rise on the corridor as discussed in Chapter 2 . The buffer width is generally between $0.3 \mathrm{~m}-3.6 \mathrm{~m}$ depending upon the availability of the right of way and funds. However, the economic analysis presented in this section does not depend on the type of separation.

\subsubsection{Operation Hours}

Congestion occurs on the I-70 freeway for three hours in the morning peak period in the WB direction. Hence the operation of HOV lane was considered for three hours during a weekday. The operation of HOV lanes was not considered on weekends because traffic congestion on the freeway is primarily due to traffic commuting to places of work in downtown of Indianapolis. Therefore, the economic evaluation was performed for 250 days of each year during the analysis period. 


\subsubsection{Occupancy Requirement}

The average vehicle occupancy on the I-70 corridor was found to be 1.07 [Roth, 2005]. This value of average vehicle occupancy was used to determine the modal split of traffic using the following equations [Alexiadis et al., 1996] as follows:

$$
\begin{aligned}
& \% \text { SOV }=[(-0.80 * \text { Average Vehicle Occupancy })+1.80] * 100=94 \% \\
& \% H O V 2=[0.667 * \text { Average Vehicle Occupancy })-0.667] * 100=4.7 \% \\
& \% H O V 3+=[100-\% \text { SOV }-\% H O V 2]=1.3 \%
\end{aligned}
$$

Therefore, it was estimated that the carpools comprise approximately $6 \%$ of the total traffic on the freeway. The traffic volume varies from one link to another and therefore the number of $2+$ carpools in the year 2006, was found to vary between 200 - 400 vehicles per hour per HOV lane in the WB direction. Hence, economic evaluation of the HOV facility was carried out for an occupancy requirement of two or more passengers per vehicle.

\subsubsection{Support Facilities}

In Section 4.3.2.2 it was determined that the park-and-ride lots could be located near Interchanges 85, 87 and 89 and provision of slip ramps should be considered near these interchanges. According to guidelines given by the California Department of Transportation [Caltrans, 2003], the slip ramps should be located such that the carpools entering I-70 from the on-ramps, have at least $200 \mathrm{~m}$ available per lane change before entering the HOV lane. Based on this guideline, it was determined that a maximum of two slip ramps can be provided on Links 1, 2 and 3 and only one slip ramp can be provided on Links 4 and 5.

In addition the implementation of appropriate ridership programs, enforcement areas and enforcement policies should be considered to ensure that the HOV lane is not underutilized and that the violation rate is not high. The economic evaluation performed in this study does not consider the construction of any new direct access ramps, park-and-ride facilities and dedicated enforcement areas. However, park-and-ride lots, transfer centers, direct access ramps, ridership programs and other support facilities should be planned strategically for a successful implementation of the HOV facility. The number of new carpools formed depends on the support facilities. Therefore, the economic evaluation performed in this study was conducted at various levels of HOV lane traffic, so that the cost-effectiveness can be determined under various scenarios.

\subsubsection{HOV Lane Traffic Estimation}

The economic analysis of a HOV lane project requires the estimation of the number of vehicles that will use the HOV lane. The HOV lane traffic volume depends on the number of HOVs (carpools) that are formed after the implementation of the HOV lane project. The number of carpools formed can vary significantly from one region to another. Several demand models for prediction of HOV demand are available as discussed in Chapter 2. However the transferability of these models to other regions and corridors is not recommended because the model parameters were calibrated specifically for a particular region.

Traffic in the HOV lane can be determined based on the average vehicle occupancy on the freeway. A high value of average vehicle occupancy on the freeway indicates that the number of passengers in each vehicle is more 
and hence there are a large number of carpools on the freeway. In this study, the economic evaluation of the HOV facility was carried out with three scenarios, where the average vehicle occupancy increases by $0 \%, 10 \%$ and $20 \%$, after the implementation of the HOV lane. The existing average vehicle occupancy on the freeway is 1.07 and a $10 \%$ and $20 \%$ increase would result in average vehicle occupancy of 1.17 and 1.27 respectively. Equation 4.1 was used to determine the percentage of carpools in total traffic under these scenarios. Figure 4.4 shows a plot of estimated percentage of high occupancy vehicles (two or more occupants per vehicle) against the average vehicle occupancy on the freeway.

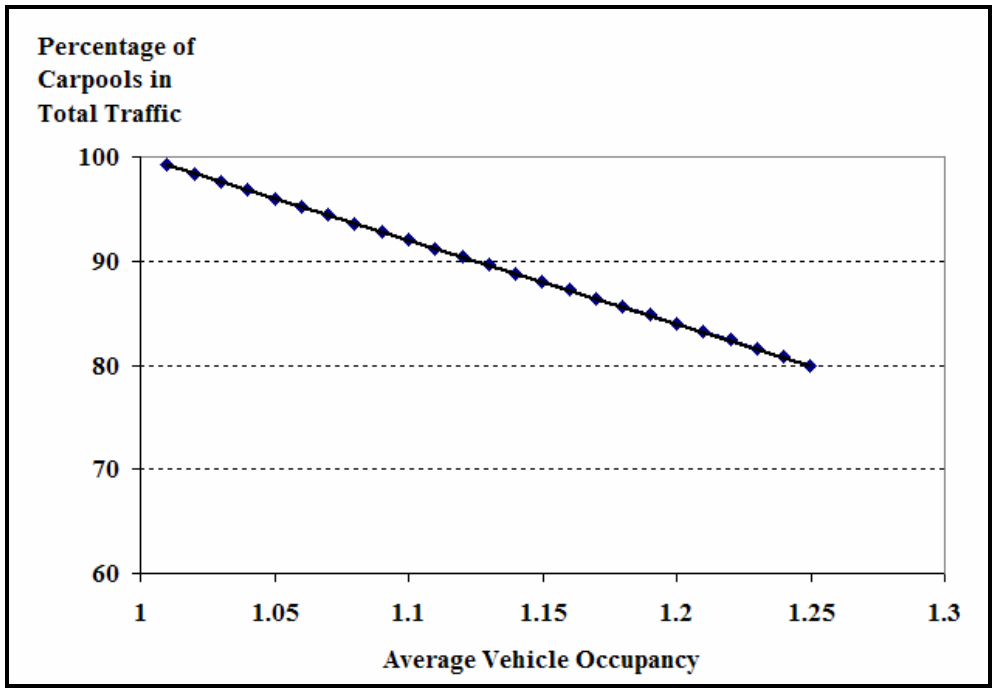

Figure 4.4: Percentage of Carpools in Total Traffic as a Function of Average Vehicle Occupancy

The growth in average vehicle occupancy indicates the increase in number of carpools on the freeway. An estimate of the number of carpools formed in the opening year, corresponding to each level of growth in average vehicle occupancy, is shown in Tables 4.4 and 4.5. For example, if the implementation of ridership programs, enforcement policies, parking incentives and other support facilities is expected to result in a growth of $10 \%$ in the average vehicle occupancy, given the average weekday daily traffic between Mileposts 15.46 and 17.33, it was estimated that 884 carpools will be formed in the opening year if Alternative 1 was implemented. However, based on the synthesis study of the HOV lane facilities, it can be assumed that all the carpools formed will not use the HOV lane even though they are eligible. The numbers presented in Tables 4.4 and 4.5 indicate the expected number of carpools using the freeway and do not represent the number of carpools using the HOV lane.

Table 4.4: Estimated Carpools Using the Freeway in Opening Year when Alternative 1 is Implemented

\begin{tabular}{|c|c|c|c|c|c|}
\hline \multirow{2}{*}{$\begin{array}{c}\text { Growth in } \\
\text { AVO }\end{array}$} & \multicolumn{5}{|c|}{ Mileposts } \\
\cline { 2 - 6 } & $14.22-15.46$ & $15.46-17.33$ & $17.33-18.98$ & $18.98-19.6$ & $19.6-20.28$ \\
\hline $0 \%$ & 359 & 350 & 287 & 210 & 129 \\
\hline $10 \%$ & 892 & 884 & 725 & 520 & 320 \\
\hline $20 \%$ & 1407 & 1355 & 1144 & 834 & 491 \\
\hline
\end{tabular}


Table 4.5: Estimated Carpools Using the Freeway in Opening Year when Alternative 2 is Implemented

\begin{tabular}{|c|c|c|c|c|c|}
\hline \multirow{2}{*}{$\begin{array}{c}\text { Growth in } \\
\text { AVO }\end{array}$} & \multicolumn{5}{|c|}{ Mileposts } \\
\cline { 2 - 6 } & $14.22-15.46$ & $15.46-17.33$ & $17.33-18.98$ & $18.98-19.6$ & $19.6-20.28$ \\
\hline $0 \%$ & 405 & 366 & 324 & 260 & 173 \\
\hline $10 \%$ & 1009 & 924 & 819 & 657 & 424 \\
\hline $20 \%$ & 1595 & 1482 & 1313 & 1023 & 679 \\
\hline
\end{tabular}

The percentage of carpool vehicles that move into the HOV lane is a function of the HOV facility length, the location and number of the ingress/egress points, the number of lane changes involved and the average HOV trip length. Alexiadis et al. [1996] developed a regression model based upon the data collected from twenty-seven HOV facilities in the country to estimate the percentage of HOVs that will use the HOV lane as a function of the differential travel time between the HOV and the general purpose lane. It was found that a maximum of approximately $80 \%$ of the total number of carpools move into the HOV lane when the occupancy requirement is $2+$ and the percentage increases to approximately $90 \%$ when the occupancy requirement is 3+ [Alexiadis et al., 1996]. The following equation was used to determine the percentage of carpools that will move into the HOV lane.

For 2+ occupancy requirement and no barrier-separation:

$\%$ HOVs in the HOV Lane $=\left[0.439+0.389 * \frac{\left(T T_{\text {GPLane }}-T T_{\text {HOVLane }}\right)}{T T_{\text {GPLane }}}\right] * 100$

Where,

$T T_{\text {GPLane }}=$ Travel time in the GP Lane

$T T_{\text {HOVLane }}=$ Travel time in the HOV Lane

\%HOVs in the HOV Lane = Percentage of carpools that move into HOV lane

In addition to the carpool vehicles, some single occupancy vehicles may also use the HOV lane even though they are not eligible. Based on the synthesis study, it was determined that the average violation rate in the country on a concurrent flow HOV lane is approximately $15 \%$. Therefore, the number of violators were added to the HOV lane traffic and removed from the general purpose lane traffic. The number of violators was calculated as follows:

$\left[\begin{array}{l}\text { Estimated violators in } \\ \text { the HOV Lane }(s)\end{array}\right]=\left[\begin{array}{l}\text { Estimated HOVs in } \\ \text { the HOV Lane }(s)\end{array}\right] *\left[\frac{\text { Violation Rate }}{100}\right]$

The final traffic volume on I-70 concurrent flow HOV lane was determined using Equations 4.2 and 4.3. The application of Equation 4.2 requires an estimate of the travel time differential between the HOV and GP lane. Since the travel time differential is not known at the beginning of the economic evaluation process, an iterative approach was used for the estimation of HOV lane traffic in each year of the analysis period. For each year of the analysis period, in the first iteration, as a starting point, it was assumed that 80\% [Alexiadis et al., 1996] of the carpool vehicles move into the HOV lane. Travel time on the HOV and the general purpose lane was calculated 
based on this assumption using the Congestion Management System Software (CMSS). Equation 4.2 was then used to calculate the percentage of HOVs that would move into the HOV lane based on the calculated travel times in the HOV and the general purpose lanes. This calculated percentage was then used in the next iteration to calculate the HOV lane traffic and the travel times in the HOV and general purpose lanes. The iterations continued as long as the error in the calculation of the HOV lane traffic was more than $10 \%$. Once the HOV lane traffic was predicted for all the years in the analysis period, the economic evaluation module of the CMSS was used to evaluate the two alternatives. The number of carpool vehicles using the HOV lane, in the opening year, when Alternatives 1 and 2 are implemented, is shown in Tables 4.6 and 4.7 respectively.

Table 4.6: Estimated HOV Lane Volume (VPH) in Opening Year when Alternative 1 is Implemented

\begin{tabular}{|c|c|c|c|c|c|}
\hline \multirow{2}{*}{$\begin{array}{c}\text { Growth in } \\
\text { AVO }\end{array}$} & \multicolumn{5}{|c|}{ Mileposts } \\
\cline { 2 - 6 } & $14.22-15.46$ & $15.46-17.33$ & $17.33-18.98$ & $18.98-19.6$ & $19.6-20.28$ \\
\hline $0 \%$ & 307 & 310 & 246 & 178 & 111 \\
\hline $10 \%$ & 775 & 736 & 620 & 440 & 280 \\
\hline $20 \%$ & 1200 & 1181 & 978 & 705 & 449 \\
\hline
\end{tabular}

Table 4.7: Estimated HOV Lane Volume (VPH) in Opening Year when Alternative 2 is Implemented

\begin{tabular}{|c|c|c|c|c|c|}
\hline \multirow{2}{*}{$\begin{array}{c}\text { Growth in } \\
\text { AVO }\end{array}$} & \multicolumn{5}{|c|}{ Mileposts } \\
\cline { 2 - 6 } & $14.22-15.46$ & $15.46-17.33$ & $17.33-18.98$ & $18.98-19.6$ & $19.6-20.28$ \\
\hline $0 \%$ & 354 & 334 & 292 & 231 & 154 \\
\hline $10 \%$ & 895 & 845 & 738 & 556 & 369 \\
\hline $20 \%$ & 1372 & 1355 & 1132 & 878 & 592 \\
\hline
\end{tabular}

\subsubsection{Impact on General Purpose Lane Speed}

The impact of HOV lane implementation on the speeds in the GP lanes was determined for each of the three scenarios of growth in average vehicle occupancy. The HOV lane traffic volume corresponding to these scenarios were determined in Section 4.3.4. The impact of HOV lane implementation on the GP lanes was determined by taking into account the conversion of single occupancy vehicles into carpools and the induced traffic in the GP lanes. The graphs in Figures 4.5 and 4.6 present the impact on speed in GP lanes. It was found that the addition of HOV lane (Alternative 1) results in a small increase in the speed on the GP lanes and that this increase is more, when more carpools use the HOV lane. However, when the HOV lane is taken (Alternative 2), the speeds on the GP lane decrease. The decrease in speed is less, when more carpools use the HOV lane. Figure 4.7 compares the speed in the GP lanes when the added lane is not operated as a HOV lane, i.e., corresponding to a road widening (RW) project, to the scenario when the added lane is operated as a HOV lane, i.e., when Alternative 1 is implemented. The improvement in average speed due to the road widening project was found to be higher than the improvement due to the addition of a HOV lane, irrespective of the growth in average vehicle occupancy. 


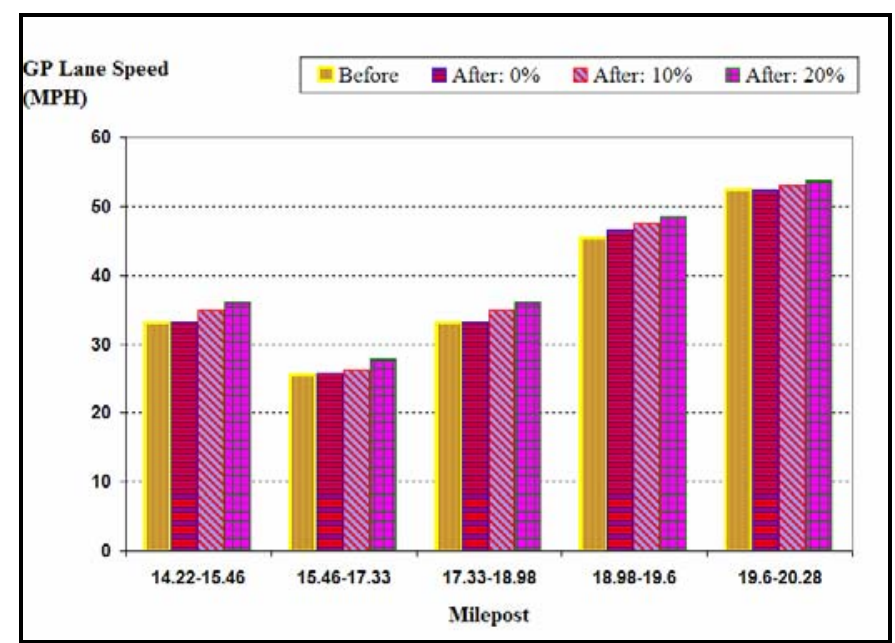

Figure 4.5: Opening Year Speeds on GP Lane Before \& After Implementation of Alternative 1

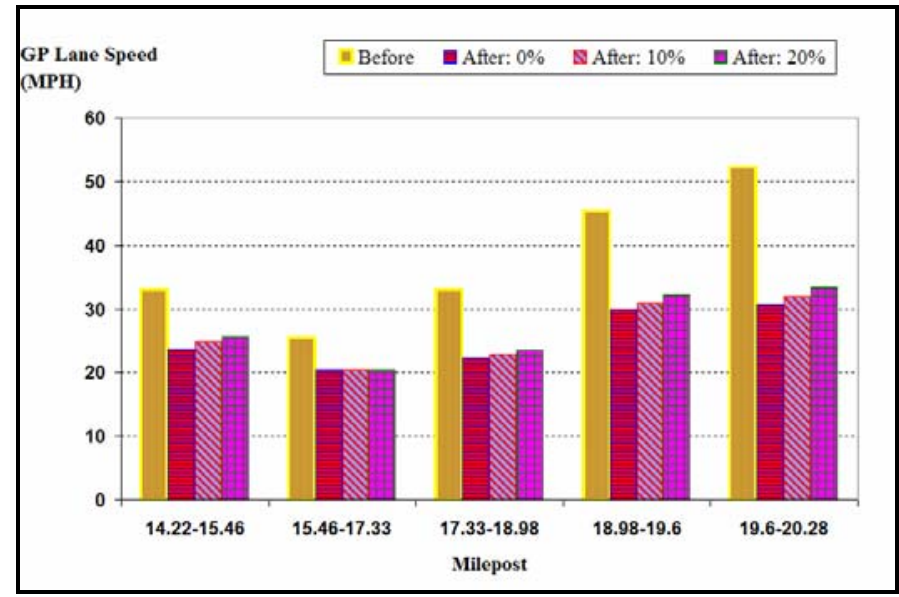

Figure 4.6: Opening Year Speeds on GP Lane Before \& After Implementation of Alternative 2

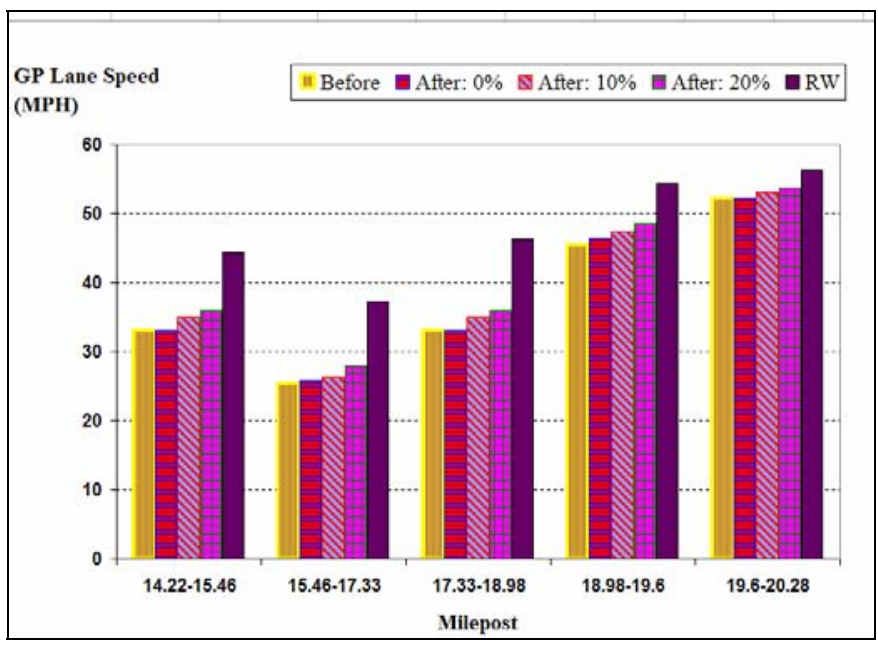

Figure 4.7: Impact on Opening Year GP Lane Speeds when added lane is not operated as HOV Lane 


\subsubsection{Economic Evaluation}

The six-mile stretch of the east leg of I-70 was divided into five links to account for the variation in the Average Weekday Daily Traffic (AWDT), number of lanes, location of interchanges and major ingress/egress points. Table 4.8 shows the characteristics of these links such as AWDT, length, lanes, peak period directional split. The average peak hour traffic was found to be approximately $8 \%$ of the AWDT. Link 1 is between interchange 83 and 85, Link 2 is between interchanges 85 and 87, Link 3 is between interchange 87 and exit 89, Link 4 is between exit 89 and Interchange 89 and Link 5 is between interchange 89 and interchange 90. Link 3 was terminated at exit 89 because more than 11,000 vehicles on I-70 EB, were found to take this exit during the afternoon peak period. The economic evaluation of the HOV lane alternatives was carried out using the Congestion Management System Software (CMSS). The input parameters required for the economic evaluation of the HOV lane project on the five links are shown in Table 4.9. These values along with the traffic information from Table 4.8 were used to evaluate the alternatives.

Table 4.8: Description of the Links on I-70

\begin{tabular}{|c|c|c|c|c|c|c|c|c|}
\hline $\begin{array}{c}\text { Link } \\
\text { ID }\end{array}$ & From & To & Length & Lanes & $\begin{array}{c}\text { EB } \\
\text { AWDT }\end{array}$ & $\begin{array}{c}\text { WB } \\
\text { AWDT }\end{array}$ & AWDT & $\begin{array}{c}\text { WB Directional } \\
\text { Split }\end{array}$ \\
\hline 1 & 14.22 & 15.46 & 1.24 & 10 & 86,835 & 124,720 & 211,555 & $59 \%$ \\
\hline 2 & 15.46 & 17.33 & 1.87 & 8 & 77,118 & 113,915 & 191,033 & $60 \%$ \\
\hline 3 & 17.33 & 18.98 & 1.65 & 8 & 65,706 & 103,531 & 169,237 & $61 \%$ \\
\hline 4 & 18.98 & 19.60 & 0.62 & 7 & 22,666 & 86,551 & 109,217 & $78 \%$ \\
\hline 5 & 19.60 & 20.28 & 0.68 & 6 & 24,502 & 56,294 & 80,797 & $70 \%$ \\
\hline
\end{tabular}

Table 4.9: Inputs to Congestion Management Software for Economic Evaluation of HOV Lane Alternatives

\begin{tabular}{|l|c|}
\hline Occupancy Requirement & $2+$ \\
\hline Truck Fleet & $13 \%$ \\
& $\left(32 \% \mathrm{SU}^{*}, 68 \% \mathrm{CU}^{* *}\right)$ \\
\hline Bus Fleet & $0 \%$ \\
\hline Automobiles & $87 \%$ \\
\hline Traffic Growth Rate & $1.0 \%$ \\
\hline Travel Time Value (Auto) & $\$ 17.00$ \\
\hline Travel Time Value (Single Unit Trucks) & $\$ 20.00$ \\
\hline Travel Time Value (Combination Unit Trucks) & $\$ 32.00$ \\
\hline Analysis Year & 2006 \\
\hline Construction Start Year & 2007 \\
\hline HOV Facility Opening Year & 2008 \\
\hline Project Life & 10 years \\
\hline Discount Rate & $4 \%$ \\
\hline
\end{tabular}

*SU: Single Unit Trucks, ${ }^{* *}$ CU: Combination Unit Trucks [Choocharukul et al. 2002] 


\subsubsection{Benefits Estimation}

The travel time savings due to the implementation of the HOV lane on the five links of I-70, corresponding to the three scenarios of growth in average vehicle occupancy, are shown in Figure 4.8. The savings due to implementation of Alternative 1 were found to increase with increase in the number of carpools using the HOV lane. The travel time savings were found to be more than zero even if there was no growth in the number of carpools on the freeway. However, most of the savings under the no growth scenario would be limited to a small fraction of the vehicles that would use the HOV lane. At the same time, HOV lane will appear empty under this scenario and hence might face public opposition. Therefore, even though this scenario is economically feasible, the implementation is not recommended. The number of carpools using the HOV lane is expected to increase with the implementation of support facilities and hence the benefits would also increase. This was confirmed by the computed travel time benefits corresponding to the $10 \%$ and $20 \%$ growth in average vehicle occupancy.

The travel time savings corresponding to the add-a-lane approach (Alternative 1) were found to be considerably higher than the take-a-lane approach (Alternative 2). The travel time savings corresponding to the takea-lane alternative were found to be negative between Mileposts 17.33 and 20.28. The savings due to the take-a-lane approach were found to decrease with increase in the number of carpools on this section of the freeway. This is because as the number of vehicles using the HOV lane increases, there is a decrease in the extent to which the travel time benefits in the HOV lane compensate for the additional travel time in the GP lane.

The travel time savings corresponding to the scenario when the added lane is not operated as a HOV lane (i.e., when road widening (RW) project is implemented), were also compared with the scenario when the added lane is operated as a HOV lane (Alternative 1). The graph corresponding to Alternative 1 in Figure 4.8(a) shows the comparison for all the links on the freeway. For example, the estimated travel time savings between Mileposts 15.46 and 17.33, due to operation of the added lane as a HOV lane are approximately $\$ 42$ million, if there is a $20 \%$ growth in average vehicle occupancy, whereas the savings due to operation of the added lane as a general purpose lane are approximately $\$ 14$ million. Hence, it can be concluded that $33 \%$ of the savings, due to implementation of Alternative 1, on this section, would be because of the added lane.

However, the operation of the added lane as a HOV lane is not always economically beneficial compared to the road widening project. For example, the travel time savings due to the addition of a general purpose lane between Mileposts 18.98 and 20.28 were found to be marginally higher than the travel time savings that would accrue due to the operation of the added lane as a HOV lane on this section. This was because the section between Mileposts 18.98 and 20.28 was relatively less congested compared to the section between Mileposts 14.22 and 18.98. 


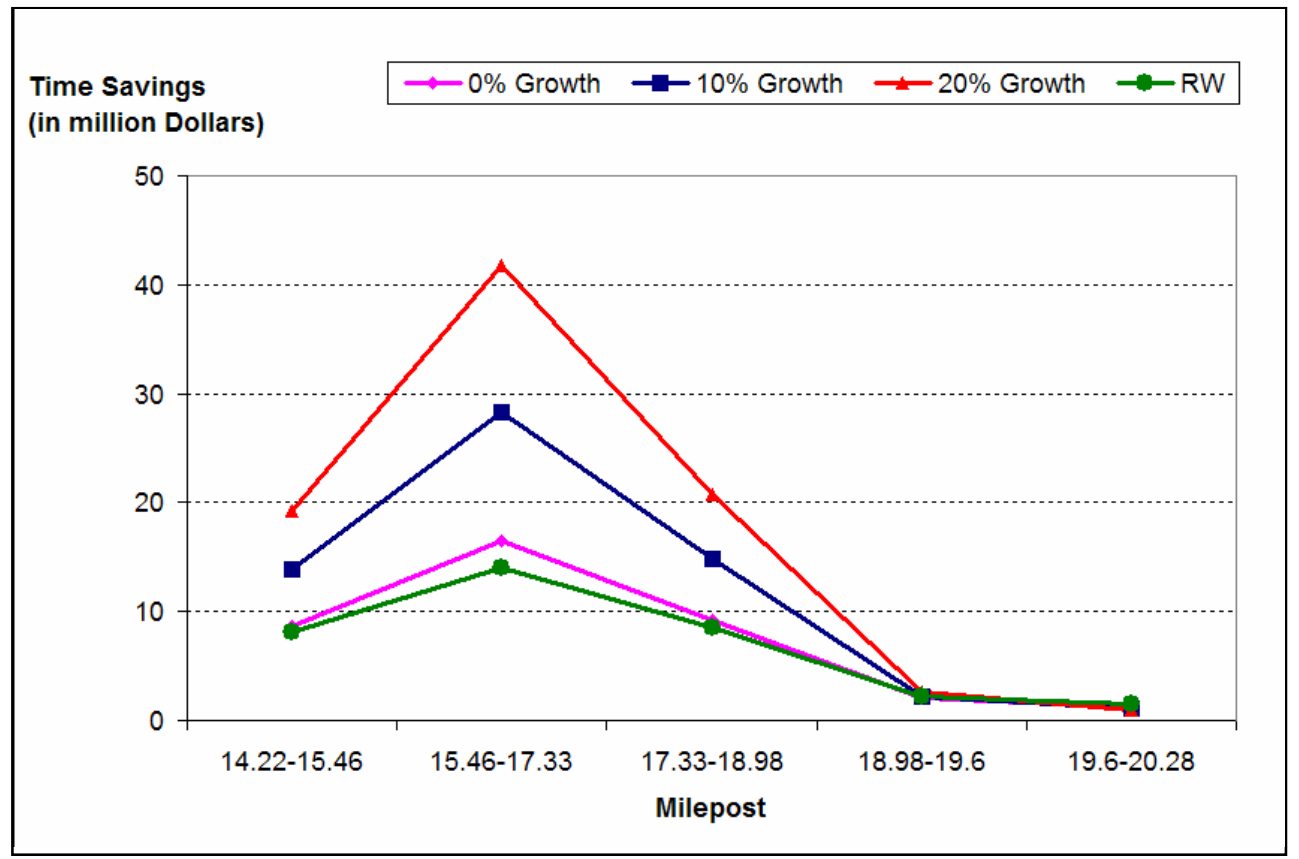

(a) Travel Time Savings for HOV Lane Project Alternative 1 and Road Widening Project on I-70

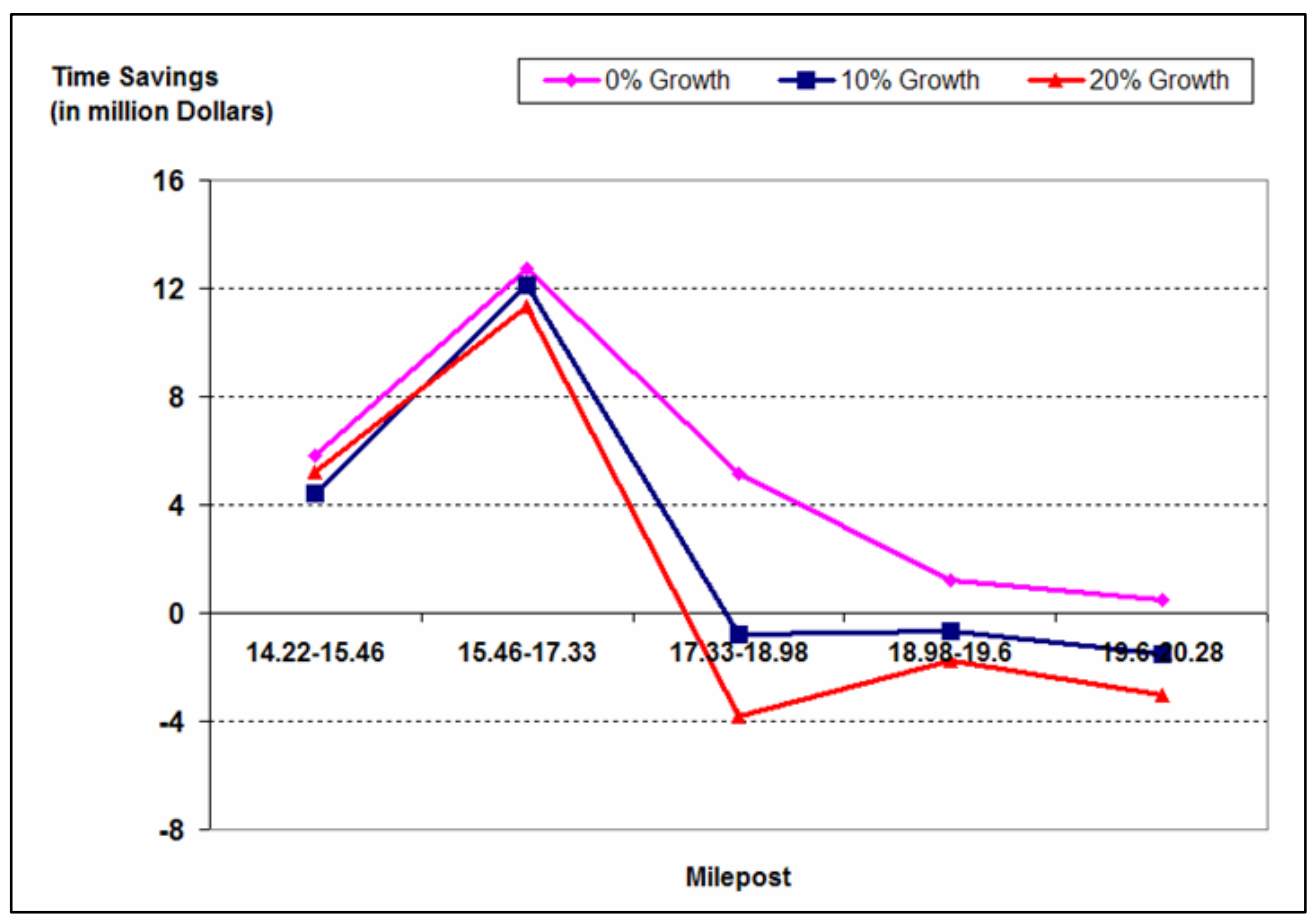

(b) Travel Time Savings for HOV Lane Project Alternative 2 on I-70

Figure 4.8: Travel Time Savings over the Analysis Period due to HOV Facility Implementation 
Figures 4.9 to 4.12 show the vehicle operating cost savings and emission savings, corresponding to the three scenarios of growth in average vehicle occupancy. The graphs are plotted for both the HOV lane alternatives. The vehicle operating cost savings are expressed in 2006 dollars whereas the emission savings are expressed in kilograms of pollutant emitted.

The vehicle operating cost savings (Figure 4.9), associated with the take-a-lane approach (Alternative 2) were found to be higher compared to add-a-lane approach (Alternative 1), on all the links except between Mileposts 15.46 and 17.33. The vehicle operating cost savings were found to increase with increase in the number of vehicles using the HOV lane, for both the alternatives.

The carbon monoxide (CO) emission savings (Figure 4.10), on the other hand, were found to be higher for the add-a-lane alternative (Alternative 1) compared to the take-a-lane alternative (Alternative 2). The savings in CO emission were found to increase as more vehicles use the HOV lane, for both the alternatives.

The nitrous oxide $\left(\mathrm{NO}_{\mathrm{x}}\right)$ emission savings (Figure 4.11), were found to be higher for the take-a-lane alternative (Alternative 1) compared to the add-a-lane alternative (Alternative 2). The savings were found to increase with increase in HOV lane traffic for both the alternatives. However, the savings on Link 1 (Mileposts 14.22-15.46) and Link 3 (Mileposts 17.33-18.98), corresponding to 20\% growth in average vehicle occupancy were found to be marginally less than the savings corresponding to $10 \%$ growth in average vehicle occupancy.

The hydrocarbon (HC) emission savings (Figure 4.12), were found to be higher for the add-a-lane alternative (Alternative 1) compared to the take-a-lane alternative (Alternative 2), on all the links. The savings were found to increase with increase in the HOV lane traffic for both the alternatives.

The savings due to the implementation of Alternative 1 (where the added lane is operated as a HOV lane), were also compared to the scenario when the added lane is not operated as a HOV lane (i.e. when road widening (RW) project is implemented). The comparison can be used to estimate the fraction of Alternative 1 benefits that would arise due to the addition of a lane. The comparison can also be used to determine whether the operation of the added lane is more beneficial if it is operated as a HOV lane or if it is operated as a GP lane. This comparison is shown in the graph corresponding to Alternative 1, in Figures 4.9 to 4.12 . The vehicle operating cost savings and emission savings were found to be negative when the added lane is operated as a general purpose lane. Therefore, it was concluded that if the added lane is operated as a general purpose lane, the vehicle operating cost and emissions will increase on the freeway. 


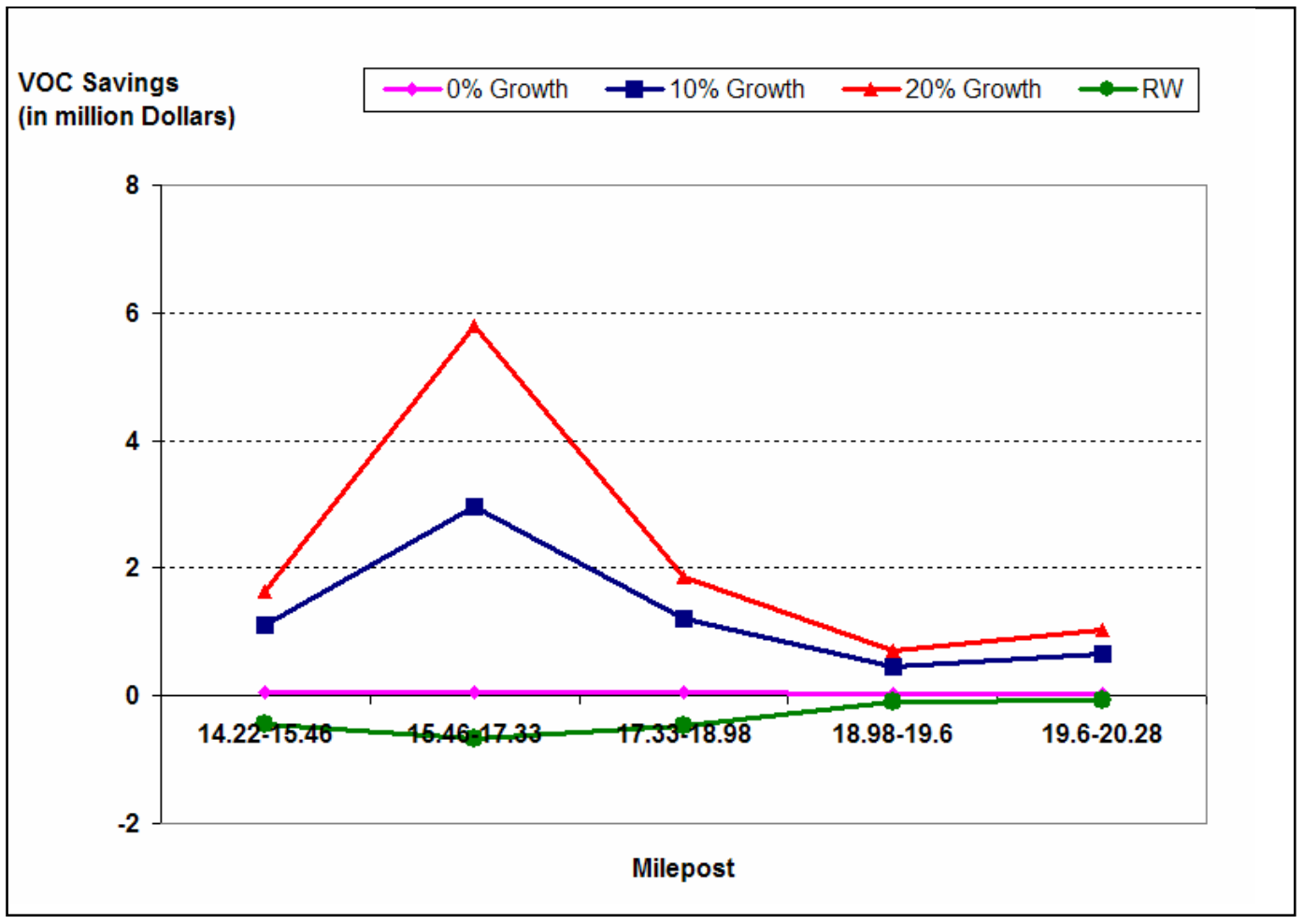

(a) VOC Savings for HOV Lane Project Alternative 1 and Road Widening Project on I-70

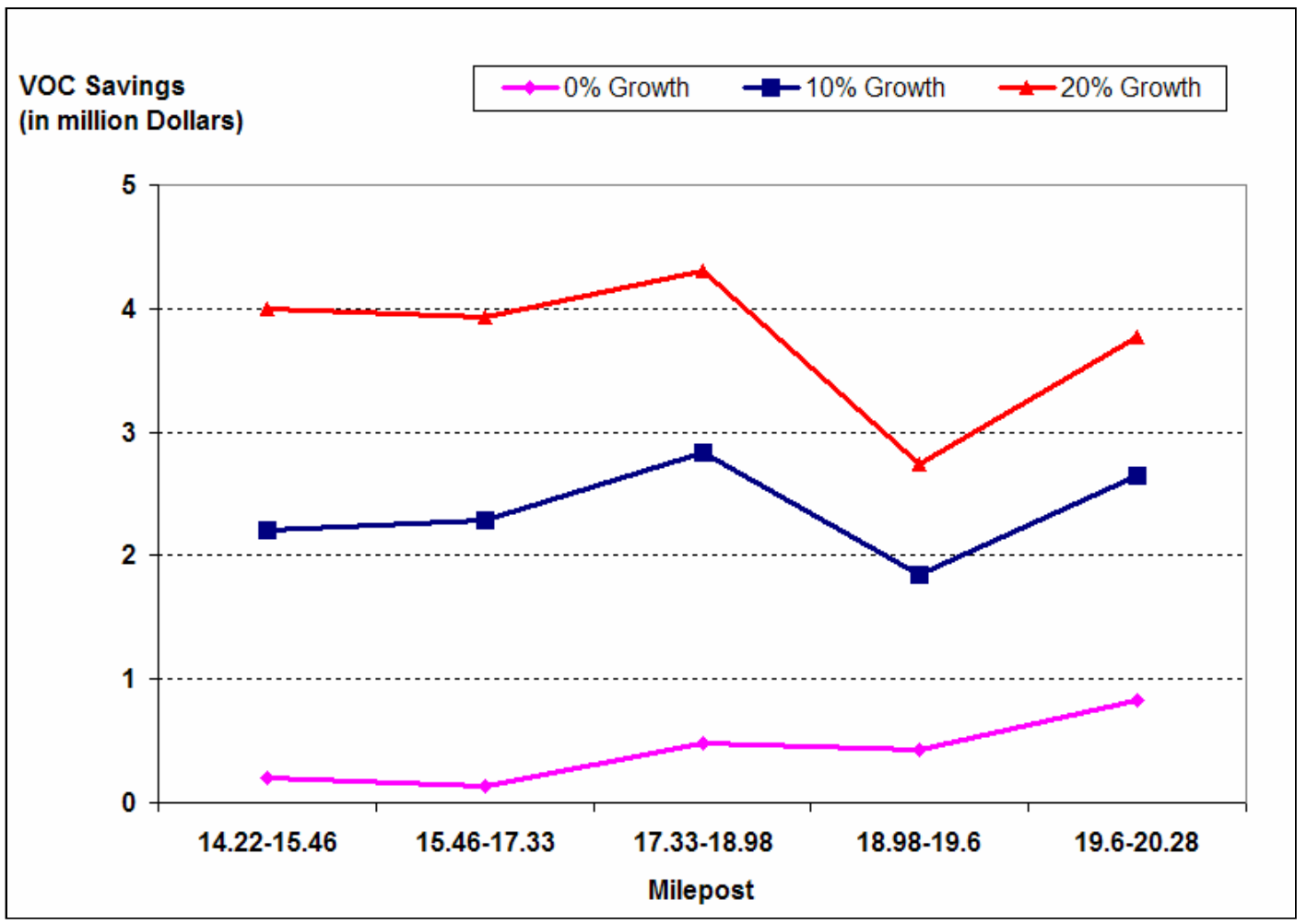

(b) VOC Emission Savings for HOV Lane Project Alternative 2 on I-70

Figure 4.9: VOC Savings over Analysis Period due to HOV Facility Implementation 


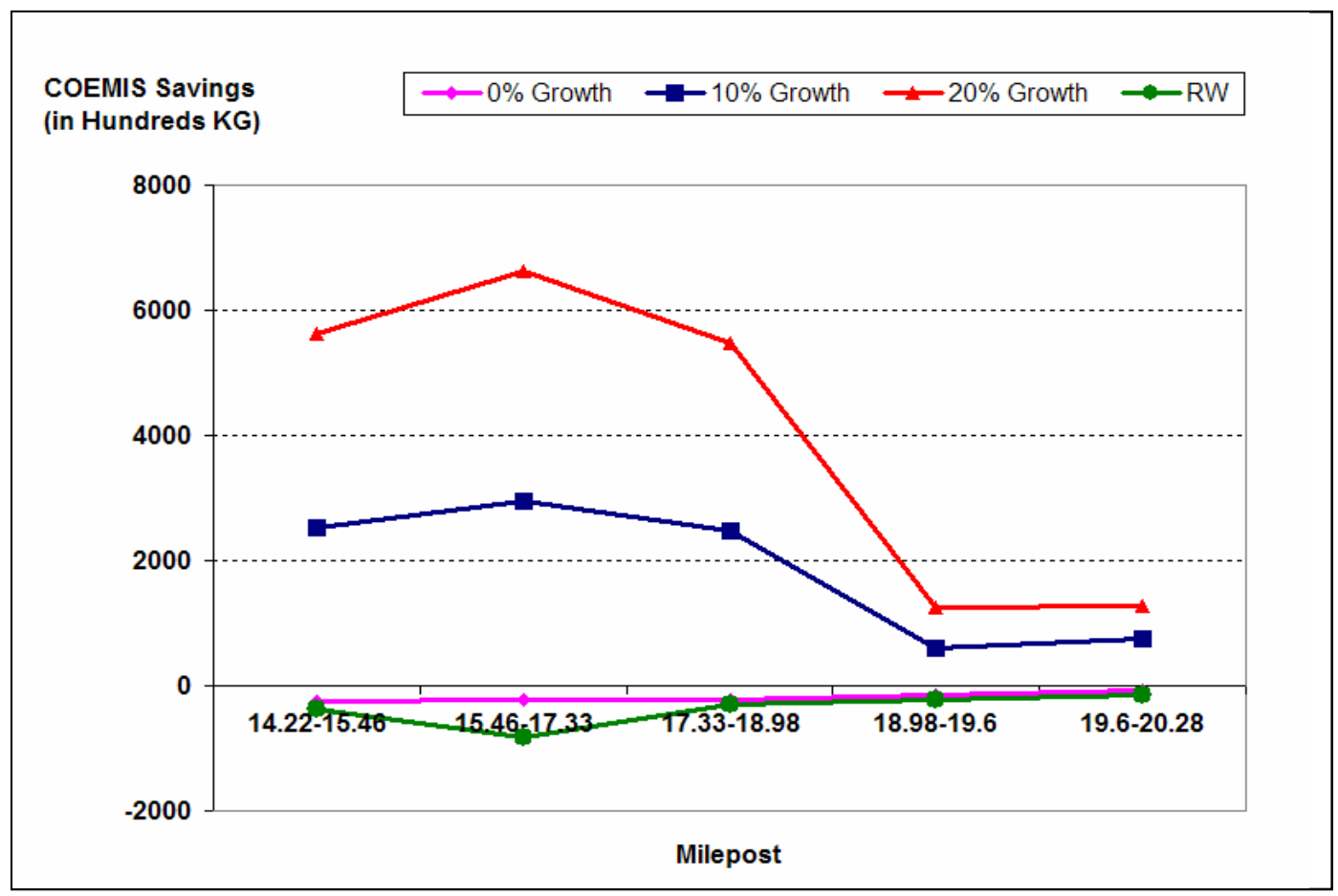

(a) CO Emission Savings for HOV Lane Project Alternative 1 and Road Widening Project on I-70

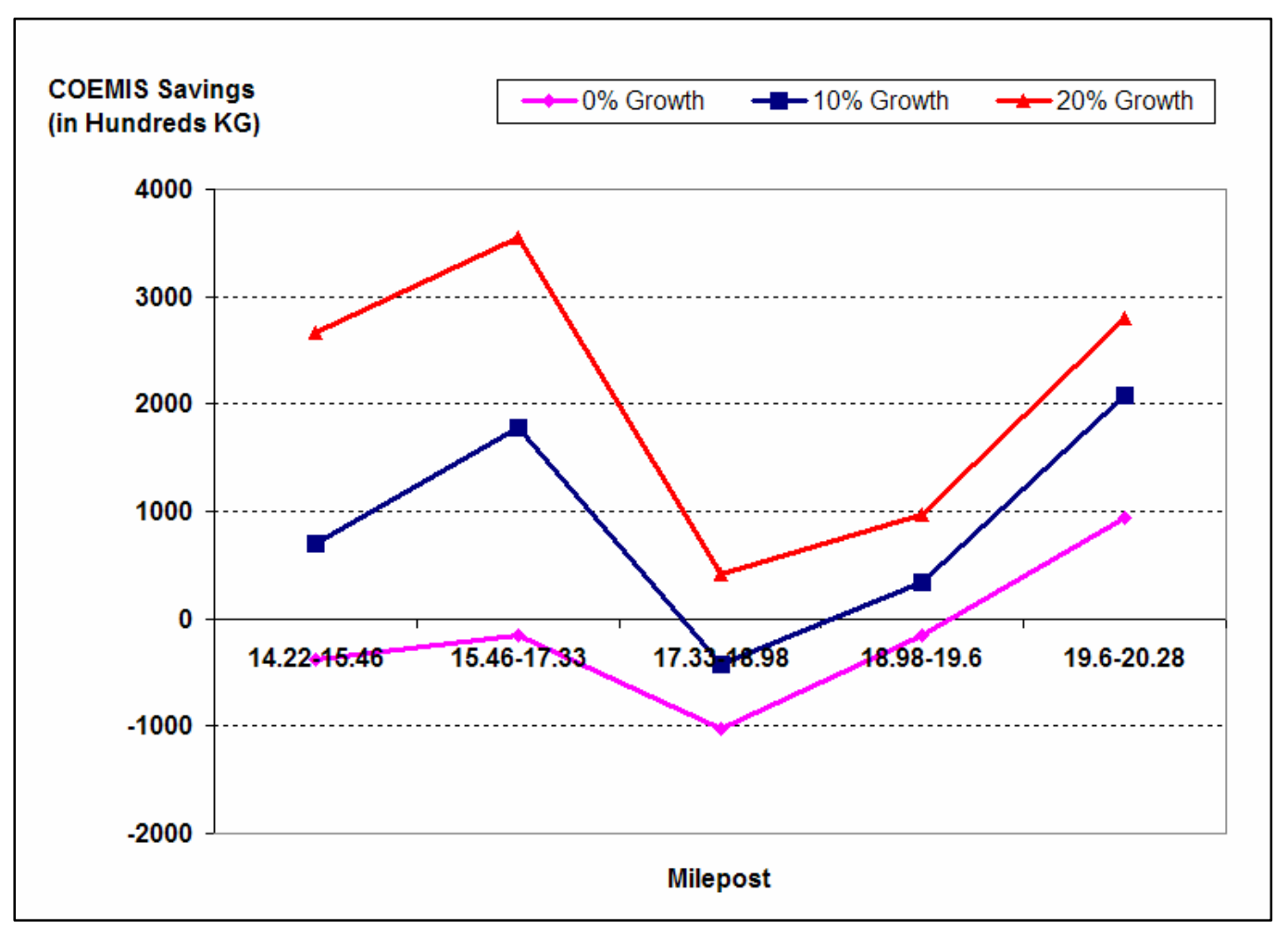

(b) CO Emission Savings for HOV Lane Project Alternative 2 on I-70

Figure 4.10: CO Emission Savings over Analysis Period due to HOV Facility Implementation 


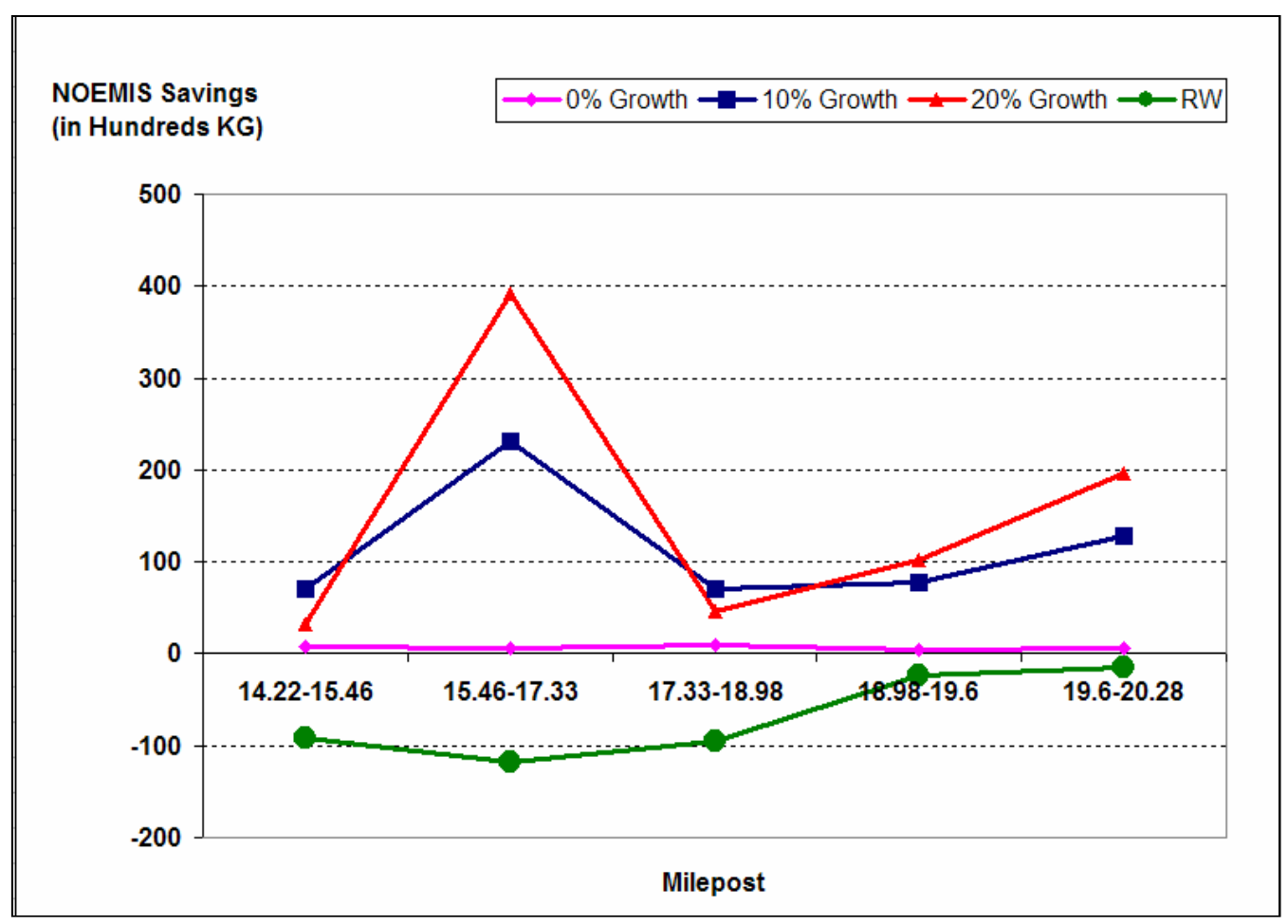

(a) $\mathrm{NO}_{\mathrm{x}}$ Emission Savings for HOV Lane Project Alternative 1 and Road Widening Project on I-70

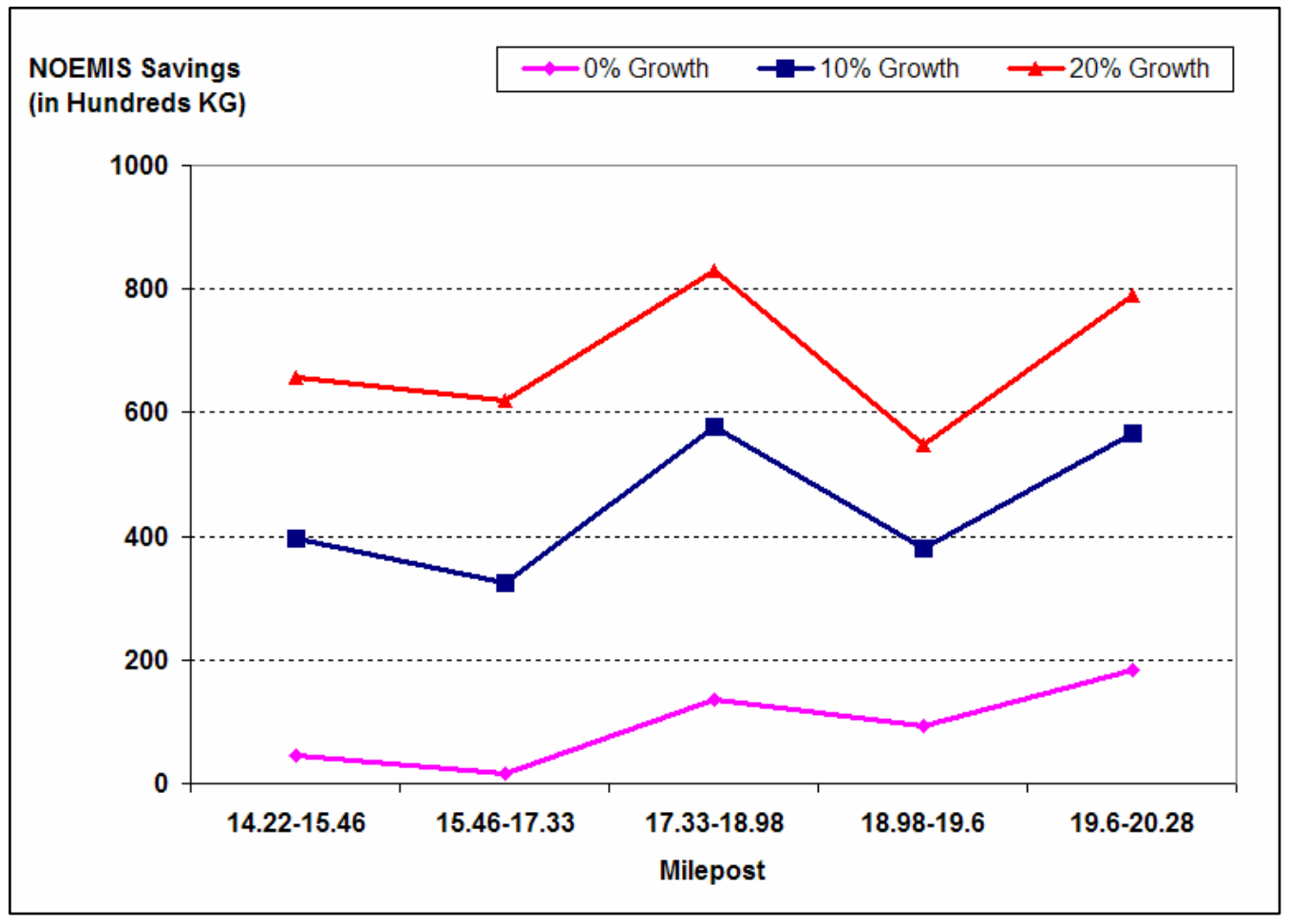

(a) $\mathrm{NO}_{\mathrm{x}}$ Emission Savings for HOV Lane Project Alternative 2 on I-70

Figure 4.11: $\mathrm{NO}_{\mathrm{x}}$ Emission Savings over Analysis Period due to HOV Facility Implementation 


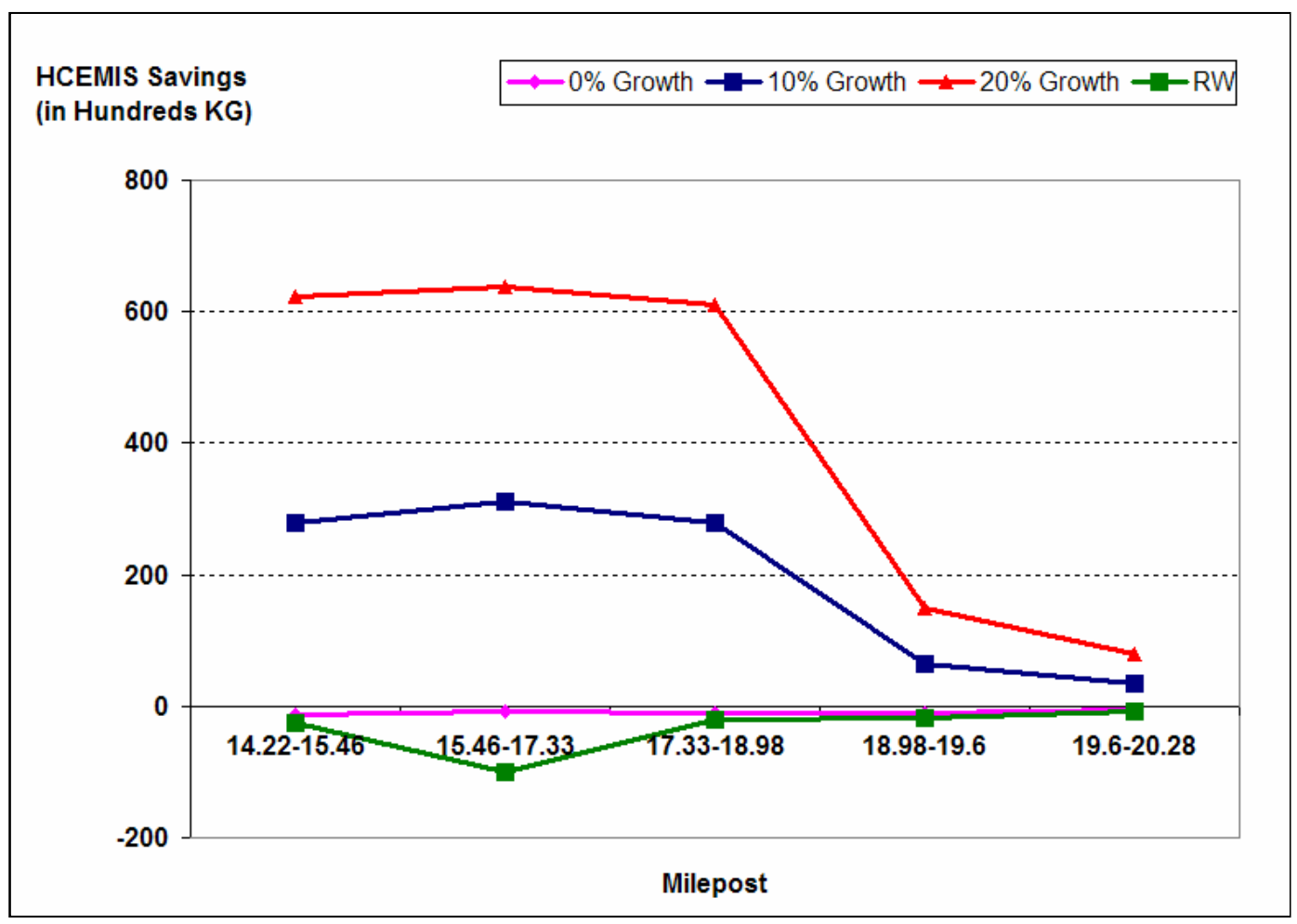

(a) HC Emission Savings for HOV Lane Project Alternative 1 and Road Widening Project on I-70

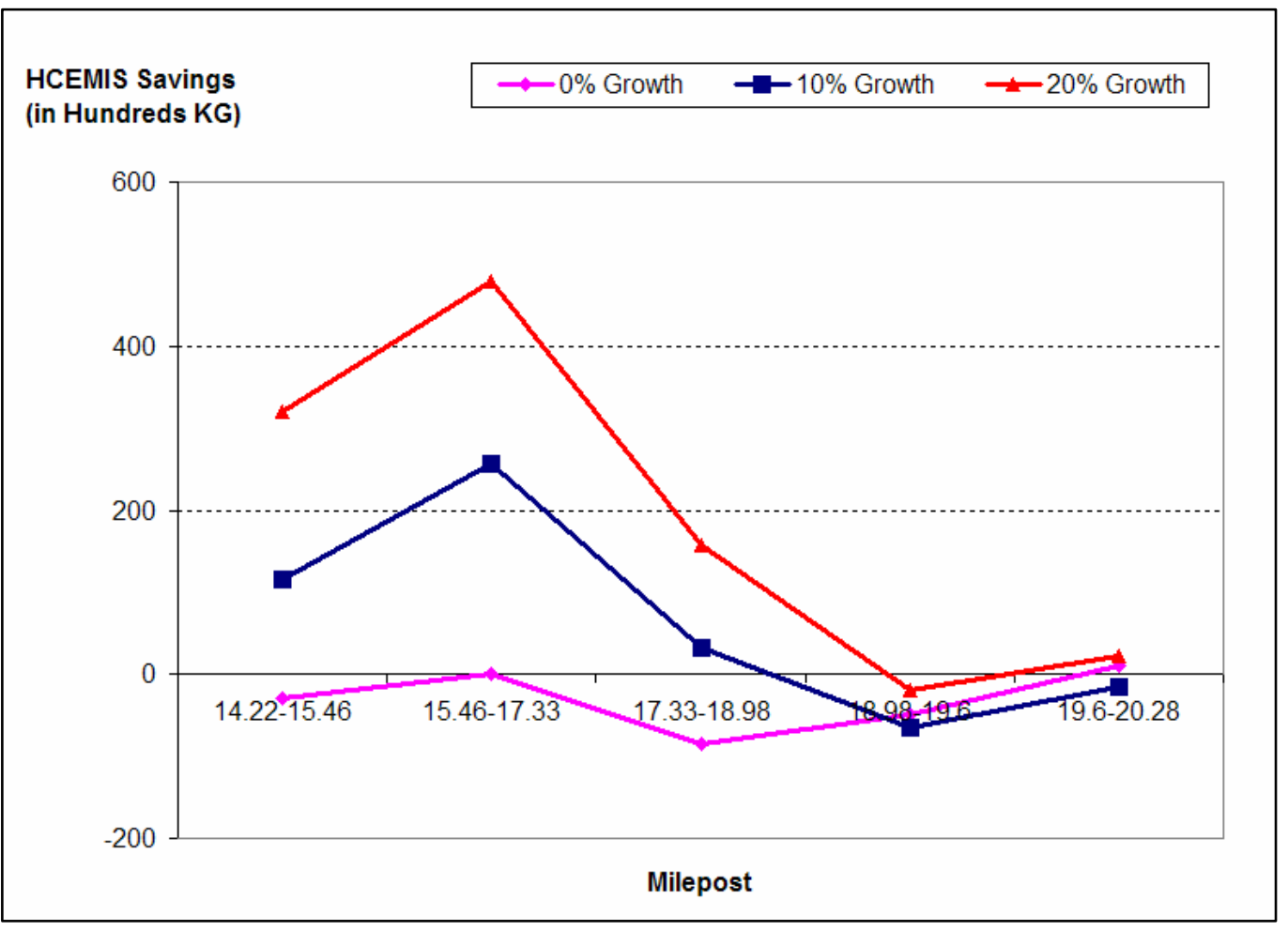

(b) HC Emission Savings for HOV Lane Project Alternative 2 on I-70

Figure 4.12: HC Emission Savings over Analysis Period due to HOV Facility Implementation 


\subsubsection{HOV Facility Costs}

The capital cost of a high occupancy vehicle lane project can vary widely from one region to another and depending upon the type of support facilities that are implemented. The construction of some of the support facilities can also be scheduled over a period of time. For example, some of the direct access ramps in Houston were constructed after the implementation of the HOV lane.

The determination of cost-effectiveness of the HOV facility can vary significantly depending upon the components that are included in the estimation of the cost. The analysis presented in this study determines the costeffectiveness for the most basic configuration of a concurrent flow HOV lane facility. The construction cost of parkand-ride lots, direct access ramps and dedicated enforcement areas was not considered while estimating the cost of the HOV facility alternatives in this study. It was also assumed that the right of way is available for I-70 and hence need not be purchased.

The costs of the concurrent flow HOV lane facilities on all the links of I-70, corresponding to the two HOV lane alternatives are shown in Table 4.10. The capital cost of the take-a-lane alternative (Alternative 2) was found to be considerably lower than the add-a-lane alternative (Alternative 1) because the construction of an additional lane is not required in this case. The estimated cost of construction of a new lane was found to be approximately $\$ 1.3$ million per lane-mile in 2006 dollars (VTPI, 2005). The cost of pavement marking was assumed equal to approximately two percent of the lane widening cost. The cost of HOV lane signing was estimated as approximately $\$ 25,000$ per lane-mile. The estimate of the sign cost was based on the preferential only lane and guide signs required at the slip ramps, at the beginning and at the end of the HOV facility.

The annual operation, maintenance and enforcement cost was calculated using the methodology described in Chapter 2 (Equation 2.5) assuming that two deployments are required per lane-mile and was found to be approximately \$26,000 per route-mile. The estimated annual operation, maintenance and enforcement cost falls within the range (\$20,000-\$30,000 per route-mile) specified by FTA (1992). This cost is shown in Table 4.10 for all the links in 2006 dollars.

Table 4.10: Cost of HOV Lane Alternatives on I-70 (2006 Dollars)

\begin{tabular}{|l|c|c|c|c|c|c|}
\hline & \multicolumn{5}{|c|}{ Mileposts } & \\
\hline & $\mathbf{1 4 . 2 2 - 1 5 . 4 6}$ & $\mathbf{1 5 . 4 6 - 1 7 . 3 3}$ & $\mathbf{1 7 . 3 3 - 1 8 . 9 8}$ & $\mathbf{1 8 . 9 8 - 1 9 . 6 0}$ & $\mathbf{1 9 . 6 0 - 2 0 . 2 8}$ & Total Cost \\
\hline Alternative 1 & $\$ 1,925,338$ & $\$ 2,903,533$ & $\$ 2,561,941$ & $\$ 962,669$ & $\$ 1,055,830$ & $\$ 9,409,312$ \\
\hline Alternative 2 & $\$ 71,538$ & $\$ 107,883$ & $\$ 95,191$ & $\$ 35,769$ & $\$ 39,230$ & $\$ 349,612$ \\
\hline $\begin{array}{l}\text { Annual Operation } \\
\text { Maintenance \& } \\
\text { Enforcement Cost }\end{array}$ & $\$ 29,736$ & $\$ 44,843$ & $\$ 39,567$ & $\$ 14,868$ & $\$ 16,307$ & $\$ 145,321$ \\
\hline
\end{tabular}

\subsubsection{B/C Ratio for HOV Implementation}

The benefit to cost ratio was calculated after aggregating the benefits and costs to their present worths at 2006 over an analysis period of ten years using a discount rate of $4 \%$. The calculated benefit-to-cost (B/C) ratio was plotted for all the links corresponding to the two alternatives. The graphs in Figure 4.13 show the $\mathrm{B} / \mathrm{C}$ ratio corresponding to 
the three scenarios of growth in average vehicle occupancy, for the two alternatives. The benefits in the benefit-tocost ratio were calculated by summing up the monetized travel time, vehicle operating cost and emission benefits. The take-a-lane alternative (Alternative 2) was found to be more cost-effective compared to the add-a-lane alternative (Alternative 1) because of the lower costs. Further, it was found that cost-effectiveness of Alternative 1 increased with increase in the number of vehicles using the HOV lane. However, cost-effectiveness of Alternative 2 was found to decrease with increase in HOV lane traffic, between Mileposts 17.33 and 20.28.

The graph corresponding to Alternative 1, in Figure 4.13(a), also compares the cost-effectiveness of the added HOV lane (Alternative 1) to the scenario when the added lane is not operated as a HOV lane (i.e., road widening in the WB direction). The economic feasibility of operating the added lane as a HOV lane was found to be higher compared to the scenario when the added lane is operated as a GP lane. However, difference in economic feasibility was relatively less significant for the section between Mileposts 18.98 and 20.28, because this section is relatively less congested.

The emission savings were monetized using the unit emission cost of pollutants shown in Table 4.11. The monetized emission savings (in 2006 million dollars) were found to be significantly lower than the monetized travel time and vehicle operating cost savings (in 2006 dollars). Hence, the monetized emission savings were found to constitute a very small fraction of the total monetized benefits that were used in the calculation of benefit-to-cost ratio in Figure 4.13. The relative magnitude of the emission savings can be compared with the travel time and vehicle operating cost savings using the graphs shown in Figure 4.14.

Table 4.11: Unit Emission Cost of Pollutants [Kang and Gillen, 1999]

\begin{tabular}{|c|c|}
\hline Pollutant & \multicolumn{2}{|c|}{ Unit Cost of Pollutant $(\$ / \mathrm{Kg})$} \\
\hline $\mathrm{HC}$ & $\$ 1.2800$ \\
\hline $\mathrm{CO}$ & $\$ 0.0063$ \\
\hline $\mathrm{NO}_{\mathrm{x}}$ & $\$ 1.2800$ \\
\hline
\end{tabular}

Figure 4.14 shows five graphs, corresponding to each of the five links, where monetized travel time and vehicle operating cost savings are plotted on the Y-axis and monetized emission savings are plotted on the X-axis. The graphs can be used to identify the alternative (add-a-lane vs. take-a-lane) and the scenario (corresponding to percentage growth in average vehicle occupancy), when all the monetized savings are significantly greater than zero.

Based on the analysis presented in Figures 4.13 and 4.14, the HOV lane Alternative 1 was found to be more cost-effective compared to the HOV lane Alternative 2. The operation of added lane as a HOV lane (Alternative 1) is economically more feasible compared to the scenario when the added lane is operated as a GP lane (road widening (RW)). The economic feasibility of Alternative 1 was found to improve with increase in the number of vehicles using the HOV lane. For Alternative 1, the scenario corresponding $20 \%$ growth in average vehicle occupancy was found to be most cost-effective. 


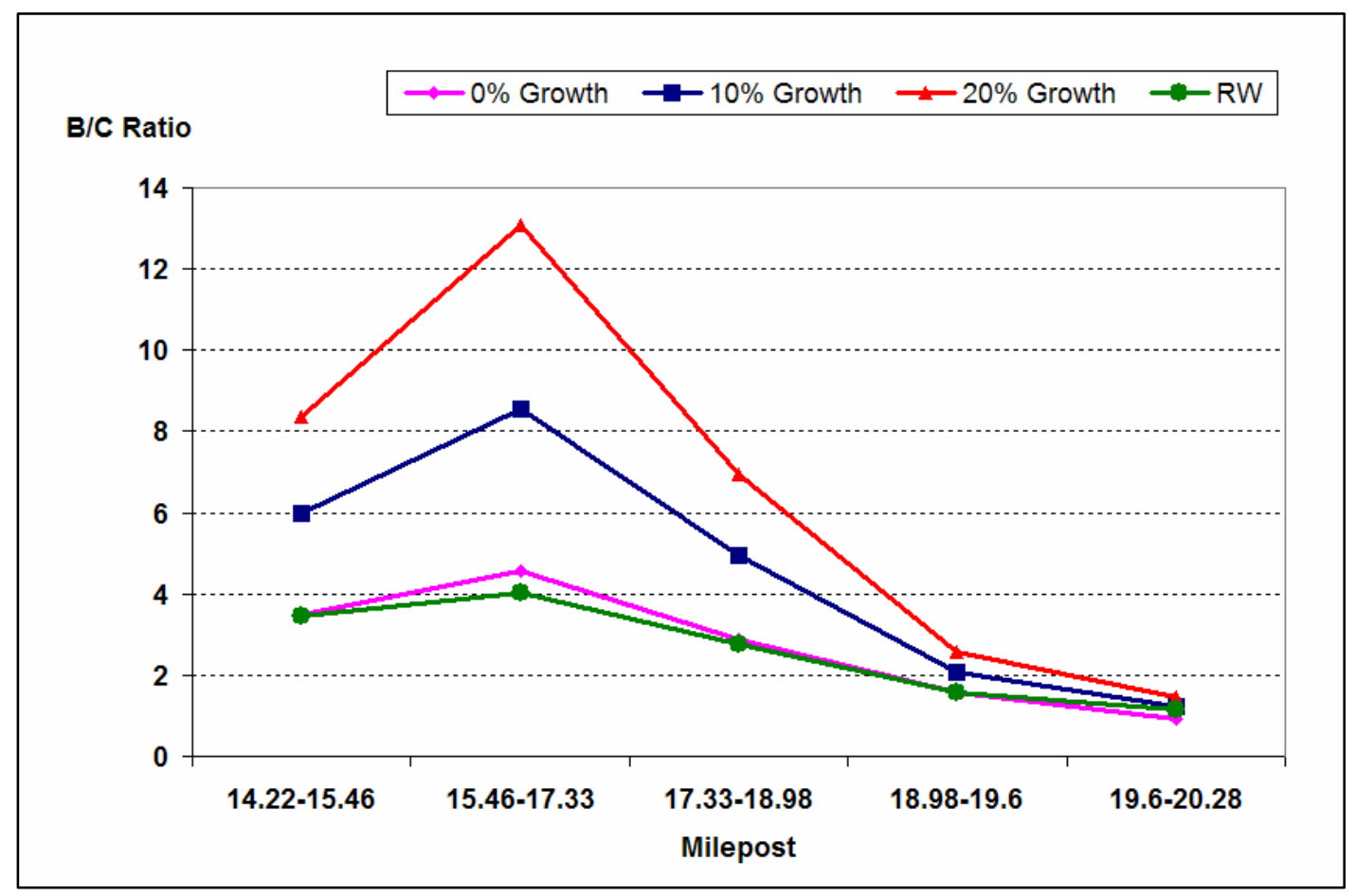

(a) B/C Ratio for HOV Lane Project Alternative 1 and Road Widening Project on I-70

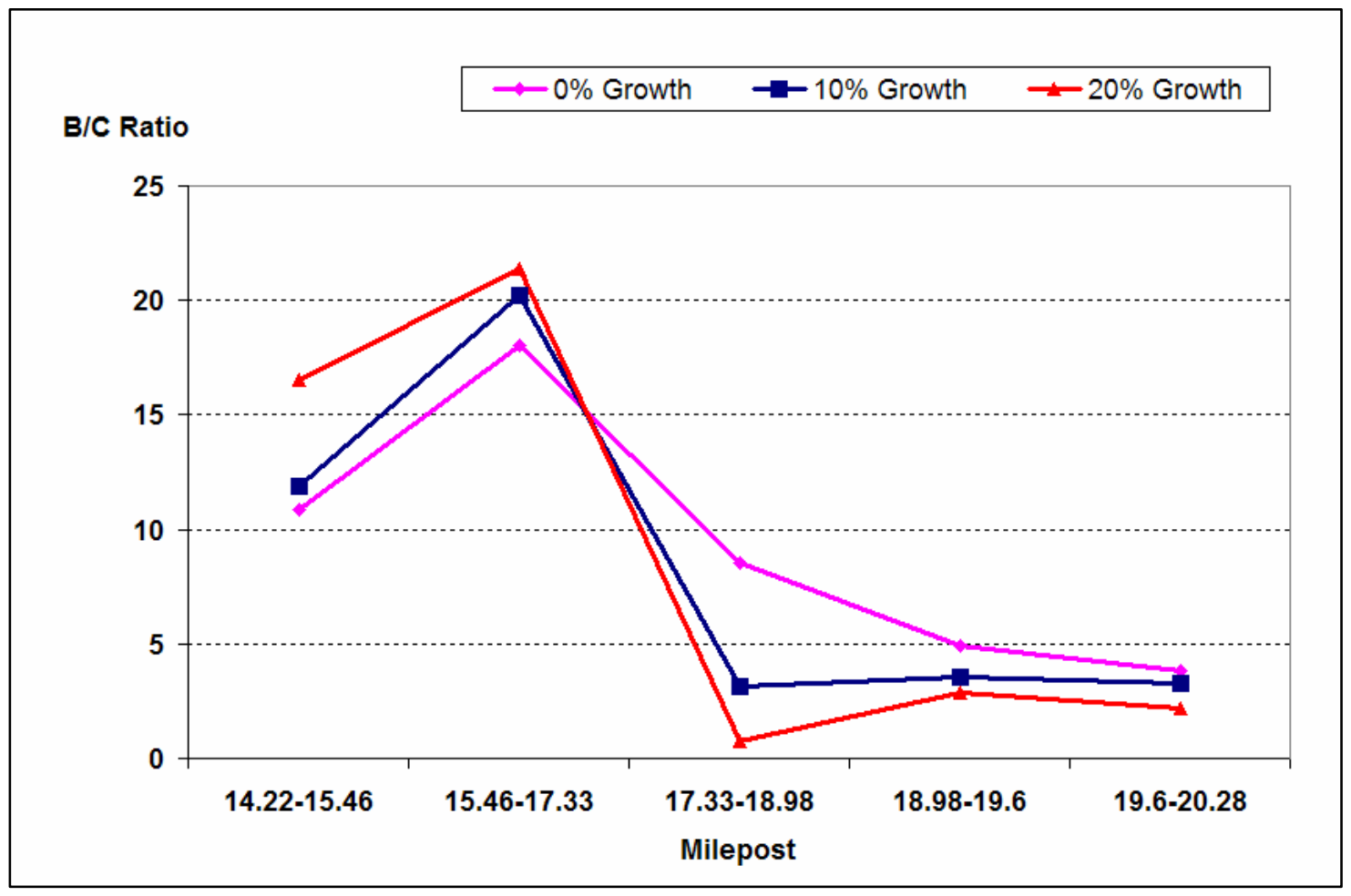

(b) B/C Ratio for HOV Lane Project Alternative 2 on I-70

Figure 4.13: Benefit to Cost Ratio of Concurrent Flow Lane HOV Facility Project Alternatives 


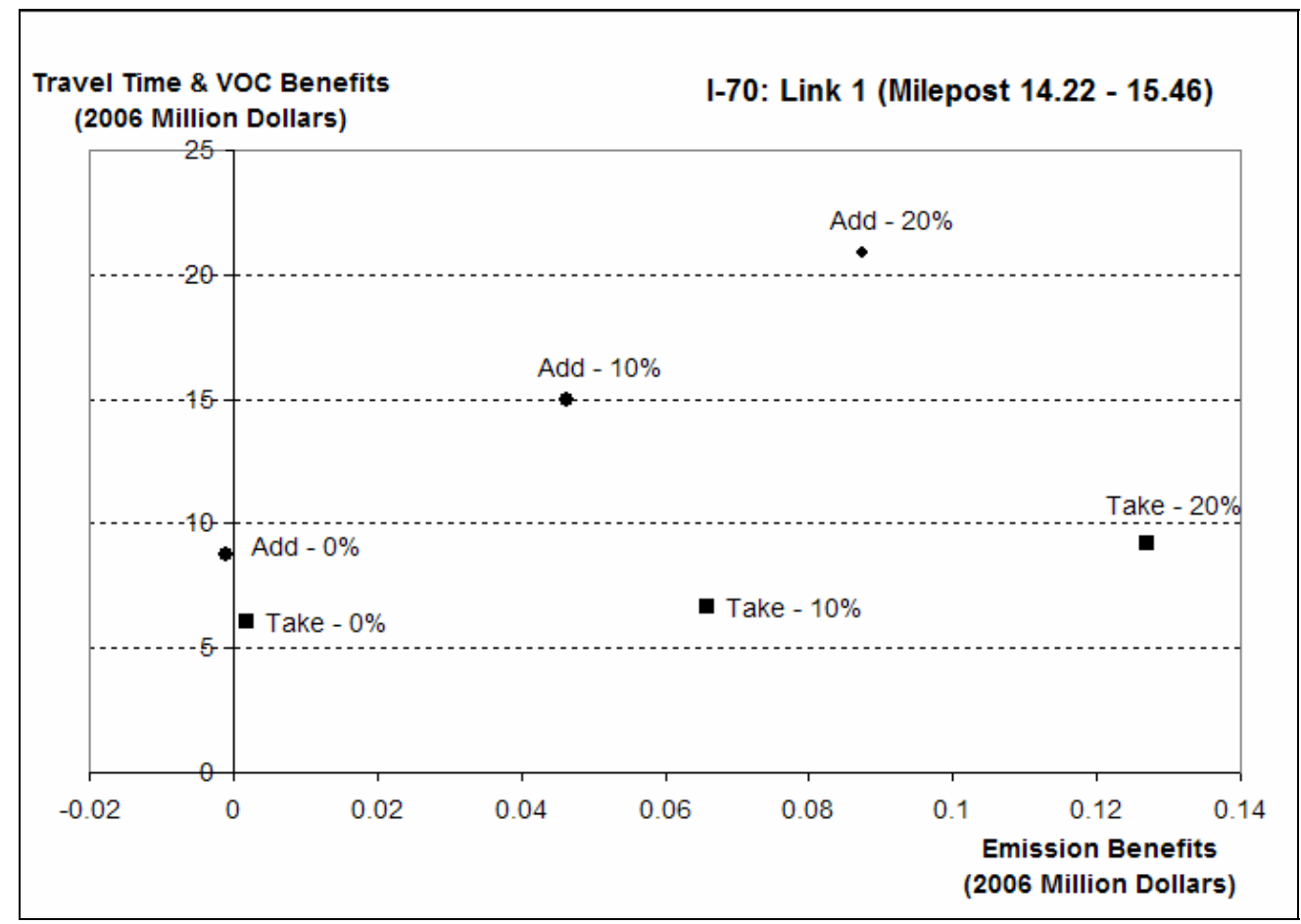

Figure 4.14(a): Comparison of Travel Time, VOC and Emission Savings over Analysis Period on Link 1

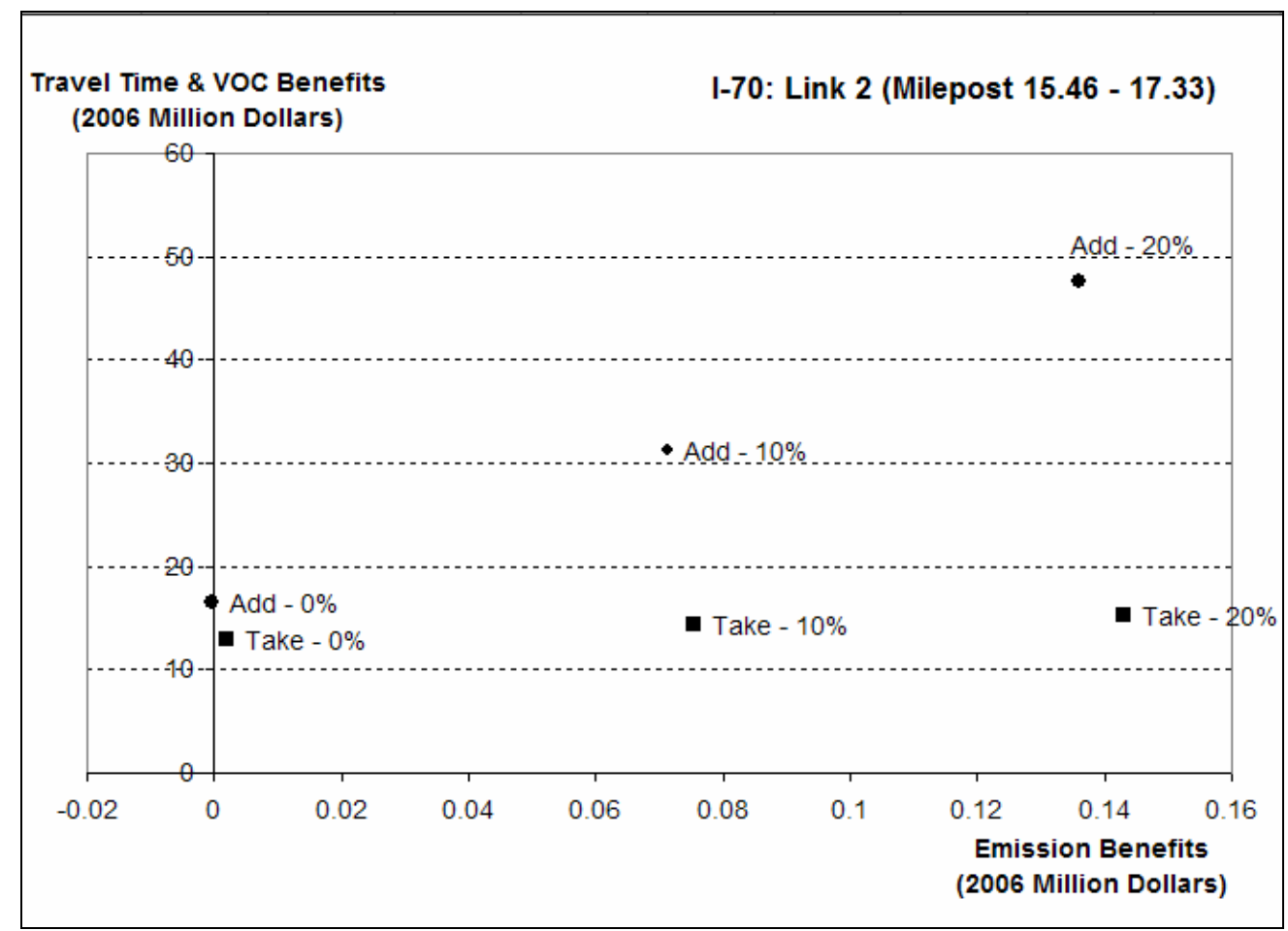

Figure 4.14(b): Comparison of Travel Time, VOC and Emission Savings over Analysis Period on Link 2 


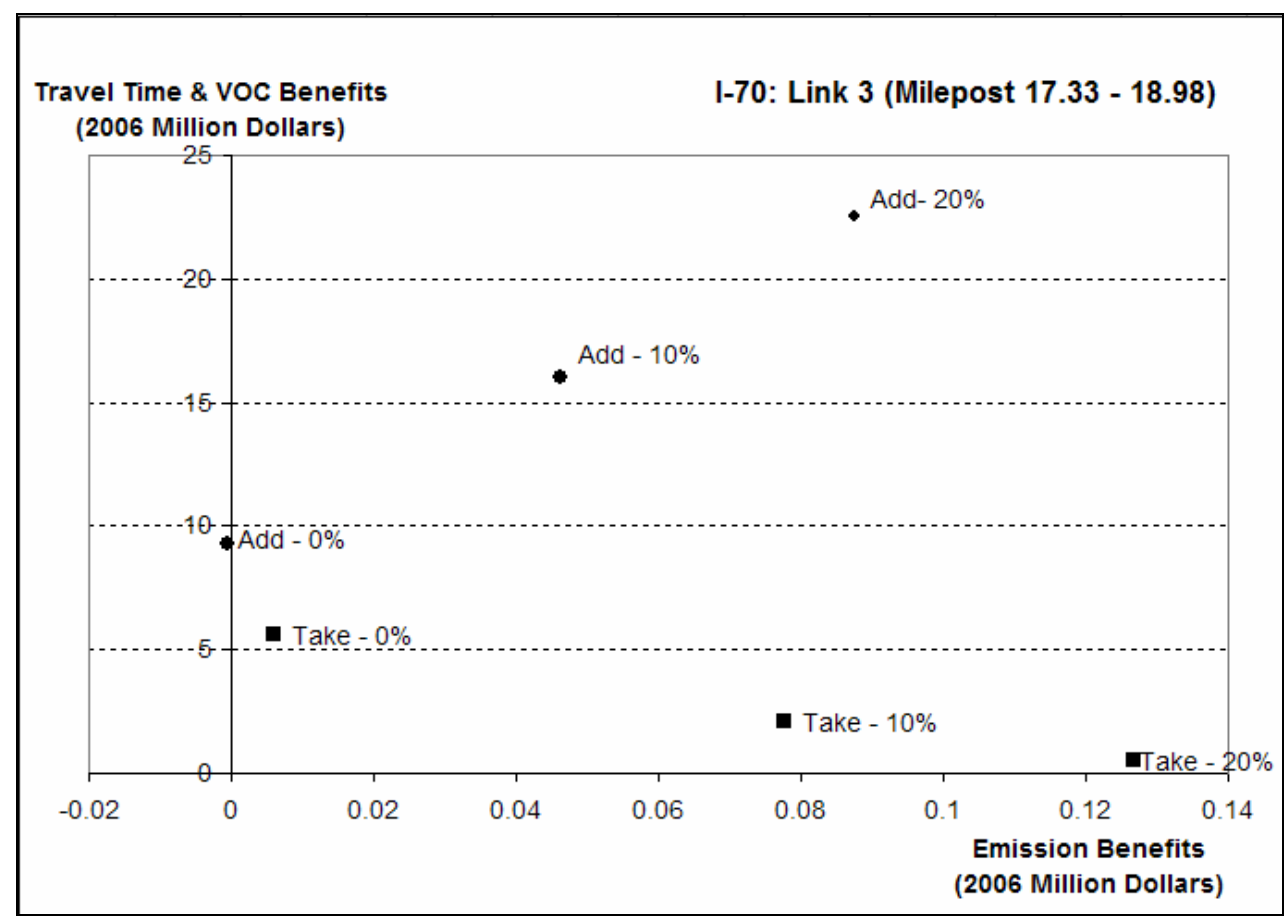

Figure 4.14(c): Comparison of Travel Time, VOC and Emission Savings over Analysis Period on Link 3

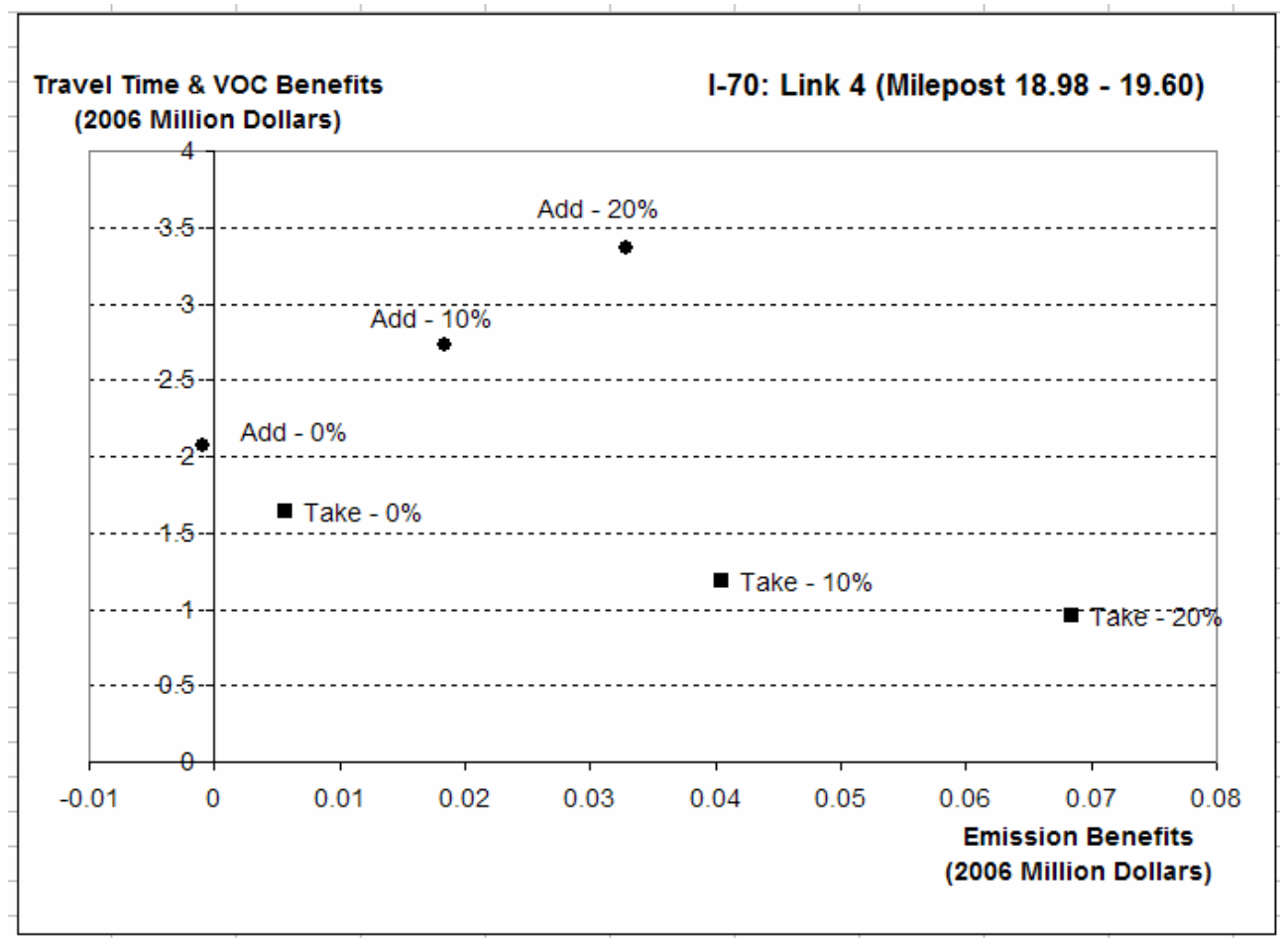

Figure 4.14(d): Comparison of Travel Time, VOC and Emission Savings over Analysis Period on Link 4 


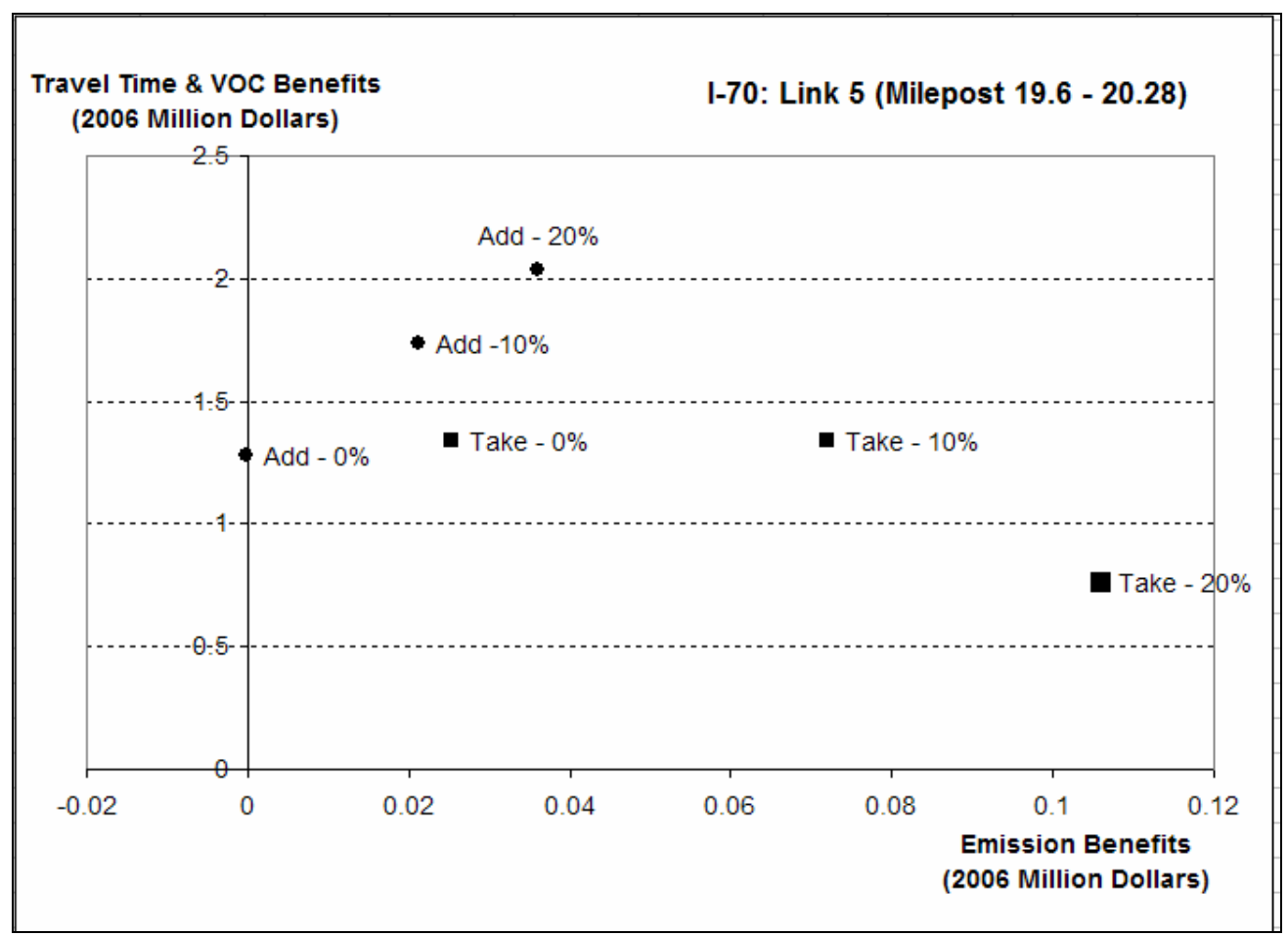

Figure 4.14(e): Comparison of Travel Time, VOC and Emission Savings over Analysis Period on Link 5

\subsubsection{HOV Lane Implementation on I-70}

The economic evaluation of add-a-lane and take-a-lane based HOV lane alternatives suggested that the implementation of the HOV lane by adding a HOV lane is the more cost-effective and economically viable alternative. However, most of the benefits, corresponding to this alternative, were found to come from the implementation of HOV lane between Mileposts 14.22 and 18.98. The section between Mileposts 18.98 and 20.28 is essentially uncongested and hence the benefits were relatively lower on this section (but B/C ratio is greater than 1 ). The average length of concurrent flow lane HOV facilities implemented in the country is approximately 8 miles [Markkula, 2004]. The implementation of HOV facility on such a small section on I-70 may adversely affect the number of carpools formed and hence limit the benefits received from the project.

Moreover, based on the guidelines presented in Chapter 2, after determining the economic feasibility of the HOV lane, it has to be ascertained that the HOV lane will not appear empty. Several states have set minimum thresholds to ensure on HOV lane traffic volume. The implementation of HOV lanes is considered when HOV lane traffic volume exceeds these minimum thresholds. For example, California uses a minimum threshold of 800 vehicles per hour per HOV lane, New Jersey has a minimum threshold of 700 vehicles per hour per HOV lane and Texas has a variable minimum threshold from 400-800 vehicles per hour per HOV lane depending upon the type of HOV lane. The HOV lane traffic should be forecasted for each link on I-70 using a travel demand model that is developed based on the socio-economic and trip characteristics of the study area. 


\subsection{FEASIBILITY OF IMPLEMENTATION OF RAMP METERING}

In Section 4.3 it was determined that the I-70 WB direction is congested during the morning peak period. The I-70 corridor becomes congested in the WB direction after vehicles coming from I-465 enter the freeway through Ramp 3224. The corridor remains congested during the morning peak period as more vehicles keep entering the freeway from the six on-ramps, downstream of Ramp 3224. Therefore, the economic feasibility of metering the on-ramps in the I-70 WB direction was determined. The ramps in the EB direction were not considered for ramp metering because the I-70 freeway is not congested in this direction during the analysis period. These on-ramps in the WB direction are (arranged in the order vehicles traveling in the WB direction would encounter them):

1) Ramp 3224- Two Lane Freeway-to-Freeway Connector Ramp

2) Ramp 3215- One Lane On-Ramp

3) Ramp 3213- One Lane On-Ramp

4) Ramp 3206- One Lane Loop On-Ramp

5) Ramp 3204- One Lane On-Ramp

6) Ramp 3196- One Lane Loop On-Ramp

7) Ramp 3194- One Lane On-Ramp

The economic evaluation was conducted assuming that the ramp meters are operational for three hours in the morning peak period between 6:00 A.M. and 9:00 A.M. A description of all the on-ramps is presented in Table 4.12. The description includes information about the hourly ramp traffic (estimated for the design year 2006) during the morning peak period, length of ramp, number of lanes on ramp and the maximum queue that can be stored on each ramp. The maximum allowable queue on these ramps was calculated using the ramp length and an assumed average bumper to bumper distance of 30 feet between vehicles. Ramp 3224 is an interstate to interstate ramp and hence requires special considerations in the design of ramp metering system (which are discussed later in Section 4.4.1).

Table 4.12: Description of On-Ramps in the I-70 WB Direction

\begin{tabular}{|c|c|c|l|c|c|c|c|c|}
\hline $\begin{array}{c}\text { Milepost } \\
\text { (Miles) }\end{array}$ & $\begin{array}{c}\text { Ramp } \\
\text { ID }\end{array}$ & $\begin{array}{c}\text { Lanes } \\
\text { (Length } \\
\text { in miles) }\end{array}$ & Description & AWDT & $\begin{array}{c}\text { Gour 1 } \\
\text { To } \\
\mathbf{7 : 0 0} \\
\text { A.M. }\end{array}$ & $\begin{array}{c}\text { Hour 2 } \\
\mathbf{7 : 0 0} \\
\text { To } \\
\mathbf{8 : 0 0} \\
\text { A.M. }\end{array}$ & $\begin{array}{c}\text { Hour 3 } \\
\mathbf{8 : 0 0} \\
\text { To } \\
\mathbf{9 : 0 0} \\
\text { A.M. }\end{array}$ & MAXQ \\
\hline 19.69 & 3224 & $2(0.8)$ & From I-465 & 25,489 & 2,304 & 3,161 & 2,633 & 282 \\
\hline 19.34 & $3215(\mathrm{~N})$ & $1(0.23)$ & From I-465 & 8,972 & 560 & 837 & 604 & 41 \\
\hline 19.08 & 3213 & $1(0.43)$ & From Shadeland Ave. & 12,336 & 330 & 661 & 945 & 76 \\
\hline 17.33 & 3206 & $1(0.12)$ & From NB Emerson Ave. & 6,218 & 450 & 492 & 350 & 23 \\
\hline 16.94 & 3204 & $1(0.23)$ & From SB Emerson Ave. & 10,919 & 903 & 1,221 & 762 & 42 \\
\hline 15.46 & 3196 & $1(0.18)$ & From NB N Rural St. & 4,395 & 201 & 275 & 254 & 34 \\
\hline 15.23 & 3194 & $1(0.27)$ & From SB Keystone Way & 11,215 & 701 & 1,046 & 755 & 49 \\
\hline
\end{tabular}


Table 4.13 shows ramp traffic volumes and freeway traffic volumes upstream of each ramp during the morning peak period. The ramps are shown in the order in which the traffic moving westbound on I-70 will encounter them. The v/c ratio on the freeway section upstream of Ramp 3224, is less than the benchmark (0.9) during the peak period. However, as the traffic enters the freeway from Ramp 3224 the freeway becomes congested and hence the traffic volume upstream of all the other ramps increases. Hence, the freeway becomes congested in the WB direction, between 7:00 A.M. to 8:00 A.M., even before the ramp traffic enters from the ramps that are downstream of Ramp 3224. Therefore, the implementation of ramp metering on Ramp 3224 will reduce traffic volumes upstream of the other ramps, as the number of vehicles entering from Ramp 3224 is regulated.

Table 4.13: Freeway Upstream and Ramp Traffic Volumes in Morning Peak Period on I-70 WB

\begin{tabular}{|c|c|c|c|c|c|c|c|c|}
\hline & & \multicolumn{7}{|c|}{ Ramp ID } \\
\hline & Hour & 3224* & 3215 & 3213 & 3206 & 3204 & 3196 & 3194 \\
\hline \multirow{3}{*}{$\begin{array}{c}\text { Freeway } \\
\text { Upstream } \\
\text { Traffic } \\
\text { (vphpl) }\end{array}$} & 6-7 AM & 1401 & 1626 & 1766 & 1741 & 1854 & 1999 & 1640 \\
\hline & 7-8 AM & 1823 & 2158 & 2367 & 2391 & 2514 & 2735 & 2243 \\
\hline & 8-9 AM & 1301 & 1634 & 1785 & 1931 & 2018 & 2132 & 1756 \\
\hline \multirow{3}{*}{$\begin{array}{c}\text { Ramp } \\
\text { Traffic } \\
\text { (vph) }\end{array}$} & 6-7 AM & 2304 & 560 & 330 & 450 & 903 & 201 & 701 \\
\hline & 7-8 AM & 3161 & 837 & 661 & 492 & 1221 & 275 & 1046 \\
\hline & 8-9 AM & 2633 & 604 & 945 & 350 & 762 & 254 & 755 \\
\hline
\end{tabular}

*On-Ramp 3224 from I-465 is a two-lane ramp in the WB direction on I-70, Freeway Capacity = $2160 \mathrm{vphpl}$

The goal of ramp metering is to regulate traffic entering the freeway from the ramps so that congested conditions do not prevail on the freeway. If the freeway section upstream of a ramp is already congested, the benefits of ramp metering are reduced because the vehicles on the ramp will have to wait for a long time before entering the freeway. Therefore, implementation of ramp metering on Ramp 3224 is crucial. The traffic volumes upstream of all the other ramps will reduce if ramp metering is implemented on Ramp 3224 thereby enhancing the benefits of ramp metering at the ramps downstream.

The analysis presented in this study evaluates the benefits of implementing traffic responsive ramp metering on the I-70 corridor for each ramp separately. This implies that, when ramp metering on Ramp 3215 is evaluated, it is assumed that ramp metering has not been implemented on the upstream Ramp 3224. The same is assumed when economic evaluation is done for the remaining ramps downstream of Ramp 3224 and 3215. Hence, the computed benefits of isolated ramp metering on all the downstream ramps are lower than the benefits that will accrue if ramp metering is implemented simultaneously on all the ramps. In other words, this report presents the economic evaluation results for isolated local traffic responsive ramp metering at each of the on-ramps on I-70 WB.

\subsubsection{Feasibility of Freeway-to-Freeway Ramp Metering}

The concept of freeway-to-freeway connector metering was developed as a tool to regulate extremely high traffic volume entering one freeway from another [Caltrans, 2005]. The freeway-to-freeway connector metering system differs from the metering of ramps from surface streets, because of the higher speeds and heavy traffic volumes on the connectors. Therefore, the metering of freeway-to-freeway connector ramps requires special considerations. 
According to Caltrans (2005), large storage capacity on ramps and advance warning signs are required on freeway-to-freeway connector ramps in order to safely operate the connector meters. The advance warning signs include a "Meter On" sign, a "Prepare to Stop" sign, a signal ahead warning sign with flashing beacons in addition to the overhead and ground mounted traffic signals. The presence of a queue override system can prevent the building up of excessive queue on the connector. Caltrans (2005) found that freeway-to-freeway connector metering cannot be implemented on ramps with inadequate storage capacity and insufficient sight distance. By regulating the access from one freeway to another, the receiving freeway benefits because of the increase in speed.

Jacobson and Landsman (1994) provided the following guidelines for implementation of freeway-tofreeway ramp metering systems:

- Consider locations where recurrent congestion is a problem or where route diversion should be encouraged

- Route diversion should be considered only at locations where suitable alternatives exist

- Consecutive metering (metering twice) should be avoided within a short distance

- Avoid metering single lane freeway-to-freeway ramps

- Ramp meters should not be installed on any freeway-to-freeway ramps unless the analysis ensures that mainline flow will be improved so that the ramp users are rewarded once they enter the freeway mainline.

- The meters can be installed on the freeway-to-freeway ramps when congestion occurs regularly on the ramp for four or more times a week during the peak period.

- If traffic queues that impede mainline traffic develop on the upstream mainline because of a freeway-tofreeway ramp meter, then the metering rate should be increased to minimize the queues on the upstream mainline, or additional storage capacity should be provided.

- Whenever possible, install meters at locations on roadways that are level or have a slight downgrade, so that heavy vehicles can easily accelerate. Also, install meters where the sight distance is adequate for drivers approaching the meter to see the queue in time to safety stop.

According to the guidelines in the ramp meter design manual prepared by the California Department of Transportation (Caltrans, 2000) the installation of ramp metering on freeway-to-freeway connector ramps should be considered when the ramp has standard lane and shoulder widths and the "tail light" sight distance is provided for a speed of $80 \mathrm{~km} / \mathrm{h}$. Several freeway-to-freeway connector ramp metering systems have been implemented in the country by various states (as listed in Chapter 3). Tables 4.14 and 4.15 present some of the locations in California and Minnesota where freeway-to-freeway ramp metering has been implemented. Figures 4.15 and 4.16 show the map of these locations in District 7, California and in Minnesota (Locations A, B and C).

Ramp 3224 is a two lane ramp that connects the I-465 freeway with the I-70 WB. The length of the ramp is approximately 0.8 miles and assuming a bumper to bumper distance of 30 feet between stopped vehicles, the queue storage capacity of the ramp was found to approximately 280 vehicles. Implementation of ramp metering on this ramp can reduce congestion on the I-70 freeway by regulating the number of vehicles entering I-70 WB in the morning peak period. Hence the economic feasibility of implementation of ramp metering on this ramp was determined along with the feasibility of implementation of ramp metering on all the other on-ramps in the I-70 WB direction. 
Table 4.14: Freeway-to-Freeway Metering Systems in District 7, California [Caltrans, 2005]

\begin{tabular}{|c|c|c|c|c|c|c|c|c|c|c|}
\hline \multirow[t]{2}{*}{ Co. } & \multirow[t]{2}{*}{ Rte } & \multirow{2}{*}{ Location } & \multirow{2}{*}{$\begin{array}{l}\text { Ramp } \\
\text { Storage } \\
\text { (veh) }\end{array}$} & \multirow{2}{*}{$\begin{array}{c}\text { Platoon } \\
\text { Metering } \\
(\text { Yes } / \mathrm{No}) \\
\end{array}$} & \multirow{2}{*}{$\begin{array}{c}\text { Total } \\
\text { Lanes } \\
\end{array}$} & \multirow{2}{*}{$\begin{array}{c}\text { Prepare } \\
\text { to Stop } \\
\text { Sign }\end{array}$} & \multirow{2}{*}{$\begin{array}{c}\text { Meter On } \\
\text { Sign }\end{array}$} & \multirow{2}{*}{$\begin{array}{c}\text { Flashing } \\
\text { Beacon }\end{array}$} & \multicolumn{2}{|c|}{$\begin{array}{l}\text { Metering Time } \\
\text { Monday - Friday }\end{array}$} \\
\hline & & & & & & & & & AM Period & PM Period \\
\hline LA & 105 & NB-405 to EB-105 & 170 & No & 2 & $\mathrm{x}$ & $x$ & $x$ & & $14: 00-19: 00$ \\
\hline LA & 105 & SB-405 to EB-105 & 346 & Yes & 2 & $x$ & $\mathrm{x}$ & $x$ & & $14: 00-19: 00$ \\
\hline LA & 105 & SB-110 to EB-105 & 165 & No & 2 & $\mathrm{x}$ & $\mathrm{x}$ & $x$ & & $14: 00-19: 30$ \\
\hline LA & 105 & NB-110 to EB-105 & 100 & No & 2 & $\mathrm{x}$ & $\mathrm{x}$ & $x$ & & $14: 00-19: 30$ \\
\hline LA & 105 & NB-710 to EB-105 & 330 & Yes & 2 & $\mathrm{x}$ & $\mathrm{x}$ & $x$ & & $14: 00-19: 30$ \\
\hline LA & 105 & SB-710 to EB-105 & 430 & No & 2 & $\mathrm{x}$ & $\mathrm{x}$ & $x$ & & $14: 00-19: 30$ \\
\hline LA & 105 & SB-110 to WB-105 & 256 & Yes & 2 & $\mathrm{x}$ & $\mathrm{x}$ & $\mathrm{x}$ & $5: 30-9: 30$ & $14: 00-19: 30$ \\
\hline LA & 105 & NB-710 to WB-105 & 364 & No & 2 & $x$ & $\mathrm{x}$ & $x$ & $5: 30-9: 30$ & $14: 00-19: 00$ \\
\hline LA & 105 & SB-710 to WB-105 & 100 & Yes & 1 & $\mathrm{x}$ & $x$ & $x$ & $5: 30-9: 30$ & \\
\hline LA & 110 & WB-105 to SB-110 & 182 & No & 2 & $x$ & $x$ & $x$ & \multicolumn{2}{|c|}{ OFF } \\
\hline LA & 110 & EB- 105 to SB-110 & 74 & Yes & 1 & $\mathrm{x}$ & $\mathrm{x}$ & $x$ & \multicolumn{2}{|c|}{ OFF } \\
\hline LA & 110 & SB-5 TO SB-110 & 250 & No & 2 & $\mathrm{x}$ & $\mathrm{x}$ & $x$ & \multicolumn{2}{|c|}{ OFF } \\
\hline LA & 110 & EB/WB-105 to NB-110 & 275 & Yes & 3 & $x$ & $x$ & $x$ & $6: 00-10: 00$ & $14: 00-18: 00$ \\
\hline LA & 405 & EB $/ N B-105$ to SB-405 & 464 & Yes & 2 & $\mathrm{x}$ & $\mathrm{x}$ & $x$ & $6: 30-9: 00$ & $14: 00-19: 30$ \\
\hline LA & 405 & WB-105 to NB-405 & 282 & Yes & 2 & $x$ & $x$ & $x$ & $6: 30-11: 00$ & $13: 00-18: 30$ \\
\hline LA & 605 & EB-105 to SB-605 & 372 & Yes & 2 & $\mathrm{x}$ & $\mathrm{x}$ & $x$ & & $14: 00-19: 00$ \\
\hline LA & 605 & EB-105 to NB-605 & 318 & Yes & 2 & $\mathrm{x}$ & $\mathrm{x}$ & $x$ & $5: 30-10: 00$ & $13: 30-19: 00$ \\
\hline LA & 710 & EB $/ N B-105$ to SB-710 & 550 & Yes & 3 & $\mathrm{x}$ & $x$ & $x$ & $6: 30-9: 30$ & $14: 00-18: 30$ \\
\hline LA & 710 & EB/WB-105 to NB-710 & 580 & Yes & 2 & $x$ & $x$ & $x$ & $6: 00-10: 00$ & $14: 0018: 30$ \\
\hline
\end{tabular}

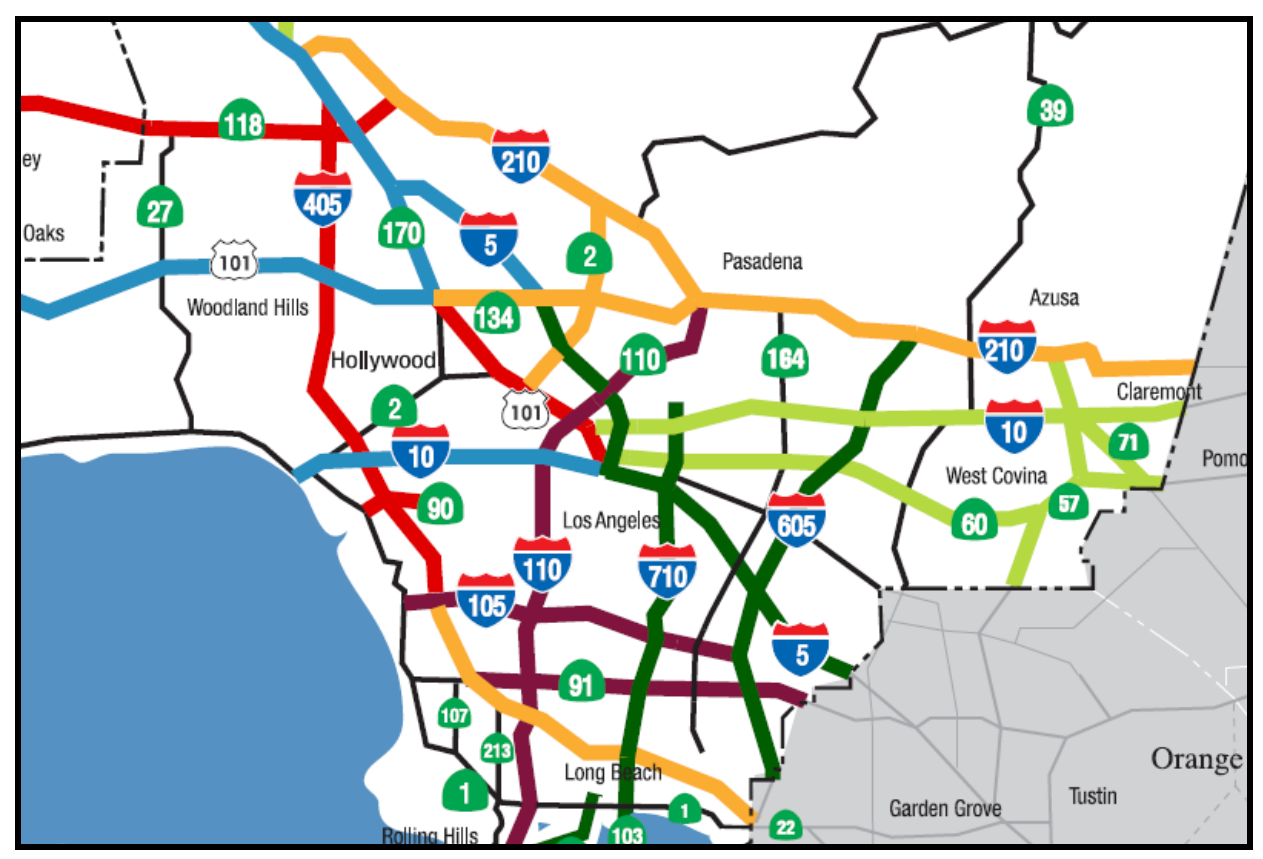

Figure 4.15: Map of Freeway-to-Freeway Ramp Metering System in District 7 [Caltrans, 2005] 
Table 4.15: Freeway-to-Freeway Ramp Metering Systems in Minnesota [Fischer, 2006]

\begin{tabular}{|c|c|c|c|c|c|}
\hline Road & Direction & Cross Street & Cross direction & $\begin{array}{c}\text { Metering } \\
\text { Start Time }\end{array}$ & $\begin{array}{l}\text { Metering } \\
\text { End Time }\end{array}$ \\
\hline I-694 & EB & I-35W & SB & $15: 00$ & $17: 45$ \\
\hline I-694 & EB & I-35W & SB & $06: 30$ & $08: 30$ \\
\hline I-694 & EB & I-35W & NB & $15: 00$ & $17: 45$ \\
\hline I-694 & EB & I-35W & NB & $06: 30$ & $08: 30$ \\
\hline I-35W & NB & I-694 & EB & $15: 00$ & $17: 45$ \\
\hline I-35W & SB & I-694 & EB & $06: 00$ & $08: 30$ \\
\hline I-35W & SB & I-694 & WB & $06: 00$ & $08: 30$ \\
\hline I-494 & SB & I-394 & WB & $15: 00$ & $17: 45$ \\
\hline I-494 & SB & I-394 & WB & $06: 00$ & $08: 30$ \\
\hline I-494 & SB & I-394 & EB & $15: 00$ & $17: 45$ \\
\hline $\mathrm{I}-494$ & SB & I-394 & EB & $06: 00$ & $08: 30$ \\
\hline I-494 & NB & I-394 & EB & $15: 00$ & $17: 45$ \\
\hline $\mathrm{I}-494$ & NB & I-394 & WB & $15: 00$ & $17: 45$ \\
\hline $35 \mathrm{~W}$ & NB & 494 & EB & $15: 00$ & $17: 45$ \\
\hline $35 \mathrm{~W}$ & NB & 494 & EB & $06: 00$ & $08: 30$ \\
\hline $35 \mathrm{~W}$ & NB & 494 & WB & $15: 00$ & $17: 45$ \\
\hline $35 \mathrm{~W}$ & NB & 494 & WB & 06:00 & $08: 30$ \\
\hline $35 \mathrm{~W}$ & SB & 494 & WB & $15: 00$ & $17: 45$ \\
\hline $35 \mathrm{~W}$ & SB & 494 & EB & $15: 00$ & $17: 45$ \\
\hline 494 & EB & $35 \mathrm{~W}$ & SB & $15: 00$ & $17: 45$ \\
\hline 494 & EB & $35 \mathrm{~W}$ & NB & $15: 00$ & $17: 45$ \\
\hline 494 & WB & $35 \mathrm{~W}$ & SB & $06: 20$ & $08: 30$ \\
\hline
\end{tabular}

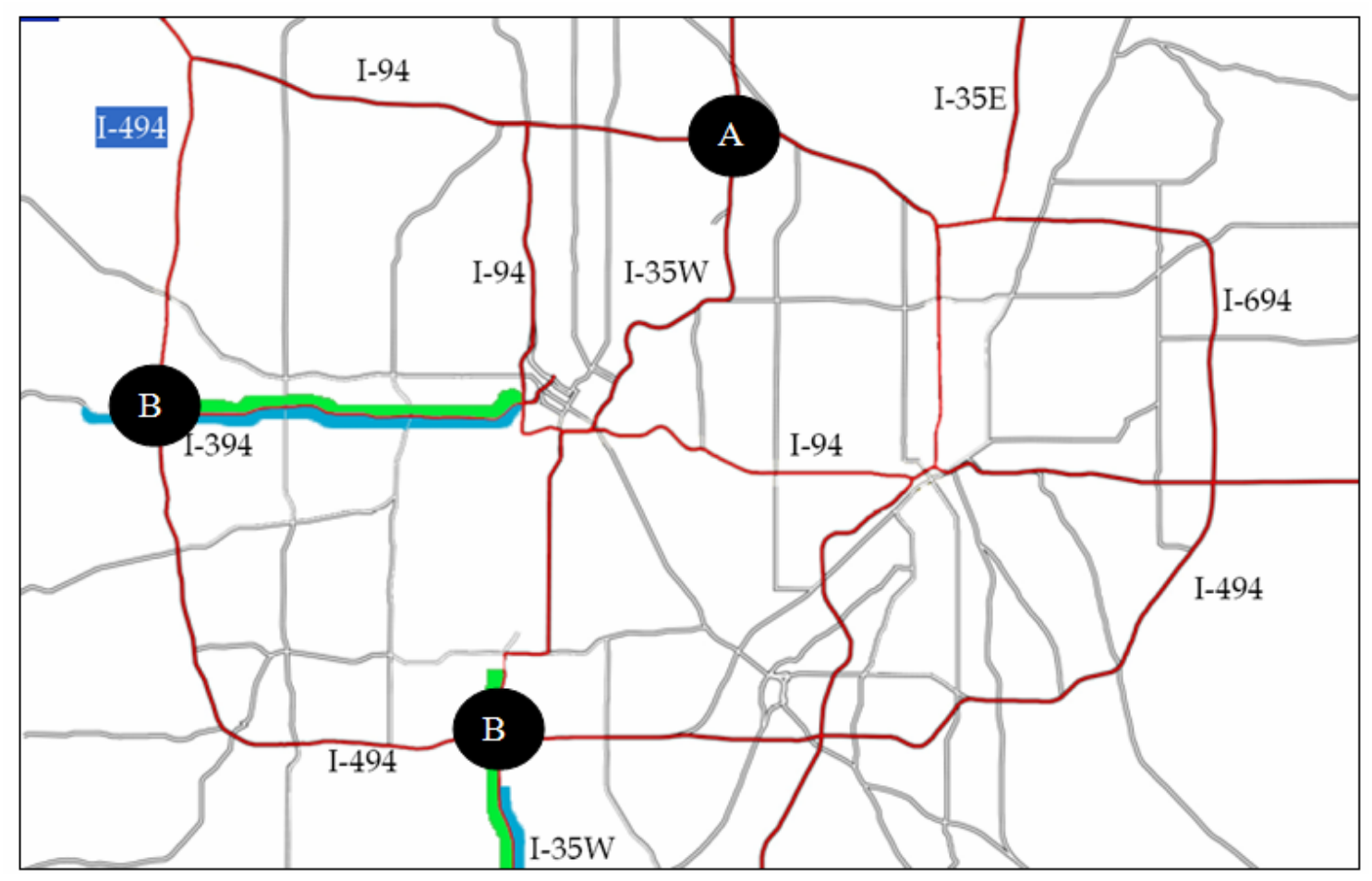

Figure 4.16: Map of Freeway-to-Freeway Ramp Metering System in Minnesota [Fischer, 2006] 


\subsubsection{Economic Evaluation of Ramp Metering}

This section presents the estimated travel time, fuel and emission savings due to the implementation of isolated, traffic-responsive ramp metering on all the seven on-ramps in WB direction. Economic evaluation of local, trafficresponsive ramp metering was performed to determine the feasibility of implementation of ramp metering on the onramps in the WB direction. The evaluation was done for an analysis period of 10 years at a $4 \%$ discount rate.

The impact of ramp metering on traffic behavior was simulated using a mathematical simulation model [Kang and Gillen, 1999] that was developed based on the cell transmission model [Daganzo, 1993]. The cell transmission model is a simple and fairly accurate traffic model to predict traffic evolution over time and space. The model can also simulate phenomenon such as building, propagation and dissipation of queues.

The demand capacity algorithm (described in Chapter 3) was used for the evaluation of ramp metering in this study. The simulation model calculates the ramp metering rate based on the local traffic conditions and updates it on the basis of real time measurement of traffic variables. The hourly traffic volume on the ramps and on the section of freeway upstream of the ramps was fed into the mathematical simulation model as input to calculate the travel time savings, emission savings and fuel cost savings for each of the seven on-ramps in the WB direction on I70. The program starts metering the ramp at the instant the sum of inflow from the freeway and the on-ramp becomes greater than the capacity of the cell downstream of the merge.

However, when the ramp queue is greater than the allowable ramp storage, the metering rate is calculated using the maximum number of vehicles that can be stored on the ramp. For example, if the maximum queue that can be stored on the ramp is 40 vehicles, and the ramp queue length is more than 40 vehicles, then, regardless of the current density of the merge cell, the extra queue on the ramp (i.e., queue length minus 40 ) is permitted to advance to freeway. Because of this flushing operation from congested on-ramps, the benefit of ramp metering is reduced.

\subsubsection{Costs of Ramp Metering}

The cost of the traffic responsive ramp metering system on I-70 was calculated based on the methodology for ITS equipment deployment presented in Chapter 3. Table 4.16 shows the updated costs for each component in 2006 dollars. The costs were computed for a system comprising of seven ramp meters in the I-70 WB direction. The costs have been computed by assuming one lane on the ramp and four lanes on the freeway. It is assumed that the loop detectors are installed on five lanes in the vicinity of each ramp (four on freeway lanes and one on ramp lane). Therefore, approximately thirty-five loop detectors will be required for the seven ramps on the I-70 corridor under study. In addition ramp meter, processor and communication from ramp meter to processor have to be provided on each of the seven ramps. A common communication hub can be provided for all the ramp meters in the system. The average capital cost of the ramp metering project was calculated approximately as $\$ 185,000$ for a local traffic responsive ramp meter on each ramp. 
Table 4.16: Total Cost of Ramp Metering \& Cost per Ramp for On-Ramps on I-70

\begin{tabular}{|l|c|c|c|}
\hline \multicolumn{1}{|c|}{ Component } & Unit Costs & Quantity & Total \\
\hline Initial Costs & & & $\$ 12,761$ \\
\hline Analysis and Design & $\$ 12,761$ & 1 & $\$ 3,828$ \\
\hline Publicity & $\$ 3,828$ & & \\
\hline Installation Costs & & 1 & $\$ 127,610$ \\
\hline Fixed Costs & & & \\
\hline Communication Hub & $\$ 127,610$ & 7 & $\$ 706,040$ \\
\hline Variable Costs & & 35 & $\$ 98,260$ \\
\hline Communication from & $\$ 100,863$ & 7 & $\$ 55,829$ \\
\hline Detector to meter & $\$ 2,807$ & 7 & $\$ 312,644$ \\
\hline Detectors & $\$ 7,976$ & & $\$ 1,316,972$ \\
\hline 170 series processor & $\$ 44,663$ & & $\$ 185,000$ \\
\hline Ramp Meter & & & $\$ 18,000$ \\
\hline Total Costs & & & \\
\hline Cost per ramp & Cost & & \\
\hline $\begin{array}{l}\text { Annual Operation \& Maintenance } \\
\text { Cost (per Ramp) }\end{array}$ & $10 \%$ of Installation & & \\
\hline
\end{tabular}

\subsubsection{Benefits of Ramp Metering}

The benefits of ramp metering were calculated by summing up the monetized travel time savings, fuel cost savings and emission savings. These savings were computed over an analysis period of 10 years using a discount rate of $4 \%$.

\section{(a) Travel Time Savings}

The travel time savings obtained due to the implementation of ramp metering on Ramp 3224 are presented in Table 4.17. Traffic from I-465 merges on to I-70 via Ramp 3224 which is located near the I-465 and I-70 interchange (refer to Figure 4.5). Ramp 3224 is the first on-ramp in the WB direction on the I-70 corridor under study. Table 4.17 shows that the vehicle hours saved on the freeway due to the implementation of ramp metering on this ramp are more than the vehicle-hours spent on the ramp by the vehicles waiting to enter the freeway. Hence the delay incurred on the ramps is compensated by the travel time savings on the freeway thereby resulting in net travel time savings for the overall system.

The average travel time saved per vehicle in the first year is 9.8 secs $/ \mathrm{hr}$. The time savings decrease thereafter until the tenth year. This is because the freeway demand increases every year, thereby further increasing congestion on the freeway regardless of the magnitude of the ramp travel demand. Also, the ramp delay increases at a higher rate than the rate of growth of freeway travel time savings. In such a scenario, ramp metering does not save as much travel time as it could have if the freeway section upstream of the ramp was relatively uncongested. Therefore the implementation of ramp metering does not mitigate congestion on the freeway. However, it reduces the rate at which congestion would have grown on the freeway by controlling the number of vehicles entering from the ramp. Therefore, it is more appropriate to use the term of "delay savings" rather than "travel time savings" to represent the benefits of ramp metering on I-70. 
Table 4.17: Total Vehicle Hours and Travel Delay at Morning Peak on Ramp 3224

\begin{tabular}{|c|c|c|c|c|c|c|c|c|}
\hline Year & \multicolumn{2}{|c|}{ Without Metering } & \multicolumn{2}{c|}{ With Metering } & \multicolumn{5}{c|}{ Change } \\
\hline & Freeway & Ramp & Freeway & Ramp & Freeway & Ramp & Net & Average \\
\hline & (veh-hr) & (veh-hr) & (veh-hr) & (veh-hr) & (veh-hr) & (veh-hr) & (veh-hr) & (sec/hr) \\
\hline 1 & 7589.7 & 59.1 & 6785.7 & 790.8 & 804.0 & -731.7 & 72.3 & 9.8 \\
\hline 2 & 7981.7 & 60.4 & 7180.7 & 795.5 & 801.0 & -735.0 & 66.0 & 8.9 \\
\hline 3 & 8377.7 & 61.8 & 7579.4 & 799.4 & 798.3 & -737.6 & 60.7 & 8.1 \\
\hline 4 & 8777.6 & 63.1 & 7981.8 & 802.7 & 795.7 & -739.6 & 56.1 & 7.4 \\
\hline 5 & 9181.4 & 64.5 & 8388.3 & 805.6 & 793.1 & -741.1 & 52.0 & 6.8 \\
\hline 6 & 9589.3 & 66.0 & 8798.6 & 808.1 & 790.6 & -742.1 & 48.5 & 6.3 \\
\hline 7 & 10001.2 & 67.5 & 9212.9 & 810.3 & 788.3 & -742.8 & 45.4 & 5.8 \\
\hline 8 & 10417.2 & 69.0 & 9631.2 & 812.2 & 786.0 & -743.3 & 42.8 & 5.4 \\
\hline 9 & 10837.4 & 70.5 & 10053.6 & 814.0 & 783.7 & -743.4 & 40.3 & 5.1 \\
\hline 10 & 11261.7 & 72.2 & 10480.2 & 815.5 & 781.4 & -743.4 & 38.1 & 4.7 \\
\hline
\end{tabular}

The average travel time savings (seconds/hr) per vehicle in each year in the system are shown in Figure 4.17. The freeway section upstream of these ramps also becomes congested in the peak period before traffic from these ramps merges on the freeway. As a result the average travel time savings per vehicle (secs/hr) follows the same trend on all these ramps as on Ramp 3224. As the traffic grows each year, the delay savings in the system decrease but remain positive over the project life span.

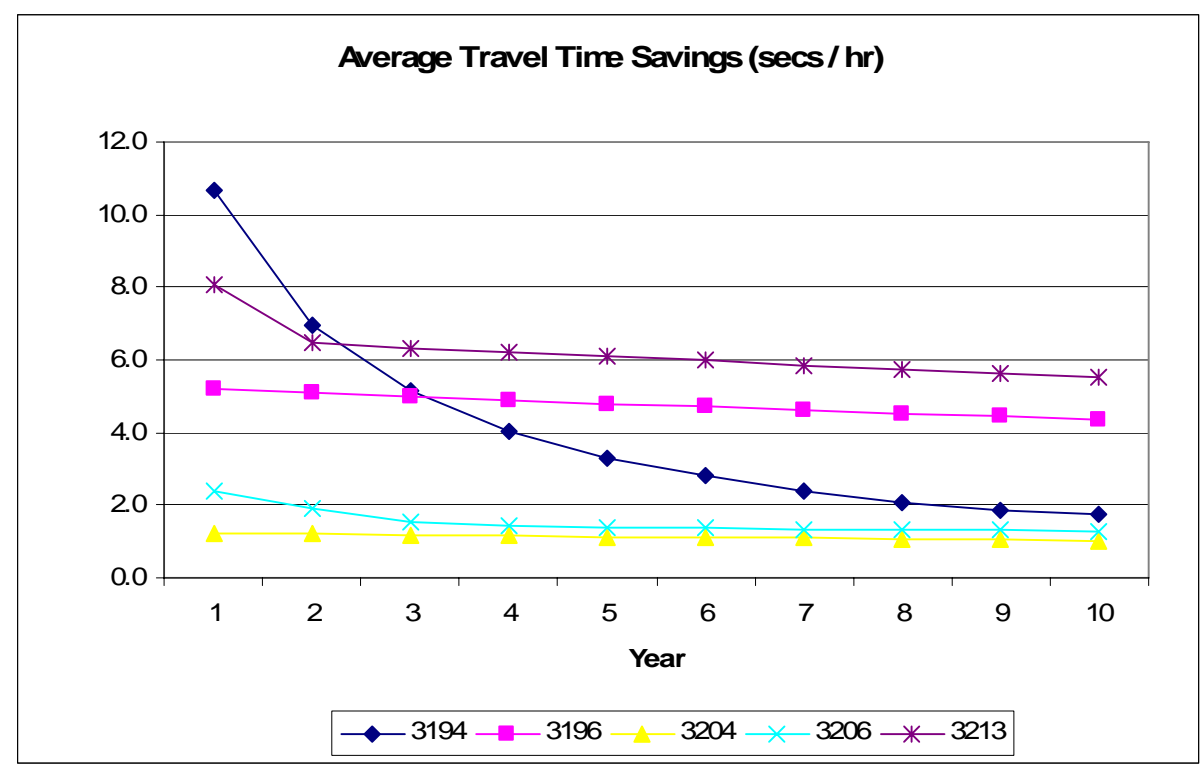

Figure 4.17: System Travel Time Savings per vehicle Due to Ramp Metering

The passenger delay savings were computed by multiplying the total delay savings per vehicle by the vehicle occupancy. The following parameters were used to estimate the net worth of travel time savings due to the implementation of ramp metering on I-70 ramps. 
- $\quad$ Traffic Split: Trucks $=13 \%$, Automobiles $=87 \%$

- Average Vehicle Occupancy: 1.07 for Automobiles; 1.0 for Trucks

- $\quad$ Travel Time Value: \$17 for Automobiles, \$24 for Trucks

\section{(b) Vehicle Operating Cost Savings}

The vehicle operating cost savings were determined by calculating the fuel cost savings. The overall fuel cost savings in the system (freeway + ramp) due to the implementation of ramp metering on Ramp 3224 are shown in Table 4.18. The following parameters were assumed:

- Average Fuel Efficiency: 20 MPG

- Fuel Cost: $\$ 2.5$ per gallon in 2006 Dollars

For the calculation of the fuel cost savings, the average hourly fuel consumption was computed by dividing the average travel speed by average fuel consumption. The hourly fuel consumption was found to be equal to three gallons/hr. The fuel cost savings were estimated by multiplying the total vehicle time savings by hourly fuel consumption and the unit price of gasoline. The annual fuel savings were found to decrease each year because of the subsequent reduction in travel time savings. This pattern was observed on all the other on-ramps on I-70 in the WB direction. It should be noted that the methodology used for the computation of fuel savings in this section, does not take into account the number of stops, number of speed changes and the acceleration/deceleration of vehicles. The computed fuel consumption savings accrue as the vehicles save time in the system.

Table 4.18: System Fuel Cost Savings Due to Metering on Ramp 3224

\begin{tabular}{|c|c|c|c|c|c|}
\hline Year & $\begin{array}{c}\text { Delay Saving } \\
\text { (vehicle-hours) }\end{array}$ & $\begin{array}{c}\text { Hourly Fuel } \\
\text { Consumption }\end{array}$ & Fuel Saving & Unit Price & $\begin{array}{c}\text { Value of } \\
\text { Fuel Saving }\end{array}$ \\
\hline & & (gallons/hr) & (gallons) & (\$/gallon) & (FY 2006\$) \\
\hline 1 & 18,877 & 3.0 & 56632 & 2.5 & 141579 \\
\hline 2 & 17,225 & 3.0 & 51674 & 2.5 & 129185 \\
\hline 3 & 15,832 & 3.0 & 47495 & 2.5 & 118737 \\
\hline 4 & 14,650 & 3.0 & 43951 & 2.5 & 109877 \\
\hline 5 & 13,573 & 3.0 & 40718 & 2.5 & 101795 \\
\hline 6 & 12,659 & 3.0 & 37976 & 2.5 & 94940 \\
\hline 7 & 11,854 & 3.0 & 35562 & 2.5 & 88906 \\
\hline 8 & 11,161 & 3.0 & 33483 & 2.5 & 83707 \\
\hline 9 & 10,523 & 3.0 & 31568 & 2.5 & 78919 \\
\hline 10 & 9,940 & 3.0 & 29819 & 2.5 & 74548 \\
\hline
\end{tabular}

\section{(c) Emission Savings}

The implementation of ramp metering reduces emissions on the freeway and increases emissions on the ramp due to queuing of vehicles. The vehicles waiting on the ramp cause consistent emissions of HC and CO. The emission rates for vehicles waiting on the ramp are expressed as idle emission rates. The idle emission rates used in this study are 0.15 grams/minute for HC and 2.5 grams/minute for CO [Kang and Gillen, 1999]. The idle emission rates for 
$\mathrm{NO}_{\mathrm{x}}$ are considered negligible. The unit cost of pollutants was obtained from Kang and Gillen (1999). A unit pollutant cost of $\$ 1.28 / \mathrm{Kg}$ was used for $\mathrm{HC}$, $\$ 0.0063 / \mathrm{Kg}$ was used for CO and $\$ 1.28 / \mathrm{Kg}$ was used for NOx. The sensitivity analysis conducted with respect to these costs showed that the $\mathrm{B} / \mathrm{C}$ ratio is indifferent to the unit cost of HC and NOx ranging from $\$ 1-\$ 6 / \mathrm{Kg}$ and from $\$ 0.001-\$ 0.012 / \mathrm{KG}$ for CO. The annual estimates of emission savings are shown in Table 4.19 for ramp metering implementation on Ramp 3224. The savings are negative which indicates that the total emissions in the system (obtained by summing up the emissions on the ramp and the freeway), increased in each year of the analysis period. Similar results were observed when ramp metering was evaluated on the other ramps.

Table 4.19: Annual Estimates of Emission Savings (KG) Due to Metering on Ramp 3224

\begin{tabular}{|c|c|c|c|}
\hline \multirow{2}{*}{ Year } & \multicolumn{3}{|c|}{$\begin{array}{c}\text { Net Savings } \\
\text { Freeway - Ramp ) }\end{array}$} \\
\hline & HC & CO & NO $_{\mathbf{x}}$ \\
\hline $\mathbf{1}$ & -1562 & -26776 & -311 \\
\hline $\mathbf{2}$ & -1584 & -27089 & -289 \\
\hline $\mathbf{3}$ & -1602 & -27342 & -271 \\
\hline $\mathbf{4}$ & -1616 & -27548 & -256 \\
\hline $\mathbf{5}$ & -1629 & -27720 & -242 \\
\hline $\mathbf{6}$ & -1639 & -27859 & -230 \\
\hline $\mathbf{7}$ & -1647 & -27972 & -220 \\
\hline $\mathbf{8}$ & -1653 & -28057 & -211 \\
\hline $\mathbf{9}$ & -1659 & -28135 & -203 \\
\hline $\mathbf{1 0}$ & -1664 & -28199 & -196 \\
\hline
\end{tabular}

\subsubsection{Benefit-Cost Ratio, Net Present Value \& IRR}

The annual benefits and costs due to the implementation of traffic responsive ramp metering on Ramp 3224 are tabulated in Table 4.20. The benefits were calculated by monetizing the travel time savings, fuel cost savings and emission savings. The estimated net present value (NPV) was equal to $\$ 2,589,807$. A benefit to cost ratio of 9.12 was obtained for this ramp and a value of 263.33 was obtained for the internal rate of return. Hence the local traffic responsive ramp metering project was found to be economically feasible for this ramp.

Table 4.20: Annual Estimates of System Benefits and Costs Due to Metering on Ramp 3224

\begin{tabular}{|c|c|c|c|c|c|c|c|c|c|c|}
\hline & \multicolumn{5}{|c|}{ Benefits } & \multicolumn{4}{|c|}{ Costs } & \multirow[b]{2}{*}{ NPV } \\
\hline Year & $\begin{array}{c}\text { Fuel } \\
\text { Saving }\end{array}$ & $\begin{array}{c}\text { Time } \\
\text { Saving }\end{array}$ & $\begin{array}{c}\text { Emission } \\
\text { Savings }\end{array}$ & $\begin{array}{c}\text { Total } \\
\text { Benefit }\end{array}$ & PVB & $\begin{array}{c}\text { Const. } \\
\text { Cost } \\
\end{array}$ & $\begin{array}{c}\text { Maint. } \\
\text { Cost }\end{array}$ & $\begin{array}{c}\text { Total } \\
\text { Cost } \\
\end{array}$ & PVC & \\
\hline 0 & - & - & - & - & - & $\$ 180,000$ & - & $\$ 180,000$ & $\$ 180,000$ & $-\$ 180,000$ \\
\hline 1 & $\$ 141,579$ & $\$ 369,012$ & $-\$ 2,567$ & $\$ 508,024$ & $\$ 483,832$ & - & $\$ 18,000$ & $\$ 18,000$ & $\$ 17,143$ & $\$ 466,689$ \\
\hline 2 & $\$ 129,185$ & $\$ 336,708$ & $-\$ 2,569$ & $\$ 463,324$ & $\$ 420,249$ & - & $\$ 18,000$ & $\$ 18,000$ & $\$ 16,327$ & $\$ 403,922$ \\
\hline 3 & $\$ 118,737$ & $\$ 309,477$ & $-\$ 2,570$ & $\$ 425,644$ & $\$ 367,687$ & - & $\$ 18,000$ & $\$ 18,000$ & $\$ 15,549$ & $\$ 352,138$ \\
\hline 4 & $\$ 109,877$ & $\$ 286,384$ & $-\$ 2,570$ & $\$ 393,691$ & $\$ 323,891$ & - & $\$ 18,000$ & $\$ 18,000$ & $\$ 14,809$ & $\$ 309,082$ \\
\hline 5 & $\$ 101,795$ & $\$ 265,318$ & $-\$ 2,569$ & $\$ 364,544$ & $\$ 285,630$ & - & $\$ 18,000$ & $\$ 18,000$ & $\$ 14,103$ & $\$ 271,526$ \\
\hline 6 & $\$ 94,940$ & $\$ 247,452$ & $-\$ 2,568$ & $\$ 339,824$ & $\$ 253,582$ & - & $\$ 18,000$ & $\$ 18,000$ & $\$ 13,432$ & $\$ 240,150$ \\
\hline 7 & $\$ 88,906$ & $\$ 231,725$ & $-\$ 2,566$ & $\$ 318,064$ & $\$ 226,042$ & - & $\$ 18,000$ & $\$ 18,000$ & $\$ 12,792$ & $\$ 213,250$ \\
\hline 8 & $\$ 83,707$ & $\$ 218,173$ & $-\$ 2,563$ & $\$ 299,317$ & $\$ 202,590$ & - & $\$ 18,000$ & $\$ 18,000$ & $\$ 12,183$ & $\$ 190,407$ \\
\hline 9 & $\$ 78,919$ & $\$ 205,695$ & $-\$ 2,561$ & $\$ 282,053$ & $\$ 181,814$ & - & $\$ 18,000$ & $\$ 18,000$ & $\$ 11,603$ & $\$ 170,211$ \\
\hline \multirow[t]{2}{*}{10} & $\$ 74,548$ & $\$ 194,303$ & $-\$ 2,558$ & $\$ 266,293$ & $\$ 163,481$ & - & $\$ 18,000$ & $\$ 18,000$ & $\$ 11,050$ & $\$ 152,430$ \\
\hline & \multicolumn{4}{|c|}{ Total } & $\$ 2,908,798$ & & & & $\$ 318,991$ & $\$ 2,589,807$ \\
\hline
\end{tabular}


The economic evaluation of ramp metering on other I-70 ramps also justified economic viability of ramp metering. The net present value and $\mathrm{B} / \mathrm{C}$ ratio at $5 \%$ discount rate and the internal rate of return for isolated traffic responsive ramp metering projects on these ramps are shown in Table 4.21.

Table 4.21: Analysis of Benefits and Costs Due to Metering on I-70 WB On-Ramps

\begin{tabular}{|c|c|c|c|c|c|c|}
\hline & \multicolumn{6}{|c|}{ Ramp ID } \\
\hline & $\mathbf{3 1 9 4}$ & $\mathbf{3 1 9 6}$ & $\mathbf{3 2 0 4}$ & $\mathbf{3 2 0 6}$ & $\mathbf{3 2 1 3}$ & $\mathbf{3 2 1 5}$ \\
\hline NPV & $\$ 1,417,514$ & $\$ 1,825,135$ & $\$ 196,387$ & $\$ 311,592$ & $\$ 2,216,752$ & $\$ 2,621,611$ \\
\hline B/C & 5.44 & 6.72 & 1.62 & 1.98 & 7.95 & 9.22 \\
\hline IRR & 249.82 & 149.38 & 24.50 & 39.99 & 201.00 & 218.48 \\
\hline
\end{tabular}

\subsubsection{Sensitivity Analysis}

The economic evaluation of ramp metering presented in Section 4.4 .1 was done using the following values of the input parameters:

- $\quad$ Discount Rate $=4 \%$

- $\quad$ Travel Time Value For Auto $=\$ 17$

- $\quad$ Fuel Cost $=\$ 2.5 /$ Gallon

- $\quad$ Fuel Efficiency = $20 \mathrm{MPG}$

- $\quad$ Freeway Traffic Growth Factor $=1 \%$

- $\quad$ Ramp Traffic Growth Factor $=1 \%$

A sensitivity analysis was conducted for $B / C$ ratio with respect to each of these parameters. The results of sensitivity analysis are presented in this section. The B/C ratio was found to be greater than 1 for all the ramps in all the scenarios. The following observations were made:

- $\quad$ The B/C ratio decreases with increase in discount rate from $3 \%$ to $8 \%$ (Figure 4.18 ). The benefits include monetized travel time savings, vehicle operating cost savings and emission savings.

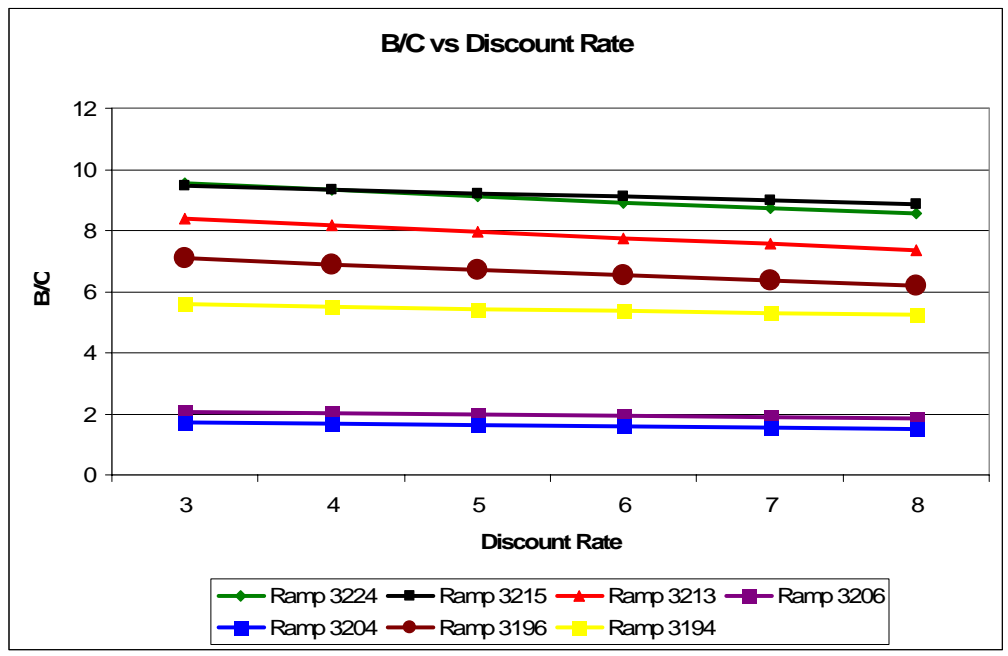

Figure 4.18: B/C Ratio of Ramp Metering Project on I-70 Ramps vs. Discount Rate 
- $\quad$ The $\mathrm{B} / \mathrm{C}$ ratio increases with increase in unit value of travel time. This is because of the net positive travel time savings associated with the implementation of ramp metering (Figure 4.19).

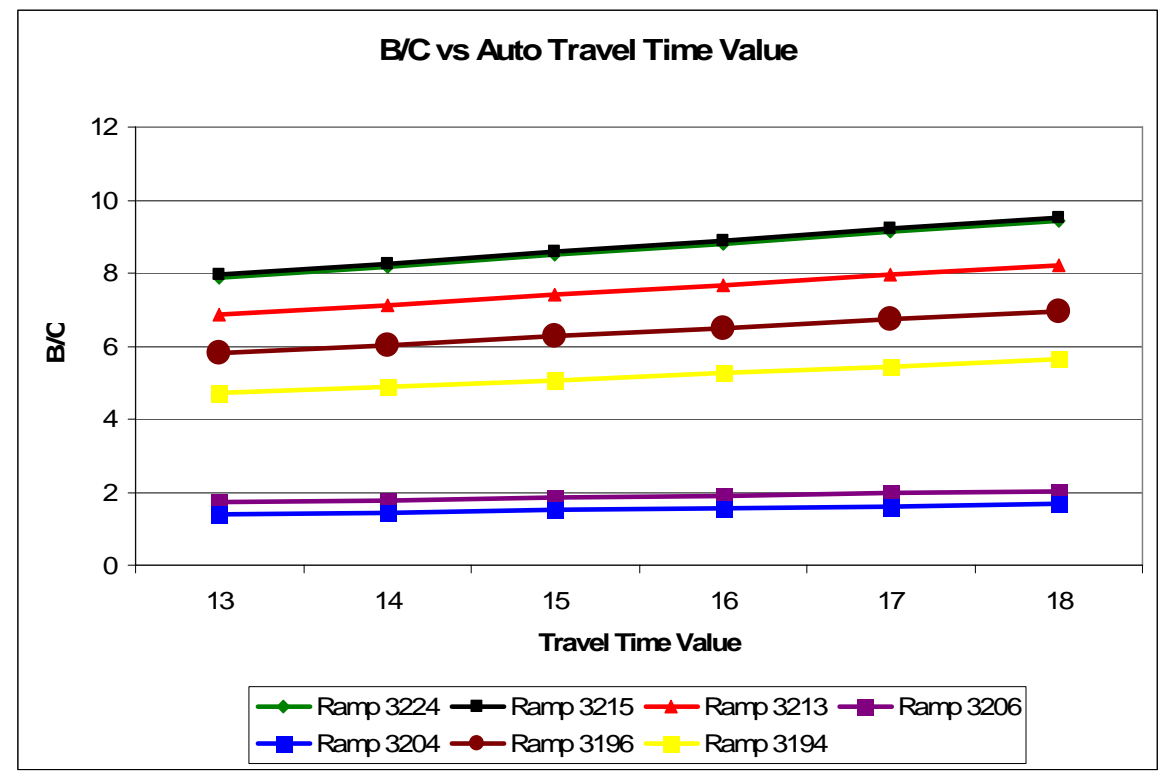

Figure 4.19: B/C Ratio of Ramp Metering Project on I-70 vs Travel Time Value

- $\quad$ The B/C ratio decreases with increase in fuel efficiency as shown in Figure 4.20. This is because as the fuel efficiency increases, the net worth of fuel consumption savings, decreases, becasuse commuters are able to travel more distance with the same amount of fuel.

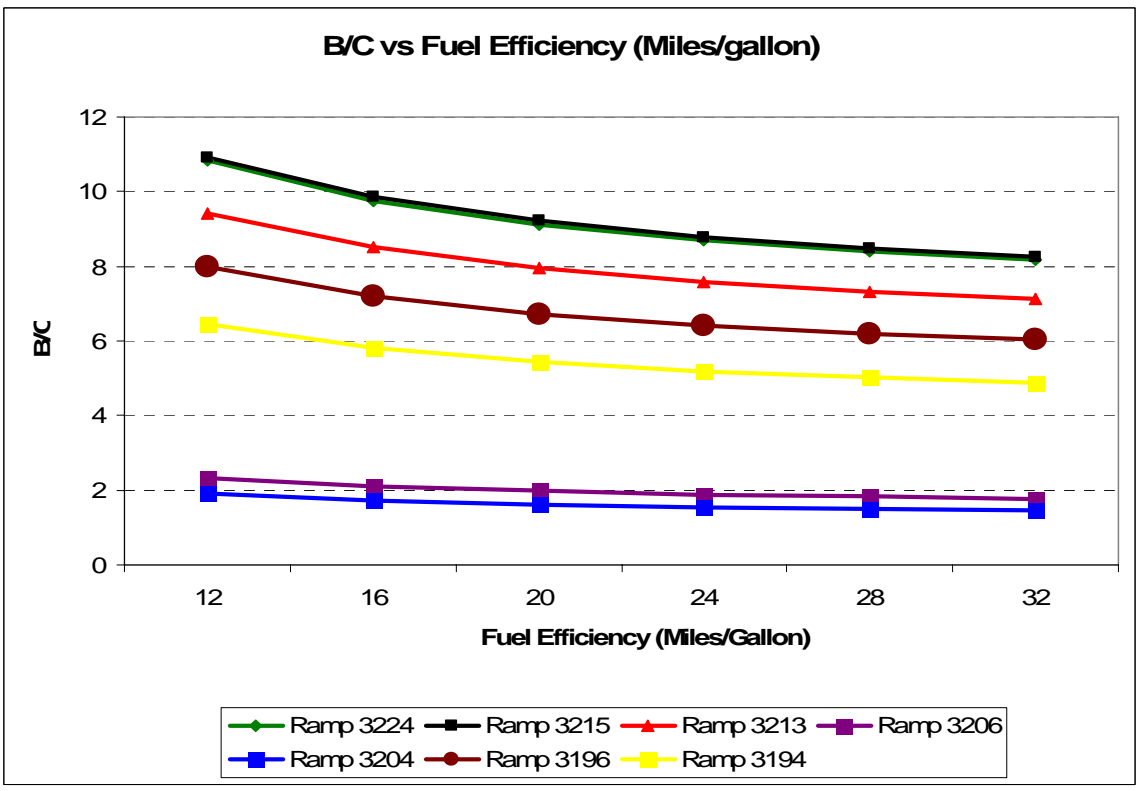

Figure 4.20: B/C Ratio of Ramp Metering Project on I-70 vs Fuel Efficiency 
- $\quad$ The B/C ratio increases with increase in fuel cost from $\$ 1.5$ to $\$ 4.0$ per gallon as shown in Figure 4.21.

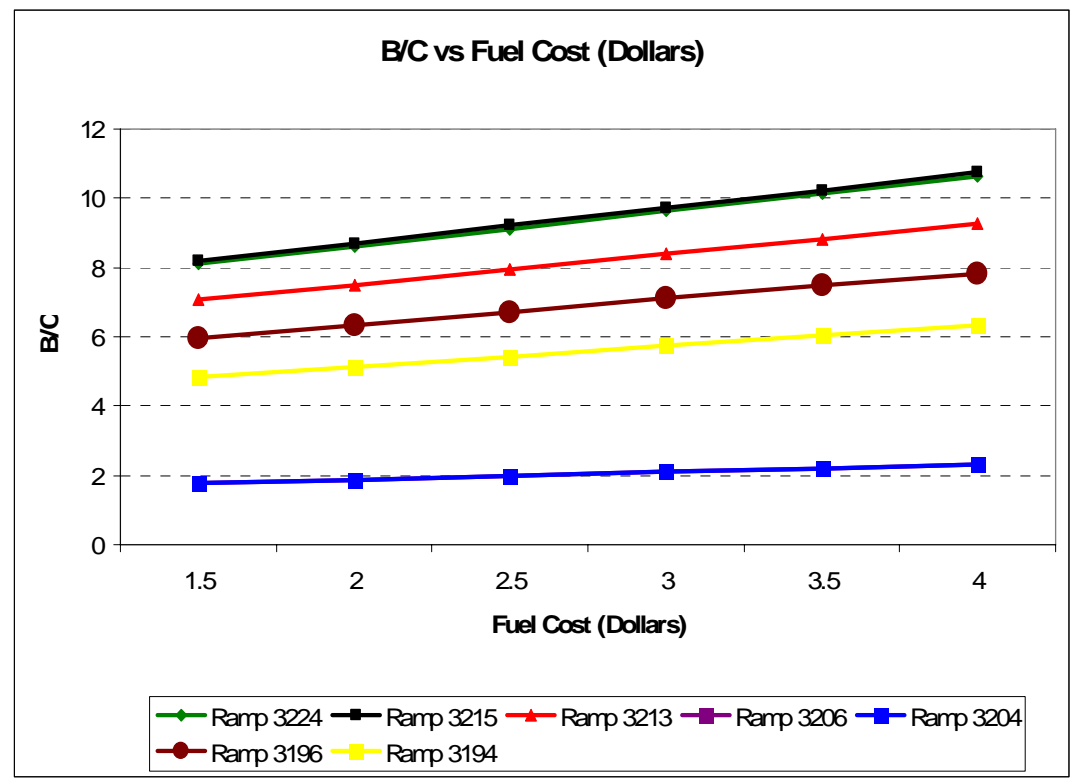

Figure 4.21: B/C Ratio of Ramp Metering Project on I-70 vs Fuel Cost (2005 Dollars)

\subsubsection{Implementation Feasibility of Ramp Metering}

The economic feasibility of local traffic responsive ramp metering was determined for the on-ramps in the WB direction on I-70. The economic feasibility of ramp metering implementation was determined on each ramp separately. Simultaneous metering of two ramps or more ramps was not evaluated in this study. The operation of ramp meters simultaneously on all the ramps is expected to yield more benefits than those determined in this study. The efficiency of ramp metering will improve and benefits will increase if the ramps that are metered simultaneously, also exchange ramp traffic information amongst themselves such that the total waiting time on all the ramps in the system is minimized. Hence, implementation of system-wide should be evaluated on the I-70 freeway. Although local traffic responsive ramp metering was found to be economically feasible, the waiting time on the ramps may create public opposition. Therefore it is important that various ramp metering strategies are evaluated, so that the best strategy can be implemented. The implementation of ramp metering on Ramp 3224, which is a freeway-to-freeway ramp requires special considerations. Ramp metering has been implemented on freeway-to-freeway ramps in several states and their experiences and lessons learnt can help in the implementation of such a system in Indiana.

\subsection{SUMMARY}

The economic feasibility of HOV facility and ramp metering was evaluated in this chapter. It was found that the operation of the added lane as a HOV lane and the implementation of individual ramp meters on the ramps are 
economically feasible on I-70. However, system-wide interconnected ramp metering is expected to yield higher benefits. Also, the implementation of ramp metering on Ramp 3224 requires special considerations.

The average length of concurrent flow HOV lane facilities in U.S. is approximately eight miles. Congestion is present on I-70 WB between Mileposts 14.22-18.98. Although the HOV lane project is economically feasible on this section, the number of carpools formed may be below the minimum threshold because of the short length of the HOV lane. The implementation of HOV lane is not recommended if the number of carpools formed is below the minimum threshold, because the HOV lanes will appear empty and may result in public opposition. The HOV lane demand should be forecasted using travel demand models developed for the Indianapolis area because the use of travel demand models transferred from other areas may result in erroneous estimation of HOV lane traffic volume if the socio-economic and demographic characteristics of the region are different. 


\section{Summary and Conclusions}

\subsection{HOV FACILITY}

\subsubsection{Summary}

A High Occupancy Vehicle lane facility is implemented to increase the person carrying capacity of the freeway. The project does not increase the vehicle carrying capacity but reduces congestion on the freeway by reducing the number of single occupancy vehicles. The facility can be implemented as an exclusive 2-directional, exclusive reversible, concurrent flow or contra flow HOV lane. The lanes in the exclusive HOV facilities are used by high occupancy vehicles only. The exclusive two-directional HOV facility is operated twenty-four hours a day in both directions whereas an exclusive reversible facility is operated in one direction for a portion of the day and in the other direction for the remaining portion of the day. The HOV lanes are closed for changing directions for a couple of hours before the lanes are operated in either direction. The concurrent flow and contra flow HOV facilities are operated during the peak periods. The concurrent flow lane facility can be operated simultaneously in both directions or in one direction during the morning peak and in the other direction during the afternoon peak. If congestion occurs in one direction only, the concurrent flow HOV lane is operated in that direction during the peak period. The contraflow HOV facility is operated by taking a lane from the opposite direction and operating it as a HOV lane during the peak period. All these HOV facility types can be operated either with $2+$ or $3+$ occupancy requirements.

The implementation of a HOV facility requires other components such as the HOV lane access ramps (direct access and slip ramps), park-and-ride lots, enforcement areas, signs, markings and ridership programs. Public education and travel pattern on the corridor play an important role in the formation of new carpools. The guidelines presented in Chapter 2 can be used to determine the economic feasibility of the HOV lane. HOV demand models specific to the region under study need to be developed to determine the person throughput and vehicle throughput in the HOV lane. The number of carpools formed may not exceed a certain maximum depending upon the travel pattern and the travel behavior in the region. The HOV lanes have been successful in mitigating congestion on freeways at several places such as California, Texas, Washington. Some of the HOV lanes in California have started becoming congested as they are carrying more than 1600 vphpl. The occupancy requirement on the HOV facility can be increased from $2+$ to $3+$ on such corridors to mitigate congestion in the HOV lane in the future. The implementation of the project can yield significant travel time benefits if pursued with proper planning and implementation.

\subsubsection{Conclusions on I-70 HOV Lane Implementation}

The I-70 corridor between I-65 and I-465 in Marion County is congested during the morning peak period (6:00 AM -to 9:00 AM) in the westbound direction. The freeway is used mostly by vehicles commuting to downtown places of work in Indianapolis during the morning peak period. A concurrent flow HOV lane facility was evaluated on this corridor and the economic feasibility of adding a new HOV lane (Alternative 1) or taking away an existing general purpose lane (Alternative 2) for HOV lane implementation was determined. The economic evaluation was 
performed assuming that the HOV lane is operated for three hours in the morning with an occupancy requirement of two or more persons per car. The following conclusions were made from the economic evaluation:

1) Both the concurrent flow HOV lane alternatives on the six-mile corridor were found to be economically viable with savings in travel time, vehicle operating costs and emissions. The savings on the section between Mileposts 14.22 and 18.98 are relatively more than the savings on the section between Mileposts 18.98 and 20.28. This is because the latter is relatively less congested.

2) The add-a-lane approach (Alternative 1) of implementing the HOV lane was found to be economically more beneficial than the take-a-lane approach (Alternative 2). Although the take-a-lane approach is more cost-effective, due to lower costs, the savings in travel time are more for the add-a-lane approach. The takea-lane approach will result in the reduction of speed in the GP lane and hence, it is not recommended. Despite of reduction in average speed on the GP lanes, due to the implementation of take-a-lane approach the total benefits were found to be more than the costs, because of the higher travel time savings incurred by the vehicles traveling in the HOV lane.

3) The benefits of adding a HOV lane (Alternative 1) were found to increase with increase in the number of carpools using the HOV lane. The HOV lane alternative was found to be economically feasible even if there is no growth in the existing number of carpools on the freeway. However the objective of the HOV lane is to increase the person movement capacity on the freeway and carry at least the same number of people as the adjacent general purpose lane, if not more. Therefore, it should be ensured that the HOV lane traffic volume exceeds the minimum threshold (for example, 800 vehicles per hour used in California).

4) The economic evaluation was performed corresponding to three scenarios of growth in average vehicle occupancy on the freeway. The HOV demand on I-70 should be predicted using a demand model that is developed for the region under study, and that accounts for the socio-economic and trip characteristics of the region. Travel demand models developed for other regions are not transferable to I-70 as the model parameters are calibrated for a different region.

5) The HOV lane on I-70 will operate at an average speed of $60 \mathrm{MPH}$ as long as the HOV lane traffic is less than 1300 vphpl. Beyond this, the speed in the HOV lane will decrease as the HOV lane gets congested. However, with an occupancy requirement of 2+, the HOV lane would carry at least 2,600 persons per hour per lane at $60 \mathrm{MPH}$ in the 1,300 vehicles which is significantly more than a congested GP lane. The average speed in the GP lane increases if the HOV lane is added and decreases if the HOV lane is implemented by taking away an existing lane.

6) The cost-effectiveness of the added HOV lane (Alternative 1) was also compared to the scenario when the added lane is operated as a GP lane (i.e. road widening project). The HOV lane alternative was found to more cost-effective compared to the road widening project. Moreover, the relative cost-effectiveness of HOV project compared to road widening, improved, with the increase in number of carpools formed on the freeway. If there is no growth in the existing number of carpools, the estimated HOV lane project benefits were found to be similar to those obtained from the road widening project. 
7) The implementation of support facilities is recommended before the implementation of the HOV lane on the I-70 corridor. Although the economic evaluation performed in this study did not include the cost of new park-and-ride facilities, enforcement areas and ridership programs, it is not suggested that these facilities should not be considered. The implementation of support facilities encourages carpooling and thereby increases the benefits from the HOV lane project, as was shown from the economic analysis corresponding to the three levels of growth in average vehicle occupancy.

\subsection{RAMP METERING}

\subsubsection{Summary}

Freeway congestion is often attributable to controllable factors such as freeway bottlenecks, the excess of entering vehicles over exiting vehicles, and disruption of the freeway traffic flow by platoon entering demand. The goal of ramp metering is to prevent congestion on the freeway by regulating the number of vehicles entering from the ramps. The main components of ramp metering include the physical infrastructure which comprises of the traffic signal, controller, loop detectors, advance warning signs and the ramp metering algorithm. The metering algorithm decides how the traffic signals at the ramps are operated, including such decisions as what happens if the queue on the ramp exceeds the maximum allowable storage of the ramp or how vehicles are released from a ramp when metering is also being done simultaneously at another ramp downstream or upstream of this ramp. The ramp metering algorithm is the most important component of the overall system. While some states have implemented local fixed time ramp metering systems, others have opted for traffic responsive system-wide ramp metering to achieve greater benefits.

\subsubsection{Conclusions on I-70 WB Ramp Metering}

The economic feasibility of local, traffic responsive ramp metering, was determined for all the seven on-ramps in the I-70 WB direction. The cost-effectiveness was computed for ramp metering project on each ramp separately (local ramp metering) assuming that no two ramp meters are being operated simultaneously. Ramp 3224 was identified as the most critical ramp on I-70 WB. The freeway is not congested upstream of this ramp, but as vehicles coming from I-465 enter I-70 through this ramp, the section of freeway downstream of this ramp becomes congested. The freeway remains congested thereafter until interchange 83. Although, Ramp 3224 is a freeway-to-freeway ramp, meters have been installed on such ramps by several states such as California, Minnesota, Texas and guidelines have been developed for the installation of signals on such ramps.

The benefits of local traffic responsive ramp metering at all the ramps downstream of Ramp 3224 are significantly reduced in the absence of ramp metering on this ramp. The economic evaluation showed that ramp metering is economically feasible on all the ramps on I-70 WB even if ramp metering is not implemented on Ramp 3224. However, the waiting time on the ramps downstream of Ramp 3224 was found to be significantly high and may result in public opposition. Because of the travel time, emission and vehicle operating cost benefits on the freeway the excessive waiting time on the ramps is compensated. The $\mathrm{B} / \mathrm{C}$ ratio of ramp metering was highest for Ramp 3224 and decreased subsequently for the ramps downstream. The benefits of ramp metering, at a ramp 
downstream, are dependent on ramp metering at the upstream ramps. The benefits of ramp metering are likely to be more if system-wide traffic responsive ramp metering is implemented on I-70. The ramp meters at all the ramps will interact to give a system optimal solution if system-wide ramp metering is implemented.

The ramp metering algorithm used in this study assumed that if the queue on the ramp exceeds the maximum allowable storage on the ramps, then ramp metering is stopped and the excess number of vehicles is allowed to enter the freeway irrespective of traffic conditions on the freeway. This phenomenon is known as flushing. However, if vehicles are not flushed on the freeway from the ramps, the excess queue on the ramp is forced to choose an alternative route and hence the traffic is diverted from the freeway. While this may give rise to public opposition to ramp metering, it may improve the freeway traffic flow by restricting the use of freeway for short local trips in the region. Moreover, educating commuters about the benefits of ramp metering can help in the implementation of such an algorithm. This will significantly increase the benefits of ramp metering and combined with system-wide ramp metering can greatly improve traffic conditions on the freeway. However, an economic evaluation of such ramp metering strategies should be done along with the impact on other parallel routes so as to achieve a system optimal solution to the congestion problem. 


\section{REFERENCES}

1) Alexiadis, V., Rhoades, K., Dowling, R., Billheimer, J., and May, A. D. (1996). Predicting High-OccupancyVehicle Facility Demand. Transportation Research Record No. 1554, TRB, pp. 99-109.

2) Caltrans (2000). Ramp Meter Design Manual. California Department of Transportation.

3) Caltrans (2003). High Occupancy Vehicle Guidelines for Planning and Operations. California Department of Transportation (Caltrans) Headquarters. Division of Traffic Operations. High Occupancy Vehicle Systems Branch. Sacramento. California.

4) Caltrans (2005). Ramp Metering Development Plan for Los Angeles and Ventura Counties. California Department of Transportation. Online Source. Accessed April 2006. Available at: www.dot.ca.gov/dist07/aboutdist7/pubs/ramp_meter/05\%20Ramp\%20Meter\%20Dev\%20Plan.pdf

5) Cambridge Systematics, Inc. (2002). Twin Cities Ramp Meter Evaluation. Phase II Evaluation Report. Prepared for Minnesota Department of Transportation.

6) Cambridge Systematics Inc. (2001). Twin Cities HOV Lane Evaluation. Secondary Research. Technical Memorandum. Online Source. Available at: www.dot.state.mn.us/information/hov/pdfs/appendix_c.pdf. Minnesota Department of Transportation. Accessed Aug. 2005.

7) Chien, S. (2001). Evaluating Ramp Metering Control Systems Using Micro Simulation for U.S. Interstate Highway I - 80. Tamkang Journal of Science and Engineering. Vol. 4, No. 4, pp. 277-292 (2001). Online Source. Available at: www2.tku.edu.tw/ tkjse/4-4/4-4-6.pdf. Accessed: October 2005.

8) Choocharukul, K., Sinha, K. C., and Nagle, J. L. (2002) Development of a Congestion Management System Methodology for the Indiana State Highway Network. Transportation Research Record 1781, Transportation Research Board, Washington, D.C.

9) Choocharukul, K. (2000). The Development of a Congestion Management System Methodology for Indiana. Thesis for Master of Science in Civil Engineering. Purdue University.

10) Chaudhary, N. A. and Messer, C. J. (2000). Design Criteria For Ramp Metering: Appendix To TxDOT Roadway Design Manual. Texas Transportation Institute, Texas A \& M University System College Station, Texas. 
11) Clark, D. C. and Scherer, W. T. (2000). A Cost-Performance Tradeoff Methodology for ITS Technology Deployment. Department of Systems Engineering, University of Virginia, Center for ITS Implementation Research.

12) Cothron, Scott, A., Skowronek, Doughlas, A. and Kuhn, Beverly, T. (2003). Enforcement Issues on Managed Lanes. Texas Transportation Institute. Accessed Online. http://managed-lanes.tamu.edu/products/reports/416011.pdf

13) Daganzo, C. F. (1993). The cell transmission model: A dynamic representation of highway traffic consistent with the hydrodynamic theory. Transportation Research, Vol. 28B, No. 4, pp. 269-287.

14) Deakin, E. (2002). Intelligent Transportation Systems: A Compendium of Technological Summaries. Online Source. Available at: http://www.uctc.net/papers/621.pdf. Accessed Dec. 2005.

15) Dudek, C. and Ullman, G. (1992). Freeway Corridor Management. National Cooperative Highway Research Program Synthesis of Highway Practice. Report 177, Transportation Research Board, Washington, D.C.

16) Environmental Protection Agency (EPA). (1998). Parking Pricing. Online Source. Available at: www.yosemite.epa.gov/aa/tcmsitei.nsf/0/034775264696a11e852565d90074fa91?OpenDocument.

Transportation Control Measures. Accessed August 2005.

17) Federal Transit Administration (FTA). (1992). High Occupancy Vehicle Lanes. Chapter 6, Characteristics of Urban Transportation Systems (CUTS) Revised Edition. Online Source. Available at: http://www.fta.dot.gov/1145_ENG_HTML.htm. Accessed. Sept. 2005.

18) Fischer J. (2006). Freeway-to-Freeway Ramp Metering Systems in Minnesota. Minnesota Department of Transportation. Personal E-mail Communication

19) Fisher I. (1997). Report on the suitability of High Occupancy Vehicle Lanes in the Greater Vancouver Regional District. Online Source. Available at: www.vcn.bc.ca/t2000bc/debate/issues/hov.html\#incsovcap. Accessed. Dec. 2005.

20) Fuhs C. and Obenberger J. (2002). HOV Facility Development: A review of National Trends. Online Source. Available at: http://www.hovworld.com/hovinventory_assets/Fuhs_Obenberger-final\%20paper.pdf. Accessed Aug. 2005. 
21) Fuhs C. (2005). High Occupancy Vehicle (HOV) Projects in Operation. Online Source. Available at: http://www.hovworld.com/hovinventory.html. Accessed Aug. 2005.

22) Fuhs, C. (2005) (1). High Occupancy Vehicle Project Costs. Personal e-mail communication.

23) Gaynor, John. (2004). Personal email communication from TXDOT, 2004, regarding Ramp Metering and HOV Study.

24) Gum, Juliana. (2004). Personal email communication from CADOT, 2004, regarding Ramp Metering and HOV Study.

25) Gunawardena, N. R. and Sinha, K. C. (1994). The Development of a Prototype Congestion Management System for the State of Indiana: Phase 1. Report FHWA/IN/JHRP-94/02. Purdue University, West Lafayette, IN.

26) Henderson, D. (2002). The State of the Practice in HOV System Performance Monitoring. Transportation Research Board (TRB) 2003 Annual Meeting CD-ROM.

27) Hourdakis, J. and Michalopoulos, P. G. (2002). Evaluation of Ramp Control Effectiveness in Two Twin Cities Freeways. Transportation Research Record 1811, Transportation Research Board, Washington, D.C.

28) ITS Sensor. (1999). New Simulation may Improve Freeway Management Strategies. The Intelligent Transportation Systems Institute, Center for Transportation Studies, University of Minnesota, Minneapolis, MN.

29) INDOT (2005). Annual Average Daily Traffic on Highways in Indiana. Online Source. Available at: http://www.in.gov/dot/. Accessed. Jan 2005.

30) Jacobson, E.L., and J. Landsman. (1994). Case Studies of Freeway to Freeway Ramp and Mainline Metering in the U.S. and Suggested Policies for Washington State," Transportation Research Board Paper 940331, Transportation Research Board Meeting, Washington, D.C.

31) Johnston, R. A., Lund, J. R., and Craig, P. P. (1995). Capacity-Allocation Methods for Reducing Urban Traffic Congestion. Journal of Transportation Engineering, Vol. 121, No. 27.

32) Kang, S. and Gillen, D. (1999). Assessing the Benefits and Costs of Intelligent Transportation Systems: Ramp Meters. California Path Research Report. UCB-ITS-PRR-99-19. ISSN 1055-1425. 
33) Kachroo, P. and Ozbay, K. (2003). Feedback Ramp Metering in Intelligent Transportation Systems. Kluwre Academi/Plenum Publishers, New York, Boston, Dordrecht, London, Moscow.

34) Kratz, James (2004). Personal email communication from TXDOT, 2004, regarding Ramp Metering and HOV Study.

35) Levinson, H., Zimmerman, S., Clinger, J., Rutherford, S., Smith, R., L., Cracknell J., Soberman R., (2003). Case Studies in Bus Rapid Transit. Volume 1. TCRP Report 90. Transportation Research Board.

36) Markkula, L. (2004). HOV Lanes: Issues and Options for Enforcement. Arizona Department of Transportation, U.S. Department of Transportation, and Federal Highway Administration

37) Maccubbin, R. P. (2003). Intelligent Transportation Systems Benefits and Costs: 2003 Update. Prepared by Mitretek Systems.

38) Maffeo, Michelle (2004). Personal email communication from Mass Highway, regarding Ramp Metering and HOV Study.

39) Martin, P., Perrin, J., Lambert, R., Wu, Peng. (2002). "Evaluate Effectiveness of High Occupancy Vehicle Lanes”. Report No. UT-03.26. Civil \& Environmental Engineering Department. University of Utah. Salt Lake City. Utah.

40) Manual of Uniform Traffic Control Devices (MUTCD). (2003). Online Source. Available at: http://mutcd.fhwa.dot.gov/. Accessed Aug. 2005

41) Metropolitan Transit Authority of Harris County, Texas (METRO). (2005). The HOV System/Guide to High Occupancy Vehicle Lanes. Online Source. Available at: www.ridemetro.org/services/areahovmap.asp. Accessed Aug. 2005.

42) Morrison, D. C., and Counts, M. (2005). Second Report of the High Occupancy Vehicle Enforcement Task Force. Virginia.

43) Minnesota Department of Transportation (MnDOT) (2001). Twin Cities Metro Area Ramp Meter Study Results Released. Online Source. Available at: www.dot.state.mn.us/rampmeterstudy/newsreleaseresults.html. Accessed: Dec. 2005. 
44) National ITS Architecture Cost Analysis. (1996). Prepared by the Architecture Development Team. Prepared for: Federal Highway Administration, US Department of Transportation.

45) Nee, J., Ishimaru, J. and Hallenbeck, M. E. (2004). HOV Lane Performance Monitoring, Washington State Transportation Center (TRAC), University of Washington, Seattle Washington.

46) O’Brien, A. (2000). New Ramp Metering Algorithm Improves System-wide Travel Time. Transportation Research News, Transportation Research Board, Washington D.C.

47) Parsons, Brinckerhoff, Quade and Douglas, Inc. (2005). High Occupancy Toll Lanes - Potential for Implementation in Atlanta. Available at: www.georgiatolls.com/pdf/HOT_Final_Report_July2005.pdf. Accessed: Feb. 2006.

48) Parsons Brinckerhoff Quade and Douglas, Inc. (2002). Orange County High Occupancy Vehicle Operations Policy Study. Orange County Transportation Authority.

49) Parsons Brinckerhoff Quade and Douglas, Inc. (2001). I-5 Southbound HOV Lane Pilot Project Task 4 Evaluation Report \#1, Baseline Conditions Report. Washington State Department of Transportation.

50) Paiewonsky, Luisa (2004). Personal email communication, regarding Ramp Metering and HOV Study.

51) PB Farradyne Inc. (1999). Florida Statewide ITS Strategic Plan. ITS Cost Analysis Issue Paper.

52) Pearson, R. (2001). Ramp Metering ITS Decision Report, Partners for Advanced Transit \& Highways, Berkeley, CA.

53) Piotrowicz, G., and Robinson J. (1995). Ramp Metering Status in North America: 1995 Update. Federal Highway Administration. U. S. Department of Transportation.

54) Poplaski R. S. and Demetsky M. J. (1994). HOV System Analysis. Virginia Transportation Research Council. Charlottesville, Virginia. Online Source. Available at: www.ntl.bts.gov/DOCS/hhov.html. Accessed August 2005.

55) Roth, Phillip. (2005). Personal email communication. Indianapolis Metropolitan Planning Organization.

56) Salek, Matthew. (2004). Colorado Highways: Ramp Meters. Online Source. Available at: http://www.mesalek.com/colo/rampmeter.html. Accessed October 2004. 
57) Skowronek, D. A., Ranft, S. E. and Cothron, A. S. (2002). An Evaluation of Dallas Area HOV Lanes, Year 2002. Texas Transportation Institute, The Texas A \& M University System, College Station, Texas.

58) Slotboom, Erik. (2003). Houston Freeways, A Historical and Visual Journey. Online Source. Available at: www.houstonfreeways.com. Accessed Oct. 2005.

59) Stockton, W. R., Daniels, G., Skowronek, D. A. and Fenno, D. W. (1999). ABC's of HOV: The Texas Experience. Texas Transportation Institute, College Station, Texas.

60) Taylor, Mark (2004). Personal email communication with UDOT, regarding Ramp Metering and HOV Study.

61) Taylor, C., Meldrum, D. and Jacobson, L. (1998). Fuzzy Ramp Metering: Design Overview and Simulation Results. Transportation Research Record 1634, Transportation Research Board, Washington, D.C.

62) TransCORE. (1999). Candidate Ramp Metering Strategies. Prepared for UDOT.

63) Transportation Research Board (2000). Highway Capacity Manual. Special Report 209. Washington D.C.

64) Turnbull K. F. (1992). An Assessment of the High Occupancy Vehicle (HOV) Facilities in North America. Texas Transportation Institute, The Texas A \& M University System, College Station. Texas.

65) Turnbull K. F. (2003). Houston Managed Lanes Case Study: The Evolution of the Houston HOV System. Texas Transportation Institute, The Texas A \& M University System, College Station. Texas.

66) Totten, M. and Settina, N. (1993) Energy Wise Options for State and Local Governments Online Source. Available at: http://solstice.crest.org/efficiency/energywise_options/ch2-4.html. Accessed August 2005

67) Victoria Transport Policy Institute (VTPI). (2005). Parking Pricing. Online Source. Available at: http://www.vtpi.org/tdm/tdm73.htm. Accessed Dec 2005.

68) Whitford, R. K. and Opsuth, J. L. (1997). Congestion Estimates for Indiana State Highway System. Report No. FHWA/IN/JHRP-96-8, Joint Highway Research Project, Purdue University West Lafayette, IN.

69) Washington State Department of Transportation (WSDOT). (2005). Ramp Meters. Online Source. Available at: http://www.wsdot.wa.gov/regions/northwest/traffic/tsmc/RampMeters/. Accessed: May 2005 